\title{
Independent Seismic Evaluation of the Diablo Canyon Unit 1 Containment Annulus Structure and Selected Piping Systems
}

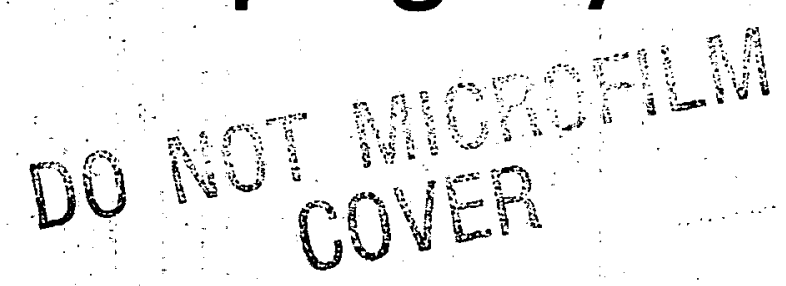

How

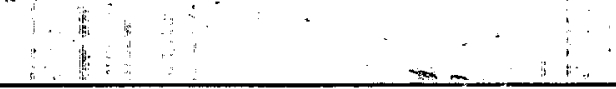

Prepared by A. J. Philippacopoulos, M, Reich, P. Bezler, C. Miller, Y. K. Wang, M. Subudhi, S. Shteyngart, P. Brown

Brookhaven National Laboratory

Prepared for

U.S. Nuclear Regulatory

Commission 


\section{DISCLAIMER}

This report was prepared as an account of work sponsored by an agency of the United States Government. Neither the United States Government nor any agency Thereof, nor any of their employees, makes any warranty, express or implied, or assumes any legal liability or responsibility for the accuracy, completeness, or usefulness of any information, apparatus, product, or process disclosed, or represents that its use would not infringe privately owned rights. Reference herein to any specific commercial product, process, or service by trade name, trademark, manufacturer, or otherwise does not necessarily constitute or imply its endorsement, recommendation, or favoring by the United States Government or any agency thereof. The views and opinions of authors expressed herein do not necessarily state or reflect those of the United States Government or any agency thereof. 


\section{DISCLAIMER}

Portions of this document may be illegible in electronic image products. Images are produced from the best available original document. 


\section{NOTICE}

This report was prepared as an account of work sponsored by an agency of the United States Government. Neither the United States. Government nor any agency thereof, or any of their employees, makes any warranty, expressed or implied, or assumes any legal liability of responsibility for any third party's use, or the results of such use, of any information, apparatus, product or process disclosed in this report, or represents that jits use by such third party would not infringe privately owned rights.

\section{Availability of Reference Materials Cited in NRC Publications}

Most documents cited in NRC publications will be available from one of the following sources:

1. The NRC Public Document Room, 1717 H Street, N.W. Washington, DC 20555

2. The NRC/GPO Sales Program, U.S. Nuclear Regulatory Commission, Washington, DC 20555

3. The National Technical Information Service, Springfield, VA 22161

Although the listing that follows represents the majority of documents cited in NRC publications, it is not intended to be exhaustive.

Referenced documents available for inspection and copying for a fee from the NRC Public Document Room include NRC correspondence and iriternal NRC memoranda; NRC Office of Inspection and Enforcement bulletins, circulars, information notices, inspection and investigation notices; Licensee Event Reports; vendor reports and correspondence; Commission papers; and applicant and licensee documents and correspondence.

The following documents in the NUREG series are available for purchase from the NRC/GPO Sales Program: formal NRC staff and contractor reports, NRC-sponsored conference proceedings, and NRC booklets and brochures. Also available are Regulatory Guides, NRC regulations in the Code of Federal Regulations, and Nuclear Regulatory Commission Issuances.

Documents available from the National Technical Information Service include NUREG series reports and technical reports prepared by other federal agencies and reports prepared by the Atomic Energy Commission, forerunner agency to the Nuclear Regulatory/Commission.

Documents available from public and special technical libraries include all open literature items? such as books, journal and periodical articles; and transactions. Federal Register notices, federal and state legislation, and congressional reports can usually be obtained from these libraries.

Documents such as theses, dissertations, foreign reports and translations, and non-NRC conference proceedings are available for purchase from the organization sponsoring the publication cited.

Single copies of NRC draft reports are available free upon written request to the Division of Technical Information and Document Control, U.S. Nuclear Regulatory Commission, Washington, DC 20555.

Copies of industry codes and standards used in a substantive manner in the NRC regulatory process. are maintained at the NRC Library, 7920 Norfolk Avenue, Bethesda, Maryland, and are available: there for reference use by the public. Codes and standards are usually copyrighted and may be purchased from the originating organization or, if they are American National Standards, from the American National Standards Institute, 1430 Broadway, New York, NY 10018. 
Independent Seismic Evaluation of the Diablo Canyon Unit Containment Annulus Structure and Selected Piping Systems

Manuscript Completed: May 1982

Date Published: August 1982

Prepared by

A. J. Philippacopoulos, M. Reich, P. Bezler, C. Miller, Y. K. Wang, M. Subudhi,

S. Shteyngart, P. Brown

Department of Nuclear Energy

Brookhaven National Laboratory

Upton, NY 11973

\section{Prepared for}

Division of Engineering

Office of Nuclear Reactor Regulation

U.S. Nuclear Regulatory Commission

Washington, D.C. 20555

NRC FIN A3377 
An independent review and dexelopment of the vertical floor spectra for the Unit 1 contaiment annulus structure of the Diablo Canyon Power Plant was carried out using a detailed three-dimensional model. The developed floor spectra were then utilized for confirmatory evaluations of two selected piping systems. The latter were evaluated by the envelope response spectrum method, and by the independent support motion response spectrum method. ASME class 2 evaluations of the two systems were also performed. Finally, a confirmatory evaluation was carried out for the model utilized by URS/Blume for the development of the vertical floor response spectra that were reported in reference (1). Sections 1.1 and 1.2 of the report summarize the work scope and the results of the study. Details pertaining to the specific areas of the work are given in sections 2 to 8 . 


\section{Acknowledgements}

The authors would like to express their gratitude to the NRC staff members for their assistance on various phases of this work. In particular to Dr. P. T. Kuo who was our monitor in all phases of this work and to Dr. M. Hartzman who monitored our efforts for the MEB. Their constructive comments and advice during the course of this work is deeply appreciated.

We would also like to thank various members of the Structural Analysis Division who contributed towards the completion of this work. The assistance of Ms. E. Gilbert and Ms. J. Murray in typing this manuscript is also appreciated. 


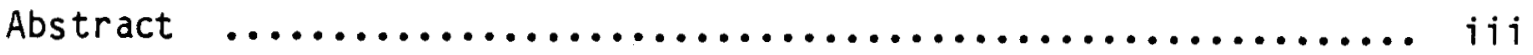

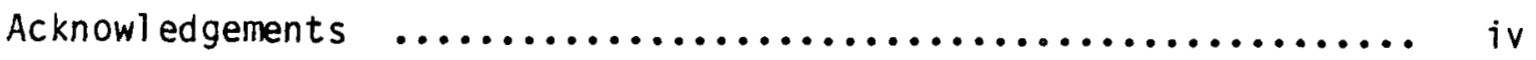

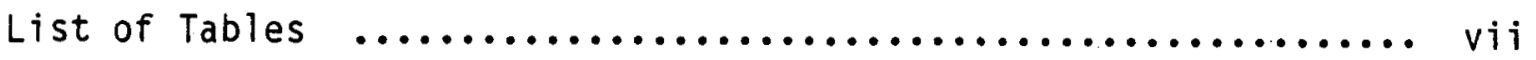

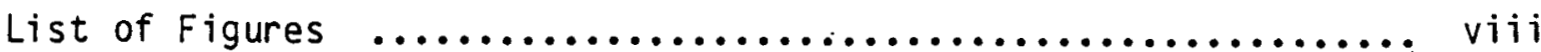

1.0 Summary of Work Scope and Synopsis of Analysis Results ......... I

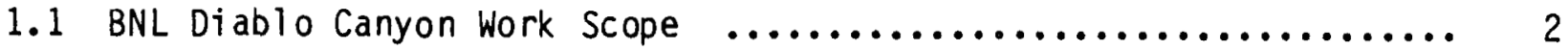

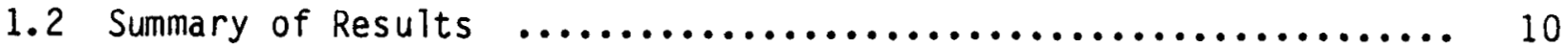

2.0 DESCRIPTION OF STRUCTURAL MATHEMATICAL MODEL $\ldots \ldots \ldots \ldots \ldots \ldots, 15$

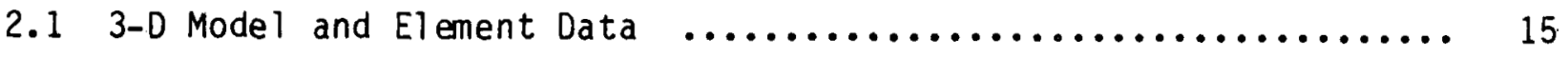

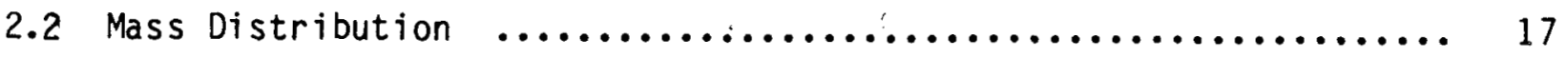

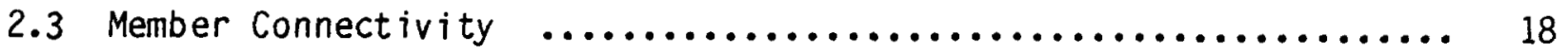

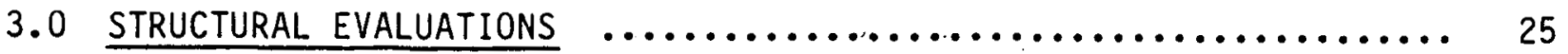

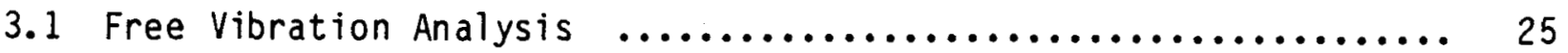

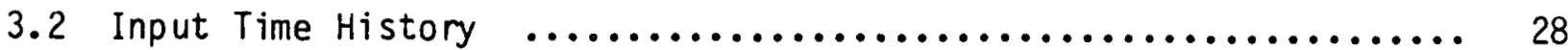

3.3 Generation of Vertical floor Response Spectra $\ldots \ldots \ldots \ldots \ldots \ldots . . .28$

4.0 VERIFICATION OF THE $3-$ D MODEL $\ldots \ldots \ldots \ldots \ldots \ldots \ldots \ldots \ldots \ldots \ldots . \ldots \ldots$

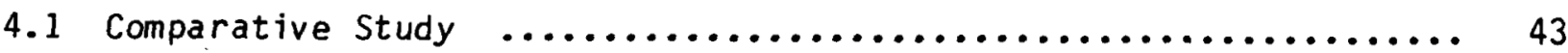

4.2 . Description of Results $\ldots \ldots \ldots \ldots \ldots \ldots \ldots \ldots \ldots \ldots \ldots \ldots \ldots, 44$

5.0 DESCRIPTION OF FLOOR RESPONSE SPECTRA FROM 3-D MODEL $\ldots \ldots \ldots \ldots 47$

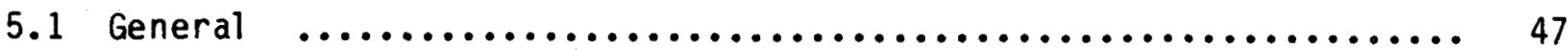

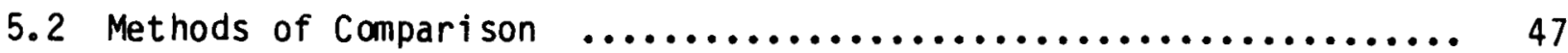

5.3 Comparison with URS/Blume Spectra $\ldots \ldots \ldots \ldots \ldots \ldots \ldots \ldots \ldots . . . \ldots 48$

6.0 TWO-DIMENSIONAL MODEL EVALUATIONS $\ldots \ldots \ldots \ldots \ldots \ldots \ldots \ldots \ldots \ldots . . \ldots 6$

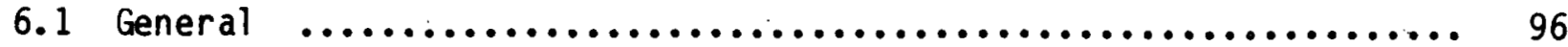

6.2 Verification of Floor Spectra Results $\ldots . \ldots \ldots \ldots \ldots \ldots \ldots . \ldots . . . .696$

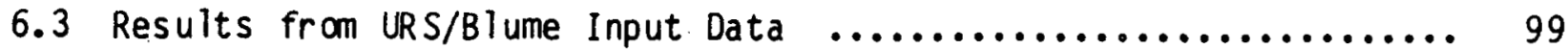

6.4 Comparison Between Raw and Broadened Spectra ................ 100 


\section{Table of Contents (cont'd)}

7.0 DESCRIPTION OF PIPING MATHEMATICAL MODEL $\ldots \ldots \ldots \ldots \ldots \ldots \ldots \ldots \ldots$

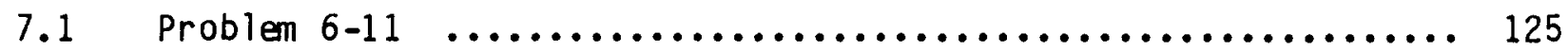

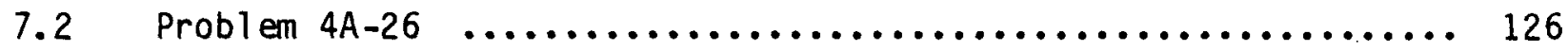

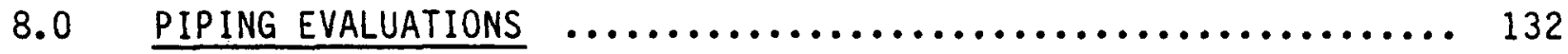

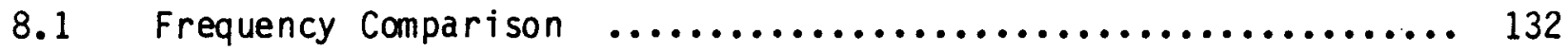

8.2 Results Based on Uni form Support Excitation $\ldots . . . \ldots \ldots \ldots \ldots . . .133$

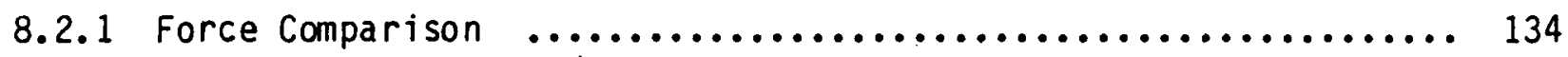

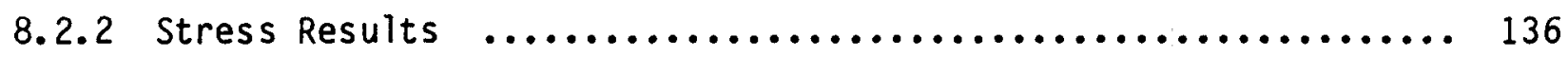

8.3 Results Based on Independent Support Excitation $\ldots \ldots \ldots \ldots \ldots . .138$

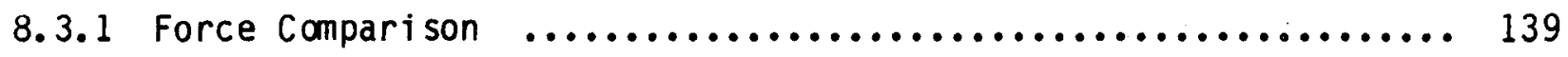

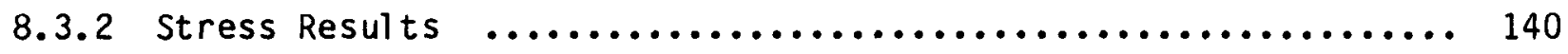

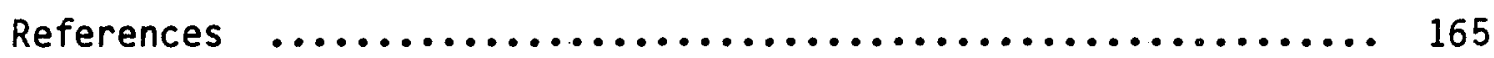


Table

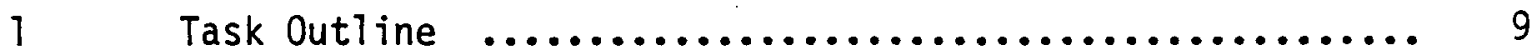

3.1 Model-Cases Evaluated for Different Boundary

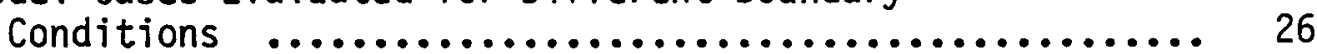

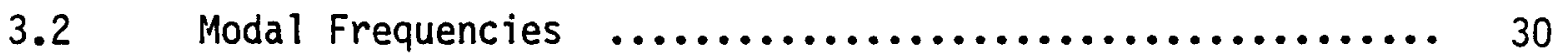

4.1 Comparison of Ten Modal Frequencies ............... 45

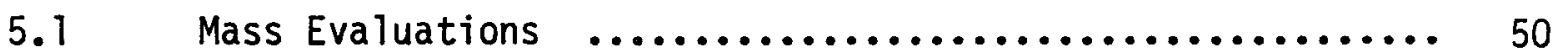

6.120 Model. Comparison of Modal Frequencies (SAPV versus

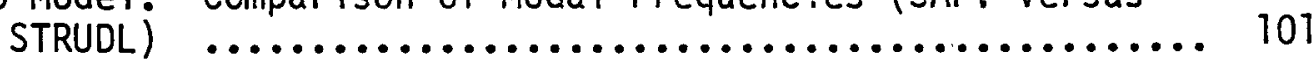

$6.22 \mathrm{D}$ Model. Comparison of Modal Frequencies (SAPV versus

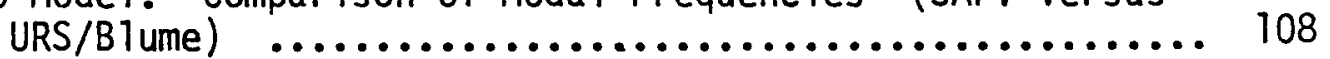

8.1 Problem 4A-26. Frequency Comparison ............... 143

8.2 Problem 6-11. Frequency Comparison ................ 144

8.3 Problem 6-11. Support Force Comparison. PG\&E Spectra .. 145

8.4 Problem 4A-26. Support Force Comparison. PG\&E Spectra .................................. 146

8.5 Problem 6-11. Problem 6-11. Support Comparison. Mode1 B Spectra ................................... 147

8.6 Problem 4A-26. Support Force Comparison. Mode7 B Spectra .................................. 148

8.7 Problem 6-17. Support Force Comparison. Model B Spectra .................................... 149

8.8 Problem 4A-2A. Support Force Comparison. Model B

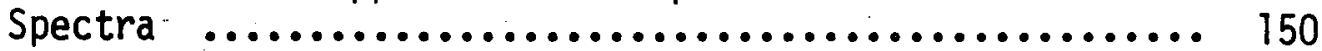

8.9 ASME Class 2 Equation 9 Satisfaction $\ldots \ldots \ldots \ldots \ldots \ldots \ldots \ldots 1$ 
2. 1 Schematic View of Containment Annulus Structure ....... Model Details for Floor at Elevation $106^{\prime}$ Model Details for Floor at Elevation 117! Model Details for Floor at Elevation $140^{\prime}$.

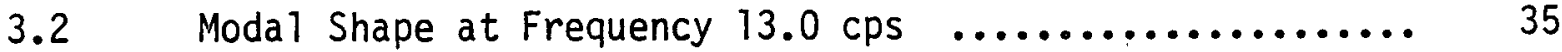

3.3 Time History Record of Input Excitation ............ 36

3:4 Evaluation of Integration Time Step. Node 152 ....... 37

3.5 Evaluation of Integration Time Step. Node 153 ....... 38

3.6 Evaluation of Integration Time Step. Node 157 ....... 39

3.7 Evaluation of Integration Time Step. Node 163 ....... 40

3.8 Evaluation of Integration Time Step. Node 166 ....... 41

3.9 Evaluation of Integration Time Step. Node 281 ....... 42

4.1 Floor Response Spectra Comparison: SAPV (BNL) versus

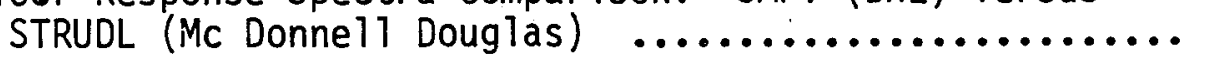

5.1 Orientation of Fan Coolers for Units 1 and 2 and Frame Orientation of URS/Blume 2D Model

5.2 Definition of Sections for a Typical Floor of the Containment Annulus Structure Unit 1

6.1 URS/Blume Mathematical Model of Containment Annulus Structure

6.2 Simplified Model of Containment Annulus Structure .....

SAPV (BNL) versus STRUDL (Mc Donnell Douglas)

20 Model. Node 41

SAPV (BNL) versus STRUDL (MC Donnell Douglas)

6.4

Node 41

\section{5}

2D Model. Node 42

SAPV (BNL) versus STRUDL (MC Donnell Douglas)

6.6

2D Model. Node 43

SAPV (BNL) versus STRUDL (MC Donnell Douglas)

20 Model. Node 44

SAPV (BNL) versus STRUDL (MC Donnell Douglas)

6.7

2D Model. Node 45

SAPV (BNL) versus STRUDL (Mc Donnell Douglas)

6.8

102

103

104

105 
Figure

Page

6.9 2D Model. SAPV (BNL) versus URS/B1ume Floor Response Spectra. Node 8 ........................... 109

$6.102 D$ Model. SAPV (BNL) versus URS/Blume Floor Response Spectra. Node 9 ............................ 110

6.11 2D Mode1. SAPV (BNL) versus URS/Blume Floor Response Spectra. Node 10 ............................. 111

6.12 2D Model. SAPV (BNL) versus URS/Blume Floor Response Spectra. Node 11 ............................ 112

6.13 2D Model. SAPV (BNL) versus URS/Blume Floor Response 113

6.1420 Model. SAPV (BNL) versus URS/BTume Floor Response Spectra. Node 19 ................................ 114

6.15 2D Mode1. SAPV (BNL) versus URS/Blume Floor Response Spectra. Node 30 ............................ 115

$6.162 \mathrm{D}$ Model. SAPV (BNL) versus URS/Blume Floor Response

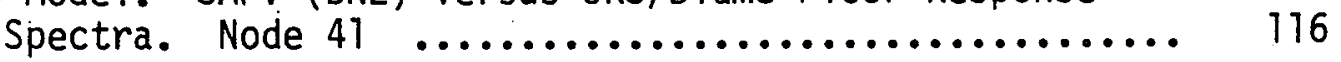

$6.172 \mathrm{D}$ Model. SAPV (BNL) versus URS/BTume Floor Response Spectra. Node 8 ............................. 117

6.18 2D Model. SAPV (BNL) versus URS/BTume Floor Response Spectra. Node 9 ............................ 118

$6.192 \mathrm{D}$ Model. Raw versus Broadened URS/Blume Floor Response

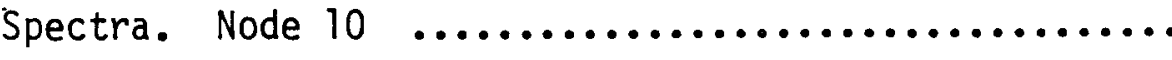

6.20 2D Model. Raw versus Broadened URS/Blume Floor Response Spectra. Node 11 ..............................

6.21 2D Mode1. Raw versus Broadened URS/BTume Floor Response Spectra. Node 12 ..............................

6.22 2D Model. Raw versus Broadened URS/Blume Floor Response Spectra. Node 19 .............................

6.23 2D Model. Raw versus Broadened URS/Blume Floor Response Spectra. Node 30 .............................

$6.242 \mathrm{D}$ Model. Raw versus Broadened URS/B 7 ume Floor Response Spectra. Node $41, \ldots \ldots \ldots \ldots \ldots \ldots \ldots \ldots \ldots \ldots \ldots . . . \ldots \ldots$ 
Figure

7.1 Isometric for Problem No. 6-11

7.2 Schematic View of Problem 6-11

7.3 Isometric View of Problem 4A-26

8.1 Problem 6-11. Envelope for 2\% Damping ............ 152

8.2 Problem 4A-26. Envelope for 2\% Damping ............ 153

8.3 Problem 6-11. Envelope for 2\% Damping. Model B $\ldots \ldots \ldots 154$

8.4 Problem 4A-26. Envelope for 2\% Damping. Model B .... 155

8.5 Problem 6-11. Mode1 B. Group 1. Spectrum .......... 156

8.6 Problem 6-11. Mode1 B. Group 2. Spectrum ......... 157

8.7 Problem 6-11. Model B. Group 3. Spectrum ......... 158

8.8 Problem 6-11. Mode1 B. Group 4. Spectrum .......... 159

8.9 Problem 4A-26. Mode7 B. Group 1. Spectrum ......... 160

8.10 Problem 4A-26. Mode1 B. Group 2. Spectrum ......... 161

8.11 Problem 4A-26. Model B. Group 3. Spectrum ......... 162

8.12 Problem 4A-26. Model B. Group 4. Spectrum ......... 163

8.13 PG\&E Horizontal Spectra for Problems $6-11$ and $4 A-26 \quad \ldots \quad 164$ 
1.0 Summary of Work Scope and Synopsis of Analysis Results

This report describes a study performed by the Brookhaven National Laboratory for the Diablo Canyon Plant of the Pacific Gas and Electric Company. This study involves seismic evaluations for the containment annulus structure and piping of the Unit 1 portion of the plant. These evaluations are based on the $7.5 \mathrm{M}$ Hosgri earthquake which is the input used in the latest stage of the seismic assessment of the Diablo Canyon Plant. 


\subsection{BNL Diablo Canyon Work Scope}

Initial work assignments

BNL involvement with the Diablo Canyon review was initiated on october 9, 1981 when members of the Structural Analysis Division were requested by NRC to attend a meeting in Bethesda, Maryland where the so-called "diagram error" made by the Pacific Gas and Electric Company (PG\&E) of California in the design of the Diablo Canyon Nuclear Power Plant, Unit 1 would be detailed by company officials and contractors. As a result of this meeting, an audit of the utilities efforts was scheduled and BNL representatives were requested to attend. The purpose of this audit which was subsequently held at the PG\&E headquarters in San Francisco, California during the period October 14-16, 1981, was to review with PG\&E the extent of the errors, their possible effects and to assess the validity of the corrective measures being adopted to requalify the plant design. The technical areas reviewed during the audit pertaining to the annulus structure whose design. was affected by the diagram error were: derivation of the floor response spectra, electrical equipment and instrumentation installations, mechanical equipment and ventilation, piping systems and their various supports, conduit and cable tray supports. BNL presented its comments to NRC regarding this audit, late in October of 1981 .

\section{First set of analytical tasks}

At the beginning of November 1981 NRC requested the Structural Analysis Division of BNL to independently develop vertical floor response spectra for the Unit 1 contaiment annulus structure of the Diablo Canyon Plant. In addition, piping systems with PG\&E designation numbers $4 A-26$ and $6-11$, located in the annulus area were to be independently reanalyzed. For the generation of the floor spectra, BNL was requested to develop and utilize a threedimensional model that closely resembled the actual structural configuration of the containment annulus. Results from this analysis would then be used as input for the two piping systems. For the analyses of the latter, uniform support excitation methods would be applied. Final instructions under this assignment included an additional check of floor spectra results with a computer code available for use to the general public. 
In order to carry out the above work, it was necessary that all required data be assembled and reviewed. Thus the first order of work was to review all information and data made available during the San Francisco meeting with PG\&E. From this effort it became apparent that a good deal of required information was not available. Essentially, we had the following:
a) an input card deck for the Newmark 7.5M Hosgri ground acceleration time history
b) a description of input data used for the two-dimensional Blume model
c) a two-page summary of the two-dimensional analysis
d) a copy of the URS/Blume report "Diablo Canyon Nuclear Plant Unit 1 Containment Structure, Dynamic Seismic Analysis for 7.5 M Hosgri Earthquake", May 1979.

In addition from our discussions at the San Francisco audit, we had a general understanding of the structural and piping system layouts. This, however, was not adequate for the detailed analysis required for the BNL review. In view of this, we immediately requested that the needed data be made available to us.

On November 20, 1981, the following PG\&E prints were transmitted to us:
Dwg. 469355 Rev. 3 Civil-Deadloads Annulus Platform Containment Structure EL 140' \& 130'

Dwg. 469356 Rev. 3 Civil-Deadloads Annulus Platform Containment Structure EL $117^{\prime}$

Dwg. 469357 Rev. 3 Civil-Deadloads Annulus Hanger Frames Contaiment Structure EL 106'

Dwg. 469358 Rev. 3 Civil-Deadloads Annulus Hanger Frames Containment Structure EL 101 ' 
These allowed us to model the inertial contributions from the equipment, piping, etc. that are located on various floors of the structure. Missing however, was information regarding the distributed weights of the various structural members comprising the annulus structure and a detailed description of member connections. Information needed for the piping evaluations was also lacking.

On December 23, 1981 we informally received a package of data from PG\&E which was formally transmitted to NRC on January 22, 1982 describing piping problems 6-11 and 4A-26. Specifically, the data transmitted for problem 6-11 corresponded to the applicant supplied list shown below:

ITEM A: Seismic Analysis 6-11 Isometric Drawing

Design Review Isometric - PG\&E Dwg. 437989

(Safety Injection, Loop 182)

ITEM B: Hanger Details and Summary Sheet

ITEM C: Piping and Insulation Specifications

ITEM D: No Valves Involved with Analys is 6-11

ITEM E: Horizontal and New Vertical Hosgri Response Spectra Seismic Analys is 6-11

ITEM F: Seismic Anchor Movements (Blume Report)

ITEM G: Design Change Notices will be sent as they become available

ITEM H: File 33 Forms (Hanger Load Tabulation)

ITEM I: Contaiment Penetration Allowables

ITEM J: Schematic Diagrams and Piping and Instrumentation Diagrams (P\&ID's)

ITEM K: Pressures, Thermal Modes and Anchor Movements

ITEM L: No Additional Dynamic Loading Conditions for Analysis 6-11

A corresponding list for problem 4A-26 was also transmitted. On January 15, 1982 the following structural drawings were received.

Dwg. 438281 Rev. 9 Annulus Platform Framing EL 117'-0" Containment Structure 
Dwg. 438282 Rev. 10 Annulus Platform Framing EL 140'-0"

Containment Structure

Dwg. 443039 Rev. 3 Structural Steel Modification of

Annulus Platform and Frames

Contaiment Structure

Dwg. 447245 Rev. 6 Annulus Hanger Frames EL 101' \& EL 106'

(Containment Structure)

Dwg. 447245 Rev. 4 Concrete Outline and Reinforcing

Annulus Platform EL 140'

Containment Structure

Based on the information received to that date a three-dimensional mode 1 of the structure was developed. Unfortunately the structural drawings received in November 1981 and in January 1982 did not contain all details pertaining to the type of connections (i.e., shear or moment) used between all the structural members comprising the annulus structure. Similar questions regarding the member connectivities used for the URS/Blume 2-D model given in the May 1979 report, previously cited, also prevailed.

In discussing these uncertainties with our technical monitor, it was decided to model the structure with shear type joints for the beam to column connections. This model is referred to as 3-D model A. Subsequently in the middle of February 1982 we were also asked to make an additional computer run considering moment connections for the beam to column framings for both the first and second floors. (This is 3-D model $B$ ). We also officially requested a confirmation from PG\&E via NRC for the actual framing connection details.

By the end of February 1982, work on the floor response spectra using the above two models was completed. In addition the piping systems were modeled 
and computer runs were made for mode shapes and frequencies. Furthermore, spectral results from 3-D model A were utilized to compute the responses of the piping systems. A comparative check using the STRUDL code for spectra generation was also made. Preliminary results of the above evaluations were presented to pertinent NRC personnel in a meeting held in Bethesda, Maryland on March 2, 1982.

\section{Second set of analytical tasks}

At the close of this meeting we were asked by NRC to extend our original work scope by including the following tasks:

(1) generate floor response spectra for a third 3-D mode1, (i.e., model C) where beam to column connections of the first, second and third floor are taken as moment type.

(2) Carry out a confirmatory computer run for the original PG\&E 2-D model using data from the San Francisco meeting.

(3) Carry out independent support excitation anaiyses for the two piping systems (using spectral imputs from 3-D analysis) and evaluate piping system response in accordance with ASME Class 2 classifications.

The above tasks with the exception of the piping runs were completed by March 15, 1982. Specific results pertaining to items (1) and (2) above were discussed with Dr. P. T. Kuo and Dr. M. Hartzman of NRC at a meeting held at BNL on March 17, 1982. It was pointed out that the floor spectra.corresponding to $3-D$ models $A, B$ and $C$ were completed and that results pertaining to the two-dimensional model did not match with those reported by URS/BIume. We felt that the reasons for the mismatch were due to the boundary conditions, degrees-of-freedom assigned to the nodes and integration parameters (i.e., time steps) used by URS/BIume. It was decided that BNL should vary the above parameters in an attempt to obtain a better match with the Blume 2-D model. In addition, it was agreed to also verify the results of the spectra from the 2-D model with spectra generated by the STRUDL-DYNAL code. 
With regards to the $3-0$ results, just as we were deciding at the close of the March 17th BNL meeting which of the 3-D models (i.e., A, B or C) most closely represented the actual structure, a courier arrived with the following PG\&E structural steel fabricators drawings:

$$
\begin{array}{ll}
\text { DC663243 - 465-2 } & \text { DC663368 }-1-1 \\
\text { DC663243 - 466-2 } & \text { DC663368 }-10-1 \\
\text { DC 663243 - 467-2 } & \text { DC663368 }-37-2
\end{array}
$$

These were the missing joining drawing details that we requested back in January. From these we readily ascertained that 3-D model B most closely resembled the actual field conditions. Thus the forthcoming piping evaluations would utilize the spectra and displacements generated from this model.

\section{Third set of analytical tasks}

In the week following the meeting our efforts were concentrated on the verification studies of the 2-D model and the completion of the various piping analysis tasks. It soon became apparent that although parameters of the 2-D model were varied, none of the parametic solutions correlated well with the URS/Blume results given in their May 1979 report. Considering the lack of agreement between the solutions and the uncertainties -in some of the parameters we requested that NRC obtain a listing of the computer input/output for the runs used to generate the spectra given in the URS/BIume report. This infomation was relayed to us by PG\&E on April 24, 1982.

In reviewing this latest information for the two-dimensional model, it became obvious that the distributed masses of the steel members were not included for the input member properties (i.e., the code input showed mass density to be input as zero). Secondly, only eighteen modes were considered, whereas the primary floor masses are lumped at the mid-spans of twenty beams comprising the five frames. The degrees-of-freedom were mixed i.e., nodes along the crane wall had one degree-of-freedom (vertical translation) whereas 
the others had two. This was not at all clear either from the discussions at San Francisco nor from the Blume report.

With respect to the boundary conditions, it also was apparent from submitted data that only beam to crane wall connections of the concrete floor at elevation 140 feet were shear type. Al1 other connections were taken to be rigid. This seems to be different from the statement given on page 11 of the URS/Blume May 1979 report.

Using the information received from PG\&E on April 24, 1982, BNL generated "raw" floor spectra which agreed with those presented in the submittal. However, these raw floor spectra are not consistent with the broadened spectra presented in the May 1979 report. Additionally, the version of the postprocessor used for the "raw spectra" submitted to BNL on Apri1 24, 1982 is dated 12/80 (program JAB/FLS PEC VER 1.0, page 24), which seems to be inconsistent with the report publication date, May 1979.

All tasks requested by NRC to date described in this section are summarized in chronological sequence for convenience in Table 1 . All of the analytical tasks were completed by the first week of May 1982. The body of this report presents the pertinent results of the study. A summary of the conclusions is presented in the next section. 


\section{$\underline{\text { Table } 1}$}

Task Outline

(1) Requested to attend October 9, 1981 Bethesda, MD meeting where PG\&E and contractors discussed the テ

(2) Participate with NRC at Dfablo Canyon audit held at PG\&E San Francisco headquarters during the period October $14-16,1981$.

(3) Present comments pertaining to PG\&E audit to NRC.

(4) Requested to independentily develop vertical floor response spectra for unit 1 containment annulus structure. Madel A (shear joints for all beam and column connections), and Model B (moment connections for 1 st and 2nd floors).

$(5) \&$ Requested to independently reanalyze piping systems with PG\&E designation numbers $4 A-26$ and $6-11$.
$(6)$

(7) Carry out check calculation for floor spectra using general public computer code.

i $\quad[(8)$ Repeat task (4) for Model $c$ (where beam to column connections for 1st, 2nd and 3rd floor are

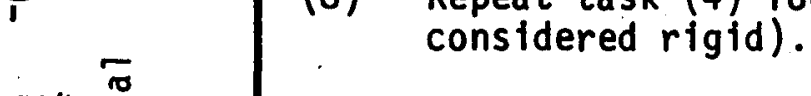

(9) Carry out confirmatory computer run for original PG\&E 2-D model.

(10)\& Carry out multiple input analysis for PG\&E piping systems $4 A-26$ and 6-11 using spectral imput from (11) 3-D analysis and evaluate in accordance with ASME class 2 classifications.

(12) Verify results of the spectra for 2-D model with spectra generated from STRUDL (McDonnell Douglas).

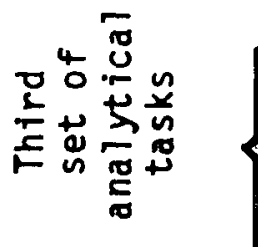

(13) Extend 2-D study varying the boundary conditions.

(14) Review input/output of URS/BI ume 1979 run. Use identical model and compare raw floor spectra.

$\{(15)$ Write report detailing results of items 4 to 14 . 


\subsection{Summary of Results}

In the previous section a chronology of the work effort was presented in order to acquaint the reader with the actual task sequence. In this section a similar chronological order will be followed. First, results for the threedimensional finite-element model floor spectra evaluations will be given. These will be followed by a synopsis of the results obtained for the two confirmatory piping system analysis. Finaliy, a summary of the findings for the confimatory two-dimensional model studies will be presented.

\section{Results of 3-D Model Studies}

As mentioned, at the request of NRC a detailed three-dimensional model of the contaiment annulus structure was developed. Because of uncertainties pertaining to structural member connections, three variations (i.e., A, B and C) of this model were analyzed. Based on the latest information made available to us during the 3 rd week in March, Model B most closely represents the actual structure. The pertinent results are as follows:

(1) Modal shapes for this structure are primarily local in nature, with relatively small sections of the structure excited for a particular frequency. This localized characteristic of the modes, however, decreases in going from model $A$ to model $C$. For model $B$ there are mixed cases, some modes affecting only local sections of the structure while others affecting greater portions of the structure.

(2) Floor response spectra generated with these models did not agree with those given in the May 1979 URS/Blume report. Both frequency shifts and differences in peak spectral acceleration magnitudes were found. This was the case for all models (i.e., A, B and C) evaluated. URS/Blume results for the top floor were consistently conservative in that they exceeded the acceleration magnitudes predicted with the BNL models. This, however, is not the case for floors one, two and three. For some frequencies the URS/Blume results for these floors were conservative, for others they were not, with no observable trend. 
The differences in the results can be attributed to:

(a) the lower mass values used by URS/Blume (see discussion pertaining to two-dimensional model results)

(b) differences in structural member connnectivity

(c) the fact that a single mass may or may not adequately represent all individual structural parts comprising a section of a floor.

(3) The BNL 3-D model floor response spectra results were also verified with the STRUDL-MCDONNELL-DOUGLAS computer program. Good agreement for both modal frequencies and floor spectra were obtained.

Results of Piping Analysis

Confirmatory evaluations were performed for PG\&E piping problem numbers 6-11 and 4A-26. These piping systems are connected to the first, second and third floors of the annulus structure. The evaluations were carried out using envelope response spectrum methods and independent support motion response spectrum methods using both PG\&E and BNL developed spectra. The PG\&E supplied spectra were entitled "New Hosgri-5 Mass Spectra". A check showed that these spectra are different from those presented in the URS/Blume 1979 report. At some frequencies the new results are higher for the piping systems and at others they are lower. Presumably, these spectra were developed from a new model of the annulus structure. A summary of the conclusions are:

1) BNL models developed from PG\&E as-built drawings were found to differ from the PG\&E models. The differences were due to the use by PG\&E of design dimensions which differ from the as-built dimensions and in errors made by PG\&E in the modeling of pipe bends. Also an overlap procedure was used in the modeling of problem $4 A-26$. The extent of overlap used in the problem seems adequate in that it meets the intent of NUREG/CR 1980.

2) BNL predictions of system frequencies differ from the PG\&E estimates, however these differences are not large.

3) BNL support force values obtained using BNL models and PG\&E supplied spectra do not match. The differences are probably due to the differences in modeling. 
4) Support forces calculated using BNL piping models and BNL 3-D Model B envelope or independent spectra substantially exceed PG\&E calculated values. The major cause for this is that Model B spectra greatly exceed the spectra used by PG\&E.

5) ASME Class 2 evaluations performed using the uniform response spectrum method indicated exceedance of service level $D$ stresses at 2 points in problem 6-11, while problem 4A-26 satisfied service level D requirements.

6) ASME Class 2 evaluations performed using the independent support response spectrum methods produced a reduction in stress levels in problem 6-11, but an increase in stress levels for problem 4A-26. For this procedure, problem 6-11 shows slight overstressing at one point, while 4A-26 still meets requirements. Its possible that independent support input excitation analyses based on the time history methods could produce results which would, depending on phasing, satisfy service level $D$ requirements.

Results of 2-D Model Studies

As mentioned in the previous section, due to the uncertainties in some of the pertinent data, various parametric studies for this model were performed. None of these, however, correlated well with the URS/Blume results given in their May 1979 report. We thus requested that NRC obtain a listing of the computer input/output for the runs used to generate the spectra given in the URS/Blume report. This information was relayed to us by PG\&E on April 24, 1982. A summary of the conclusions of this portion of the study is given bel ow.

1) A confirmatory BNL computer run with input data identical to that used by URS/Blume yielded raw floor spectra similar to those sent to BNL (in digitized format) by PG\&E on April 24, 1982 (see previous section regarding computer method). 
2) The broddened spectra presented in the May 1979 report generally correspond with the raw spectra values sent to us in April 1982. In the lower spectral frequency range however, it seems that the broadened spectra were obtained by use of mean raw spectra values.

3) A detailed review of the PG\&E supplied input/output data resulted in the following findings with respect to the 2-D model described in the May 1979 report.

(a) The weights used in the model do not correspond to those shown in the PG\&E drawings submitted to BNL during the period November 1981 March 1982 (for details of drawings see previous section). For example, for the third floor the total mass used in the model is $6.71 \mathrm{kip}-\mathrm{sec}^{2} / \mathrm{ft}$, while the value from the corresponding drawings is approximately $11.4 \mathrm{Kip}-\mathrm{sec}^{2} / \mathrm{ft}$.

(b) The computer printout sent to us (in April 1982) indicates zero mass density input for the structural members. It could be that member weights were meant to be included in the values of the lumped masses. However, if this were the case, then, again taking the third floor as an example, the total mass of all items supported by this floor as obtained fram the corresponding drawings is approximately $7.54 \mathrm{Kip} \mathrm{sec} 2 / \mathrm{ft}$. This figure which does not include the mass of the structure itself al ready exceeds the value used in the URS/Blume computation.

(c) A review of the steel fabricators drawings show that the member connections used in the 2-D URS/Blume model do not represent the conditions indicated in these drawings. 
(d) With respect to item (c) above, it should be noted that parametric studies carried out at BNL with the 2-D model showed that the floor spectra results can be significantly altered by member connectivity.

4) As with the 3-D results, the 2-D BNL SAPV results were verified with a STRUDL-MCDONNELL-DOUGLAS computer run. A good match for the modal frequency's and the floor spectra were obtained. 


\subsection{Description of Structural Mathematical Model}

The model utilized for the containment annulus of the Diablo Canyon Plant Unit 1 is described in this section of the report. The four floors of the structure are supported from the crane wall and by columns located just inside the containment. The widths of the floors are about 16 feet. The floors span circumferentially most of the $360^{\circ}$ of the annulus space located between the containment and crane wall.

The first three floors (at elevations of 101', 106' and 116') are steel frame structures consisting of girders spanning radially from the crane wall to the columns and tangentially between columns. Intermediate support beam frames are located between columns. The fourth floor (at elevation 140') consists of the same type of steel structure with an 18" concrete slab supported on the steel framework. The concrete and steel beams on this floor act independently and not as a composite. Because of the slab dimensions, the concrete slab will behave as a one-way slab spanning between the crane wall and the tangential girders at the outer colum line. A skematic drawing of this configuration is shown in Figure 2.1

\section{$2.13-D$ Model and Element Data}

A 3-D model was developed to treat the vertical response of the structure. Preliminary analysis showed the crane wall to be much stiffer than the columns and therefore it was not necessary to model this wall with shell elements for vertical analysis. In addition it was concluded that the vertical input will not be amplified in the vertical direction through the rigid crane wall. Thus, the seismic excitation applied at all of the supports of the annulus structure located on the crane wall will be the same, (i.e., the $7.5 \mathrm{M}$ Hosgri earthquake scaled to $0.5 \mathrm{~g}$ for the vertical analysis). Furthermore, each floor contains bracing members designed to restrain a rigid body rotation of the floor about a vertical axis. Since this motion will not be excited by a vertical input, these members are not included in the model.

Nodes are included at the intersection of all members with additional nodes added along the span of the beams and girders so that higher beam modes 
may be obtained. At each node (other than support nodes) the vertical displacement and rotations about the two horizontal axes are unrestrained. The remaining three degrees-of-freedom will not be excited with a vertical input and therefore need not be considered. They were restrained in the computer runs.

Details pertaining to the finite element idealization of the structure are shown in Figures 2.2 through 2.6. The numbers shown on these diagrams are nodal numbers. A general view of the 3-D finite element grid is shown in Figure 2.2. The eighteen columns, located about 20 degree intervals around the structure, may be seen in this figure. Note also the hangers which connect various parts of the first, second and third floors. The framing plans for the first through fourth floors are shown in Figures 2.3 through 2.6 respectively. The triangular elements on the fourth floor are used for the discretization of the 18 inch thick concrete slab.

Details of the 3-D model were developed from the following drawings submitted to BNL by PG\&E:

Dwg. 438281 Rev. 9 Annulus Platform Framing EL 117'-0" Containment Structure

Dwg. 438282 Rev. 10 Annulus Platform Framing EL 140'-0" Contaiment Structure

Dwg. 443039 - Rev. 3 Structural Steel Modification of Annulus Platform and Frames Contaiment Structure

Dwg. 447245 Rev. 6 Annulus Hangar Frames EL 101 \& EL 106' (Containment Structure)

Dwg. 447245 Rev. 4 Concrete Outline and Reinforcing Annulus Platform EL $140^{\prime}$ Containment Structure 
The computer runs were made with the BNL version of the SAPV finite element computer code.

The steel section properties were taken from the AISC Steel Design Handbook. Steel is taken to have a Young's Modulus of 29,000 ksi and a density of 0.2836 pound per cubic inch ( 490 pound per cubic foot). The concrete is taken to have a modulus of elasticity of $4150 \mathrm{ksi}$ and a Poisson ratio of 0.17 . The concrete density is 0.0868 pounds per cubic inch ( 150 pounds per cubic foot).

\subsection{Mass Distribution}

The structural weight is generated initially in the SAPV program based on the member geometry and density. Other weights are input as nodal masses. The basis for the calculation of the lumped masses was obtained from the following drawings transmitted to BNL by PG\&E:

Dwg. 469355 Rev. 3 Civil-Deadloads Annulus Platform Containment Structure EL $140^{\prime} \& 130^{\prime}$

Dwg. 469356 Rev. 3 Civil-Deadloads Annulus Platform Containment Structure EL $117^{\prime}$

Dwg. 469357 Rev. 3 Civil-Deadloads Annulus Hangar Frames Containment Structure EL 106'

Dwg. 469358 Rev. 3 Civil-Deadloads Annulus Hangar Frames Contaiment Structure EL 101' 
The above mentioned drawings contain information regarding point or concentrated weights and distributed weights. Amongst the first category are contributions due to (a) large bore mechanical pipes and supports, (b) mechanical equipment (c) architectural platforms and ventilation ducts and equipment. The latter category of weight includes such items as (a) mechanical small bore piping, (b) electrical conduits, trays and equipment and (c) gratings. In order to obtain the nodal masses used in the model, based on the itens mentioned above, it was necessary to subdivide the total area into tributary areas for each of the nodes in the model. The uniform loading was then multiplied by this area to determine the resulting lumped mass. The concentrated masses were then assigned to the node in whose tributary area they fell. The resultant lumped masses were then totaled for each of the floors and compared with the total weight on the drawings to verify the computation.

\subsection{Member Connectivity}

Member connections were modeled as either shear (pinned) or moment connections. All beam to beam and beam to girder connections were modeled as shear connections. All connections to the crane wall were also modeled as shear connections. The girder to column connections were modeled in accordance to the three different models used in the study (see work scope description), i.e.,

Model A: All girder to column connections treated as shear connections,

Model B: Girder to column connections in floors one and two fixed with the top two floor connections pinned,

Model C: Girder to column connections in floors one, two and three fixed with the top floor connections pinned. 


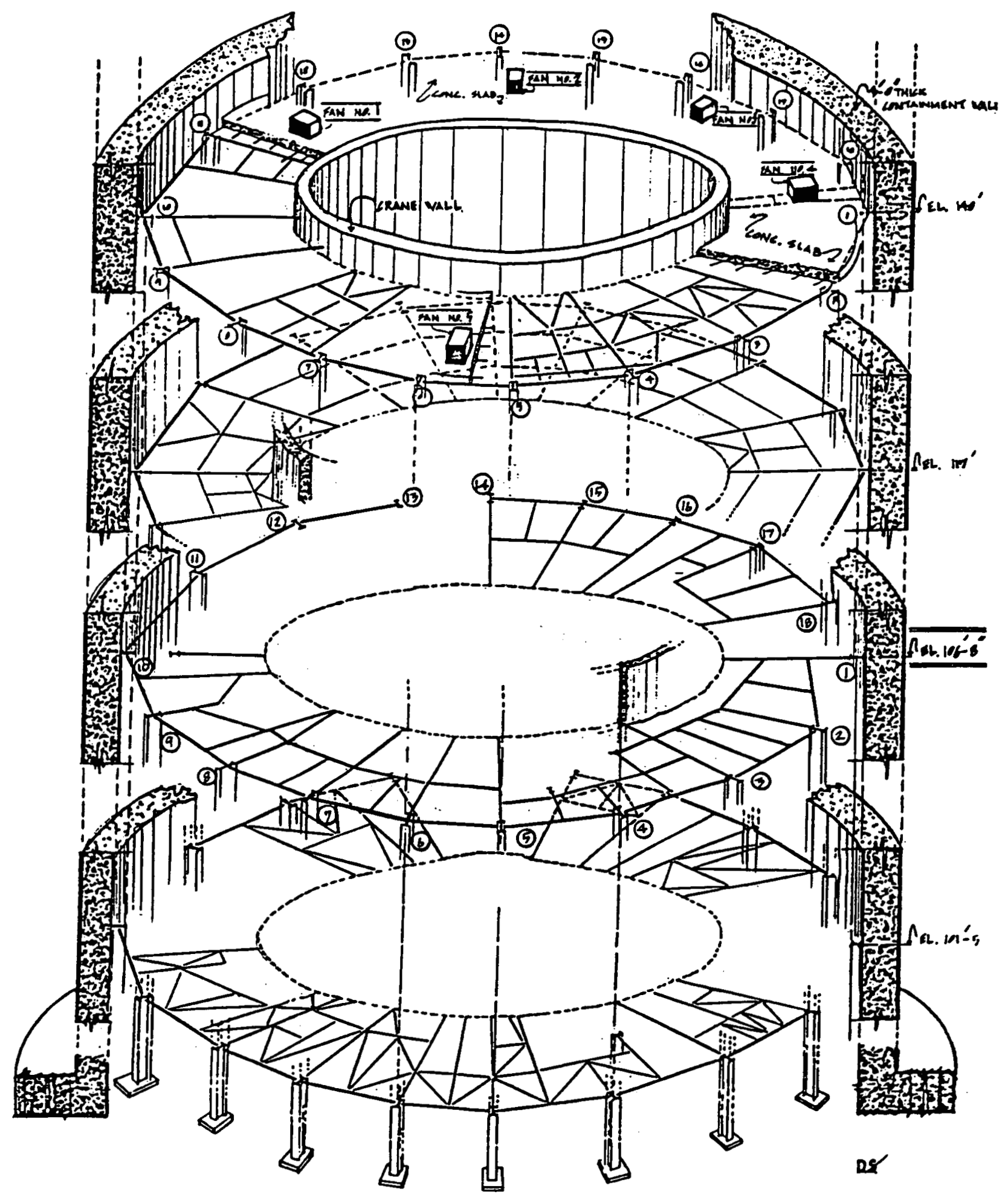

Figure 2.1 - Schematic View of Conta inment Annulus Structure 

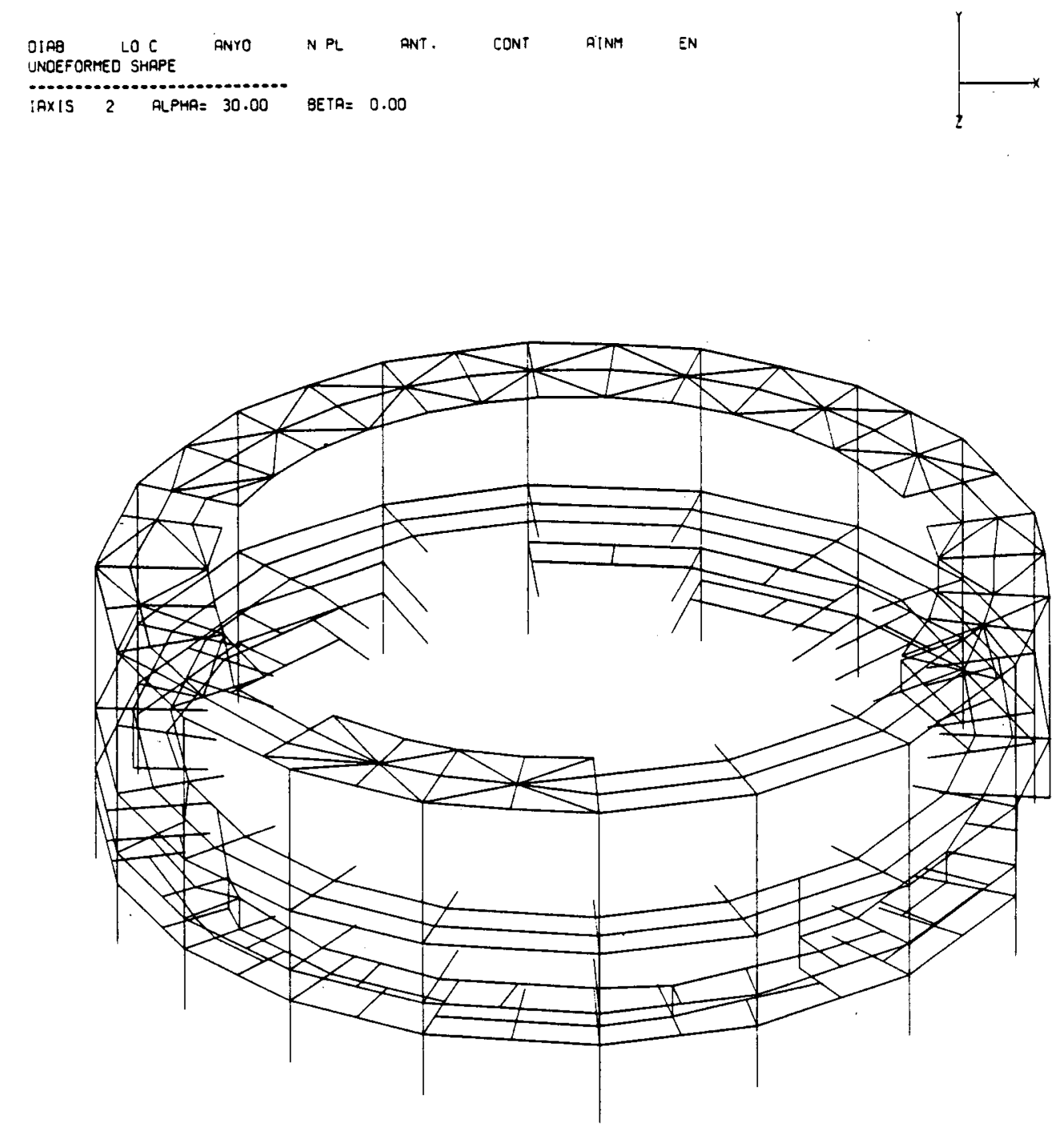

Figure 2.2 - Three-dimensional finite el ement model 


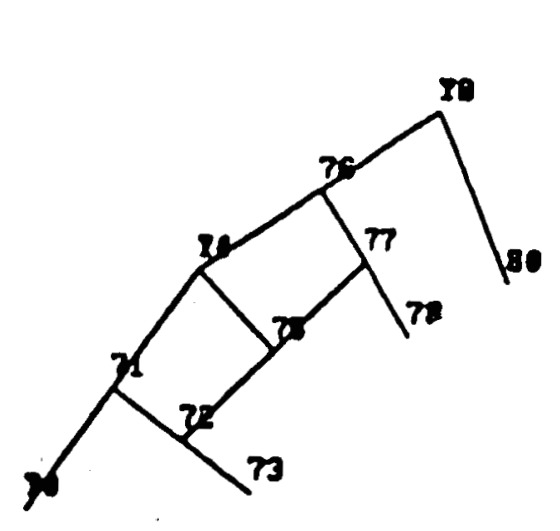

13

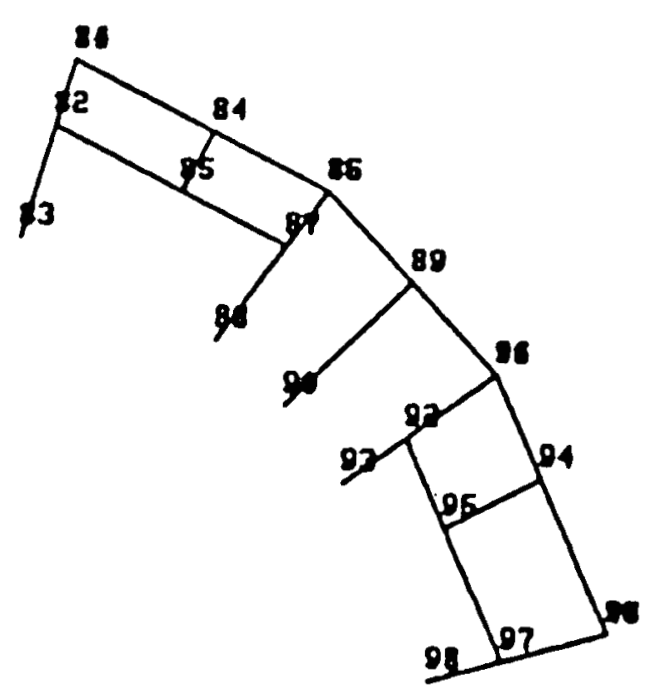

$\stackrel{1}{n}$

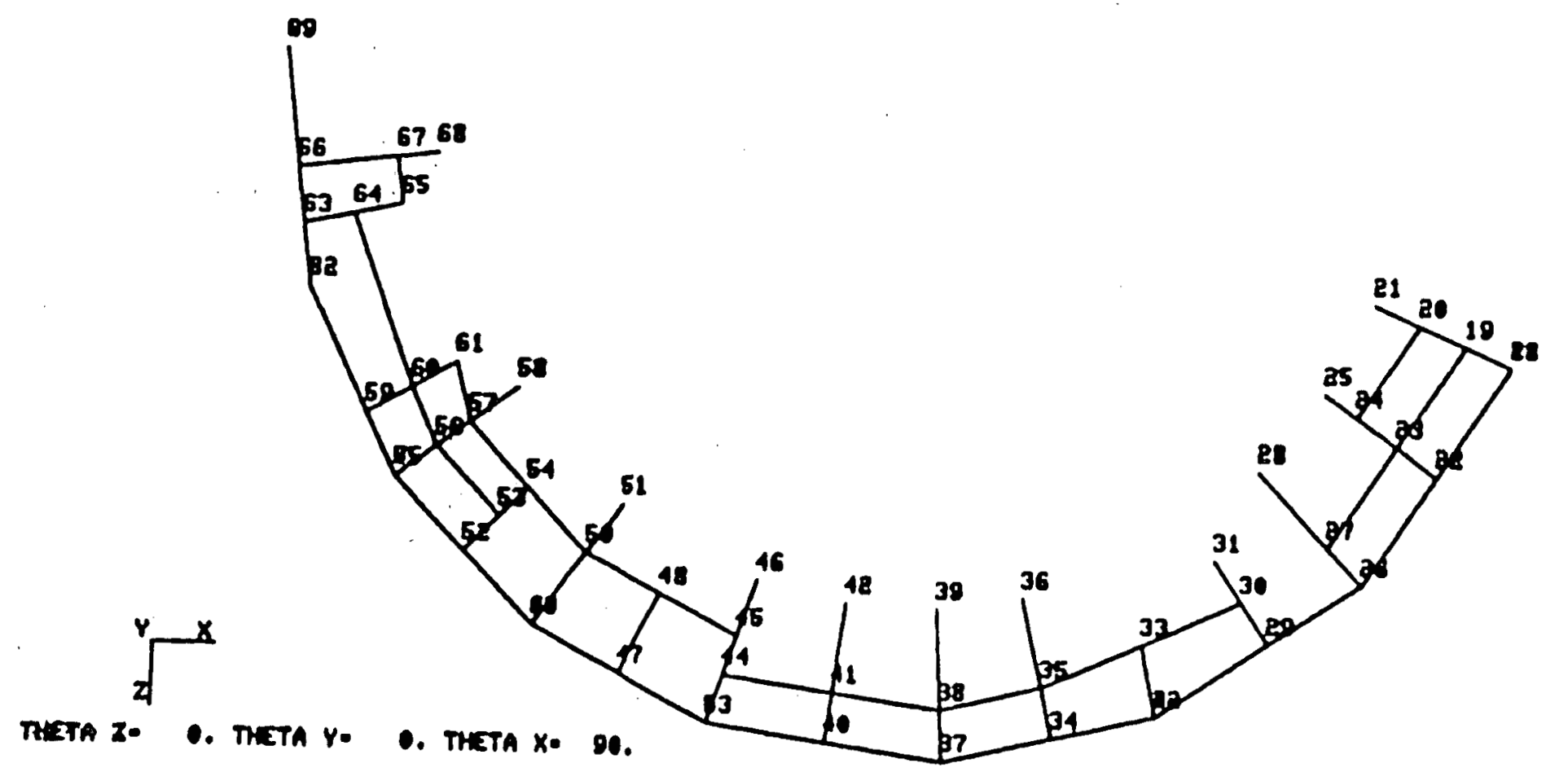

Figure 2.3 - Model Details for floor at elevation 101' 


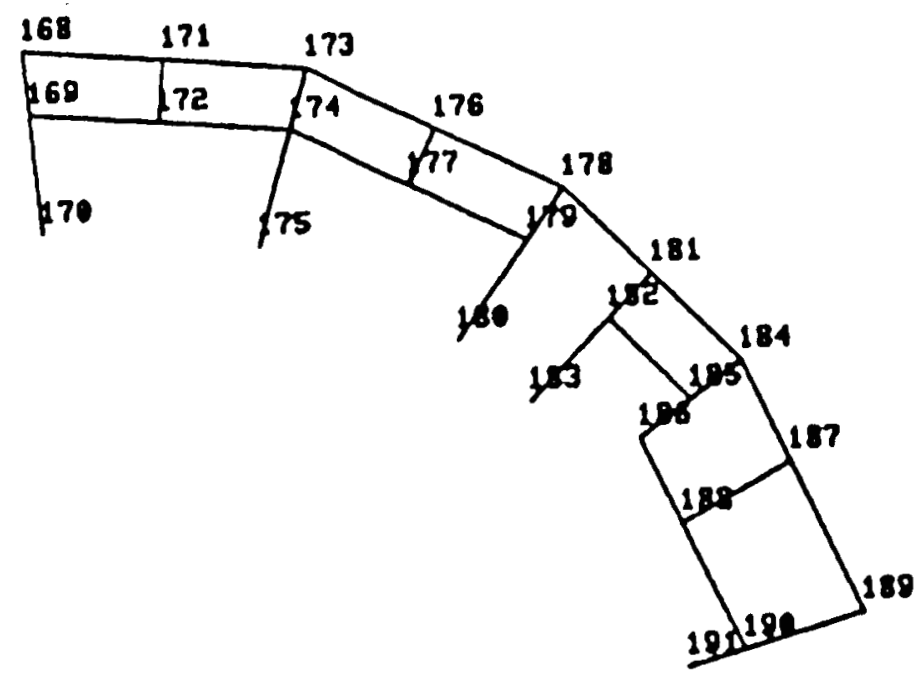

N
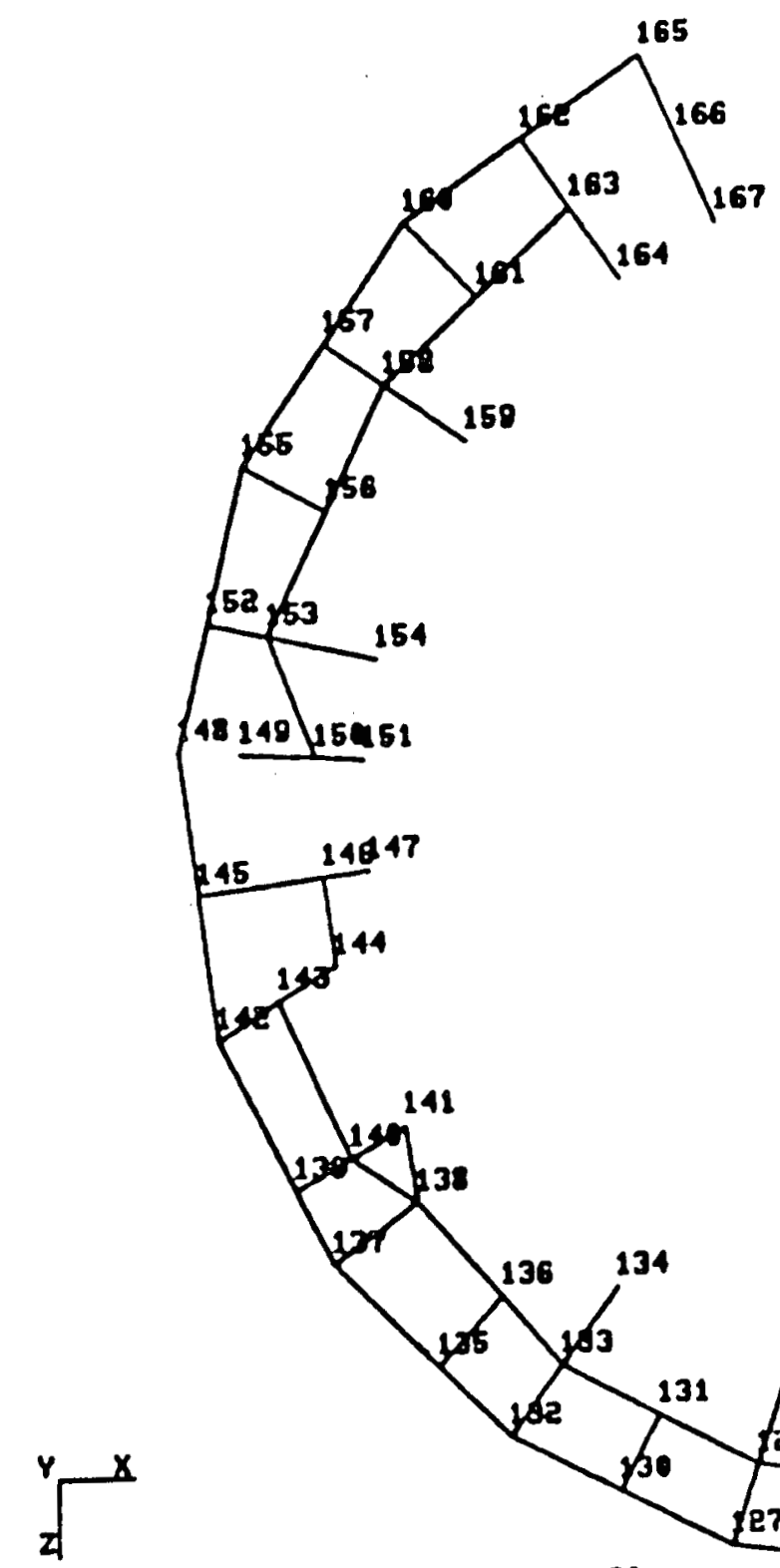

TETA Z-

-. theta y-

-. Theta $x=00$.

Figure 2.4 - Model Details for floor at elevation 106' 


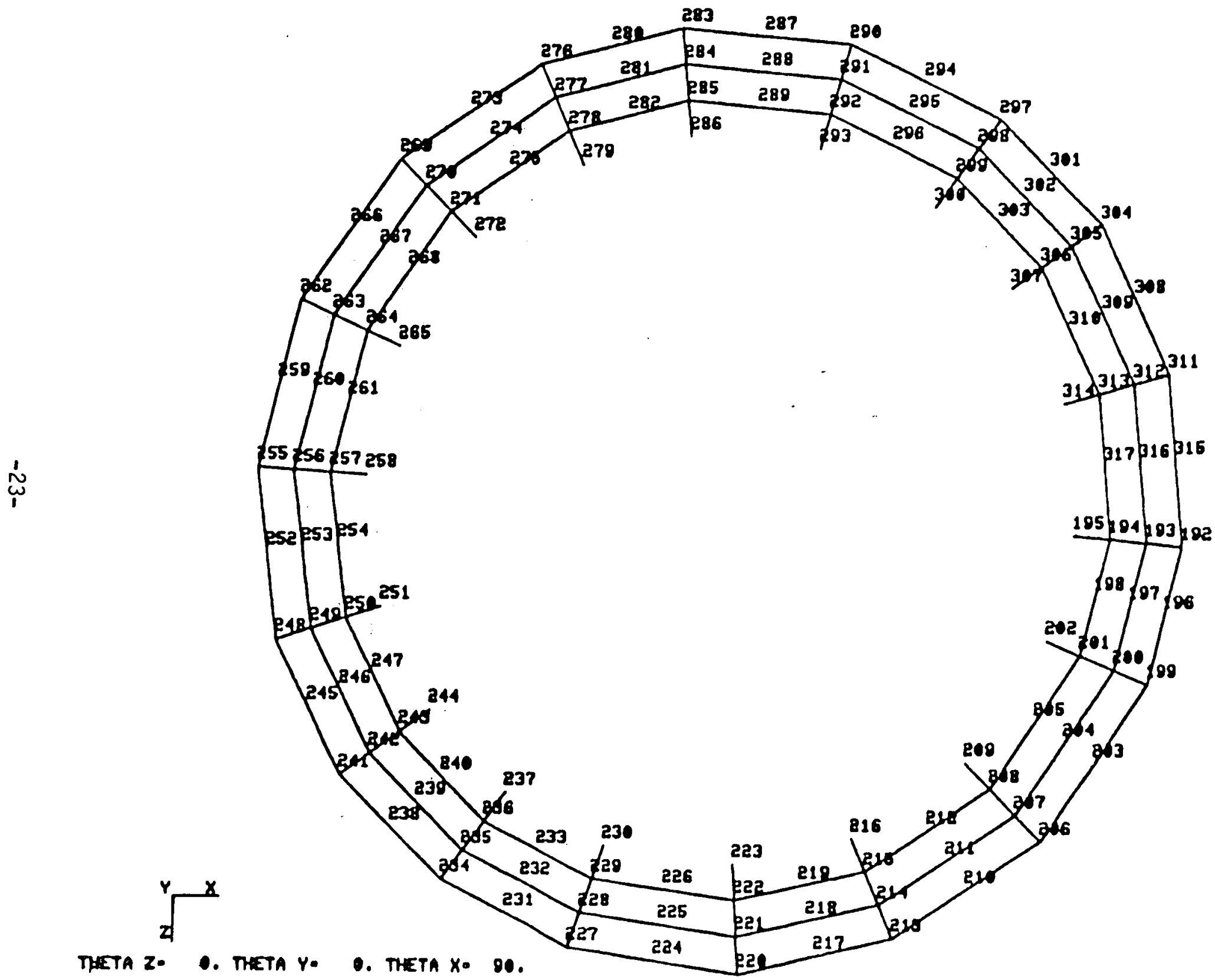

Figure 2.5 - Model Details for floor at elevation 117' 


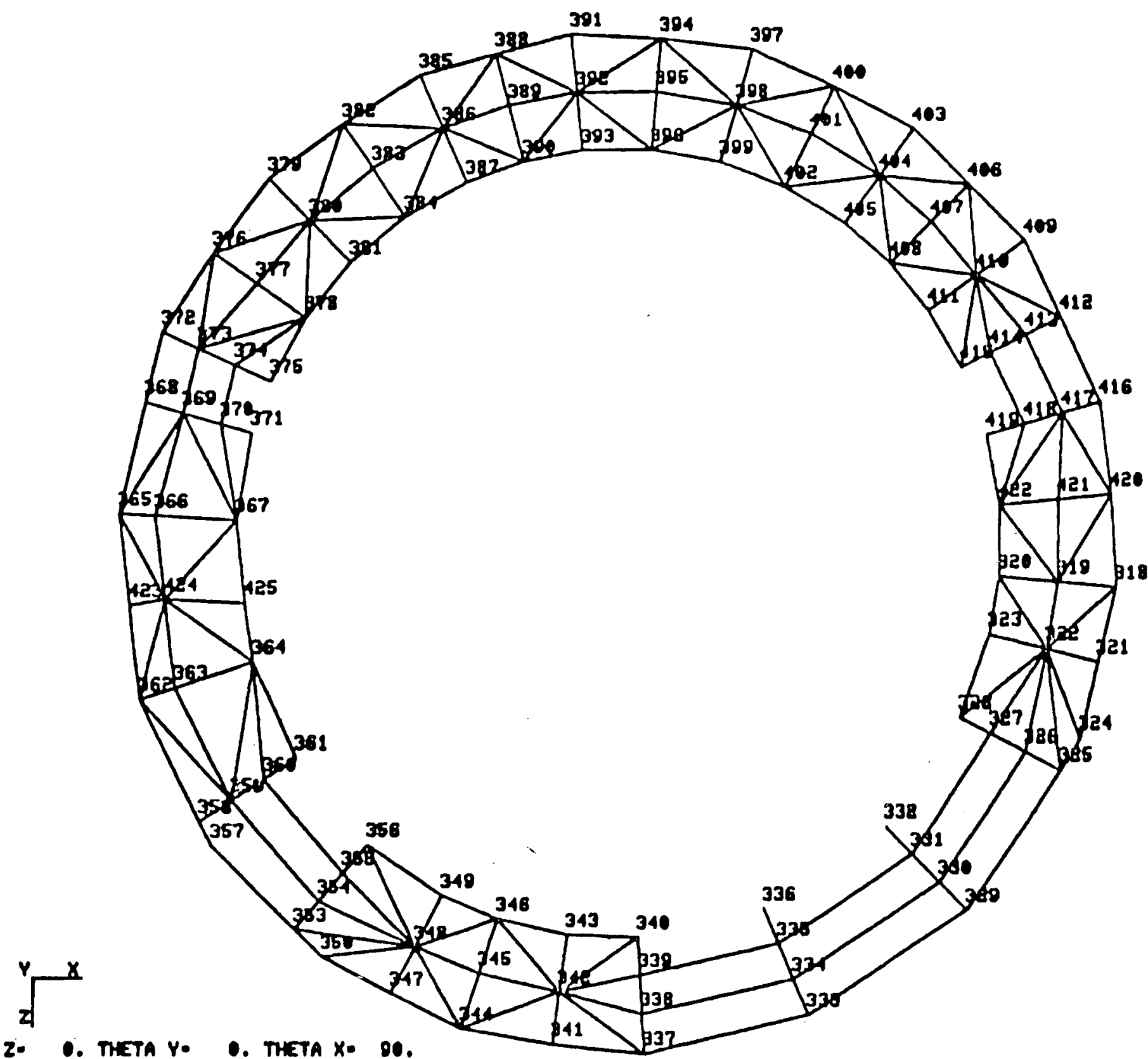

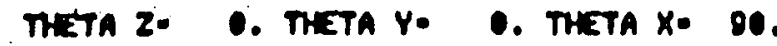

Figure 2.6 - Model Details for floor at elevation 140' 


\subsection{Structural Evaluations}

The seismic evaluations perfomed for the contaiment annulus structure required (1) a free-vibration analysis to obtain the modal characteristics of the structure, (2) a time history analysis to determine absolute acceleration response records at various locations along the structure and finally (3) the development of the floor response spectra. All structural evaluations were, as mentioned, carried out for the vertical direction only. A comparative study was also made in order to verify the computational scheme used in the BNL analysis. Following the development of the floor response spectra at the majority of the nodal points of the 30 model, representative floor response spectra were computed for the four floors of the structure. In addition the necessary floor response spectra and displacements were computed, in order to supply the input for the selected piping systems.

It should be noted that due to the uncertainties regarding the boundary conditions of the structure, all structural evaluations were repeated for three different types of connectivity between the structural members.

Each of the above items are discussed in detail in the paragraphs that follow.

\subsection{Free-vibration analysis}

The modal characteristics of the structure i.e., modal shapes and frequencies were obtained in the vertical direction. Three cases were studied depending on the boundary conditions utilized for the mathematical model.

The first case, i.e., model A, corresponds to a pin-connected model in which all member connections are considered as shear type. The other two cases, i.e., models $B$ and $C$, involve beam-to-column connections which are moment type. Specifically in the second case, the beam to column connections of the first and second floor at elevations 101' and 106', respectively, are considered to be moment type, while in the third case, the beam to column 
connections of the first, second and third floor (el. 101', 106' and 117') are moment type. Table 3.1 summarizes the cases used in the structural evaluations. With exception of the different types of boundary conditions applied, all three models have the same characteristics, i.e., stiffness and mass as those described in paragraph 2.1. As mentioned in the work scope section, this classification of the structural mathematical model became necessary, due to the uncertainty regarding the boundary conditions encountered during the course of this work.

Table 3.1

Model-cases evaluated for different boundary conditions

Model case

Model characteristics

A

A11 member connections

are shear type

B

Beam-to-column conections

for the floors at elevations

$101^{\prime}$ and $106^{\prime}$ are moment type

C

Beam-to-column connections

for the floors at elevations

$101^{\prime}, 106^{\prime}$ and $117^{\prime}$ are moment

type. 
In terms of stiffness, it appears that the structure is characterized by weak elastic coupling. From the modal analysis performed for all models, i.e., $A, B$ and $C$, it was found that many of the modes are local in nature. This result was expected due to the physical arrangement of the structural components of the containment annulus structure. Coupling effects between the floors are mainly introduced by the presence of the columns, the crane wall and the various hangers.

From the obtained modes, it was concluded that they are either of very localized type or are spread over sections throughout all the floors. A typical localized mode which excites basically a small portion of the structure at $10 \mathrm{w}$ frequency $(11.8 \mathrm{cps})$ is depicted in Figure 3.1 . The dotted lines indicate the undeformed shape of the structure. It is observed that in this mode only some steel beams of the top floor (el. 140') participate whereas the concrete part is not excited. These beams are located at an opening arrangement in the floor. From Figure 3.1 it is concluded that most of the activity at this modal frequency occurs at the second floor. Another mode obtained at a frequency of $13 \mathrm{cps}$ is shown in Figure 3.2. Again the dotted lines indicate the undeformed shape of the structure. This mode is spread over a larger portion of the structure than that of the one discussed previously. The third floor is the most effected at this modal frequency whereas all other floors also participate over a larger section of the structure than in the previous case. It is to be noted that a small part of the concrete slab of the top floor not excited before (Figure 3.1) is now (Figure 3.2) excited in this mode.

Three free-vibration analyses were performed corresponding to the three model types $A, B$ and $C$. The number of very localized modes decreased from case $A$ to $C$. While it was felt that modes up to $20 \mathrm{cps}$ may be sufficient to campute. structural responses based on the modal superposition technique, we nevertheless, at NRC's request included higher modes. The number of modes required to cover a frequency range up to 33 cps was found to be very large, due to the fact that the structural modes are close-spaced. At very close frequency values, different parts of the structure are excited. Specifically 
a total of 158 modes were required to reach a frequency of value $33.12 \mathrm{cps}$. The corresponding modal frequencies are given in Table 3.2. These values are for model A. Frequencies for model $B$ are given in Table 3.2.1.

\subsection{Input Time History}

The input acceleration time history used for all structural evaluations is the Newmark $7.5 \mathrm{M}$ Hosgri earthquake scaled by $2 / 3$ for $0.5 \mathrm{~g}$ peak value. The characteristics of the digitized record for this input are:

$\begin{array}{lll}\text { peak acceleration: } & 0.50 \mathrm{~g} \\ \text { time interval }: & 0.01 \mathrm{sec} \\ \text { data points }: & 2400\end{array}$

The input acceleration record is shown in Figure 3.3. This figure is taken from page 46 of reference 1.

\subsection{Generation of Vertical Floor Response Spectra}

In generating the vertical floor response spectra for the containment annulus structure of the Unit 1 Diablo Canyon Plant the time history method was used. First the vertical absolute acceleration time histories at the nodal points of the structure were evaluated. For this purpose, the freevibration characteristics of the structure (modal shapes and frequencies) described in paragraph 3.1 were utilized to uncouple the equations of motion of the structure. The time histories of the vertical nodal accelerations were obtained by employing the modal superposition technique. Modal damping equal to $7 \%$ of the critical was employed in these evaluations.

It should be noted that for unconditionally stable schemes of numerical integration, i.e., Wilson- $\theta$ method, a time step $\Delta t=T / 10$ ( $T$ is the shortest period of interest) is generally adequate for accurate response calculations. A time step equal to 0.001 seconds was used for the integration of the modal equations. The accuracy of the results obtained by utilizing this integration 
time step was further investigated. Particularly, a finer time increment $\Delta t=$ 0.0005 seconds was also used to compute structural responses. The latter were then compared with those previously computed with $\Delta t=0.001$ seconds. From this comparison it was concluded that the integration time step of 0.001 seconds is sufficient. Typical results of this comparison are demonstrated in Figures 3.4 to 3.9. Finally, all structural responses were computed for a total duration of 15.00 seconds. Essentially, the peak responses occured within this time duration.

Following the evaluation of the nodal absolute accelerations, the floor response spectra were generated by employing standard techniques. For this purpose, the absolute acceleration time histories were used as input to a single degree-of-freedom system and acceleration spectra were computed. These spectra were developed for 2, 3 and 4 percent equipment damping. Thus the spectral damping values used, concur with the values used by the Pacific Gas and Electric Company (see Ref. [1]).

The above procedure for the generation of vertical floor response spectra, based on time history analysis, was repeated three times in order to cover all models i.e., A, B and C, (see Table 3.1). Each time, the floor response spectra at more than two-hundred nodal points for the above three spectral damping values were computed. Approximately two-thousand spectral curves were generated under the present study. 
Table 3.2

MODAL FREQUENCIES

MODEL A

\begin{tabular}{|c|c|c|c|c|c|c|c|}
\hline $\begin{array}{c}\text { Mode } \\
\text { No. }\end{array}$ & $\begin{array}{l}\text { Freq. } \\
\text { (cps) }\end{array}$ & $\begin{array}{c}\text { Mode } \\
\text { No. }\end{array}$ & $\begin{array}{l}\text { Freq. } \\
\text { (cps) }\end{array}$ & $\begin{array}{l}\text { Mode } \\
\text { No. }\end{array}$ & $\begin{array}{l}\text { Freq. } \\
\text { (cps) }\end{array}$ & $\begin{array}{c}\text { Mode } \\
\text { No. }\end{array}$ & $\begin{array}{l}\text { Freq. } \\
\text { (cps) }\end{array}$ \\
\hline 1 & 6.59 & 21 & 12.19 & 41 & 14.34 & 61 & 16.60 \\
\hline 2 & 6.71 & 22 & 12.24 & 42 & 14.39 & 62 & 16.62 \\
\hline 3 & 7.71 & 23 & 12.35 & 43 & 14.48 & 63 & 16.71 \\
\hline 4 & 7.75 & 24 & 12.95 & 44 & 14.81 & 64 & 16.92 \\
\hline 5 & 8.52 & 25 & 13.10 & 45 & 14.83 & 65 & 17.05 \\
\hline 6 & 8.76 & 26 & 13.25 & 46 & 14.85 & 66 & 17.15 \\
\hline 7 & 9.39 & 27 & 13.28 & 47 & 14.98 & 67 & 17.28 \\
\hline 8 & 9.45 & 28 & 13.45 & 48 & 15.28 & 68 & 17.39 \\
\hline 9 & 9.66 & 29 & 13.49 & 49 & 15.39 & 69 & 17.63 \\
\hline 10 & 10.13 & 30 & 13.56 & 50 & 15.58 & 70 & 17.81 \\
\hline 11 & 10.40 & 31 & 13.67 & 51 & 15.62 & 71 & 17.83 \\
\hline 12 & 10.73 & 32 & 13.82 & 52 & 15.82 & 72 & 17.91 \\
\hline 13 & 11.07 & 33 & 13.85 & 53 & 15.90 & 73 & 18.11 \\
\hline 14 & 11.22 & 34 & 13.87 & 54 & 15.94 & 74 & 18.18 \\
\hline 15 & 11.54 & 35 & 13.90 & 55 & 16.07 & 75 & 18.27 \\
\hline 16 & 11.65 & 36 & 13.95 & 56 & 16.12 & 76 & 18.28 \\
\hline 17 & 11.87 & 37 & 13.97 & 57 & 16.12 & 77 & 18.36 \\
\hline 18 & 12.07 & 38 & 14.01 & 58 & 16.19 & 78 & 18.45 \\
\hline 19 & 12.14 & 39 & 14.20 & 59 & 16.25 & 79 & 18.50 \\
\hline 20 & 12.19 & 40 & 14.22 & 60 & 16.45 & 80 & 18.65 \\
\hline
\end{tabular}


Table 3.2 (cont'd)

MODAL FREQUENCIES

MODEL A

\begin{tabular}{|c|c|c|c|c|c|c|c|}
\hline $\begin{array}{l}\text { Mode } \\
\text { No. }\end{array}$ & $\begin{array}{l}\text { Freq. } \\
\text { (cps) }\end{array}$ & $\begin{array}{l}\text { Mode } \\
\text { No. }\end{array}$ & $\begin{array}{l}\text { Freq. } \\
\text { (cps) }\end{array}$ & $\begin{array}{l}\text { Mode } \\
\text { No. }\end{array}$ & $\begin{array}{l}\text { Freq. } \\
\text { (cps) }\end{array}$ & $\begin{array}{l}\text { Mode } \\
\text { No. }\end{array}$ & $\begin{array}{l}\text { Freq. } \\
\text { (cps) }\end{array}$ \\
\hline 81 & 18.80 & 101 & 21.30 & 121 & 23.92 & 141 & 27.06 \\
\hline 82 & 18.84 & 102 & 21.52 & 122 & 24.13 & 142 & 27.10 \\
\hline 83 & 18.88 & 103 & 22.04 & 123 & 24.24 & 143 & 27.69 \\
\hline 84 & 18.93 & 104 & 22.17 & 124 & 24.29 & 144 & 27.93 \\
\hline 85 & 19.07 & 105 & 22.30 & 125 & 24.38 & 145 & 28.14 \\
\hline 86 & 19.11 & 106 & 22.45 & 126 & 24.54 & 146 & 28.42 \\
\hline 87 & 19.41 & 107 & 22.50 & 127 & 24.56 & 147 & 28.43 \\
\hline 88 & 19.44 & 108 & 22.63 & 128 & 24.78 & 148 & 28.88 \\
\hline 89 & 19.61 & 109 & 22.69 & 129 & 24.94 & 149 & 28.96 \\
\hline 90 & 19.73 & 110 & 22.74 & 130 & 25.12 & 150 & 29.21 \\
\hline 91 & 19.82 & 111 & 22.79 & 131 & 25.17 & 151 & 29.50 \\
\hline 92 & 19.87 & 112 & 22.97 & 132 & 25.36 & 152 & 29.50 \\
\hline 93 & 19.94 & 113 & 22.99 & 133 & 25.38 & 153 & 29.89 \\
\hline 94 & 20.01 & 114 & 23.09 & 134 & 25.51 & 154 & 30.66 \\
\hline 95 & 20.16 & 115 & 23.25 & 135 & 25.91 & 155 & 31.03 \\
\hline 96 & 20.34 & 116 & 23.42 & 136 & 26.27 & 156 & 32.18 \\
\hline 97 & 20.37 & 117 & 23.44 & 137 & 26.56 & 157 & 32.32 \\
\hline 98 & 20.59 & 118 & 23.48 & 138 & 26.60 & 158 & 33.12 \\
\hline 99 & 20.66 & 119 & 23.60 & 139 & 26.91 & & \\
\hline 100 & 20.83 & 120 & 23.67 & 140 & 27.02 & & \\
\hline
\end{tabular}


Table 3.2 (cont'd)

MODAL FREQUENCIES

MODEL B

\begin{tabular}{|c|c|c|c|c|c|c|c|}
\hline $\begin{array}{l}\text { Mode } \\
\text { No. }\end{array}$ & $\begin{array}{l}\text { Freq. } \\
\text { (cps) }\end{array}$ & $\begin{array}{l}\text { Mode } \\
\text { No. }\end{array}$ & $\begin{array}{l}\text { Freq. } \\
\text { (cps) }\end{array}$ & $\begin{array}{l}\text { Mode } \\
\text { No. }\end{array}$ & $\begin{array}{l}\text { Freq. } \\
\text { (cps) }\end{array}$ & $\begin{array}{l}\text { Mode } \\
\text { No. }\end{array}$ & $\begin{array}{l}\text { Freq. } \\
\text { (cps) }\end{array}$ \\
\hline 1 & 9.91 & 21 & 14.46 & 41 & 17.14 & 61 & 19.10 \\
\hline 2 & 11.18 & 22 & 14.50 & 42 & 17.30 & 62 & 19.39 \\
\hline 3 & 11.40 & 23 & 14.66 & 43 & 17.41 & 63 & 19.42 \\
\hline 4 & 11.79 & 24 & 14.82 & 44 & 17.59 & 64 & 19.60 \\
\hline 5 & 11.99 & 25 & 15.39 & 45 & 17.74 & 65 & 19.65 \\
\hline 6 & 12.14 & 26 & 15.53 & 46 & 17.80 & 66 & 19.77 \\
\hline 7 & 12.18 & 27 & 15.71 & 47 & 17.92 & 67 & 19.89 \\
\hline 8 & 12.97 & 28 & 15.84 & 48 & 18.04 & 68 & 19.97 \\
\hline 9 & 13.04 & 29 & 15.93 & 49 & 18.10 & 69 & 20.16 \\
\hline 10 & 13.17 & 30 & 15.98 & 50 & 18.15 & 70 & 20.25 \\
\hline 11 & 13.21 & 31 & 16.12 & 51 & 18.26 & 71 & 20.30 \\
\hline 12 & 13.52 & 32 & 16.22 & 52 & 18.27 & 72 & 20.37 \\
\hline 13 & 13.63 & 33 & 16.26 & 53 & 18.36 & 73 & 20.40 \\
\hline 14 & 13.83 & 34 & 16.31 & 54 & 18.50 & 74 & 20.61 \\
\hline 15 & 13.89 & 35 & 16.45 & 55 & 18.60 & 75 & 20.72 \\
\hline 16 & 13.89 & 36 & 16.57 & 56 & 18.71 & 76 & 20.83 \\
\hline 17 & 14.00 & 37 & 16.60 & 57 & 18.80 & 77 & 21.28 \\
\hline 18 & 14.20 & 38 & 16.63 & 58 & 18.88 & 78 & 21.31 \\
\hline 19 & 14.35 & 39 & 17.00 & 59 & 18.93 & 79 & 21.49 \\
\hline 20 & 14.39 & 40 & 17.07 & 60 & 19.00 & 80 & 21.80 \\
\hline
\end{tabular}


Table 3.2 (cont'd)

MODAL FREQUENCIES

MODEL B

\begin{tabular}{|c|c|c|c|c|c|c|c|}
\hline $\begin{array}{l}\text { Mode } \\
\text { No. }\end{array}$ & $\begin{array}{l}\text { Freq. } \\
\text { (cps) }\end{array}$ & $\begin{array}{l}\text { Mode } \\
\text { No. }\end{array}$ & $\begin{array}{l}\text { Freq. } \\
\text { (cps) }\end{array}$ & $\begin{array}{l}\text { Mode } \\
\text { No. }\end{array}$ & $\begin{array}{l}\text { Freq. } \\
\text { (cps) }\end{array}$ & $\begin{array}{l}\text { Mode } \\
\text { No. }\end{array}$ & $\begin{array}{l}\text { Freq. } \\
\text { (cps) }\end{array}$ \\
\hline 81 & 22.06 & 101 & 24.67 & 121 & 28.43 & 141 & 32.56 \\
\hline 82 & 22.23 & 102 & 24.78 & 122 & 28.53 & 142 & 33.30 \\
\hline 83 & 22.38 & 103 & 24.98 & 123 & 28.93 & & \\
\hline 84 & 22.49 & 104 & 25.17 & 124 & 28.95 & & \\
\hline 85 & 22.62 & 105 & 25.19 & 125 & 29.17 & & \\
\hline 86 & 22.71 & 106 & 25.47 & 126 & 29.57 & & \\
\hline 87 & 22.85 & 107 & 25.70 & 127 & 29.67 & & \\
\hline 88 & 22.98 & 108 & 26.03 & 128 & 29.98 & & \\
\hline 89 & 23.09 & 109 & 26.65 & 129 & 30.05 & & \\
\hline 90 & 23.20 & 110 & 26.75 & 130 & 30.18 & & \\
\hline 91 & 23.26 & .111 & 26.97 & 131 & 30.47 & & \\
\hline 92 & 23.33 & 112 & 27.10 & 132 & 30.51 & & \\
\hline 93 & 23.42 & 113 & 27.30 & 133 & 30.69 & & \\
\hline 94 & 23.67 & 114 & 27.38 & 134 & 30.79 & & \\
\hline 95 & 23.91 & 115 & 27.42 & 135 & 31.11 & & \\
\hline 96 & 24.13 & 116 & 27.50 & 136 & 31.79 & & \\
\hline 97 & 24.28 & 117 & 27.72 & 137 & 31.96 & & \\
\hline 98 & 24.39 & 118 & 27.78 & 138 & 32.05 & & \\
\hline 99 & 24.53 & 119 & 27.95 & 139 & 32.29 & & \\
\hline 100 & 24.55 & 120 & 28.16 & 140 & 32.45 & & \\
\hline
\end{tabular}



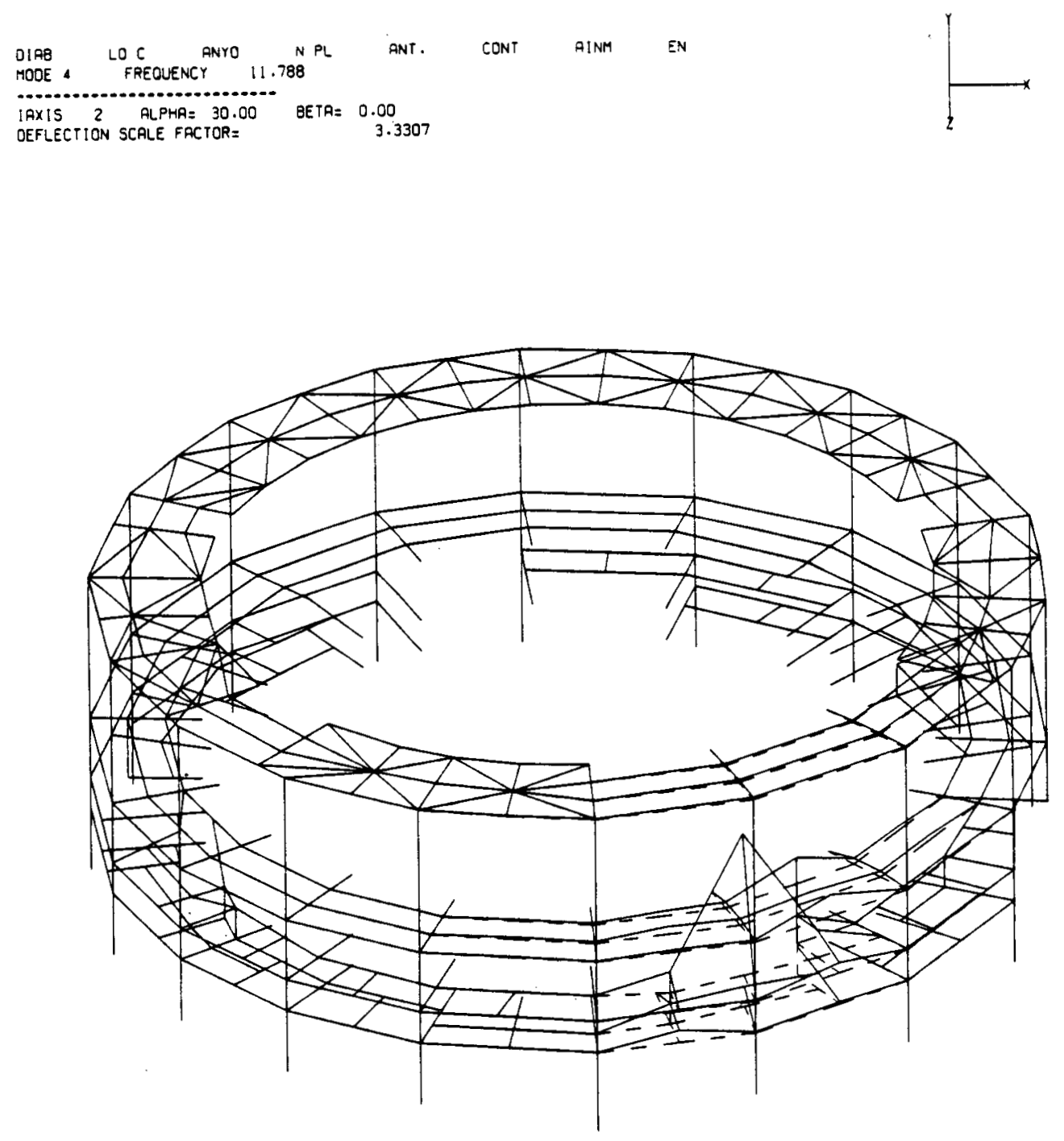

Figure 3.1 - Modal shape at frequency $11.8 \mathrm{cps}$ 

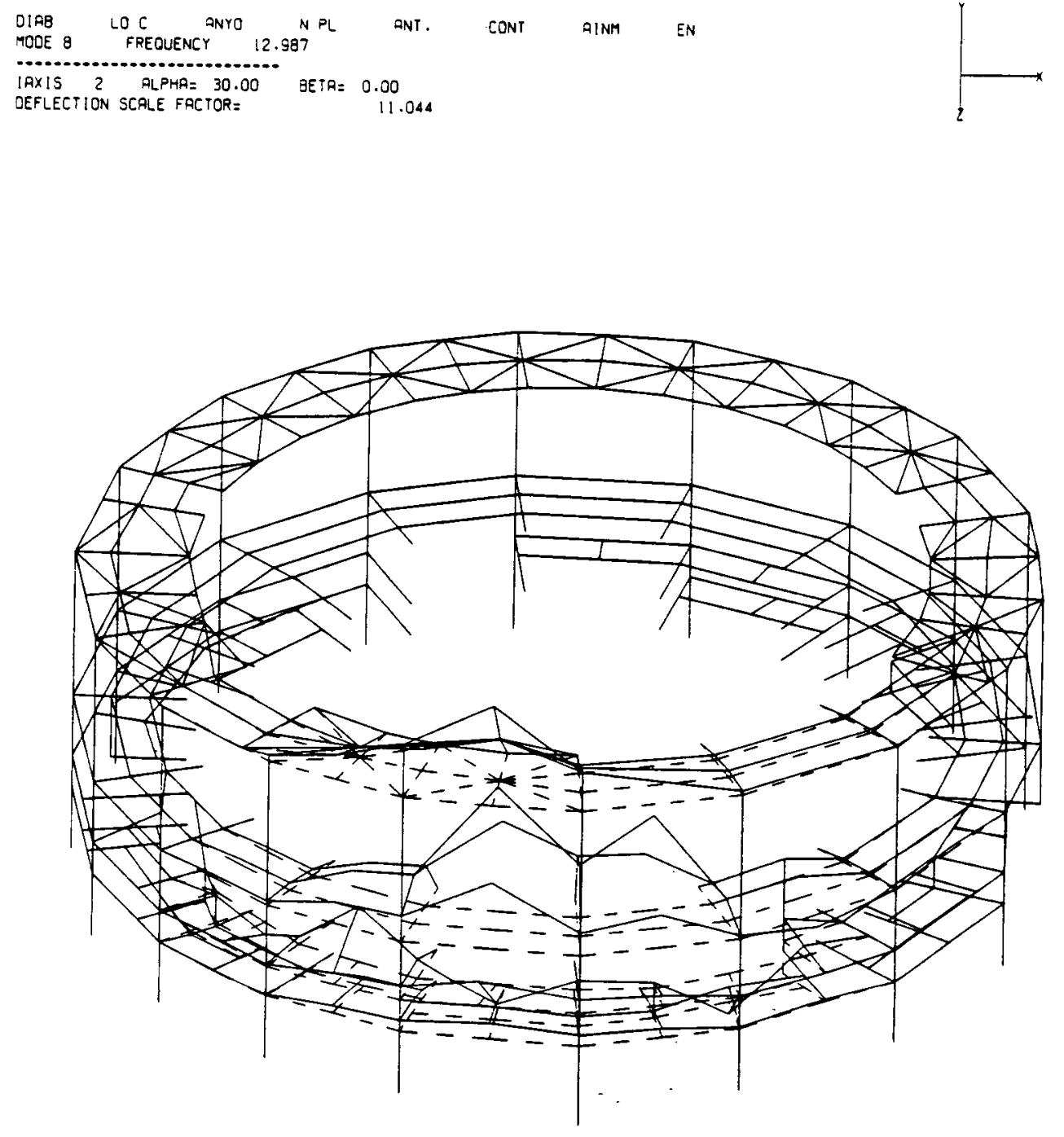

Figure 3.2 - Modal shape at frequency $13.0 \mathrm{cps}$ 


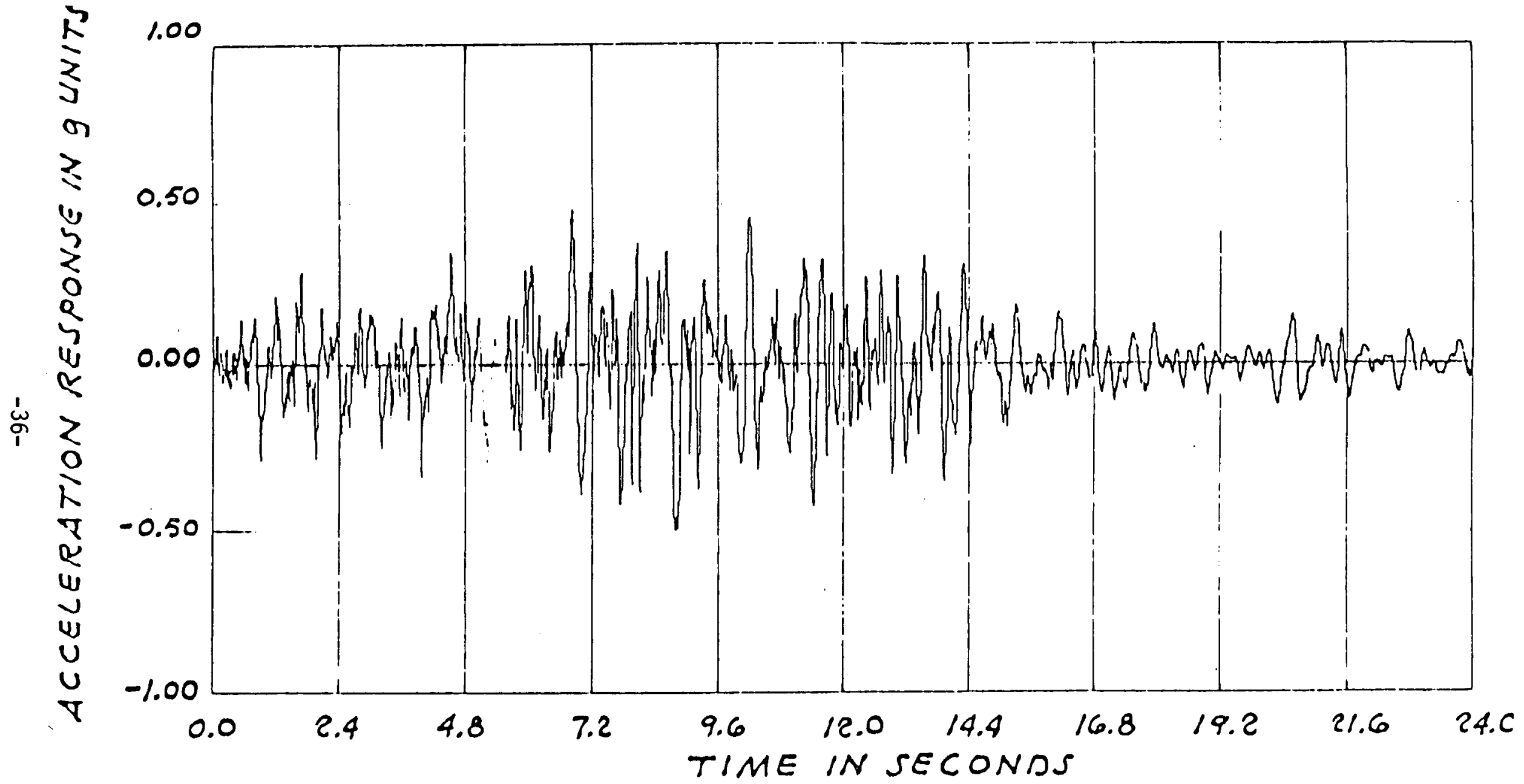

Figure 3.3 - Time history record of input excitation. 
EFFECT OF INTEGRATION TIME STEP

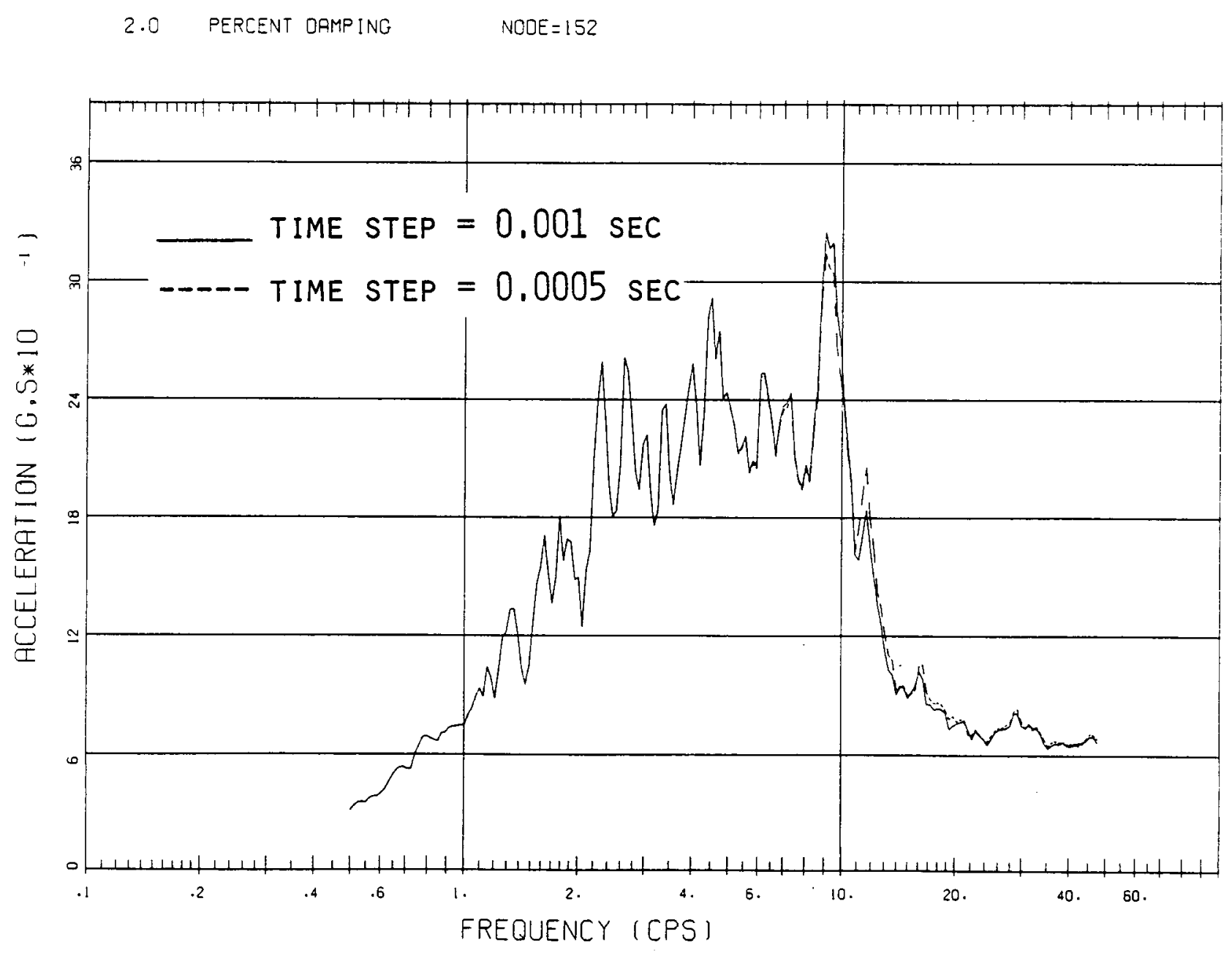

Figure 3.4 - Evaluation of Integration Time Step. Node 152 
EFFECT OF INTEGRATION TIME STEP

2.0 PERCENT DRMPING NODE $\equiv 153$

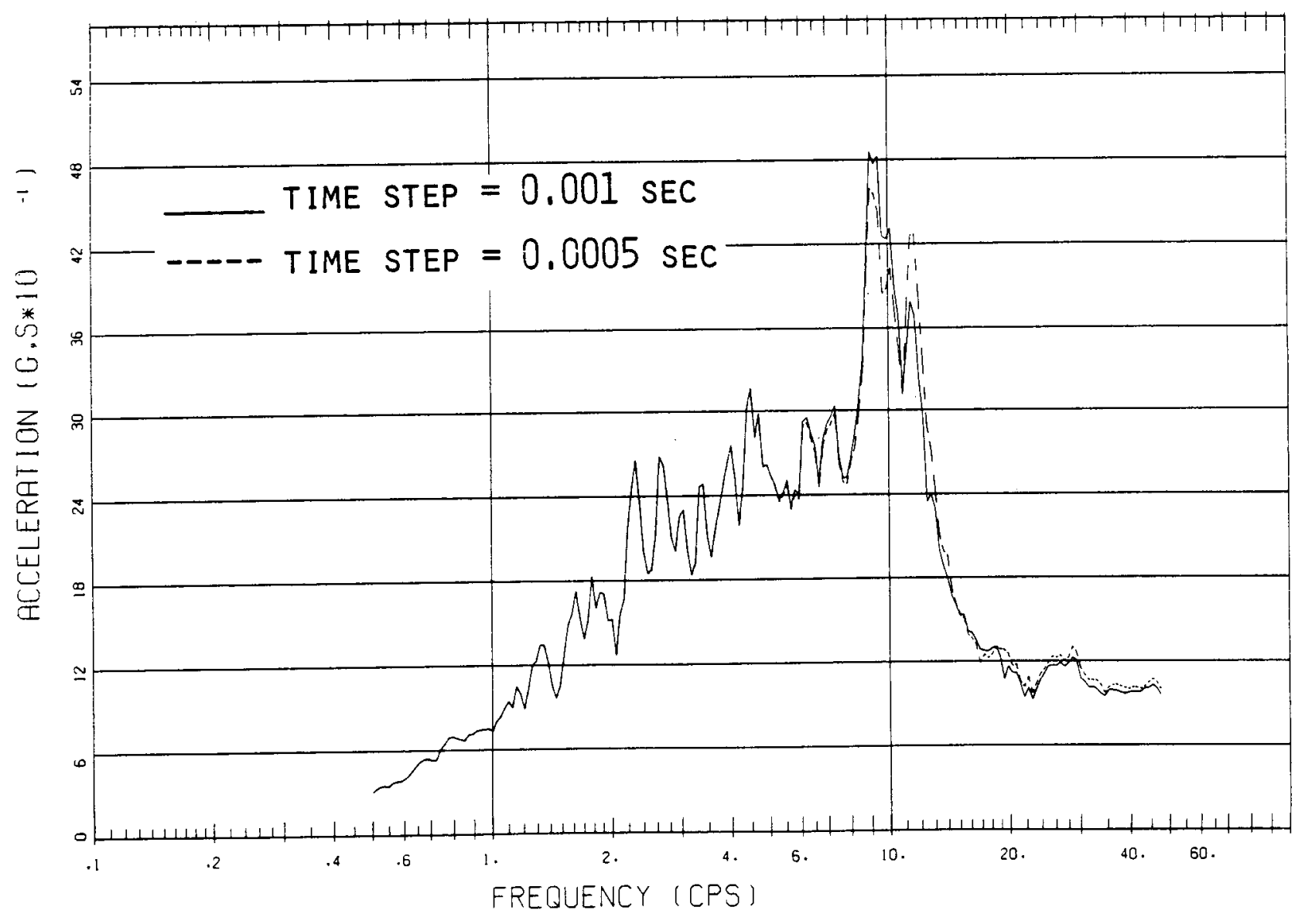

Figure 3.5 - Evaluation of Integration Time Step. Node 153 


\section{EFFECT OF INTEGRATION TIME STEP}

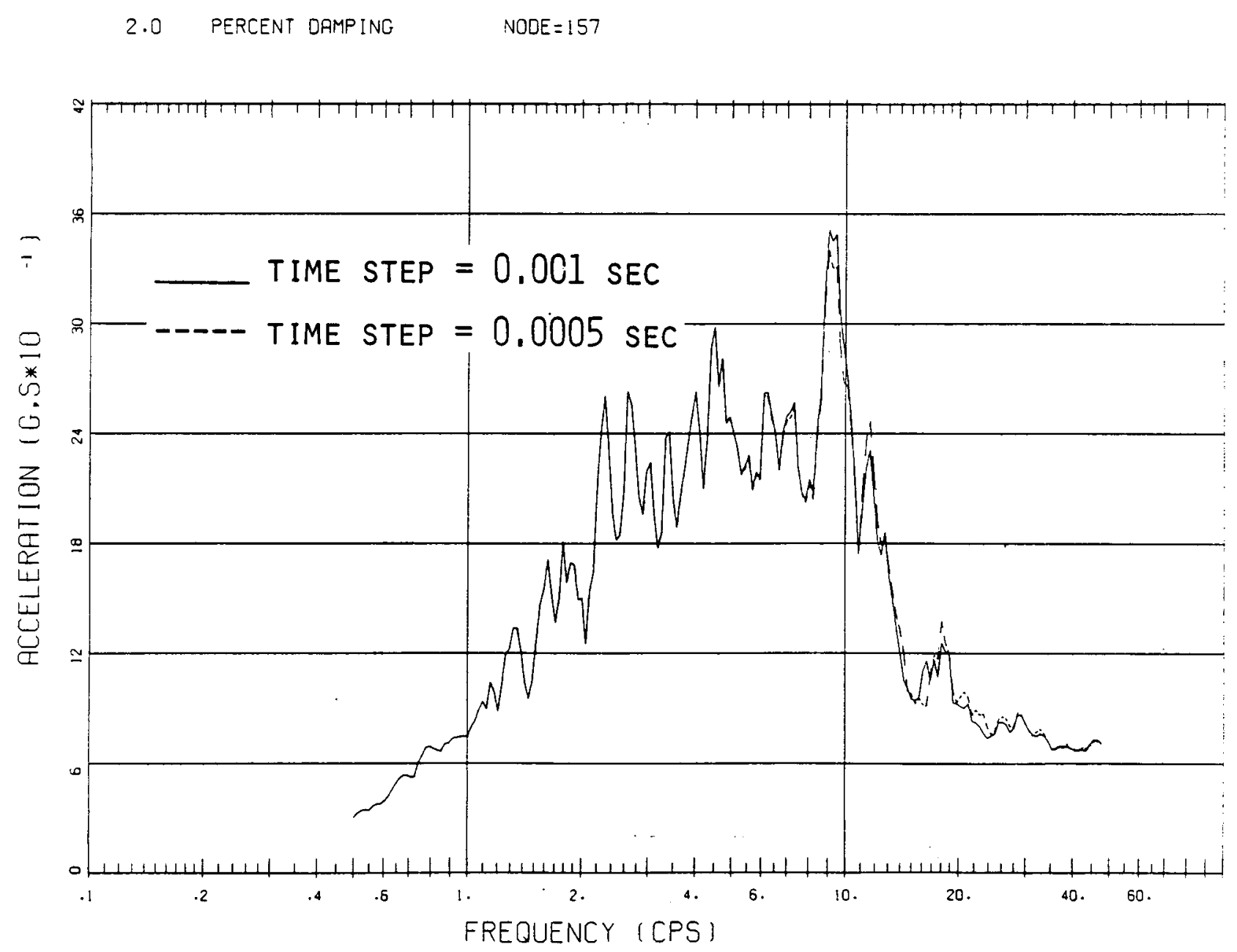

Figure 3.6 - Evaluation of Integration Time Step. Node 157 


\section{EFFECT OF INTEGRATION TIME STEP}

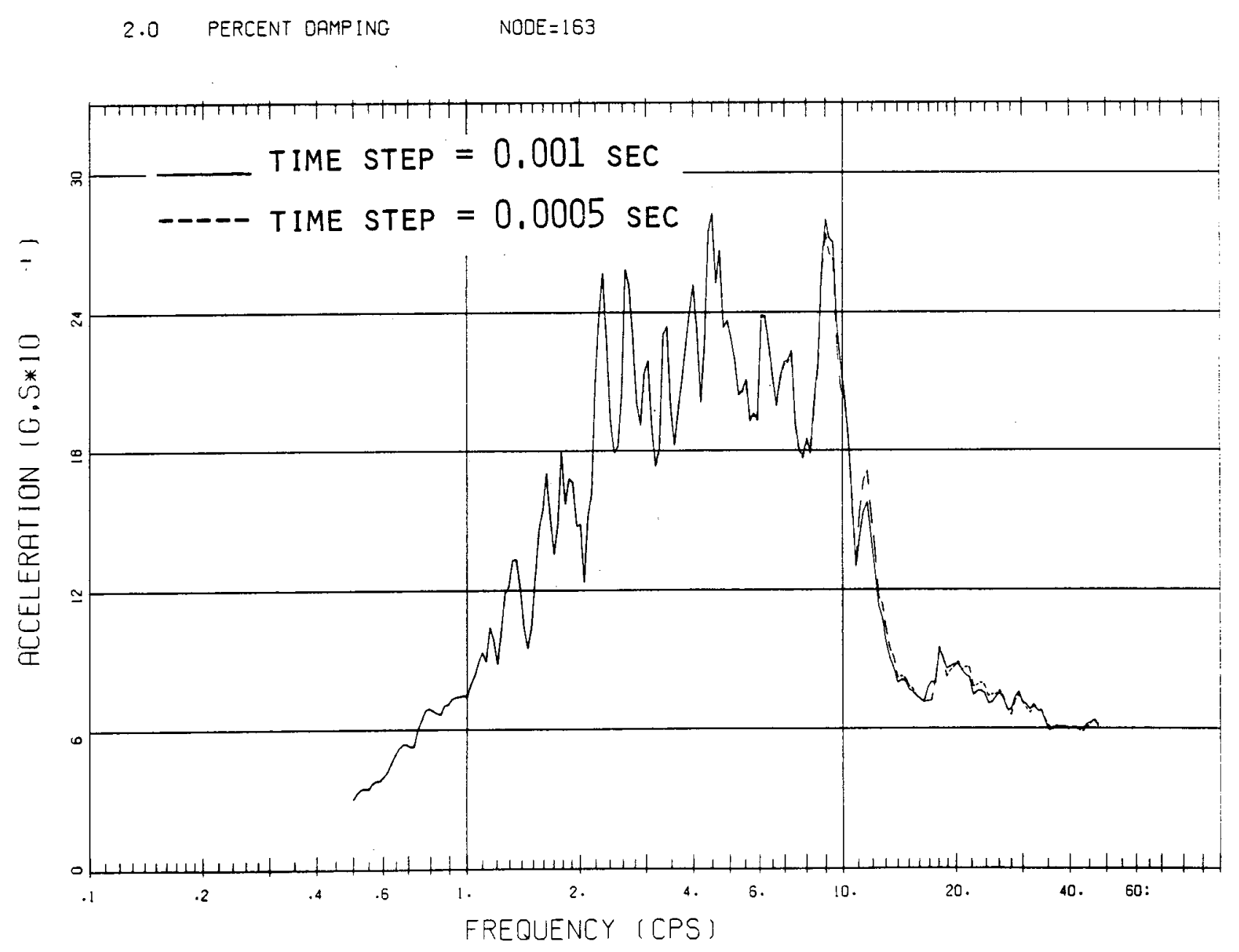

Figure 3.7 - Evaluation of Integration Time Step. Node 163 
EFFECT OF INTEGRation TIME STEP

2.0. PERCENT OAMPING NODE $=166$

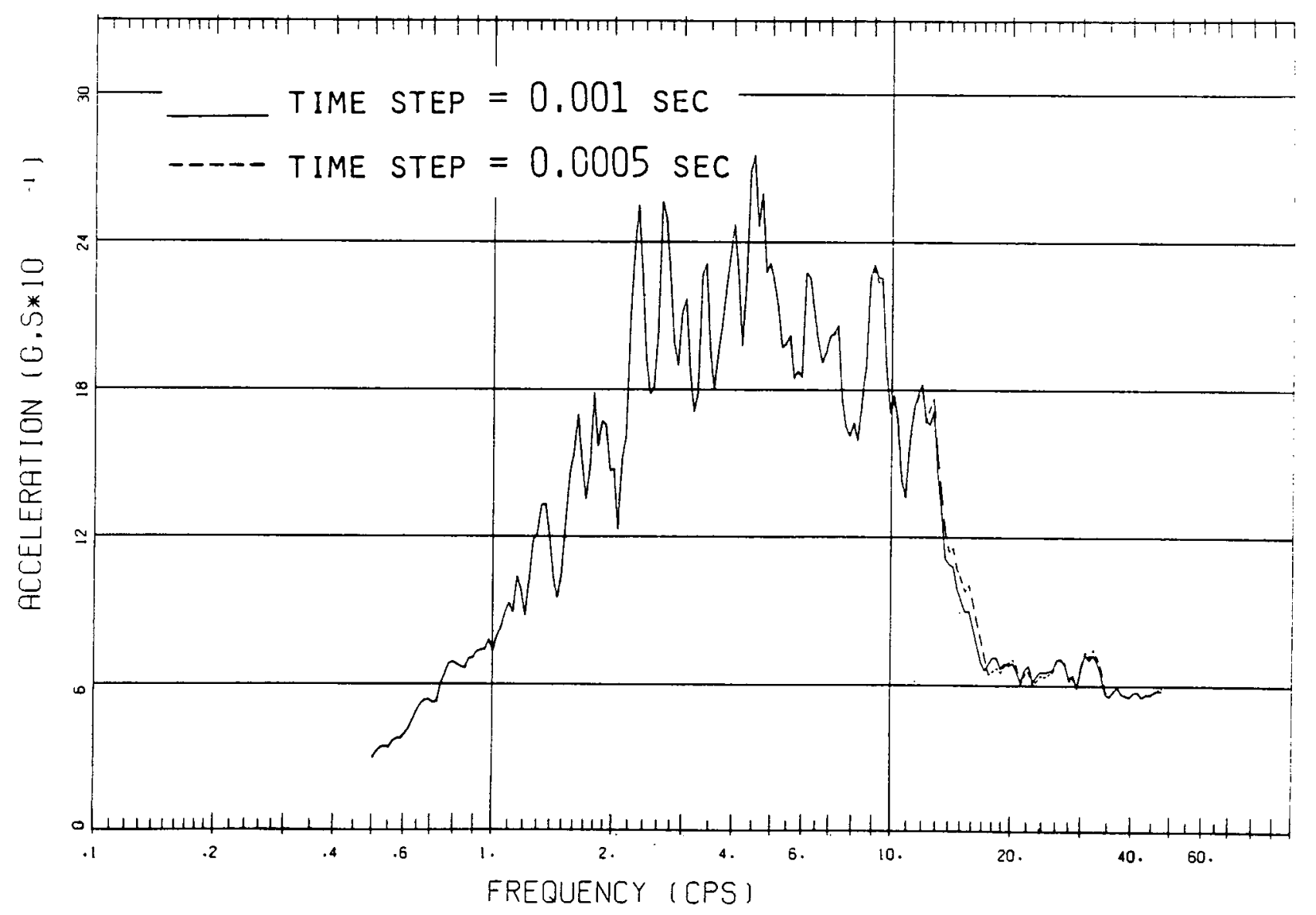

Figure 3.8 - Evaluation of Integration. Time Step. Node 166 


\section{EFFECT OF INTEGRATION TIME STEP}

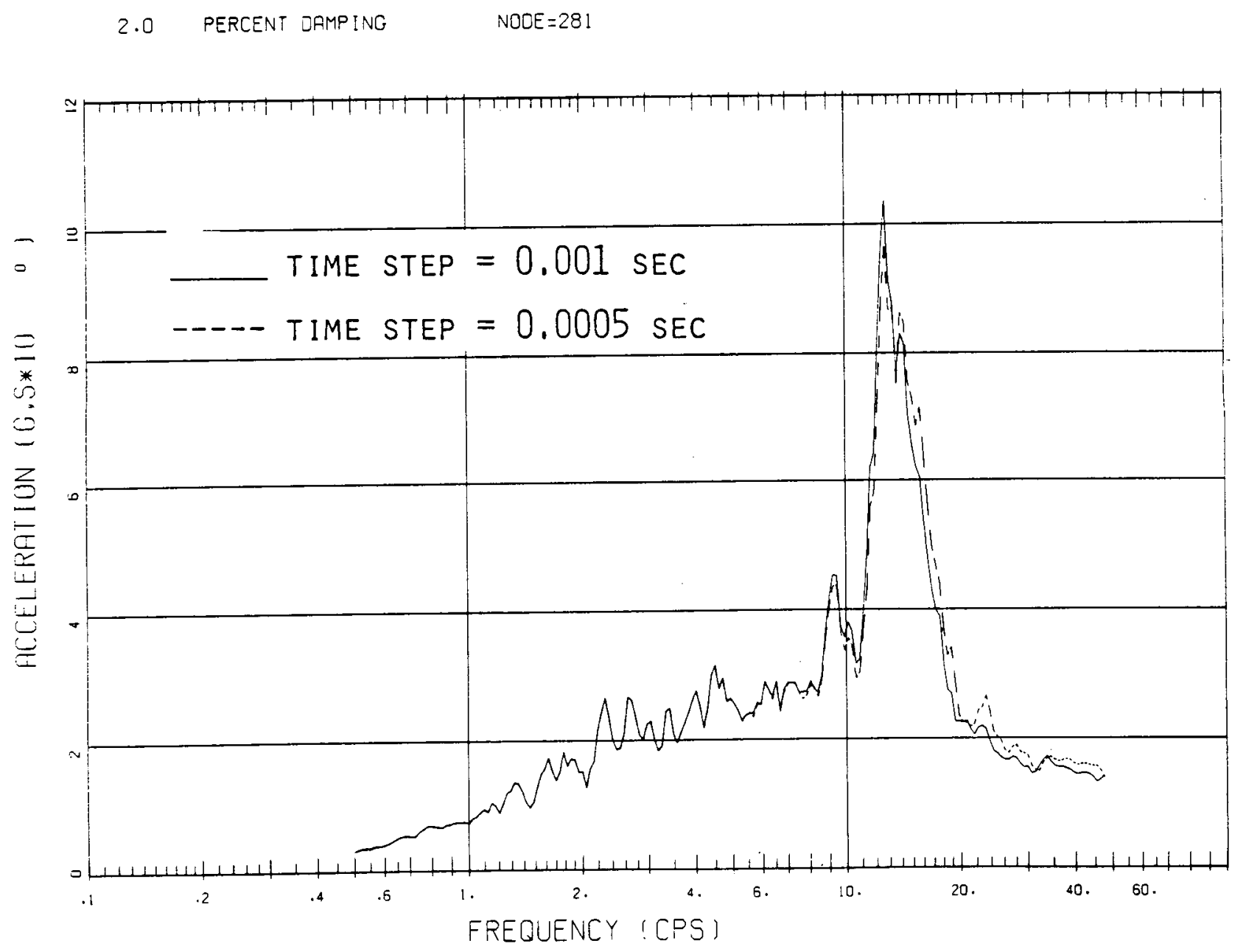

Figure 3.9 - Evaluation of Integration Time Step. Node 281 
4.0 Verification of the 3D Model

4.1 Comparative Study

For the BNL studies reported here the SAPV(2) computer code was utilized. As originally developed this code did not include some of the features required to perform floor response spectra generation. The BNL version of the SAPV code includes special features which have been incorporated over the years into the original SAPV code. Specifically for floor response spectra generation the following options are available:

1) option for computing absolute accelerations

2) restart option for the integration of modal equations

3) option for generating response spectra

For the eigenvalue extraction the subspace iteration method was applied. Due to the large amount of modes involved, it was necessary to modify the portion of the SAPV code dealing with the eigenvalue solution. These modifications were made for the CDC 7600 computer system at the Brookhaven National Laboratory. As mentioned before, a total of 158 modes were required to reach the frequency of $33.12 \mathrm{cps}$. These modes were taken from a computer run in which 190 modes were evaluated.

The original SAPV code also had to be modified in order to include the option of computing absolute acceleration responses required for the generation of the floor response spectra. In addition, due to the combined requirement of the large number of modes together with small integration time step, a restart option was introduced into the code. All response records were evaluated for fifteen thousands time steps, with a time interval equal to 1 msecs. Finally, a spectrum generator was incorporated into the code. This generator is similar to that used in the SIM code (3). 
At NRC's request, a task dealing with computer code verification was undertaken. The objective of this task was to verify the BNL SAPV version with a different computer code avallable in the public domain. After discussions between NRC and BNL, it was agreed that the STRUDL computer program of McDonnel 1 Douglas Automation Company be utilized for this purpose.

Floor response spectra were generated by using both the BNL SAPV version and the STRUDL MCDonnell Douglas computer codes. The results obtained by both codes were compared. Details of this task are given in the next paragraph.

\subsection{Description of Results}

As mentioned, a comparative computer study was made in order to verify the results obtained from the BNL 3-D model of the containment annulus structure. The results obtained from BNL's version of SAPV were compared with those obtained from the MCDonnell Douglas STRUDL-DYNAL computer code.

For this purpose input data of the 3-D model were prepared according to the input requirements of the STRUDL code. Computer runs were made to evaluate the modal shapes and frequencies. Comparative results for the first ten modes from both codes are shown in Table 4.1. As can be seen, the results are quite close.

Additionally, floor response spectra were generated by both codes and compared as shown in Figure 4.1. The solid line represents the STRUDL-DYNAL results while the circled points represent results obtained from SAPV. As can be seen from the figure, the results compare very well. 
Table 4.1

\section{Comparison of Ten Modal Frequencies \\ Computer Codes}

Mode No.

\section{1}

2

3

4

5

6

7

8

9

10
$\operatorname{SAP}(B N L)$

6.58

6.71

7.71

7.75

8.52

8.76

9.39

9.45

9.66

10.13
STRUDL (MCDONNELL DOUGLAS)

6.45

6.55

7.52

7.91

8.36

8.54

9.18

9.33

9.49

9.87 


\section{DIFBLO CANYON PLANT \\ UNIT 1 \\ CONTAINMENT ANNULUS STRUCTURE \\ SAP VERSUS STRUOL SPECTRA}

2.J PERCENT DAMPING

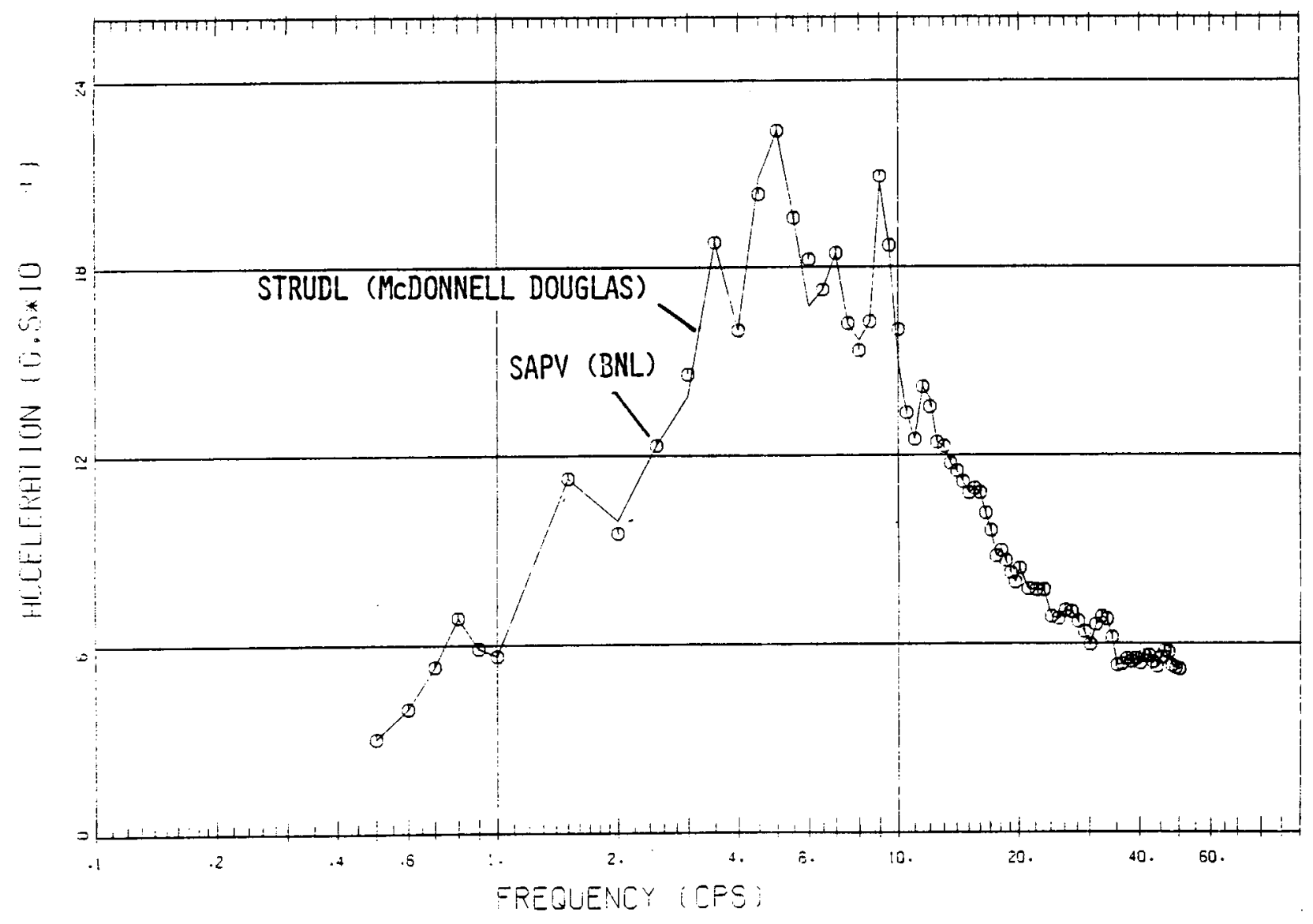

Figure 4.1 - Floor response spectra comparison: SAPV (BNL) versus STRUDL (McDonnel1 Douglas) 


\subsection{Description of Floor Response Spectra from 3-D Model}

\subsection{General}

As mentioned, the BNL work was concentrated on the development and evaluation of a detailed three-dimensional model that closely resembles the actual structure. In fact, three variations of this basic model (i.e., models $A, B$ and $C$ ) were evaluated. For each model floor response spectra were generated at the majority of the nodal points for three levels of equipment damping (i.e., 2, 3 and 4 percent).

Given the large volume of data produced and the lack of modeling correspondence between the BNL and the URS/Blume models, three different methods were utilized for comparative purposes. These are discussed below.

\subsection{Methods of Comparison}

Comparisons were made by the following methods:

(1) floor response spectra from the 3-D model most closely corresponding to the vertical planes defined by the locations of the five fan coolers were compared directly to those of the URS/BIume spectra. This is represented schematically in Figure 5.1. This figure shows the orientations of the fan coolers for Units 1 and 2. It also shows the orientation of the frames used in the URS/Blume 2-D model. As can be seen, this orientation corresponds to the Unit 2 configuration. This, in fact, is the so-called diagram error. Due to the error the following correspondence can be determined:

$\begin{array}{cc}\text { Unit 1 } & \text { URS/Blume } \\ \text { Fan Cooler No. } & \text { Frame No. } \\ 1 & 5 \\ 2 & 1 \\ 3 & 2 \\ 4 & 3 \\ 5 & 4\end{array}$


The BNL floor spectra from model B obtained at these locations are shown on pages 56 thru 75. In these figures the dashed line shows the corresponding URS/Blume broadened spectra for $2 \%$ equipment damping. Whenever the dashed line becames dotted this indicates that the values of this portion of the curve cannot be scaled.

(2) The second comparison involved the development of average spectra over sections of the floors. These sections are the same for all four floors of the structure. Each section is formed by the bisectors of the angles defined by the actual locations of the fan coolers. Sections of a typical floor corresponding to the Unit 1 of the plant are shown in Figure 5.2. As can be seen, the five sections of the floor are numbered in accordance with the fan coolers, i.e, section one corresponds to fan cooler one, etc. In order to obtain the áverage spectra for a given section the floor spectra for all nodes located on that floor in that section were simply averaged for each spectral frequency and for each damping value. These spectra, for model. B are shown on pages 76 thru 95. In these figures the dashed line shows the corresponding URS/Blume broadened spectra for $2 \%$ equipment damping. Whenever the dashed line becomes dotted this indicates that the values of this portion of the curve cannot be scaled.

(3) For the third comparison envelope spectra from all nodal points for each floor and each section, as described in (2) above, were developed. These results are plotted together with the corresponding average spectra and presented on pages 76 thru 95. In these figures the dashed line shows the corresponding URS/BI ume broadened spectra for $2 \%$ equipment damping. Whenever the dashed line becomes dotted this indicates that the values of this portion of the curve cannot be scaled.

\subsection{Comparison with URS/Blume Spectra}

The comparison matrices that follow summarize the results obtained for each of the three comparison methods discussed in Section 5.2. If the number one (1) appears in the matrix the URS/Blume results are more conservative and are thus acceptable. If the URS/B1ume results are not acceptable (i.e., not 
conservative), then a zero (0) will appear at the corresponding element of the matrix. Furthemore for each zero there will be either a subscript $P$ or $F$. The former indicates differences in peak values and the latter in frequency. If both subscripts appear both frequency shifts and peak magnitude differences were apparent.

By inspection of these comparison matrices the following conclusions may be drawn:

(1) URS/Blume floor spectra for the fourth floor are conservative in all methods of comparison.

(2) URS/Blume floor spectra for the fourth fan cooler location and for all floors are conservative, for the first and second methods of comparison.

(3) Comparisons with the BNL average spectra indicated a greater conservatism in the URS/Blume results than the other two types of comparisons.

(4) The least conservative results were obtained in comparing URS/Blume spectra with the BNL envelope spectra. In our opinion envelope spectra are more appropriate than average spectra.

(5) In all comparison methods the URS/Blume results for the third floor were found to be nonconservative.

(6) As noted in the matrices, frequency shifts of the dominant spike of the floor response spectra between BNL and URS/Blume were found. In comparing the mass values used by the URS/BIume in their five-frame model of the contaiment annulus structure, with those obtained from the drawings transmitted by $P G \& E$, it was found that lower mass values were used. Table 5.1 summarizes the results of this comparison. Total mass values are given on a floor-by-floor basis. It's possible that some of the differences are due to the lower mass values used in the model. 
Table 5.1

MASS EVALUATIONS (K-SEC/FT)

\begin{tabular}{|c|c|c|c|c|c|c|c|c|c|c|c|}
\hline \multirow{2}{*}{ ELEVATION } & \multicolumn{6}{|c|}{ URS/BLUME DATA } & \multicolumn{5}{|c|}{ DATA FROM DRWS. TRANSMITED TO BNL } \\
\hline & $\begin{array}{c}\text { FRAME } \\
1\end{array}$ & $\begin{array}{c}\text { FRAME } \\
2 \\
\end{array}$ & $\begin{array}{c}\text { FRAME } \\
3\end{array}$ & $\begin{array}{c}\text { FRAME } \\
4\end{array}$ & $\begin{array}{c}\text { FRAME } \\
5\end{array}$ & TOTAL & CONCENTR & DISTR. & $\begin{array}{l}\text { SUB } \\
\text { TOTAL }\end{array}$ & TRUUCTUR & TOTAL \\
\hline $101^{\prime}$ & 0.29 & 0.29 & 0.18 & 0.36 & 0.30 & 1.52 & 1.13 & 0.55 & 1.68 & 1.40 & 3.08 \\
\hline $106^{\prime}$ & 0.63 & 0.5 & 0.31 & 0.69 & 0.70 & 2.68 & 2.53 & 0.30 & 2.83 & 1.71 & 4.54 \\
\hline $117^{\prime}$ & 1.25 & 1.07 & 1.94 & 1.55 & 1.90 & 6.71 & 3.04 & 4.50 & 7.54 & 3.89 & 11.43 \\
\hline $140^{\prime}$ & 8.72 & 7.95 & 9.18 & 10.49 & 10.55 & 46.89 & 30.71 & 2.89 & 33.60 & 34.15 & 67.79 \\
\hline
\end{tabular}


COIPPARISON MATRIX

COMPARISON TYPE: AT FAN COOLER LOCATIONS

\begin{tabular}{|c|c|c|c|c|c|}
\hline FLOOR COOLER & 1 & 2 & 3 & 4 & 5 \\
\hline 1 & $0_{p}$ & 1 & 1 & 1 & 1 \\
\hline 2 & $o_{p}$ & 1 & $0_{P F}$ & 1 & $0_{P F}$ \\
\hline 3 & $0_{P F}$ & $0_{P F}$ & $0_{F}$ & 1 & $o_{p}$ \\
\hline 4 & 1 & 1 & 1 & 1 & 1 \\
\hline
\end{tabular}

$$
\begin{aligned}
\text { NOTE: } & 1 \text { - ACCEPTABLE } \\
& 0-\text { NON-ACCEPTABLE } \\
& \text { P - DIFFERENCES. IN PEAK VALUES } \\
\text { F } & - \text { FREQUENCY SHIFTS } \\
\text { PF } & - \text { BOTH }
\end{aligned}
$$




\section{COMPARISON MATRIX}

COIIPARISON TYPE: AVERAGE SPECTRA

\begin{tabular}{|c|c|c|c|c|c|}
\hline FLOOR & 1 & 2 & 3 & 4 & 5 \\
\hline 1 & 0 & 1 & 1 & 1 & 1 \\
3 & 1 & 1 & $0_{P F}$ & 1 & $0_{P F}$ \\
4 & $0_{P F}$ & $0_{P F}$ & $0_{F}$ & 1 & $0_{P}$ \\
\hline
\end{tabular}

$$
\text { NOTE: } \begin{aligned}
& 1-\text { ACCEPTABLE } \\
& 0-\text { NON-ACCEPTABLE } \\
& \text { P DIFFERENICES IN PEAK VALUES } \\
\text { F } & - \text { FREQUENCY SHIFTS } \\
\text { PF } & - \text { BOTH }
\end{aligned}
$$


COIPPARISON MATRIX

COMPARISON TYPE: ENVELOPE SPECTRA

\begin{tabular}{|c|c|c|c|c|c|}
\hline SECTION & 1 & 2 & 3 & 4 & 5 \\
\hline 1 & $0_{P}$ & 1 & $0_{P F}$ & $0_{P F}$ & $0_{P F}$ \\
\hline 3 & $0_{P}$ & $0_{P F}$ & $0_{P}$ & $0_{F}$ & $0_{P F}$ \\
\hline 4 & $0_{P F}$ & $0_{P F}$ & $0_{P F}$ & $0_{F}$ & $0_{P}$ \\
\hline
\end{tabular}

$$
\text { NOTE: } \begin{aligned}
& 1-\text { ACCEPTABLE } \\
& 0-\text { NON-ACCEPTABLE } \\
P & - \text { DIFFERENCES IN PEAK VALUES } \\
F & - \text { FREQUENCY SHIFTS } \\
\text { PF } & - \text { BOTH }
\end{aligned}
$$




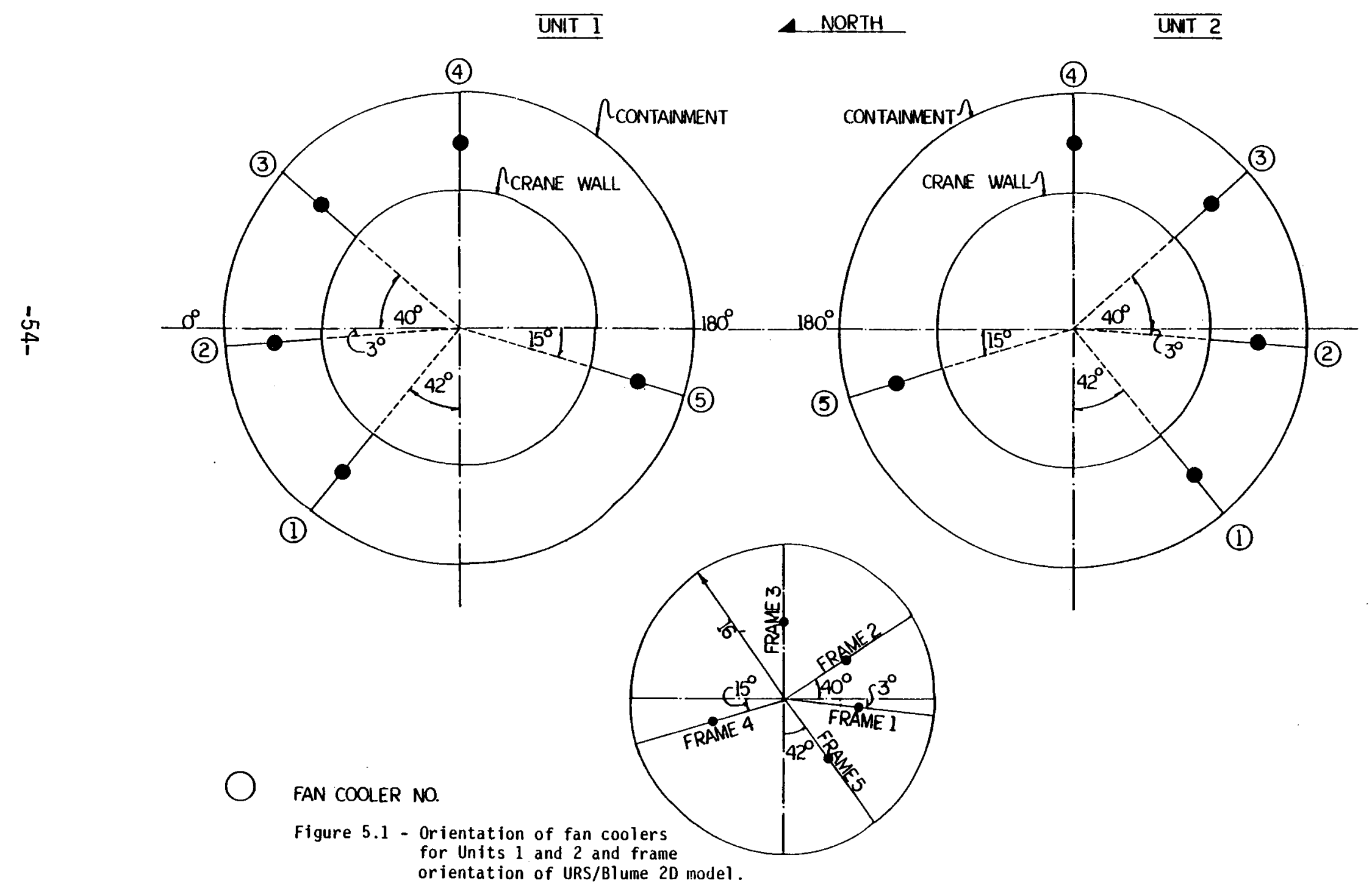




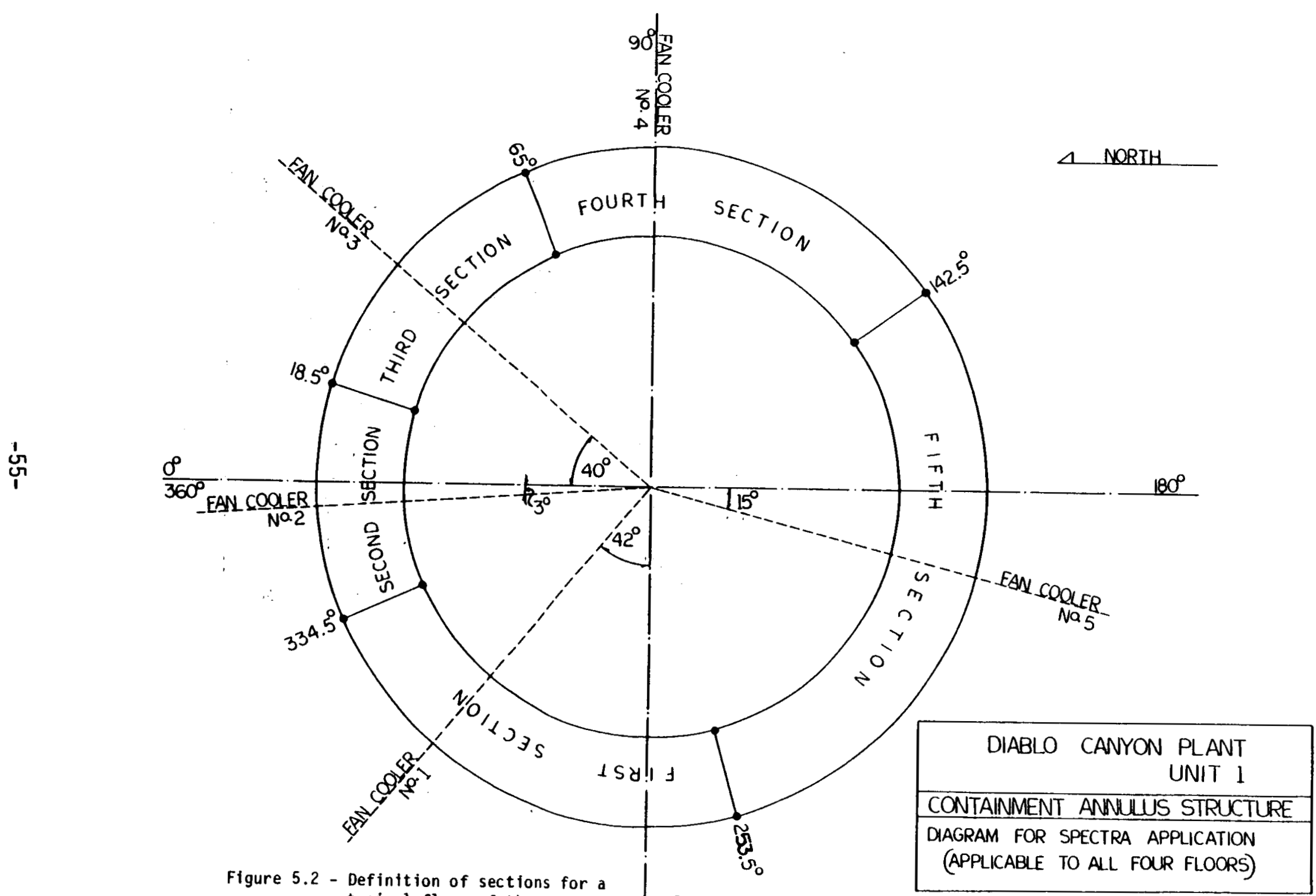

Figure 5.2 - Definition of sections for a typical floor of the conta inment $270^{\circ}$ annulus structure Unit 1. 
DIABLO CANYON PLANT

UNIT 1

CONTAINMENT ANNULUS STRUCTURE

$F L O O R=1$

FAN COOLER NO. $=1$

EQUIPMENT DAMPING $=234$ PERCENT

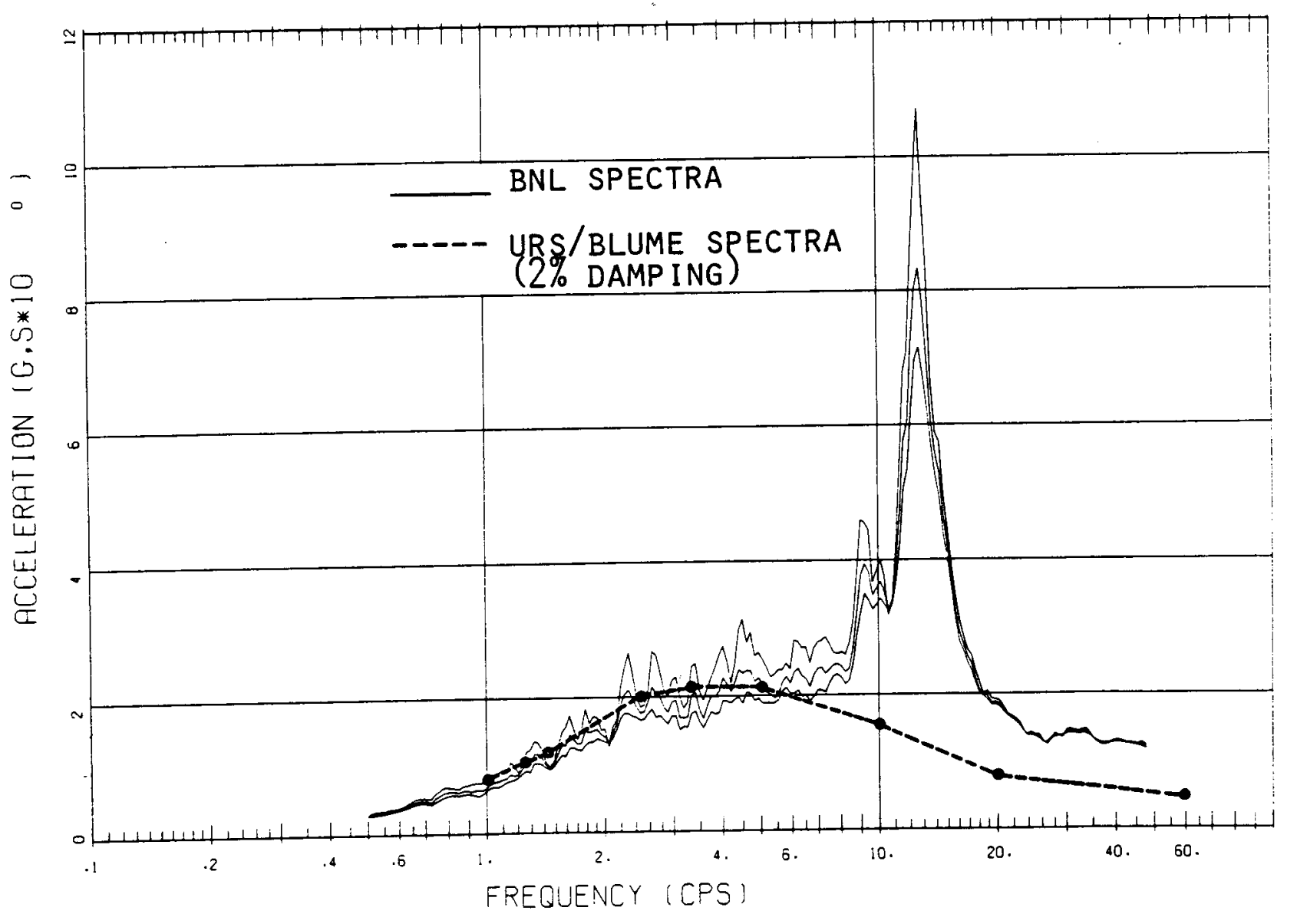



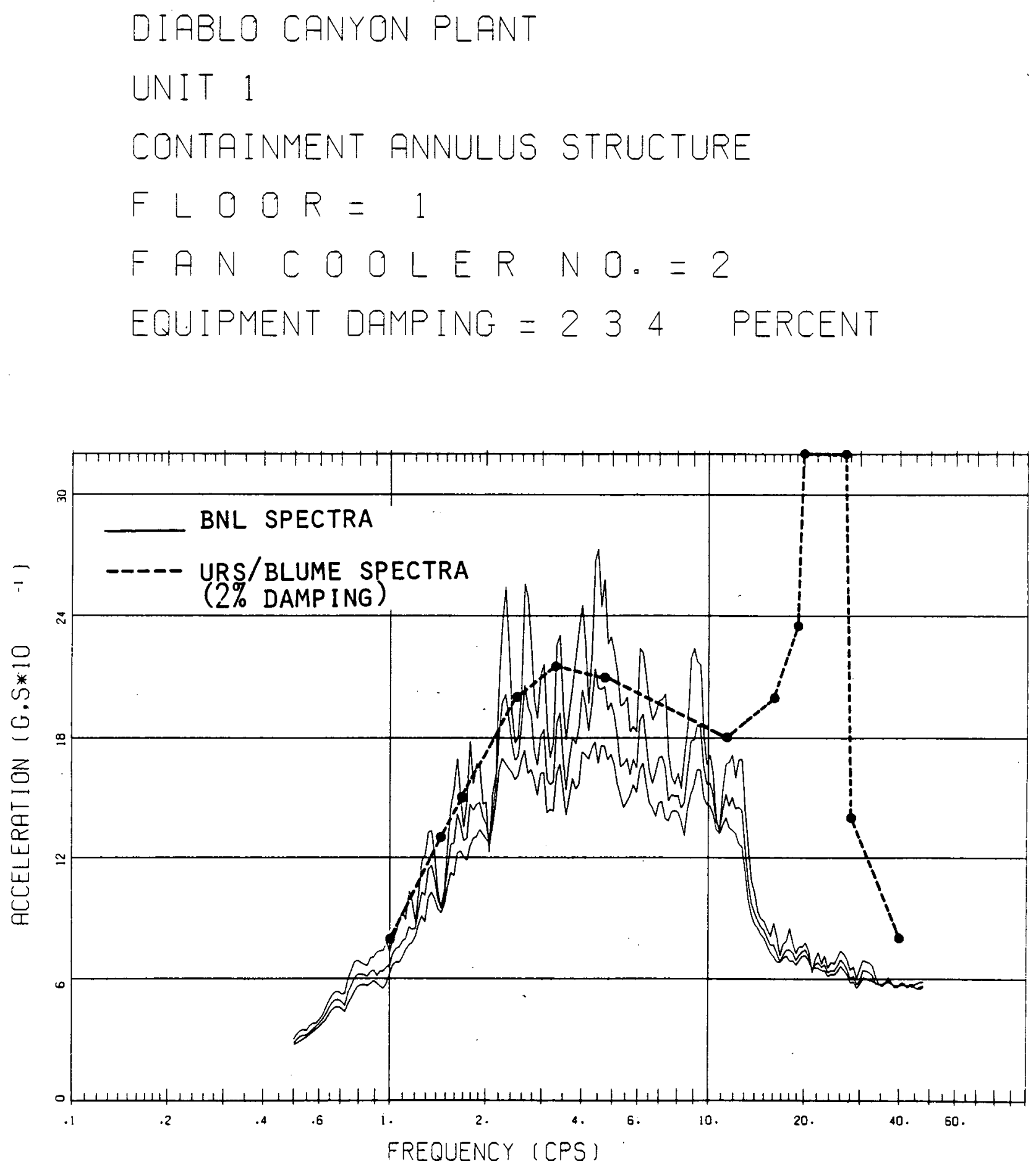
DIABLO CANYON PLANT

UNIT 1

CONTAINMENT ANNULUS STRUCTURE

$F L O O R=1$

FAN COOLER NO. $=3$

EQUIPMENT DAMPING $=234$ PERCENT

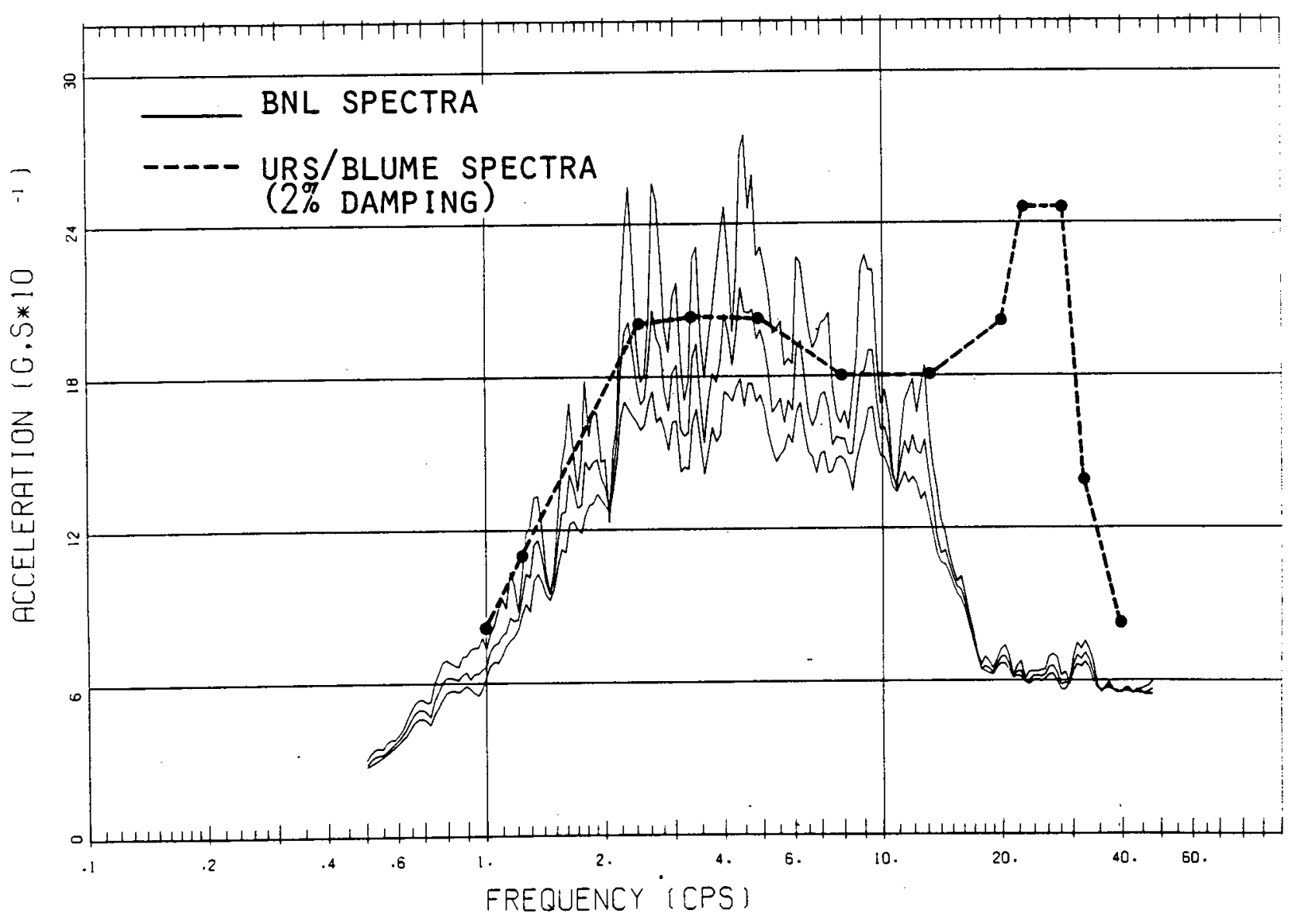


DIABLO CANYON PLANT

UNIT 1

CONTAINMENT ANNULUS STRUCTURE

$F L O O R=1$

FAN COOLER NO. $=4$

EQUIPMENT DRMPING a 2334 PERCENT

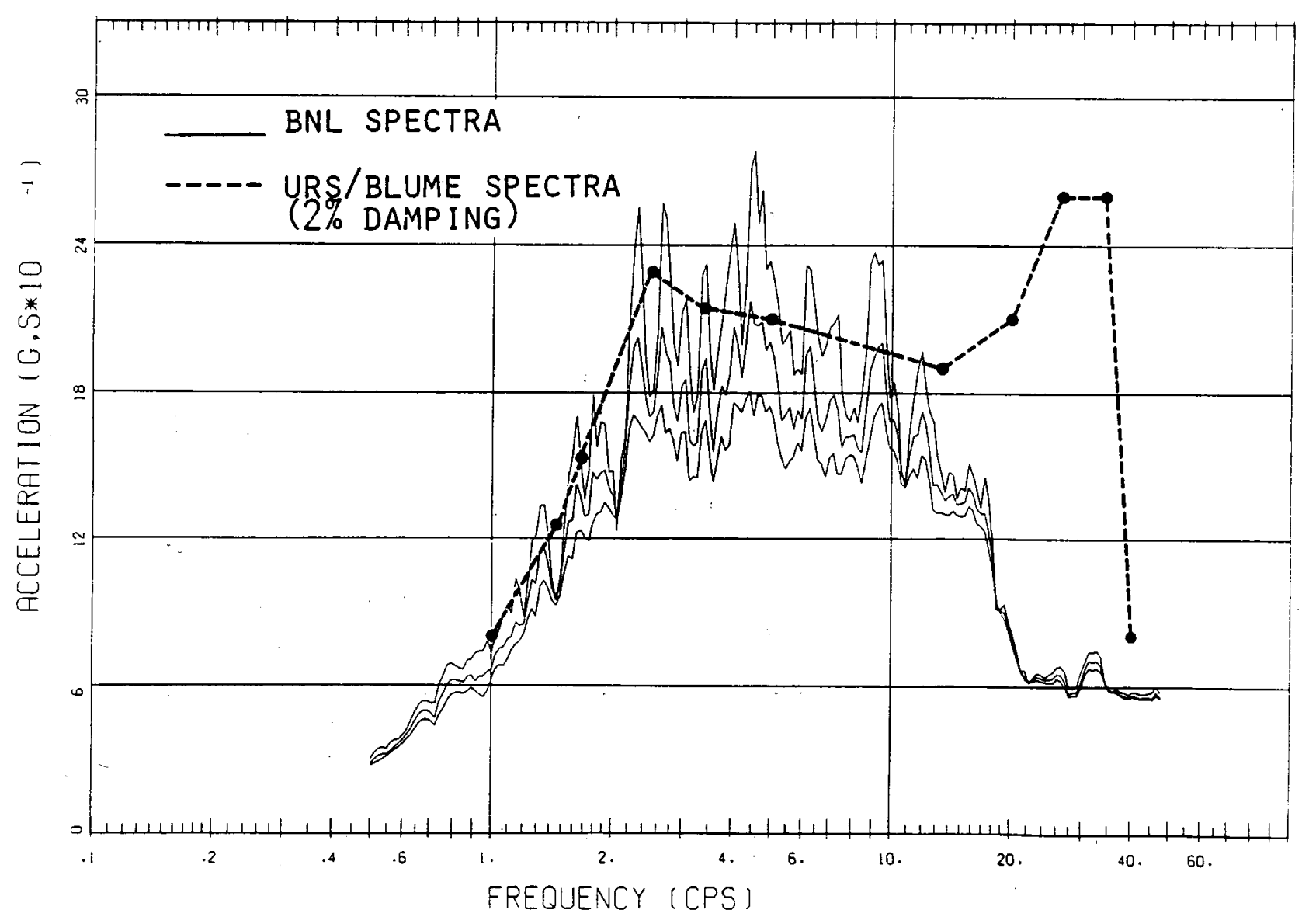


DIABLO CANYON PLANT

UNIT 1

CONTAINMENT ANNULUS STRUCTURE

$F L O O R=1$

$F A N C O O L E R N O=5$

EQUIPMENT DAMPING $=\begin{array}{llll}2 & 3 & 4 & \text { PERCENT }\end{array}$

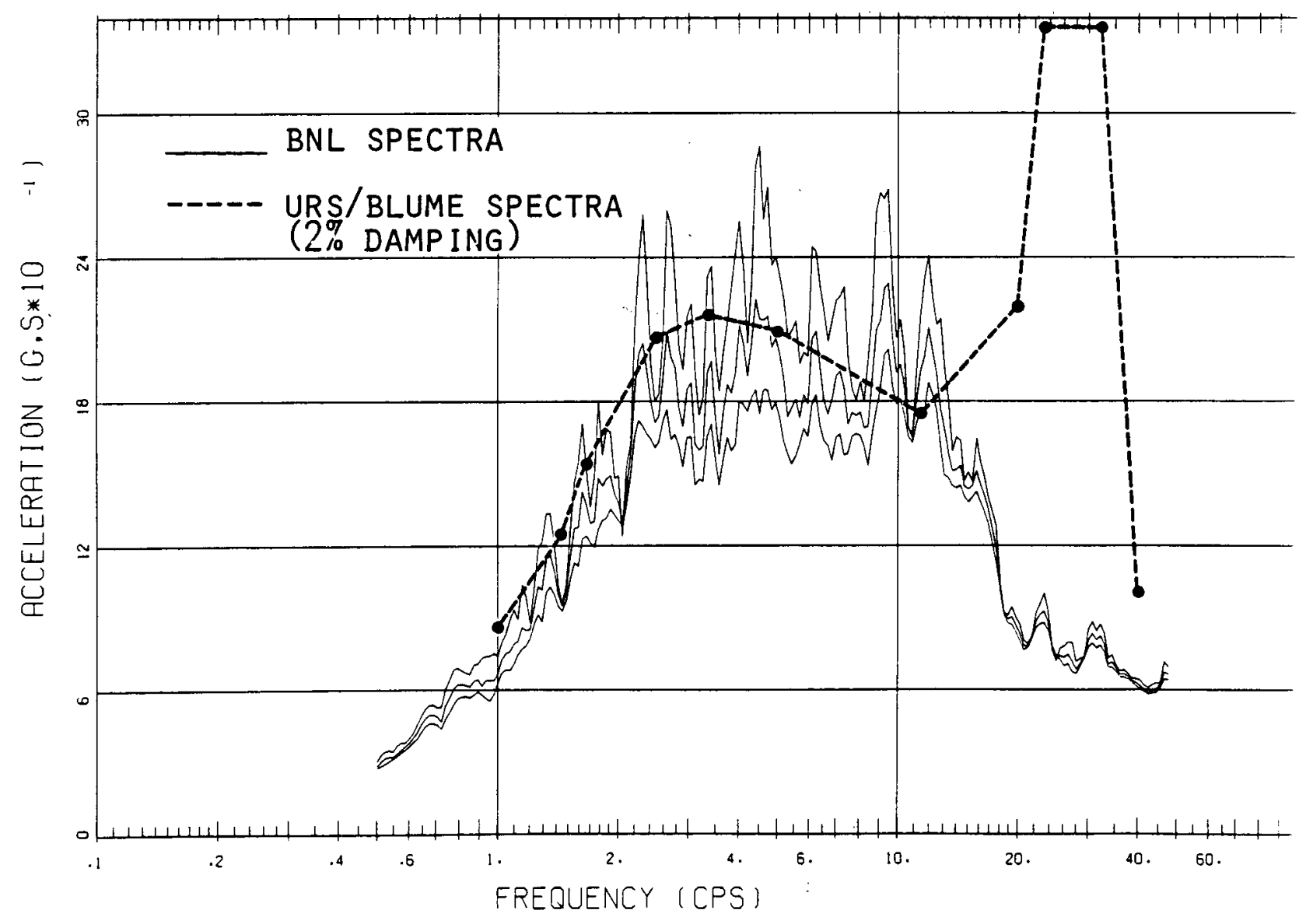



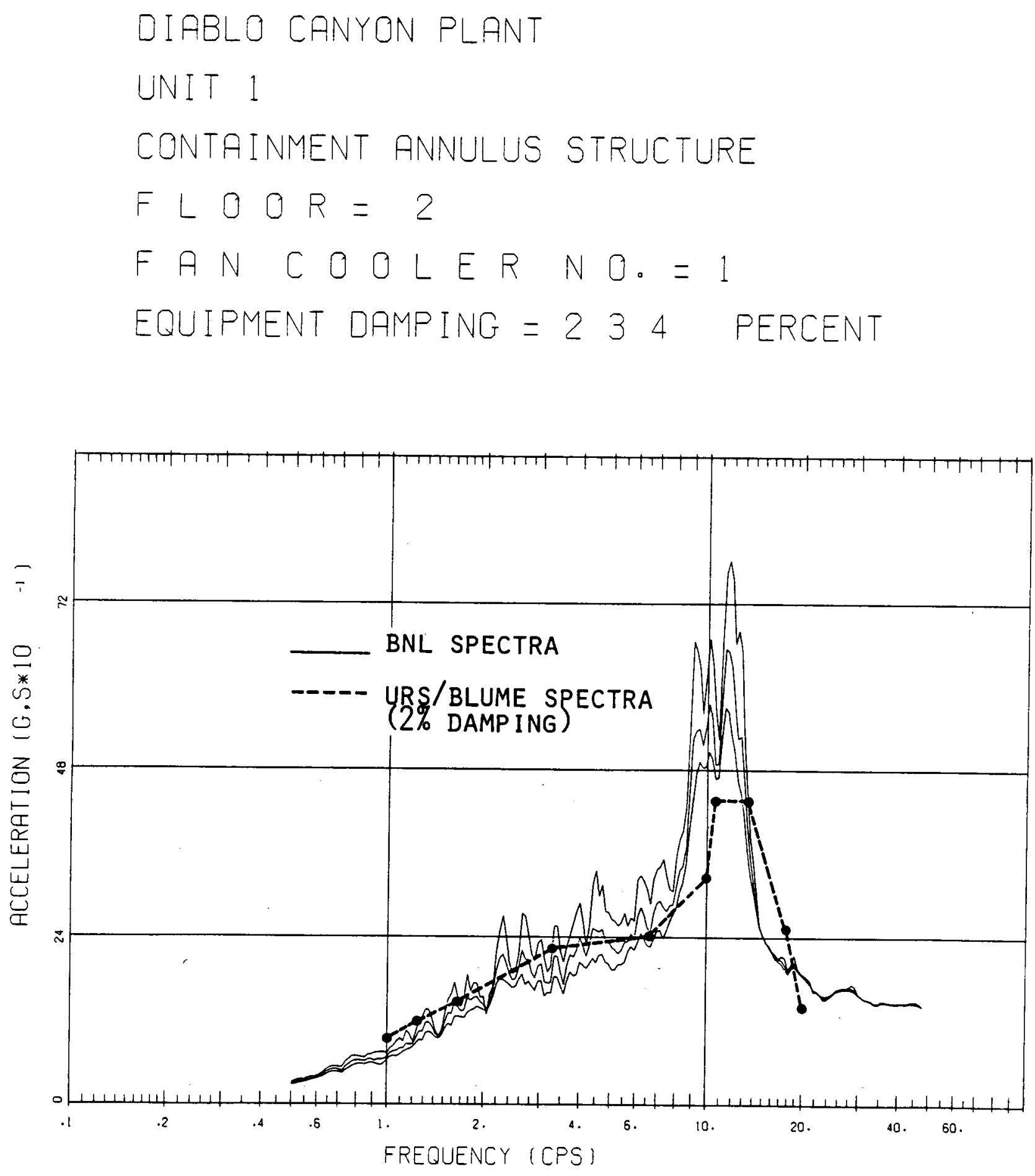

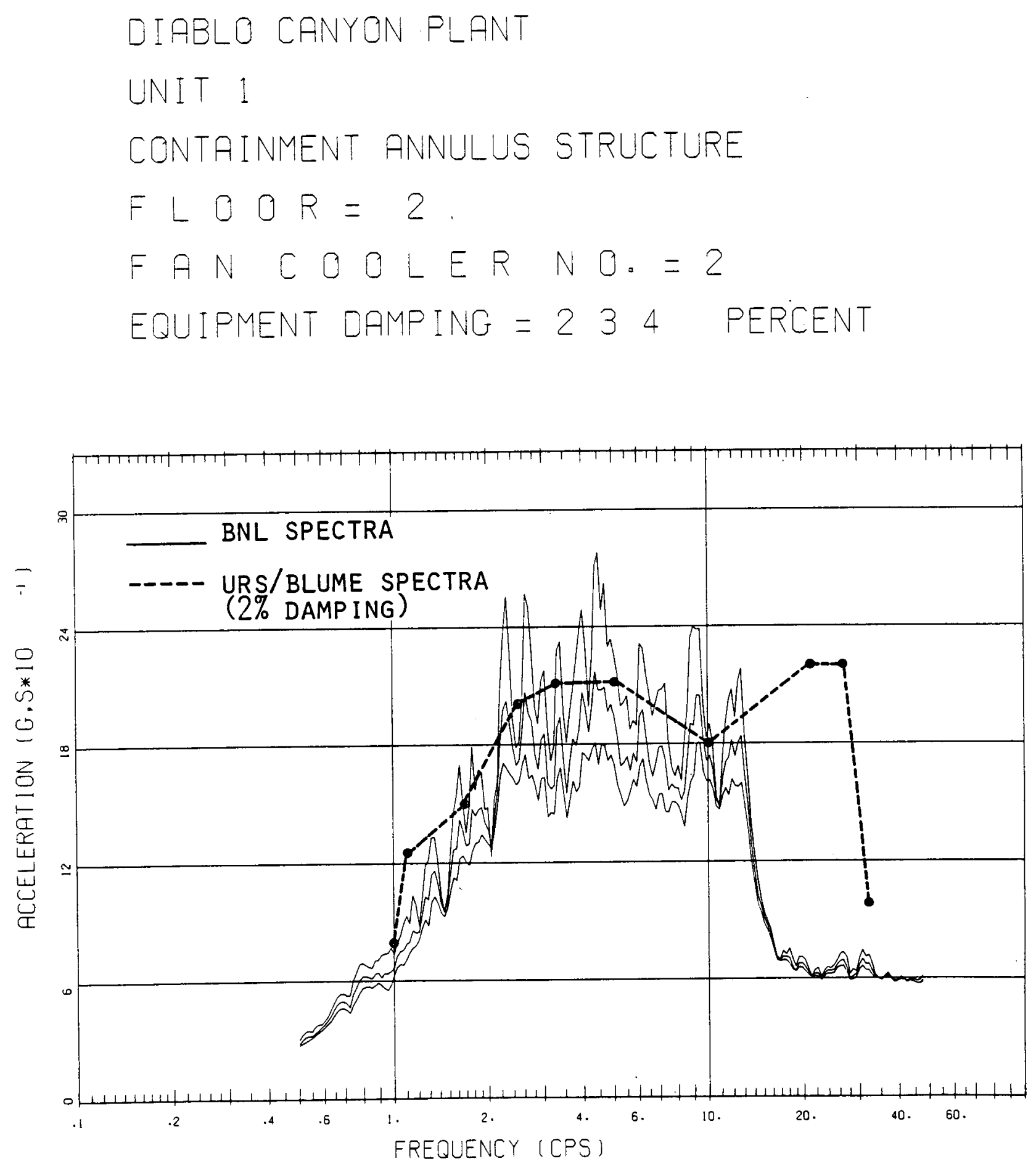

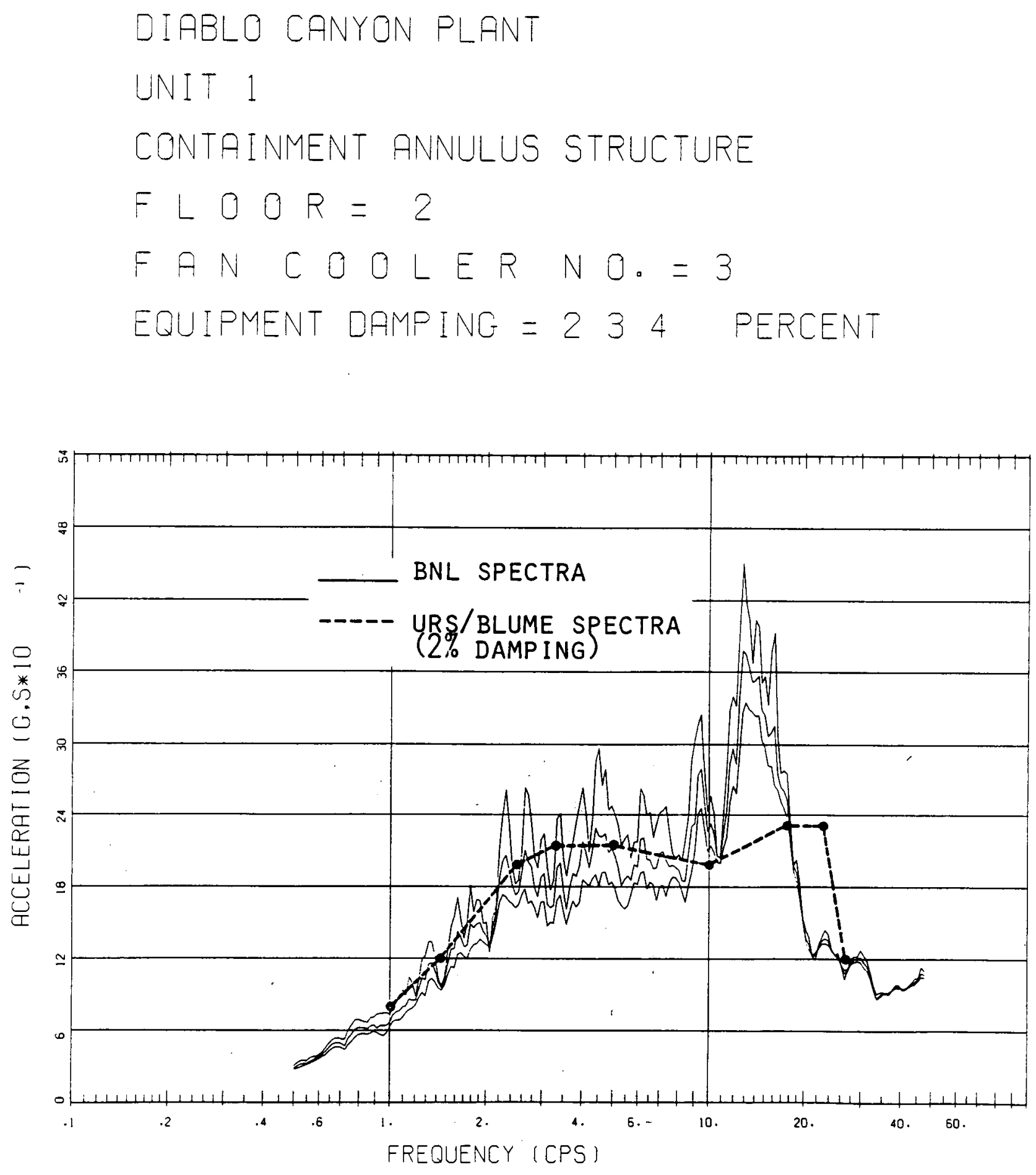
DIABLO CANYON PLANT

UNIT 1

CONTAINMENT ANNULUS STRUCTURE

$F L O O R=2$

FAN COOLER NO. $=4$

EQUIPMENT DAMPING $=\begin{array}{llll}2 & 3 & 4 & \text { PERCENT }\end{array}$

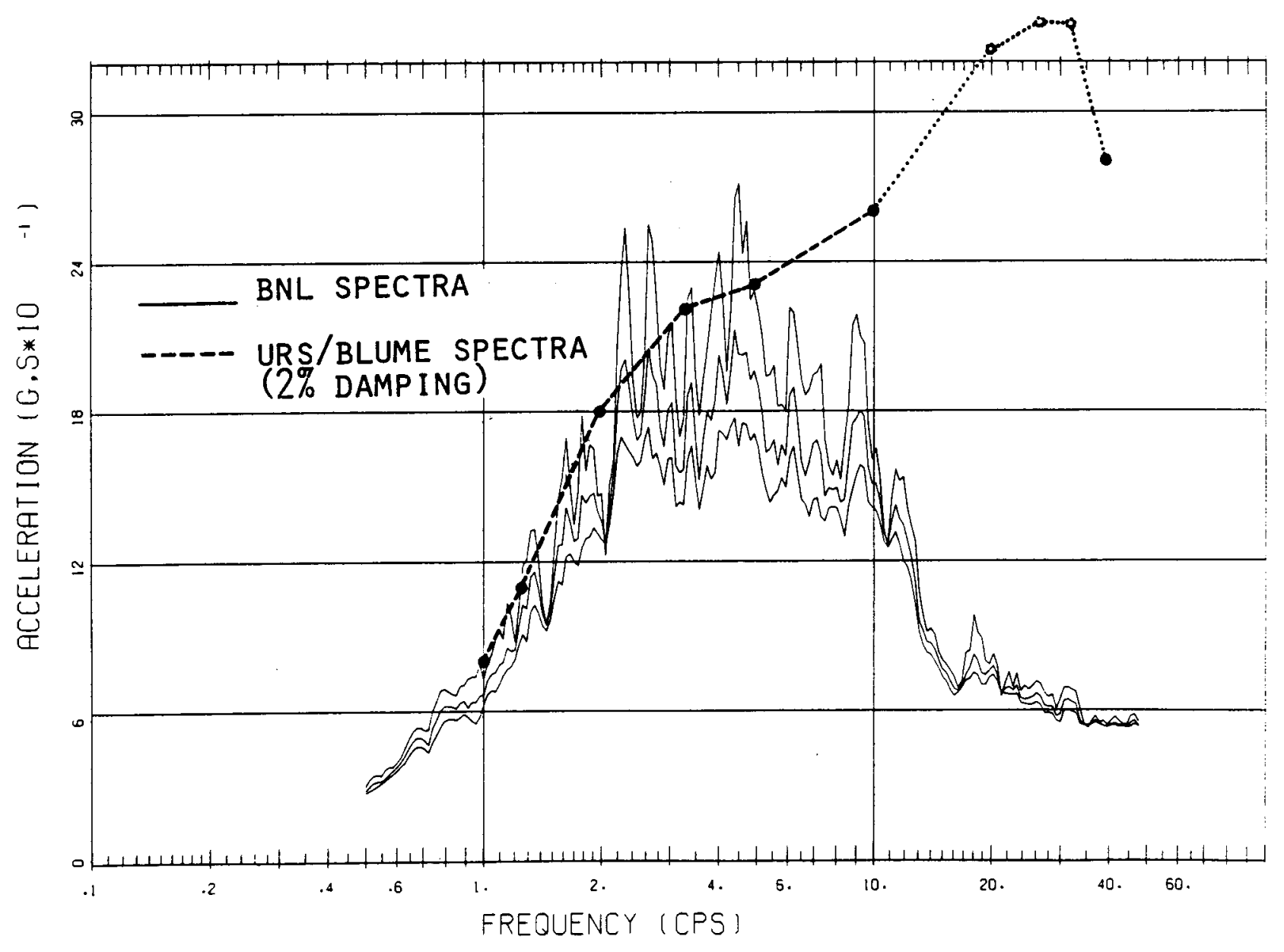


DIABLO CANYON PLANT

UNIT 1

CONTAINMENT ANNULUS STRUCTURE

$F L O O R=2$

FAN COOLER NO. $=5$

EQUIPMENT DAMPING $=\begin{array}{llll}2 & 3 & 4 & \text { PERCENT }\end{array}$

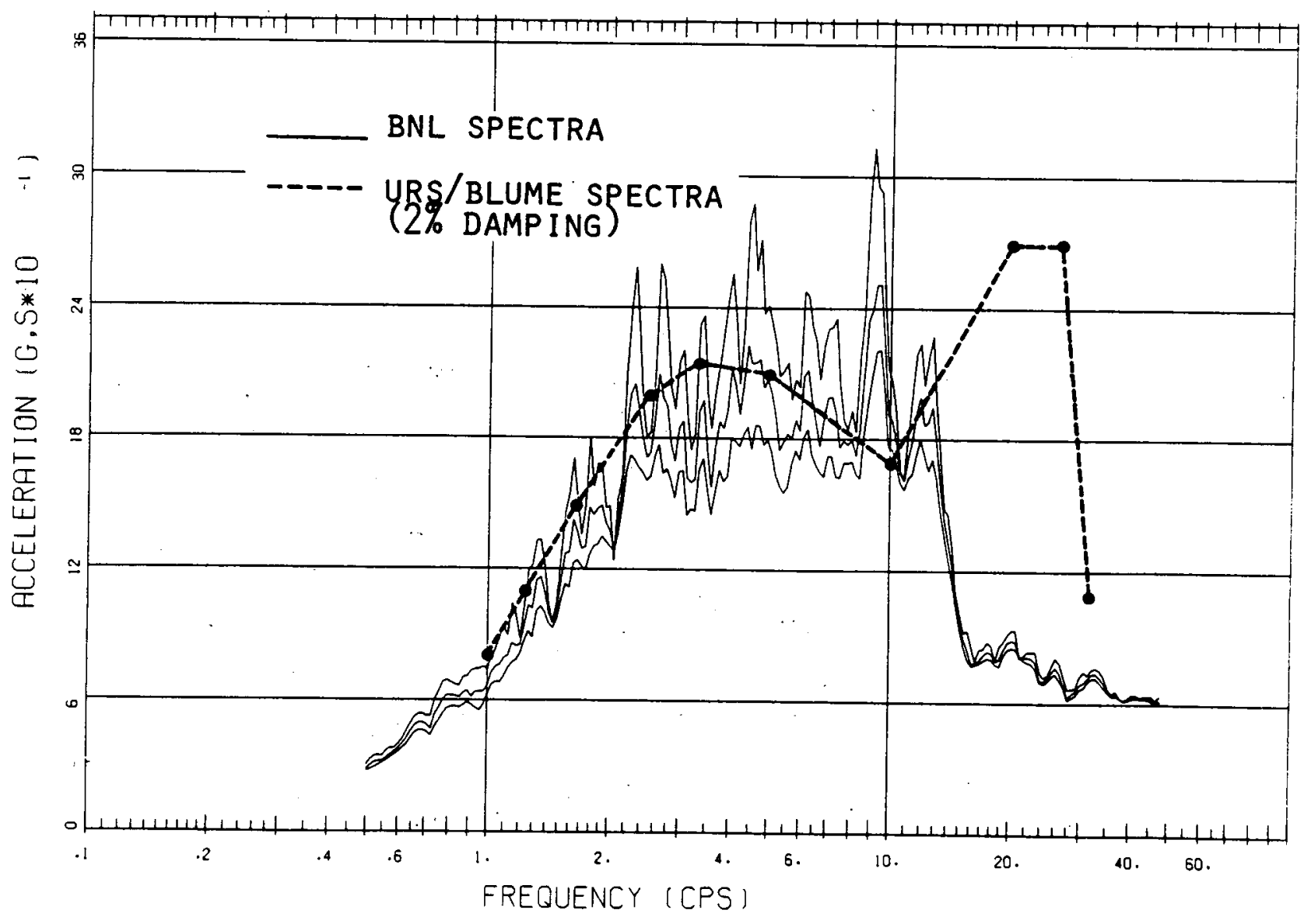


DIABLO CANYON PLANT

UNIT 1

CONTAINMENT ANNULUS STRUCTURE

$F L O O R=3$

FAN COOLER NO. $=1$

EQUIPMENT DAMPING a 2344 PERCENT

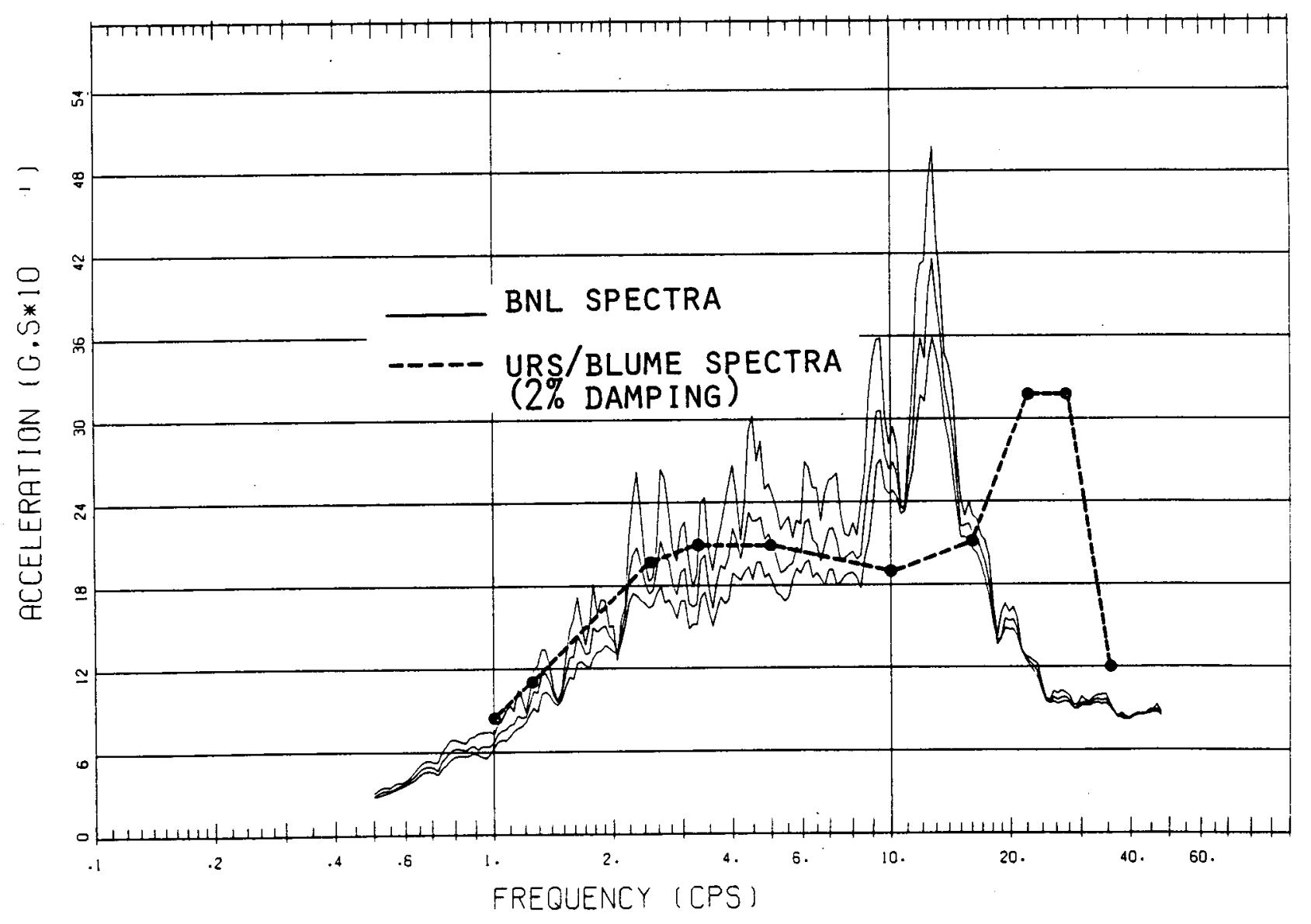




\section{DIABLO CANYON PLANT}

UNIT 1

CONTAINMENT ANNULUS STRUCTURE

$F L O O R=3$

FAN COOLER NO. $=2$

EQUIPMENT DAMPING $=234$ PERCENT

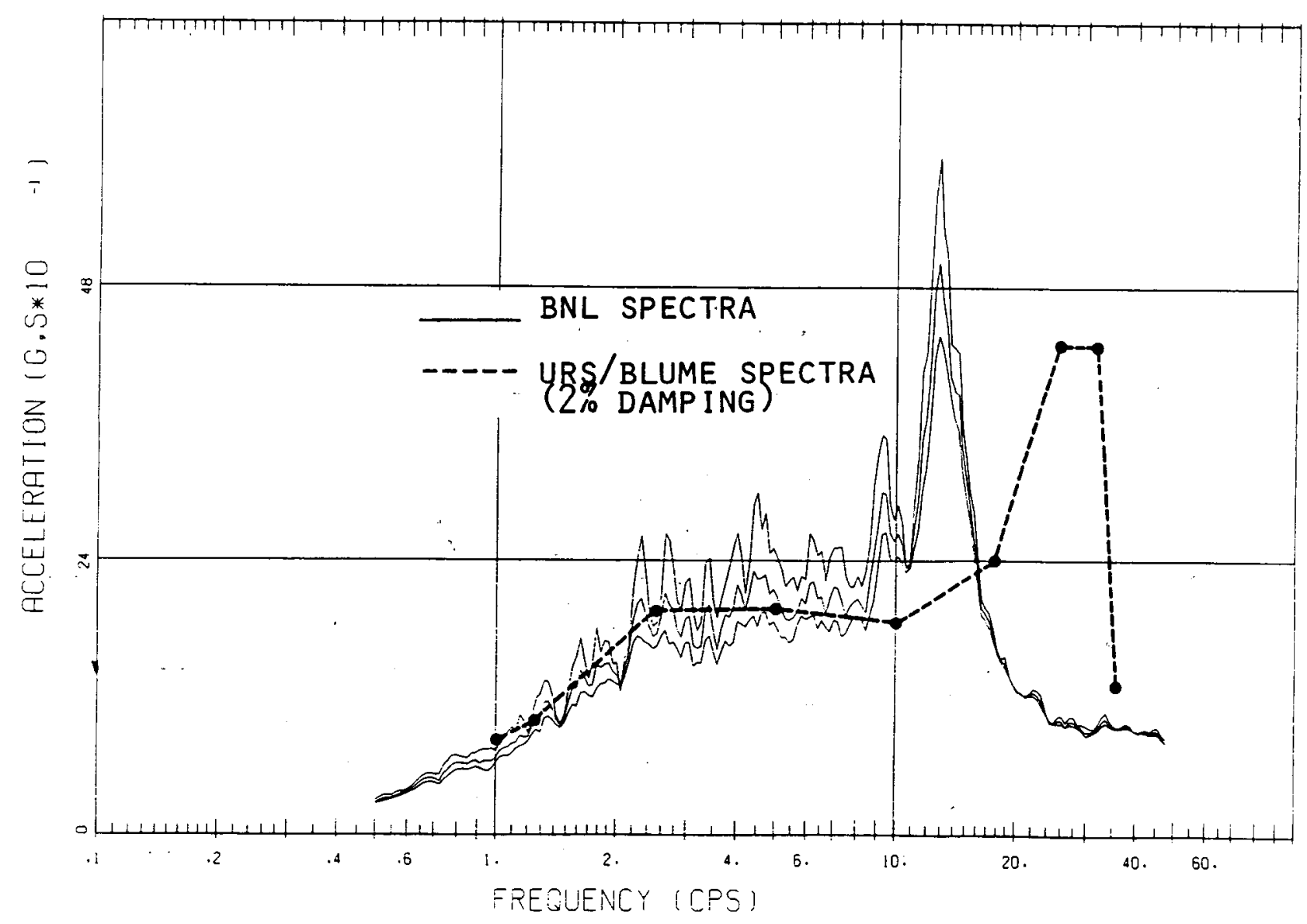




\section{DIABLO CANYON PLANT}

UNIT 1

CONTAINMENT ANNULUS STRUCTURE

$F L O O R=3$

FAN COOLER NO. $=3$

EQUIPMENT DAMPING $=\begin{array}{llll}2 & 3 & 4 & \text { PERCENT }\end{array}$

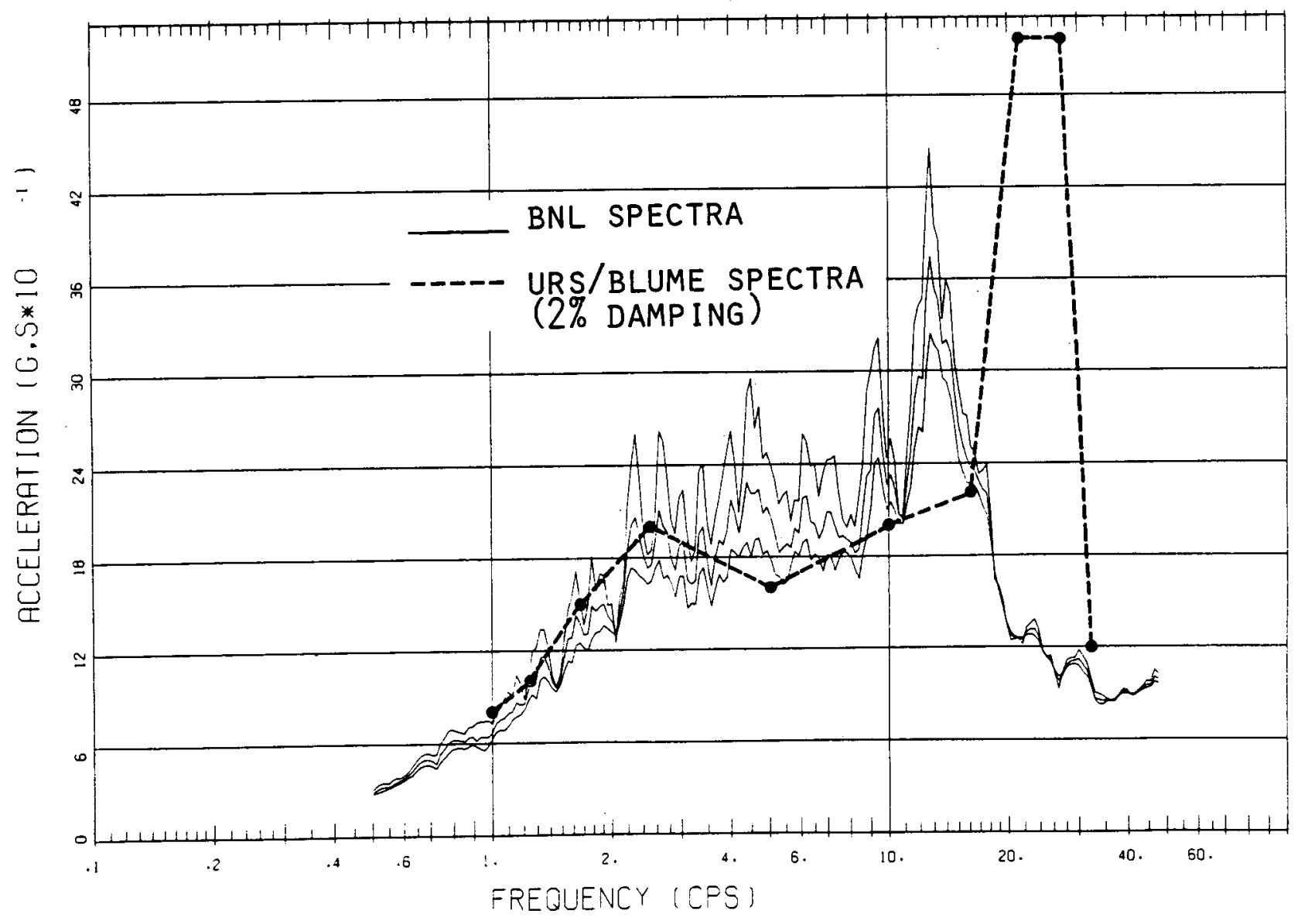




\section{DIABLO CANYON PLANT}

UNIT 1

CONTAINMENT ANNULUS STRUCTURE

$F L O O R=3$

FAN COOLER NO. $=4$

EQUIPMENT DAMPING $=2 \begin{array}{llll}3 & 4 & \text { PERCENT }\end{array}$

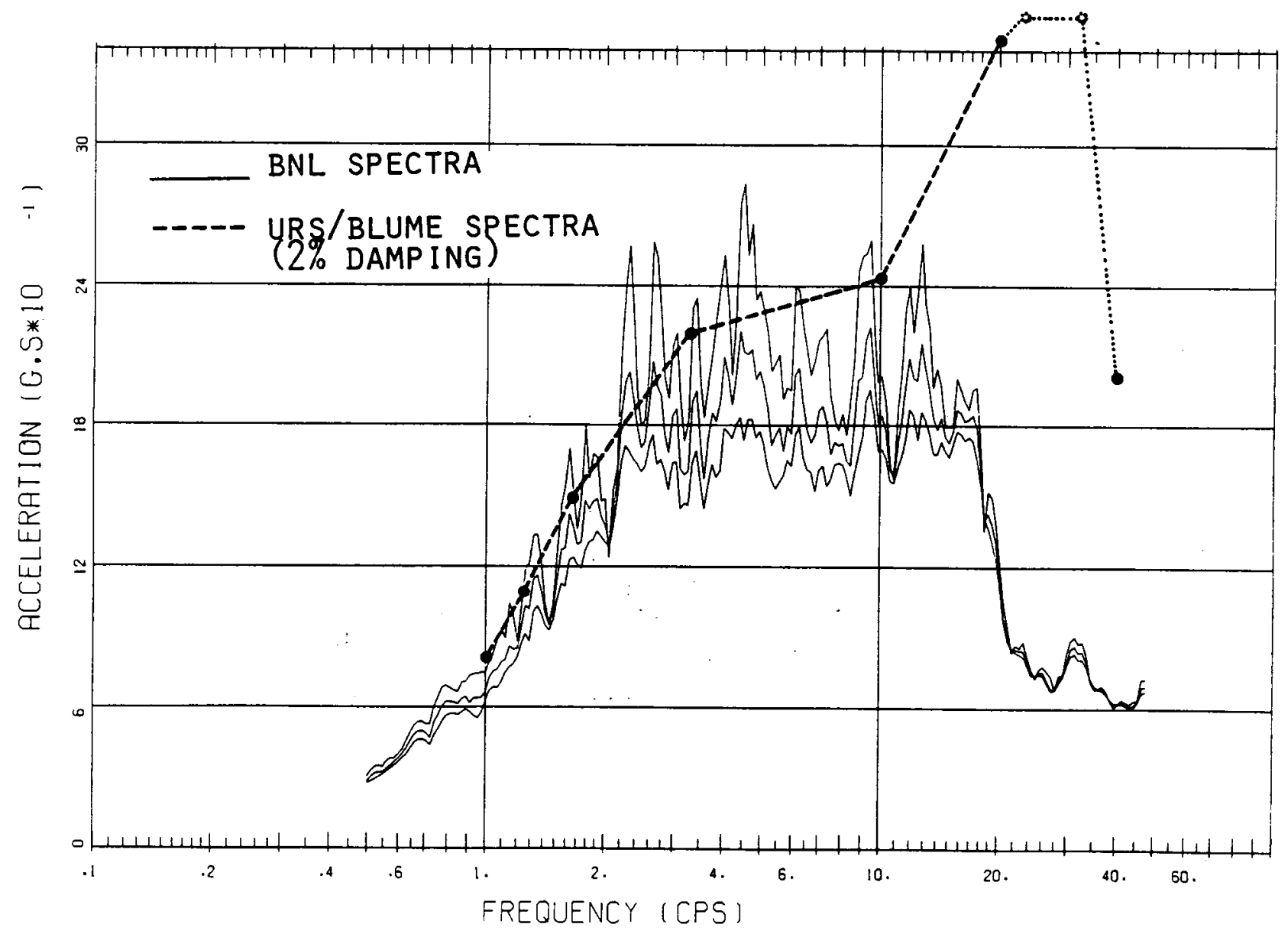




\section{DIABLO CANYON PLANT \\ UNIT 1 . \\ CONTAINMENT ANNULUS STRUCTURE \\ $F L O O R=3$ \\ FAN COOLER NO. $=5$ \\ EQUIPMENT DAMPING $=234$ PERCENT}

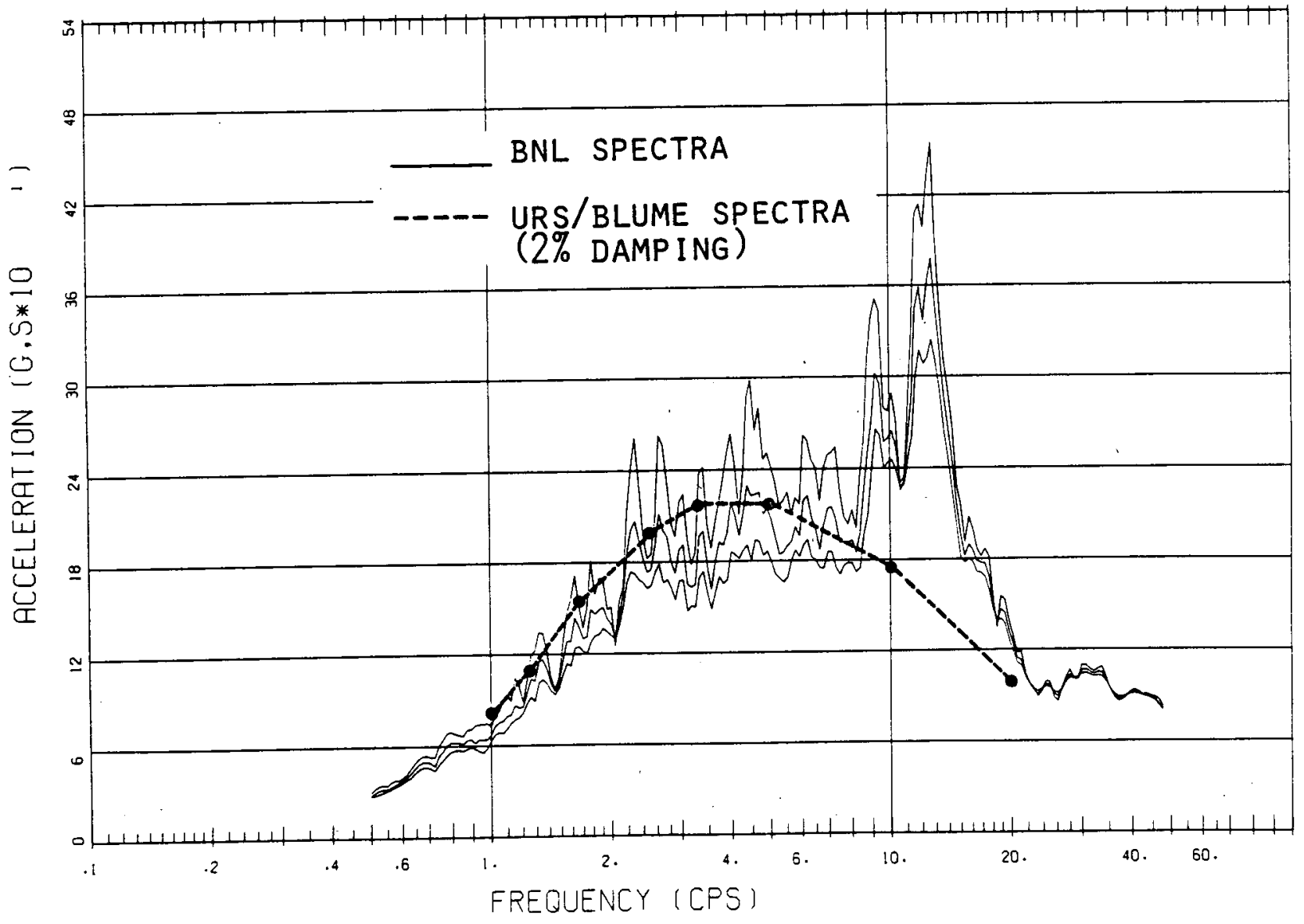


DIABLO CANYON PLANT

UNIT 1

CONTAINMENT ANNULUS STRUCTURE

$F L O O R=4$

FAN COOLER NO. $=1$

EQUIPMENT DAMPING $=\begin{array}{llll}2 & 3 & 4 & \text { PERCENT }\end{array}$

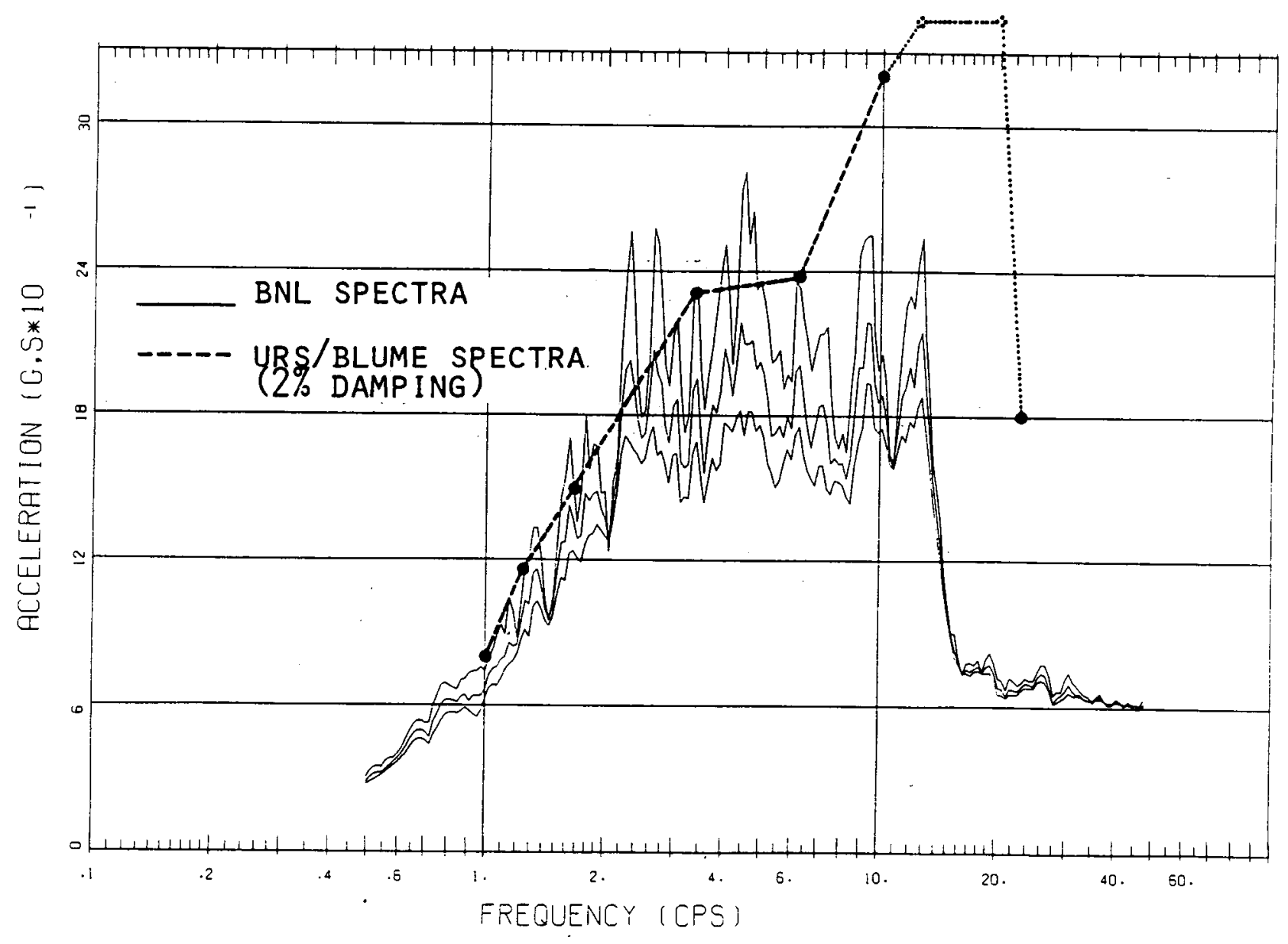




\section{DIABLO CANYON PLANT}

UNIT 1

CONTAINMENT ANNULUS STRUCTURE

$F L O O R=4$

FAN COOLER NO. $=2$

EQUIPMENT DAMPING $=2.34$ PERCENT

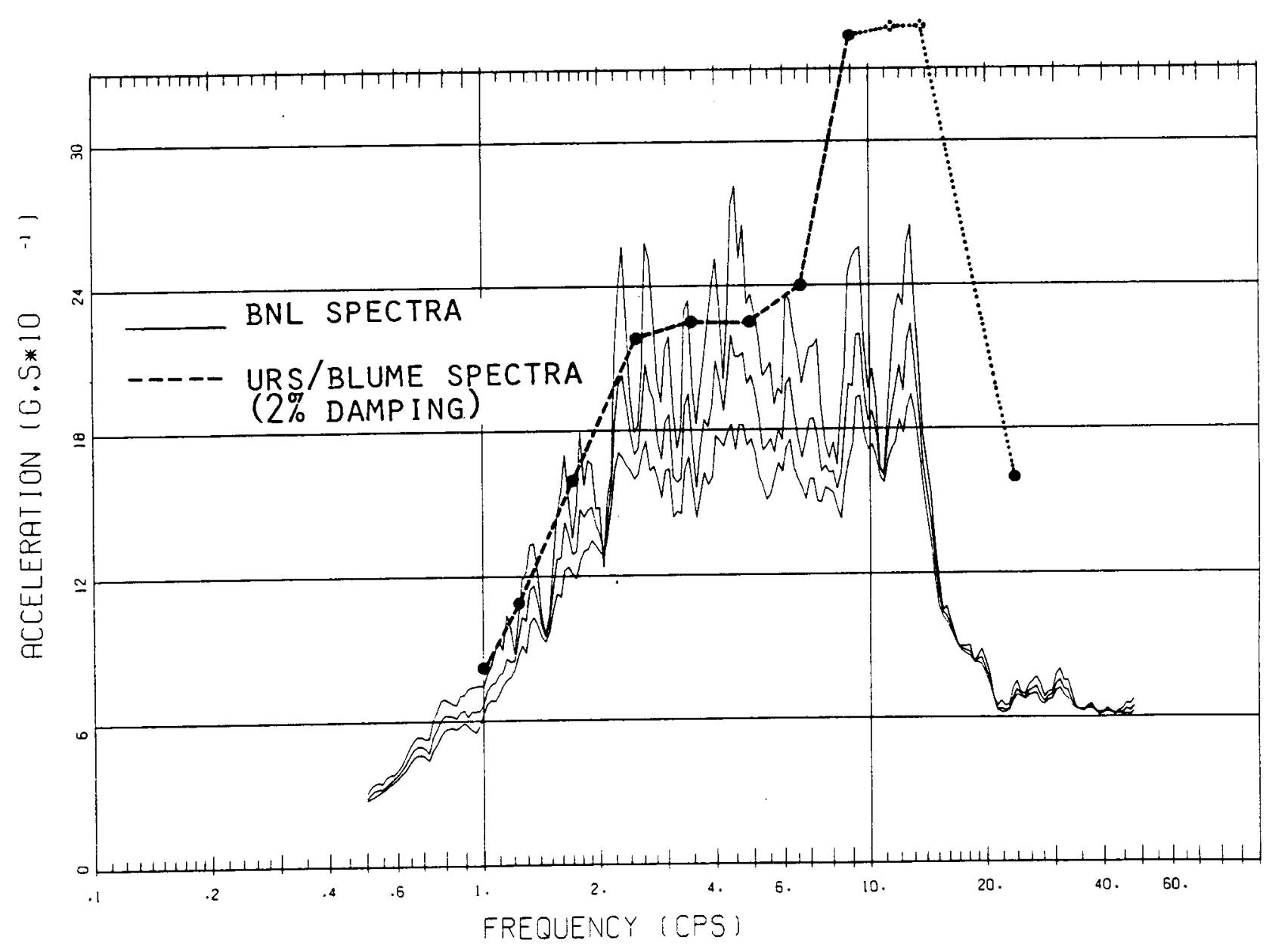



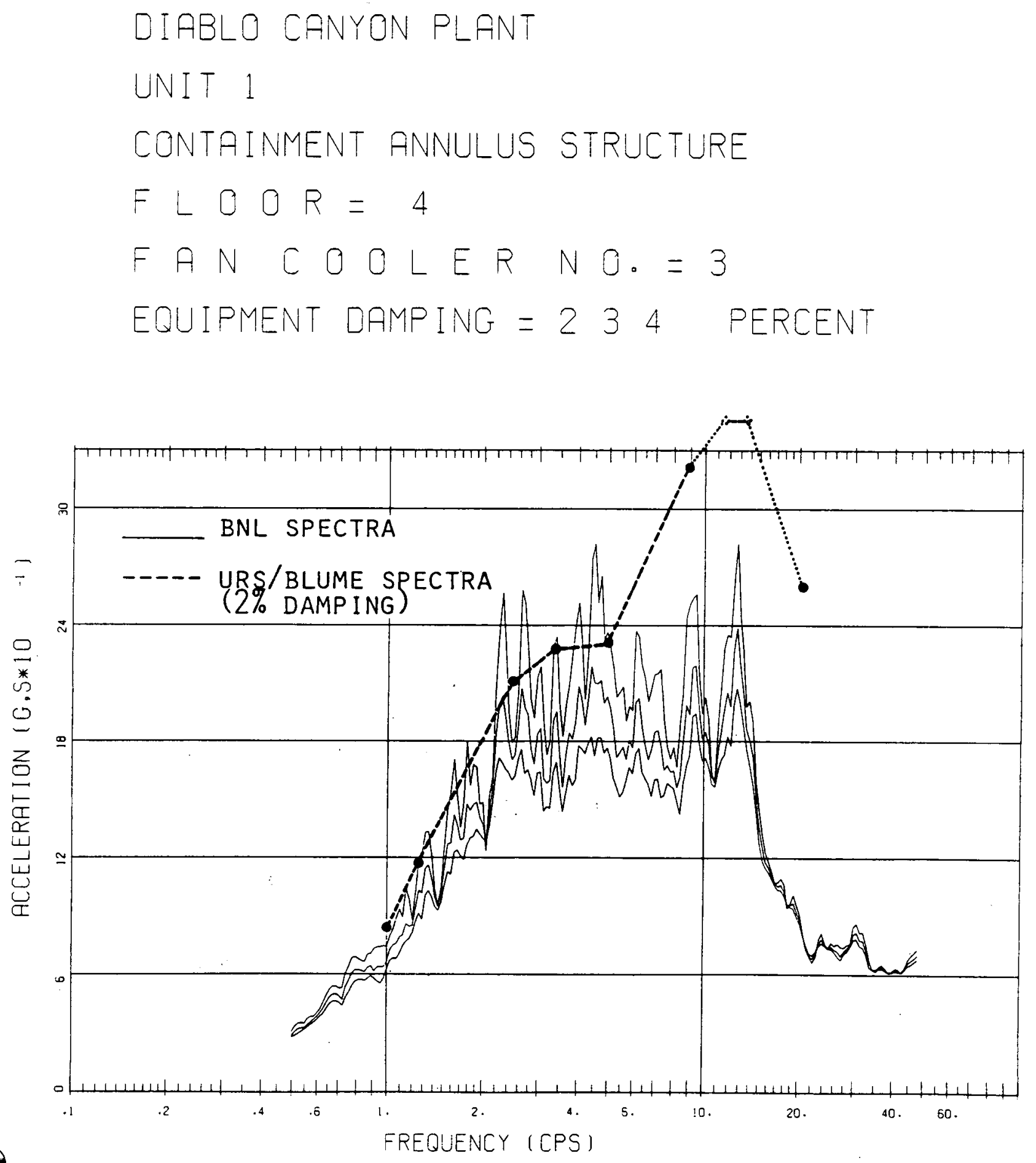
DIABLO CANYON PLANT

UNIT 1

CONTAINMENT ANNULUS STRUCTURE

$F L O O R=4$

FAN COOLER NO. $=4$

EQUIPMENT DAMPING $\square 2334$ PERCENT

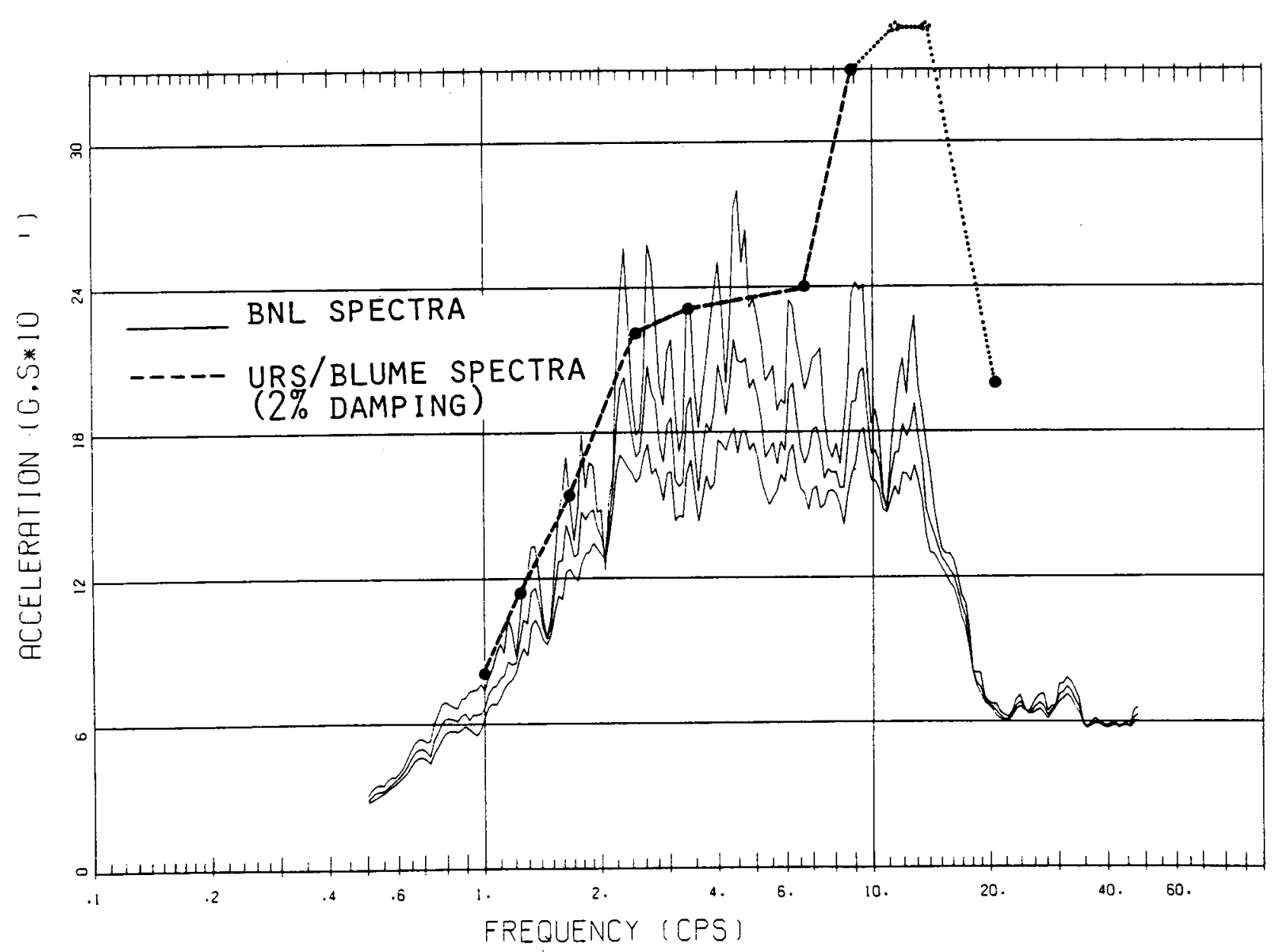


DIABLO CANYON PLANT

UNIT 1

CONTAINMENT ANNULUS STRUCTURE

$F L O O R=4$

FAN COOLER NO. $=5$

EQUIPMENT DAMPING $=2 \begin{array}{llll}3 & 4 & \text { PERCENT }\end{array}$

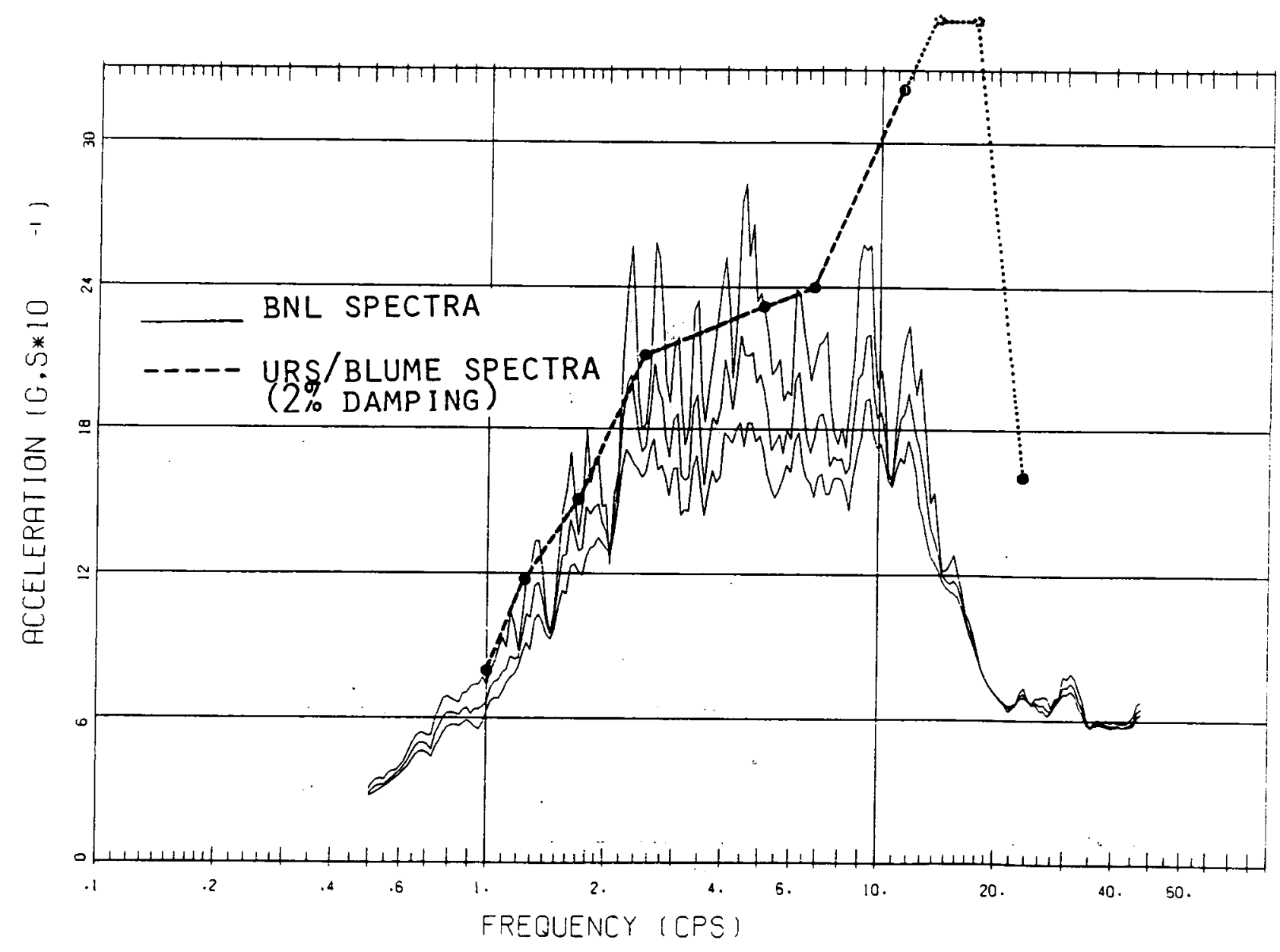


DIABLO CANYON PLANT

UNIT 1

CONTAINMENT ANNULUS STRUCTURE

$F L O O R=1$

$S E C T$ I ON NO. $=1$

EQUIPMENT DAMPING $=2.0$ PERCENT

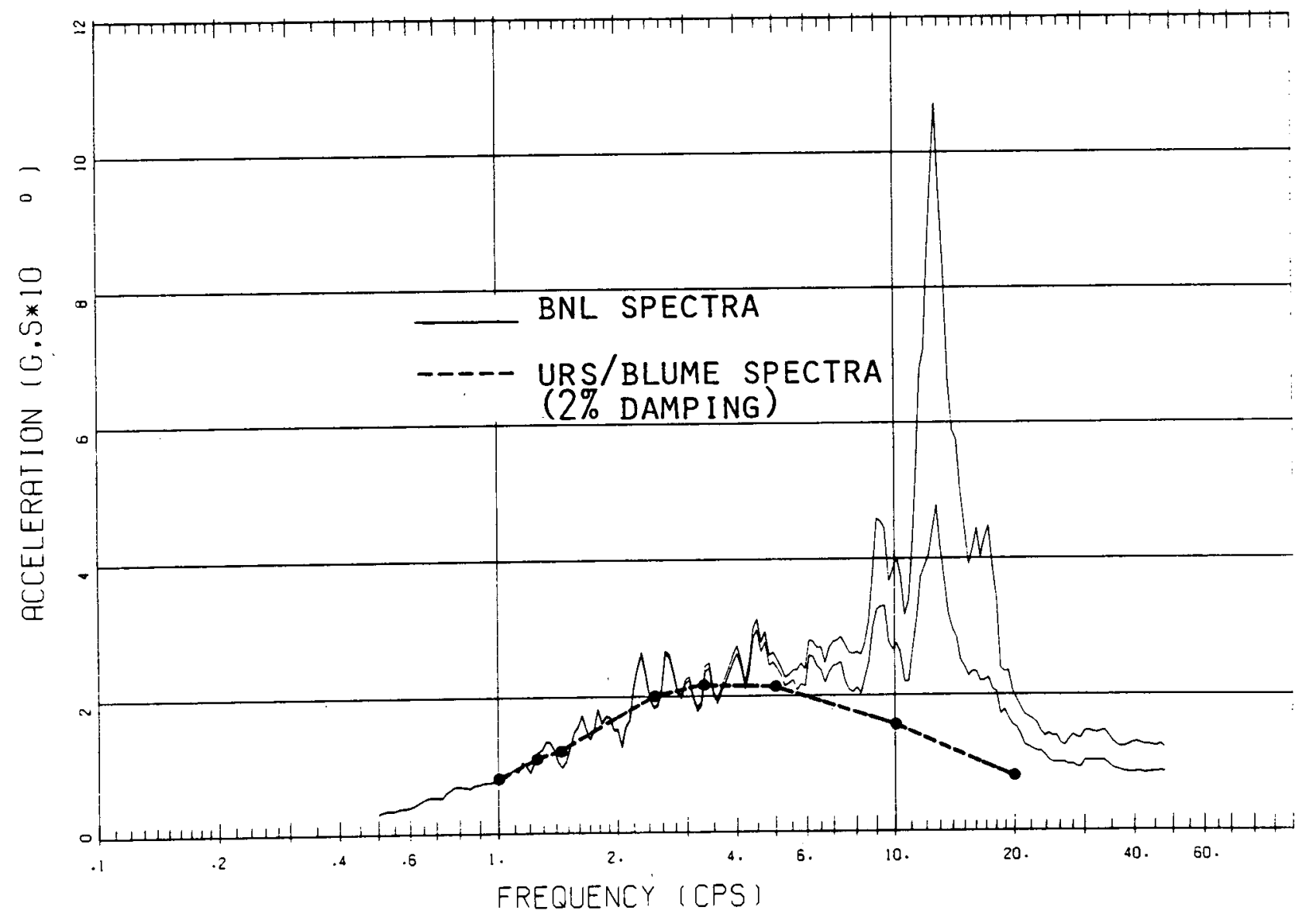




\section{DIABLO CANYON PLANT}

UNIT 1

CONTAINMENT ANNULUS STRUCTURE

$F L O O R=1$

SECTI ON NO. $=2$

EQUIPMENT DAMPING $=2.0$ PERCENT

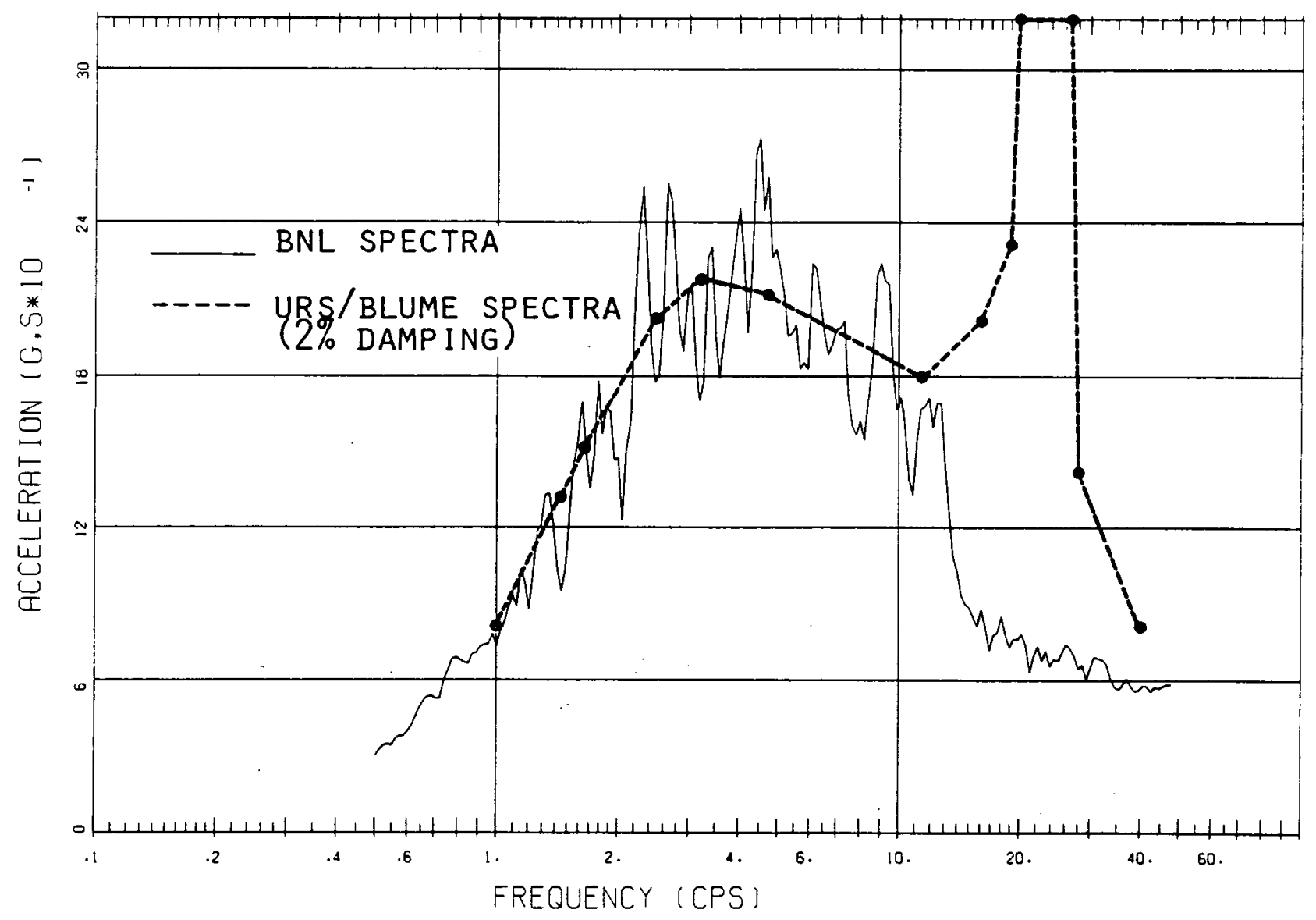




\section{DIABLO CANYON PLFNT}

UNIT 1

CONTAINMENT ANNULUS STRUCTURE

$F L O O R=1$

SECTIONNO.=3

EQUIPMENT DFMPING $=2.0$ PERCENT

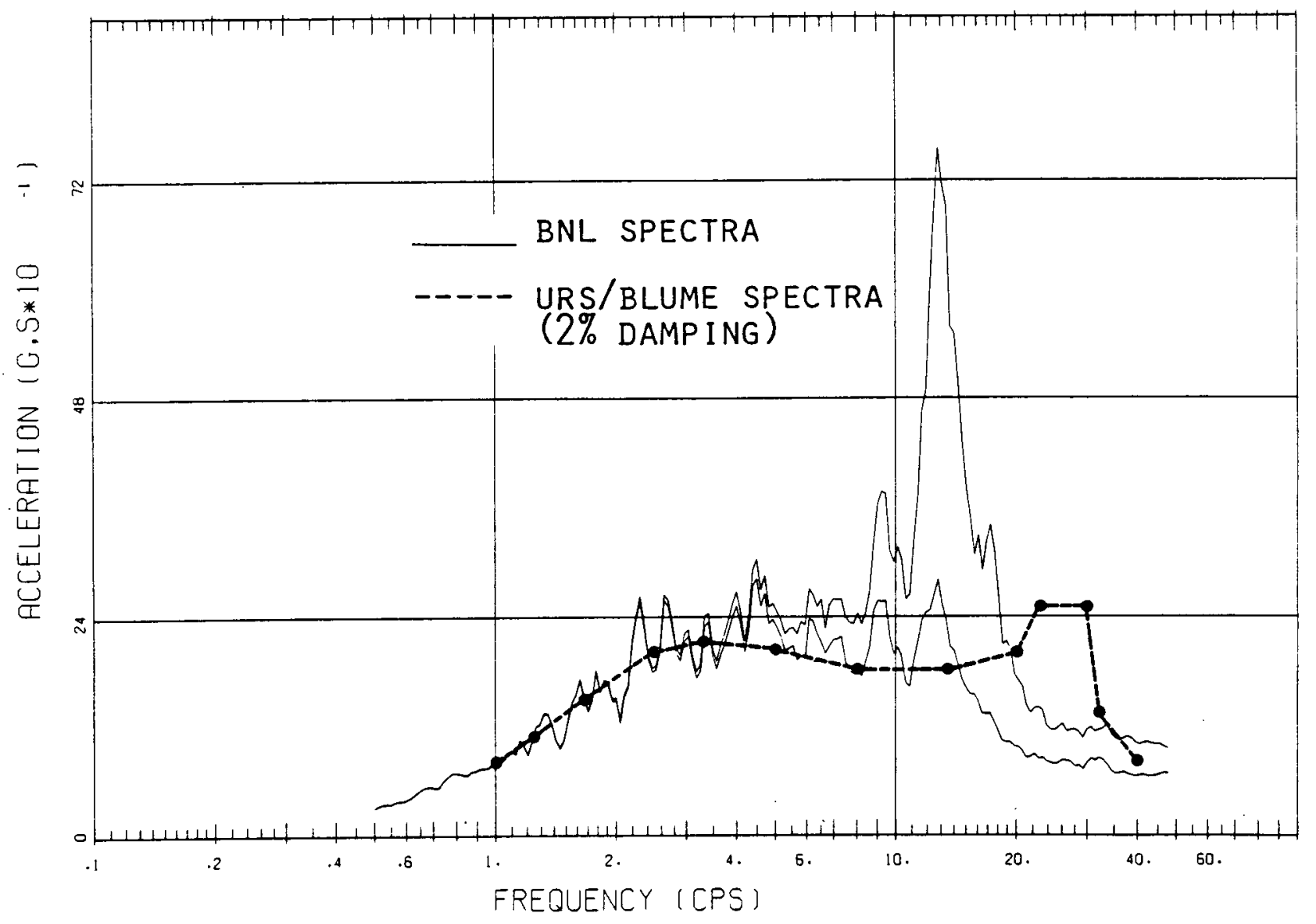




\section{DIABLO CANYON PLANT}

UNIT 1

CONTAINMENT ANNULUS STRUCTURE

$F L O O R=1$

SECTI ONNO.=4

EQUIPMENT DAMPING $\square 2.0$ PERCENT

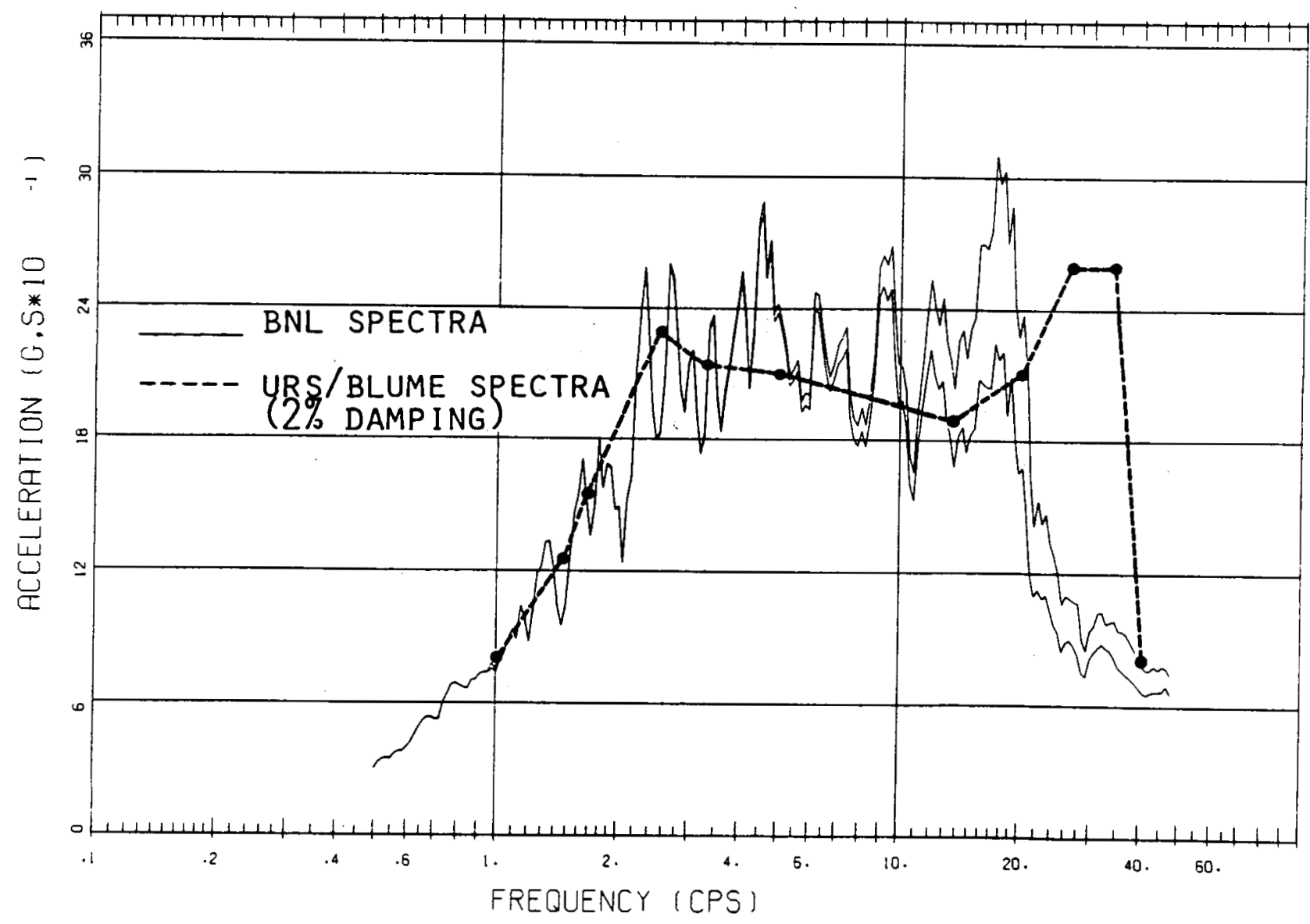




\section{DIABLO CANYON PLANT}

UNIT 1

CONTAINMENT ANNULUS STRUCTURE

$F L O O R=1$

SECTIONNO.=5

EQUIPMENT DAMPING $=2.0$ PERCENT

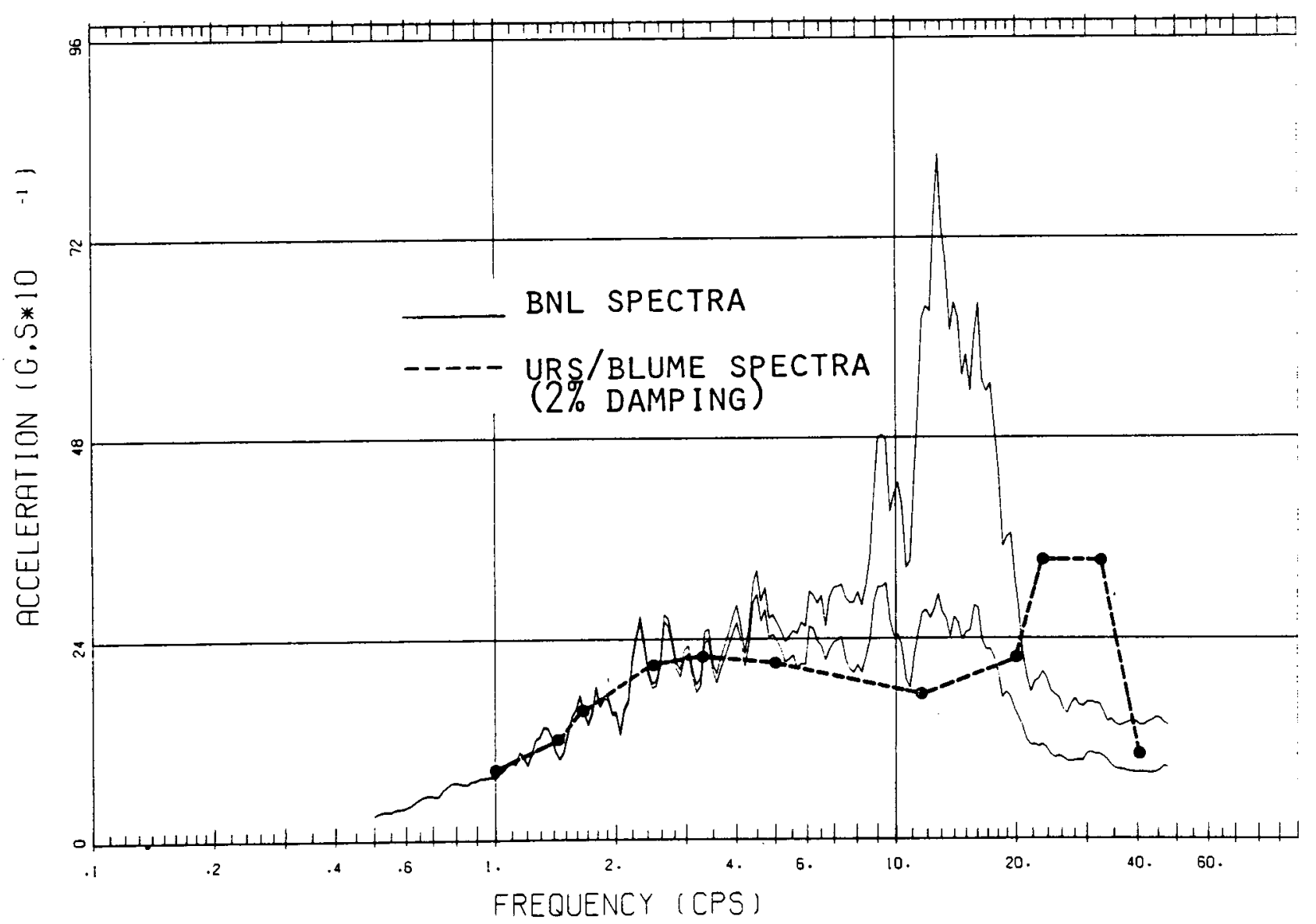


DIABLO CANYON PLANT

UNIT 1

CONTAINMENT ANNULUS STRUCTURE

$F L O O R=2$

$S E C T$ I O N N O. = 1

EQUIPMENT DAMPING $=2.0$ PERCENT

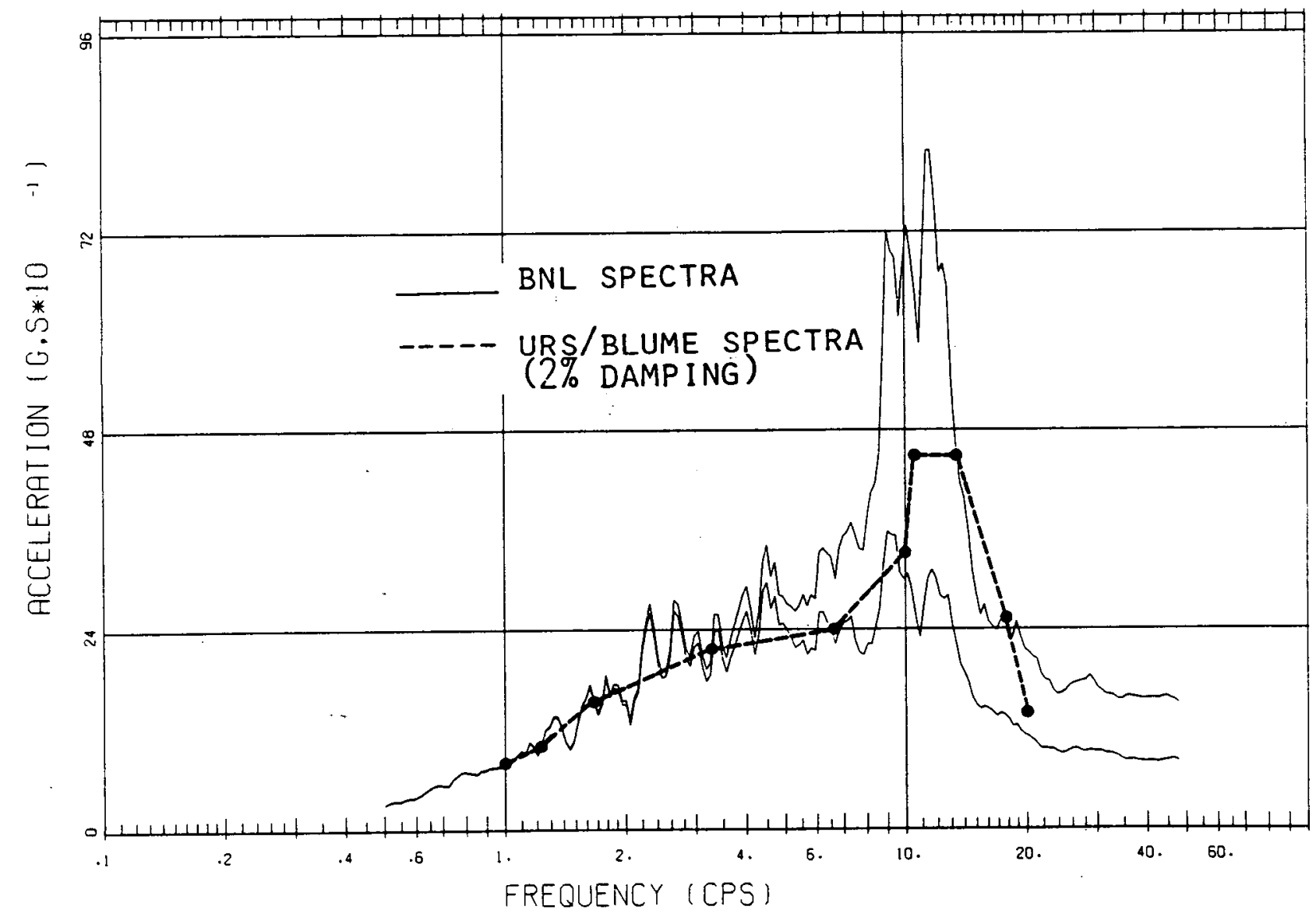



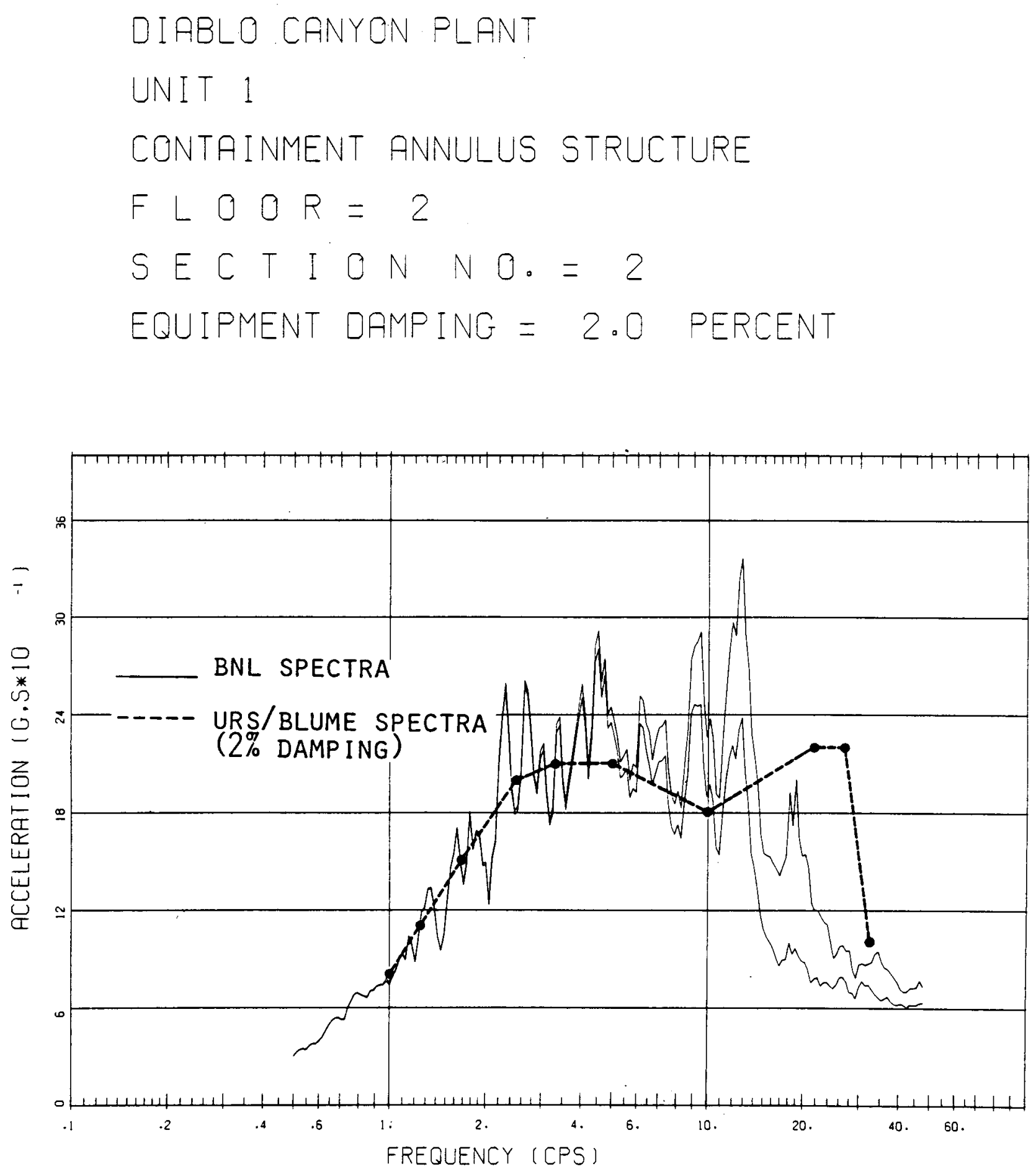

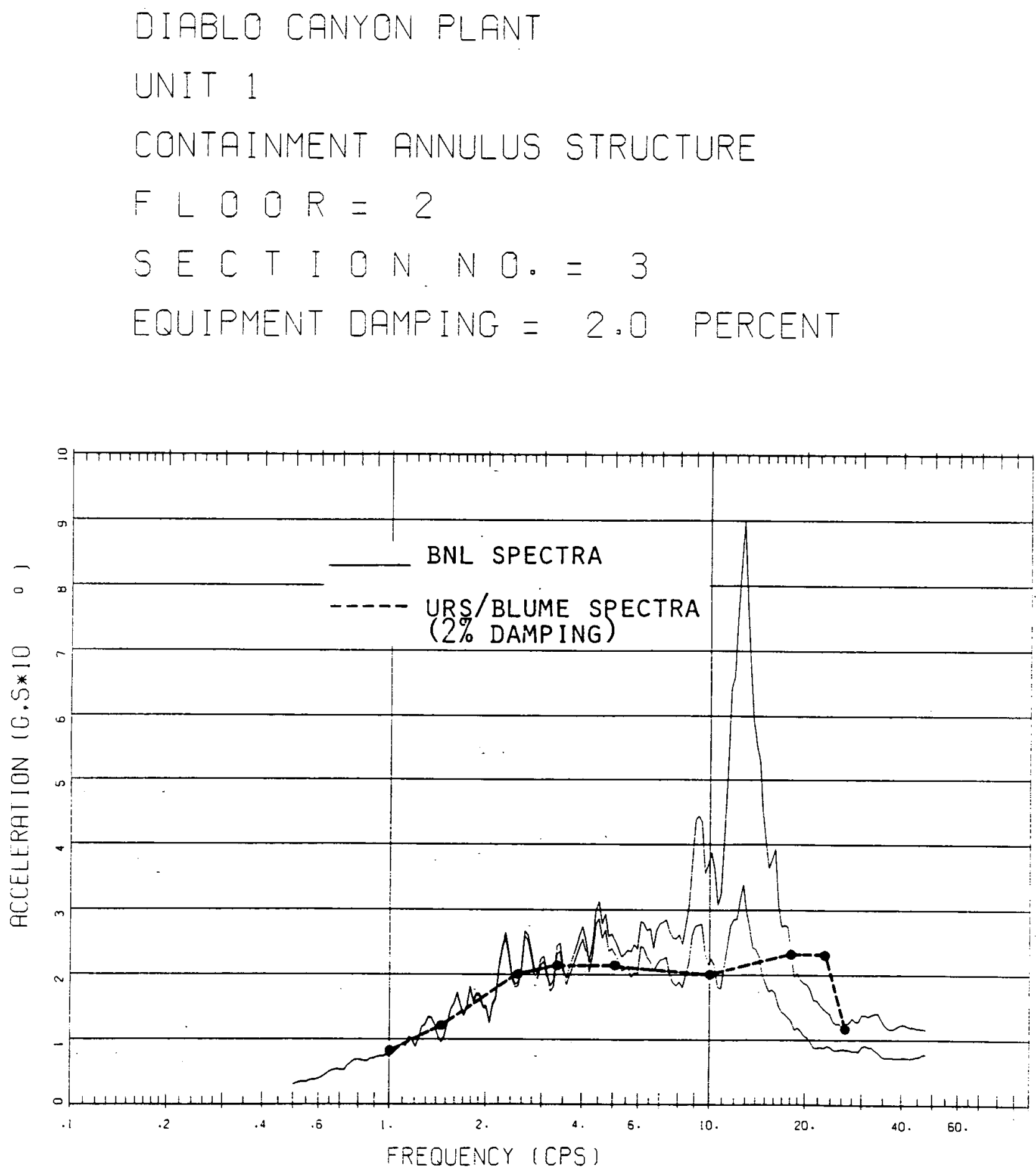
DIABLO CANYON PLANT

UNIT 1

CONTAINMENT ANNULUS STRUCTURE

$F L O O R=2$

SECTI ON NO. $=4$

EQUIPMENT DPMPING $=2.0$ PERCENT

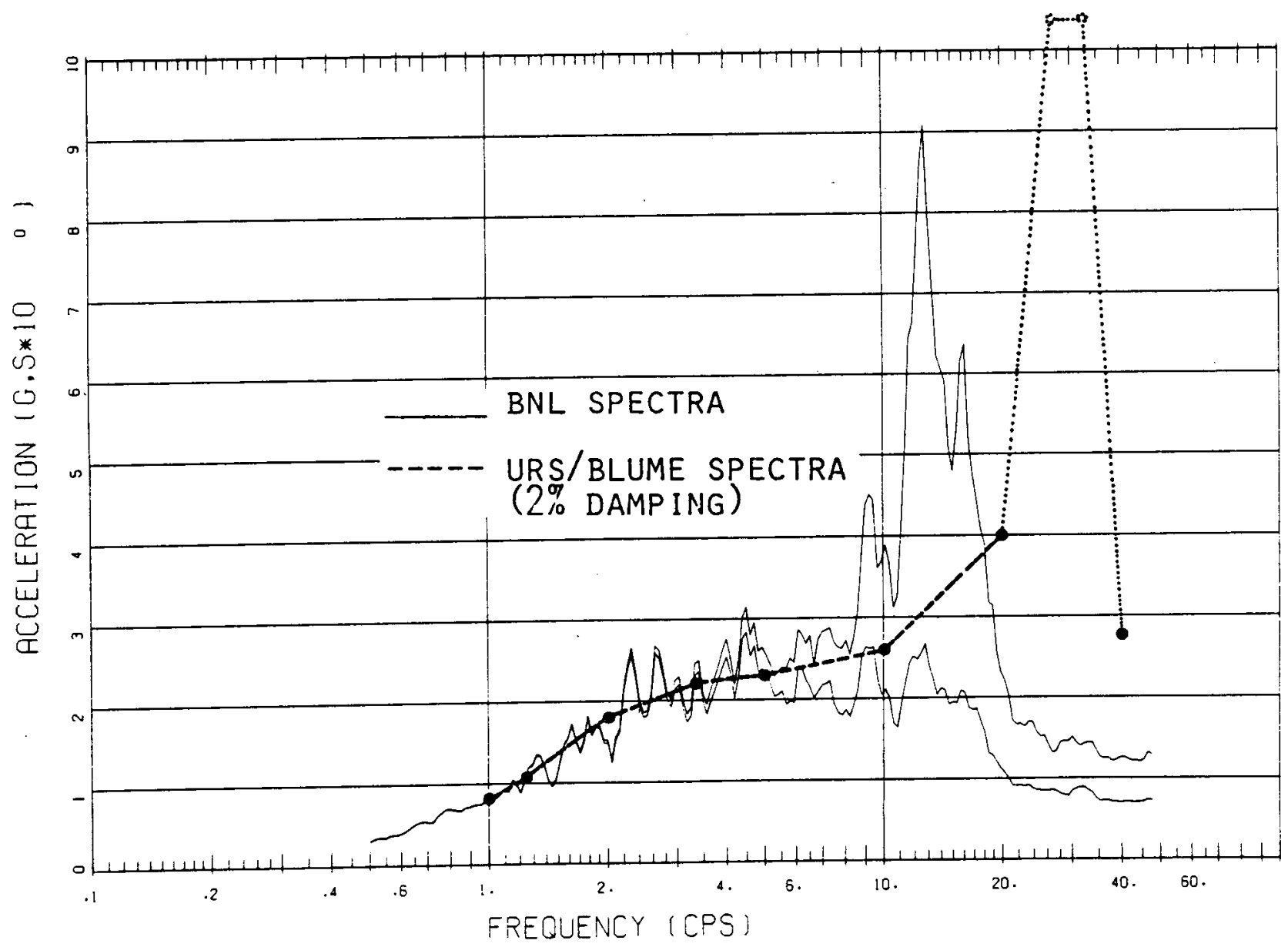




\section{DIABLO CANYON PLANT \\ UNIT 1 \\ CONTAINMENT ANNULUS STRUCTURE \\ $F L O O R=2$ \\ SEC T I O N NO. $=5$ \\ EQUIPMENT DAMPING $=2.0$ PERCENT}

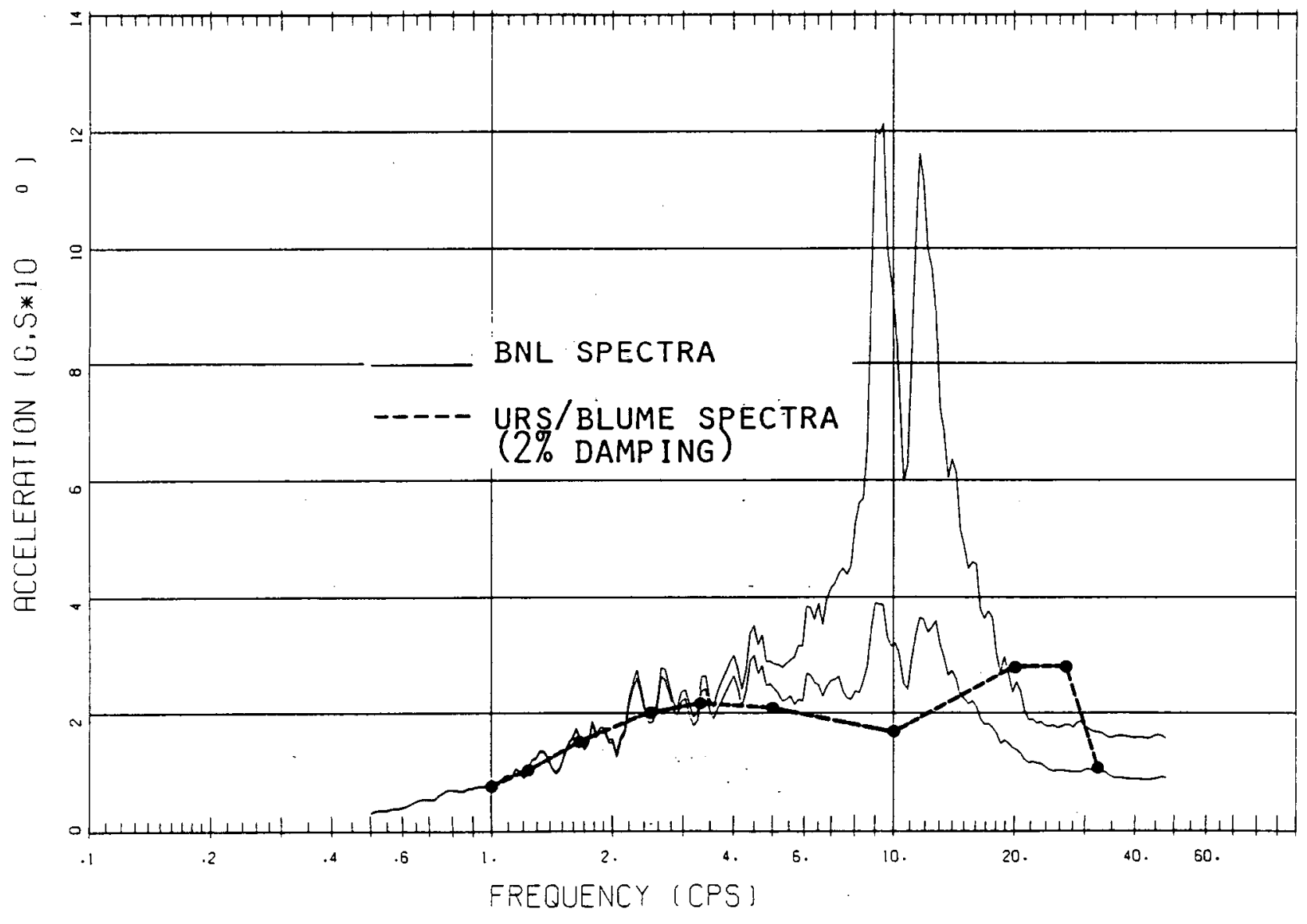



DIABLO CANYON PLANT

UNIT 1

CONTAINMENT ANNULUS STRUCTURE

$F L O O R=3$

SECTION NO. = 2

EQUIPMENT DAMPING $=2.0$ PERCENT

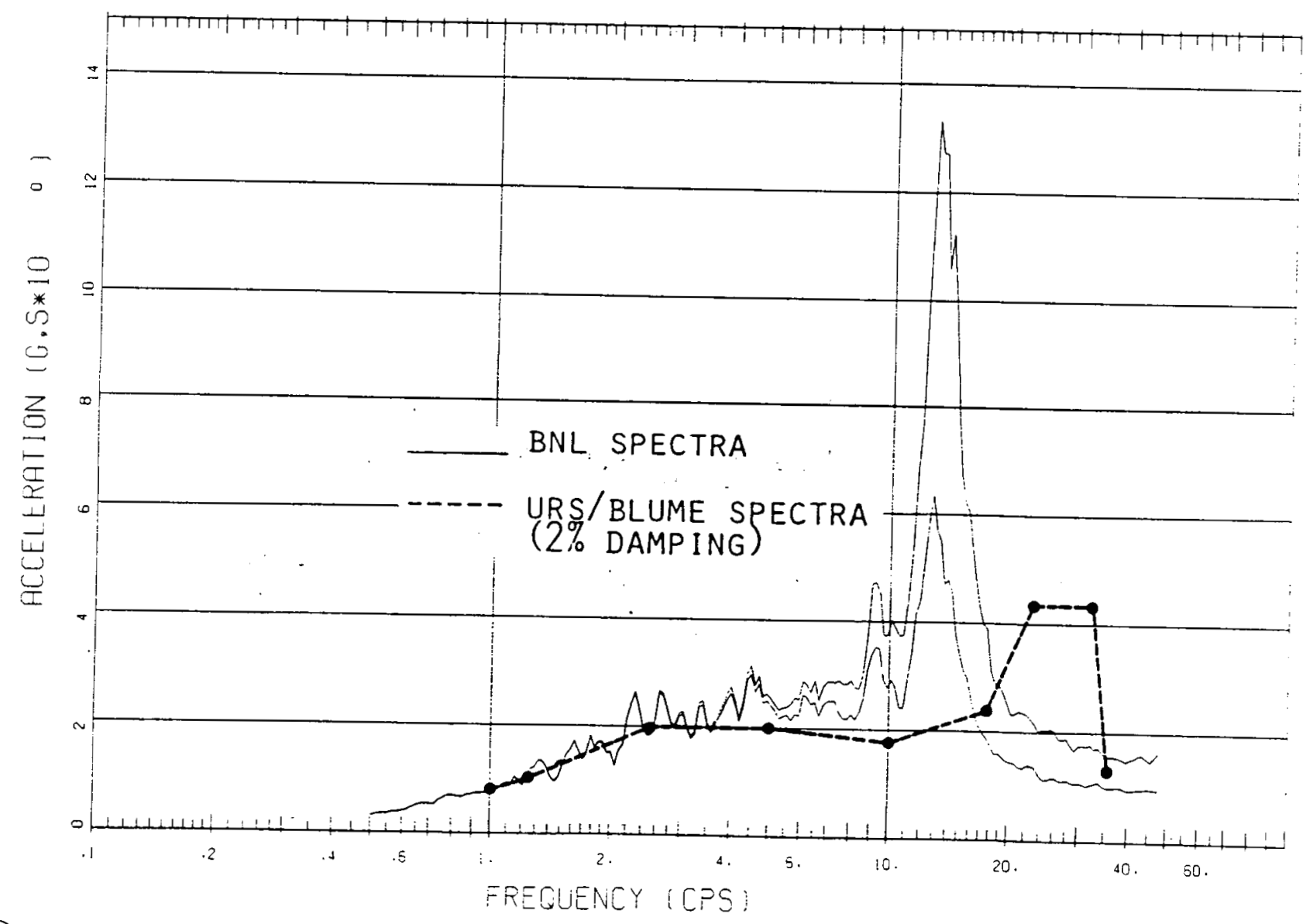




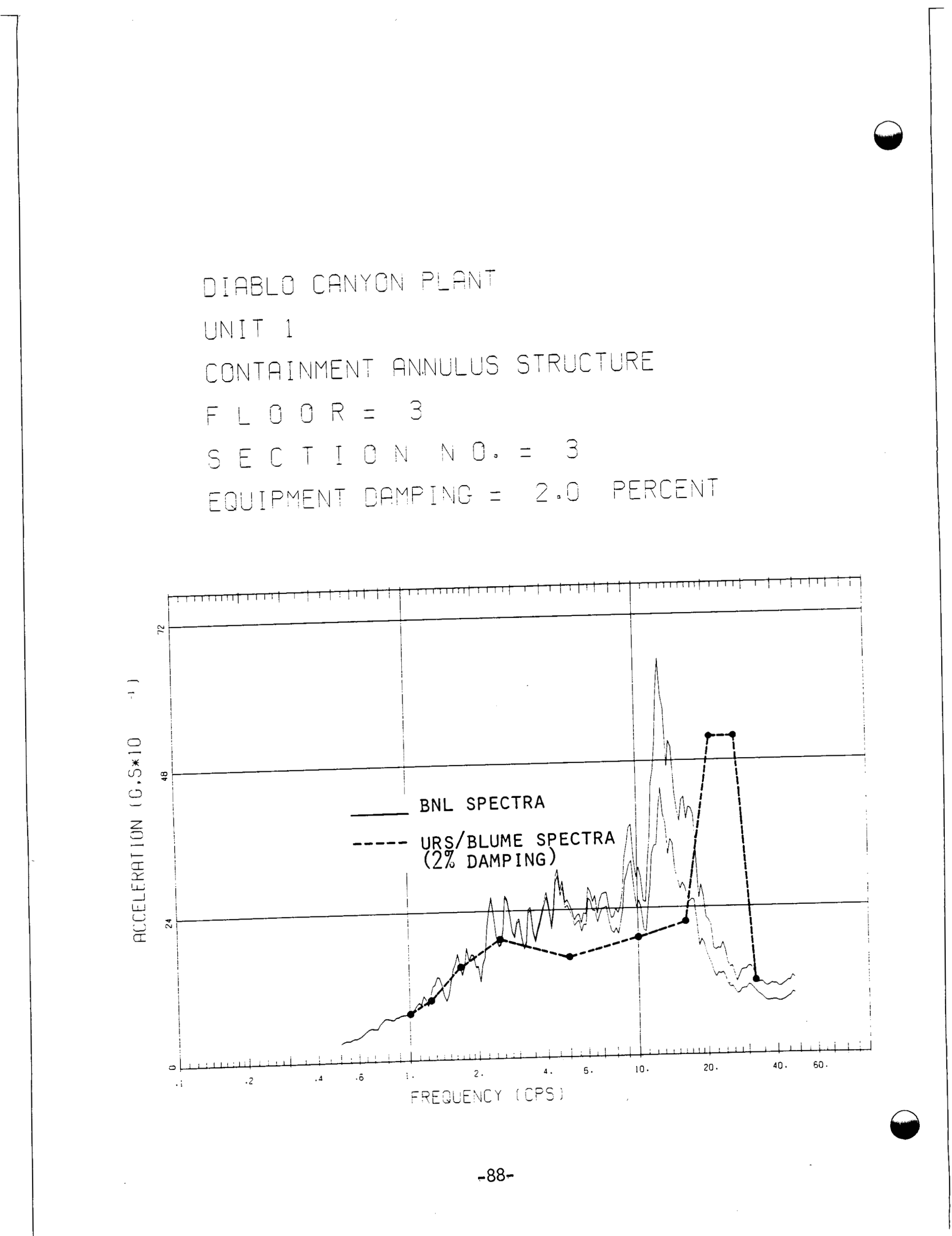




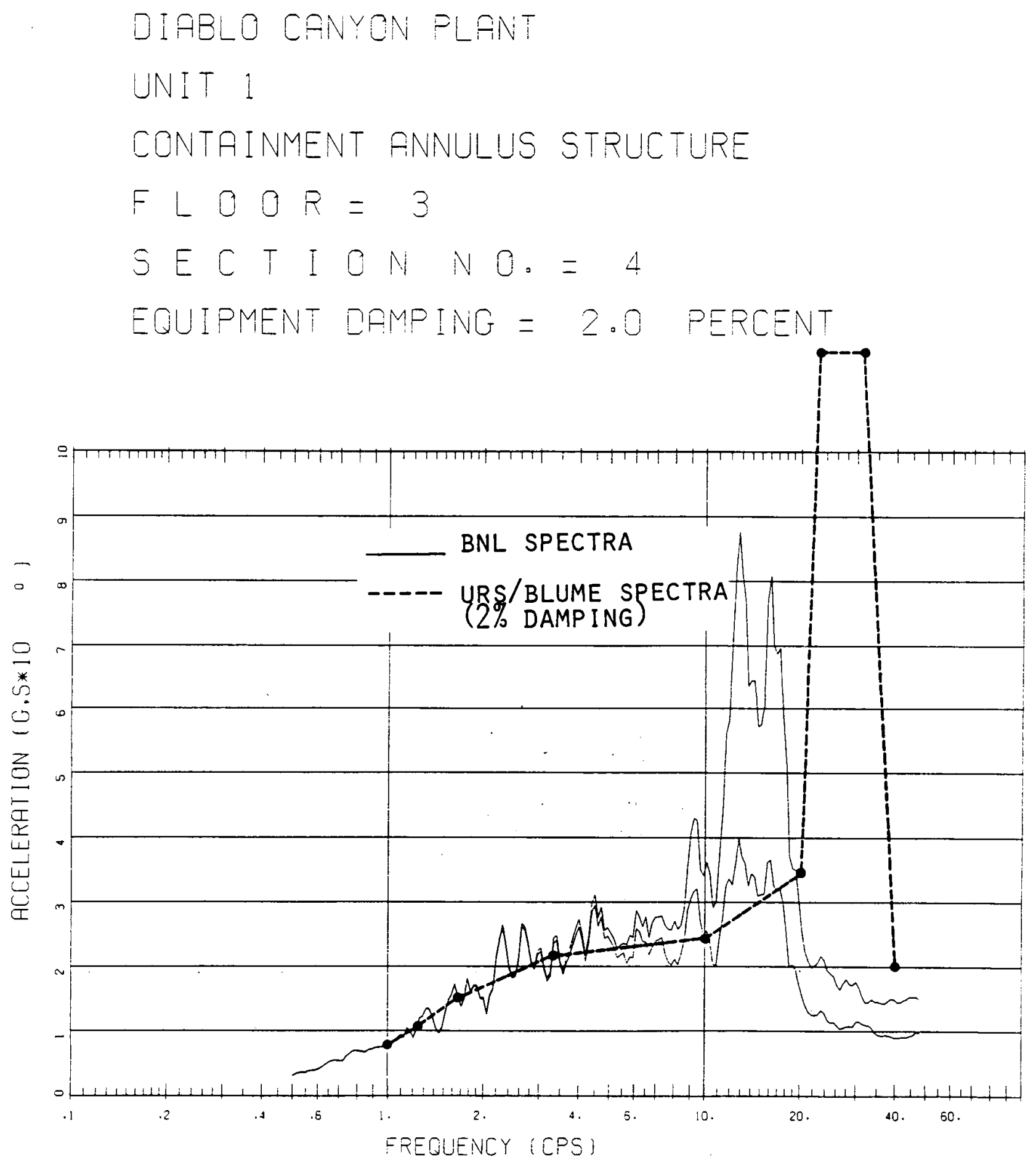


DIABLO CANYON PLFNT

UNIT 1

CONTAINMENT ANNULUSS STRUCTURE

$F L O O R=3$

SECTI ONNO. $=5$

EQUIPMENT DAMPING $=2.0$ PERCENT

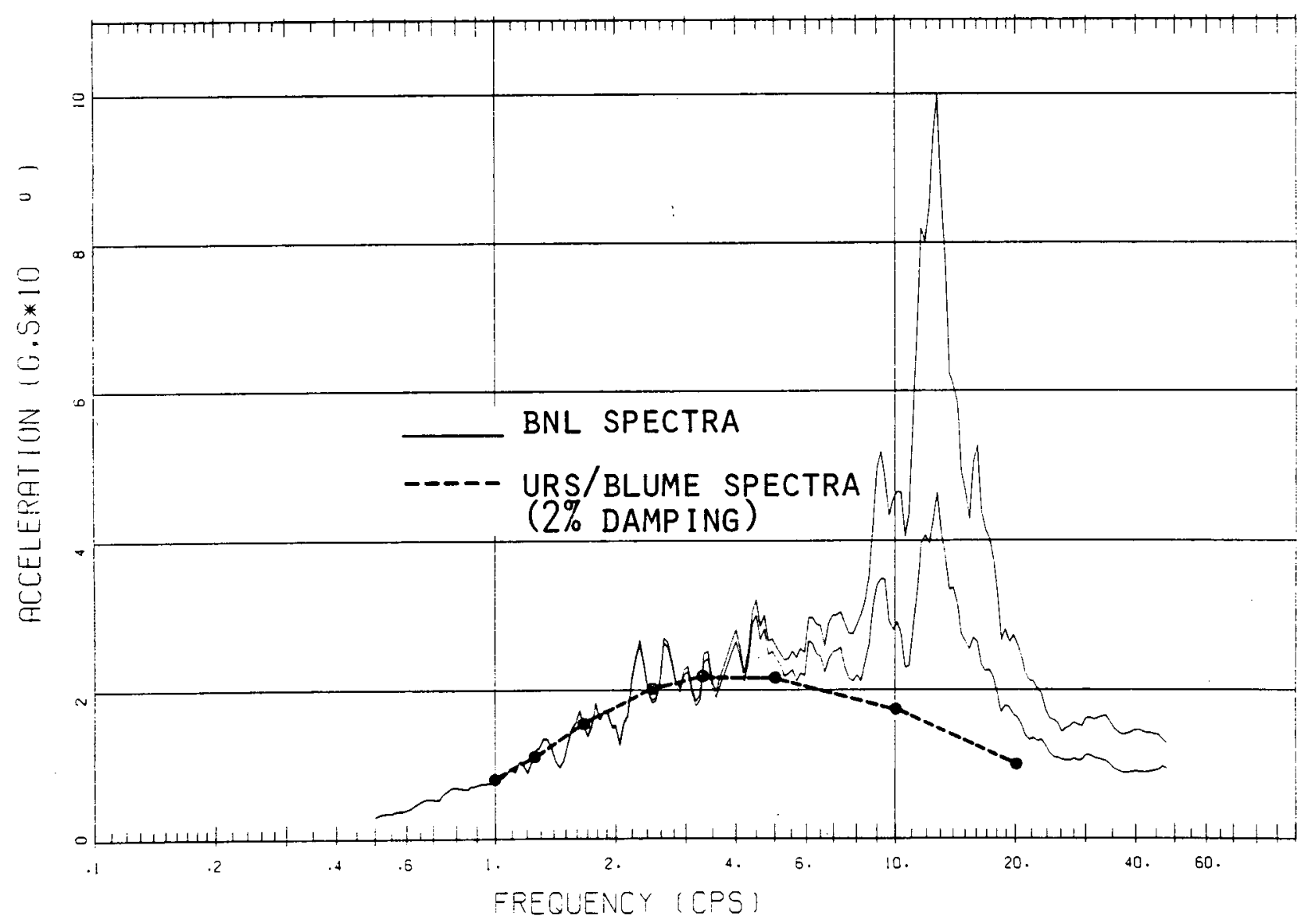




\section{DIABLO CANYON PLANT}

UNIT 1

CONTAINMENT PANULUS STRUCTURE

$F L O O R=4$

SECTIONNO.=

EQUIPMENT DAMPING $=2.0$ PERCENT

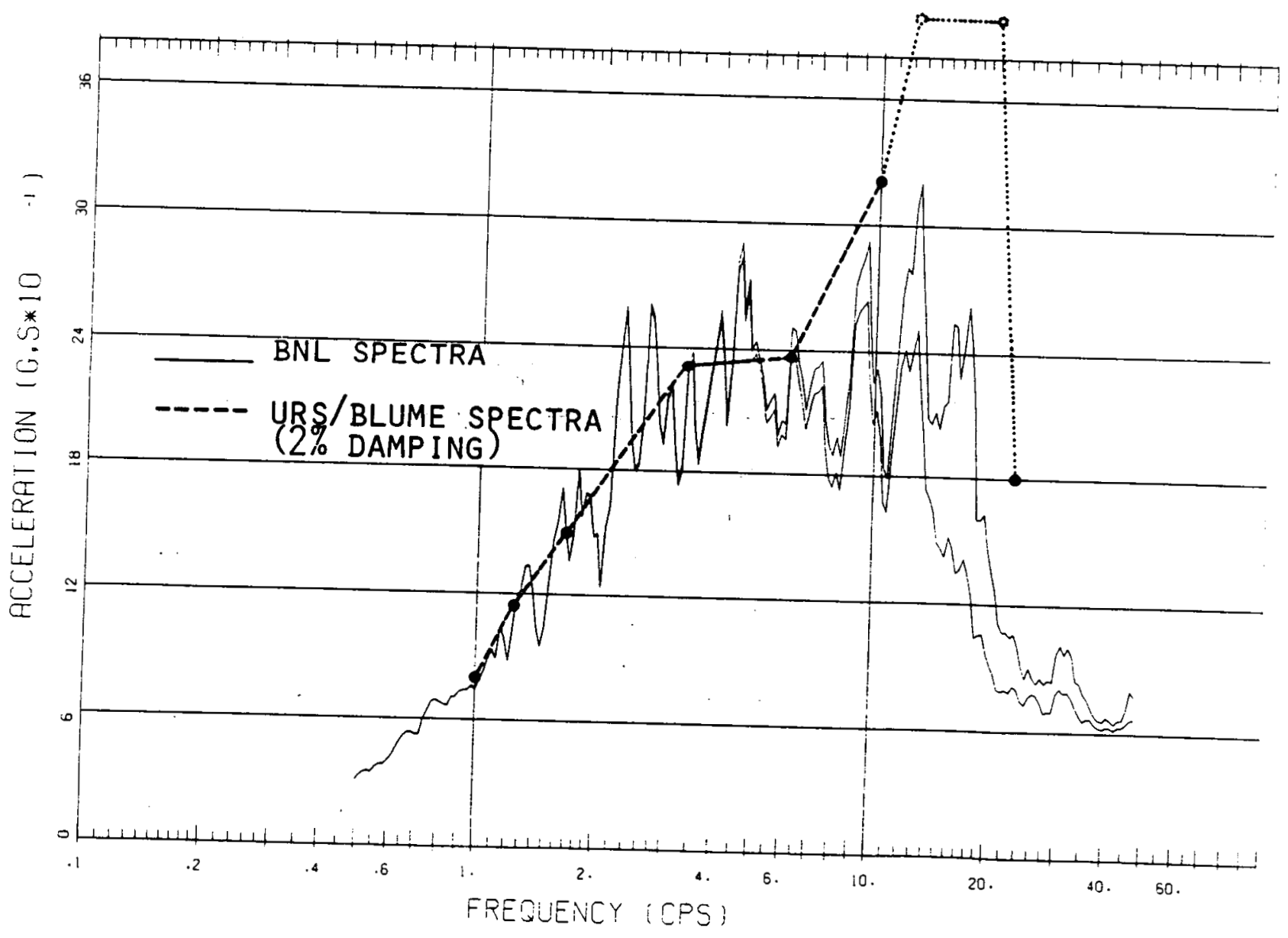




$$
\begin{aligned}
& \text { DIABLO CANYON PLANT } \\
& \text { UNIT } 1 \\
& \text { CONTAINMENT ANNULUS STRUCTURE } \\
& F L O O R=4 \\
& \text { SE C I ON NO= }=2 \\
& \text { EQUIPMENT DFMPING }=2.0 \text { PERCENT }
\end{aligned}
$$

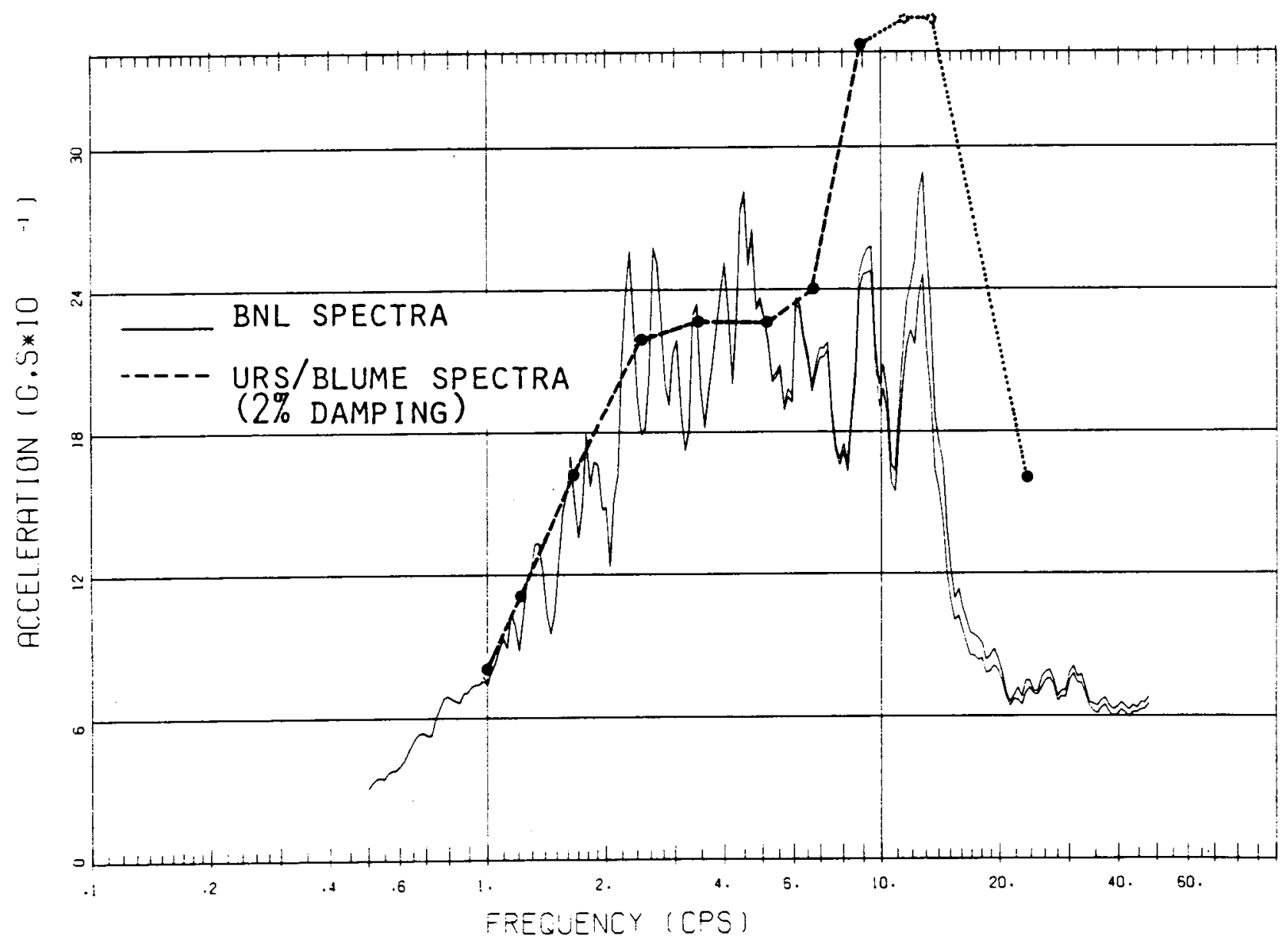


DIABLO CANYON PLANT

UNIT 1

CONTAINMENT ANNULUS STRUCTURE

$F L O O R=4$

SECTION NOO= 3

EQUIPMENT DAMPING $\square \quad 2.0$ PERCENT

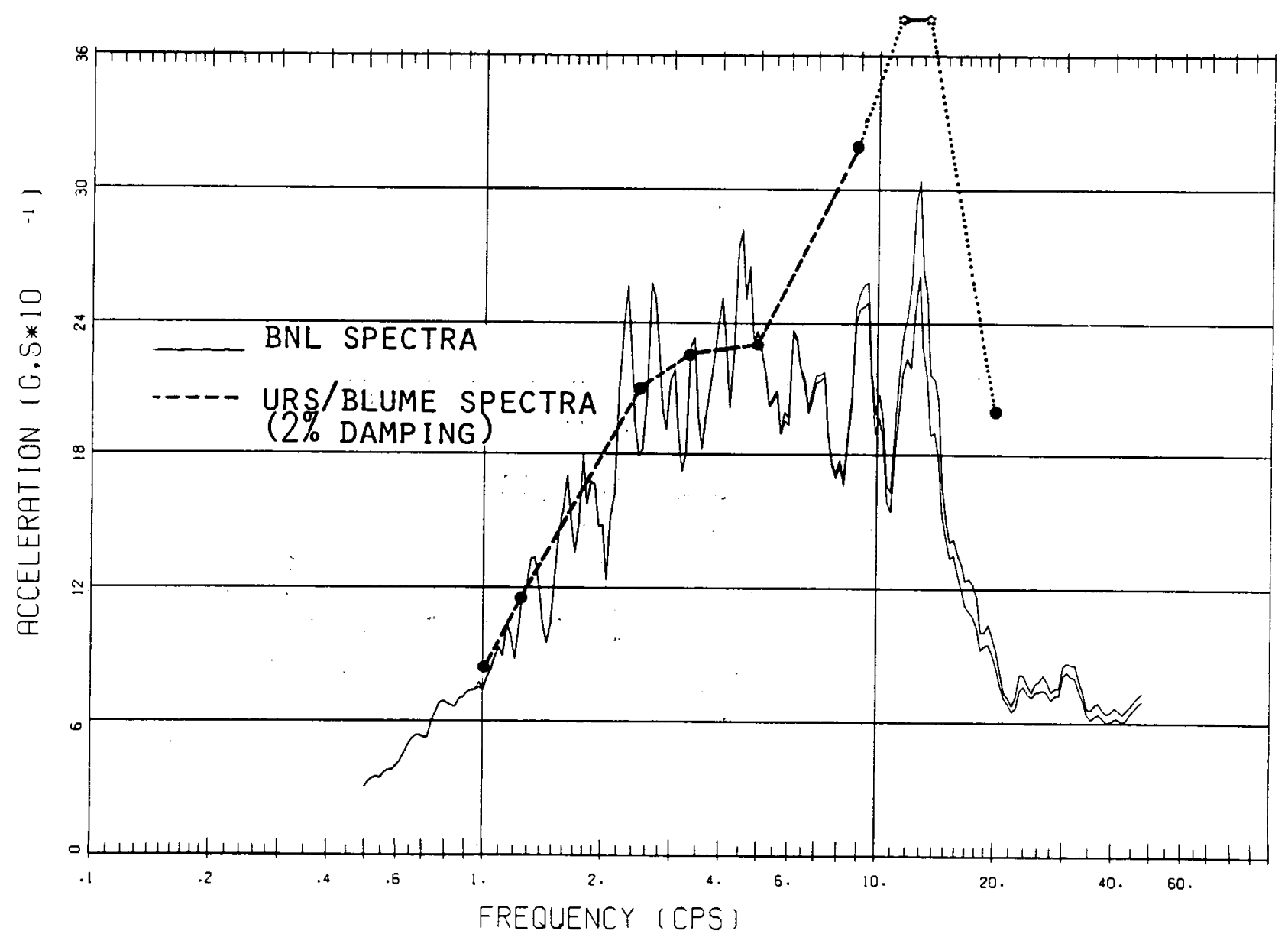


DIABLO CANYON PLANT

UNIT 1

CONTAINMENT ANNULUS STRUCTURE

$F L O O R=4$

SECTIONNO.=4

EQUIPMENT DAMPING $=2.0$ PERCENT

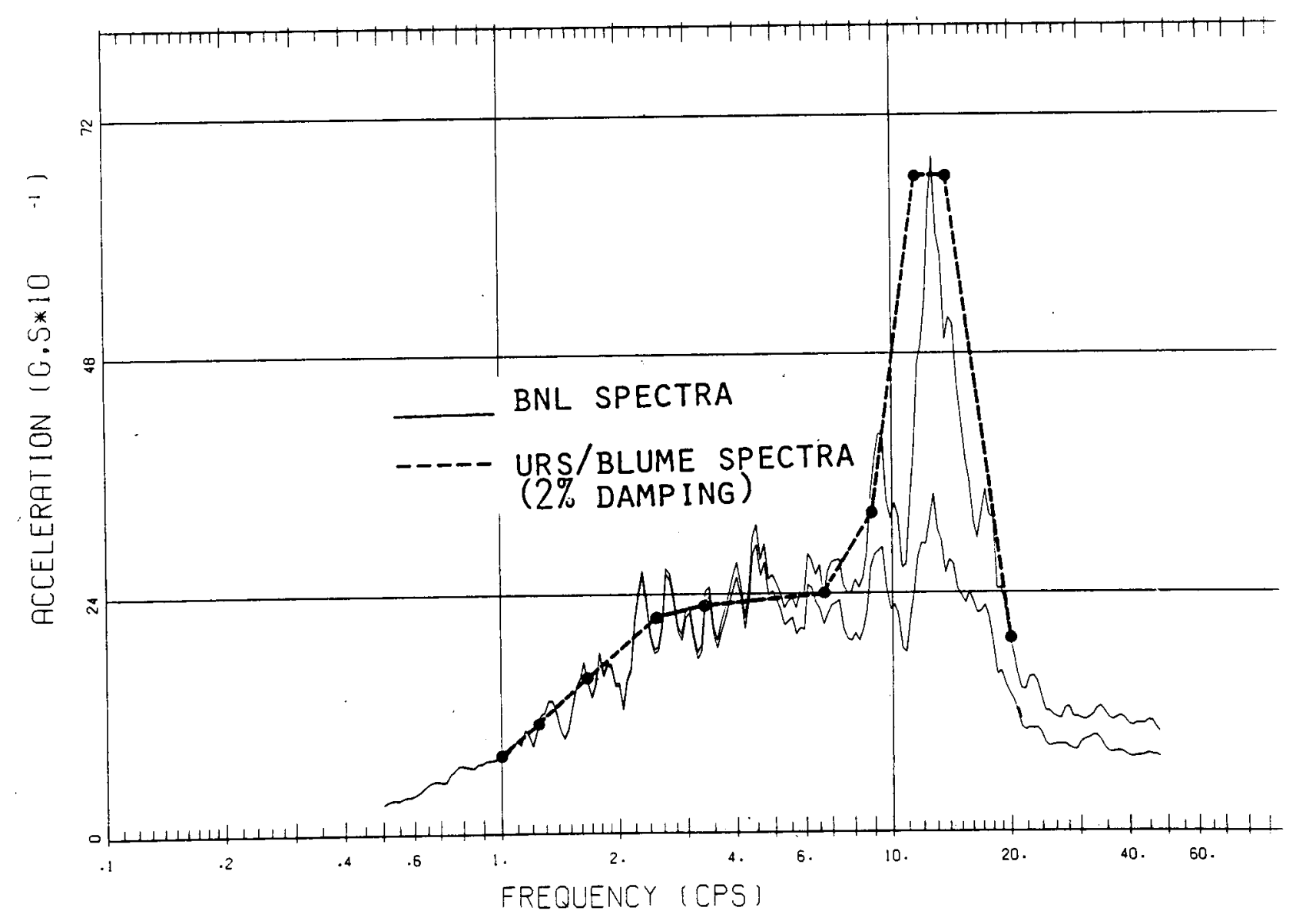


DIABLO CANYON PLANT

UNIT 1

CONTAINMENT ANNULUS STRUCTURE

$F L O O R=4$

SECTIONNO.= 5

EQUIPMENT DAMPING a 2.0 PERCENT

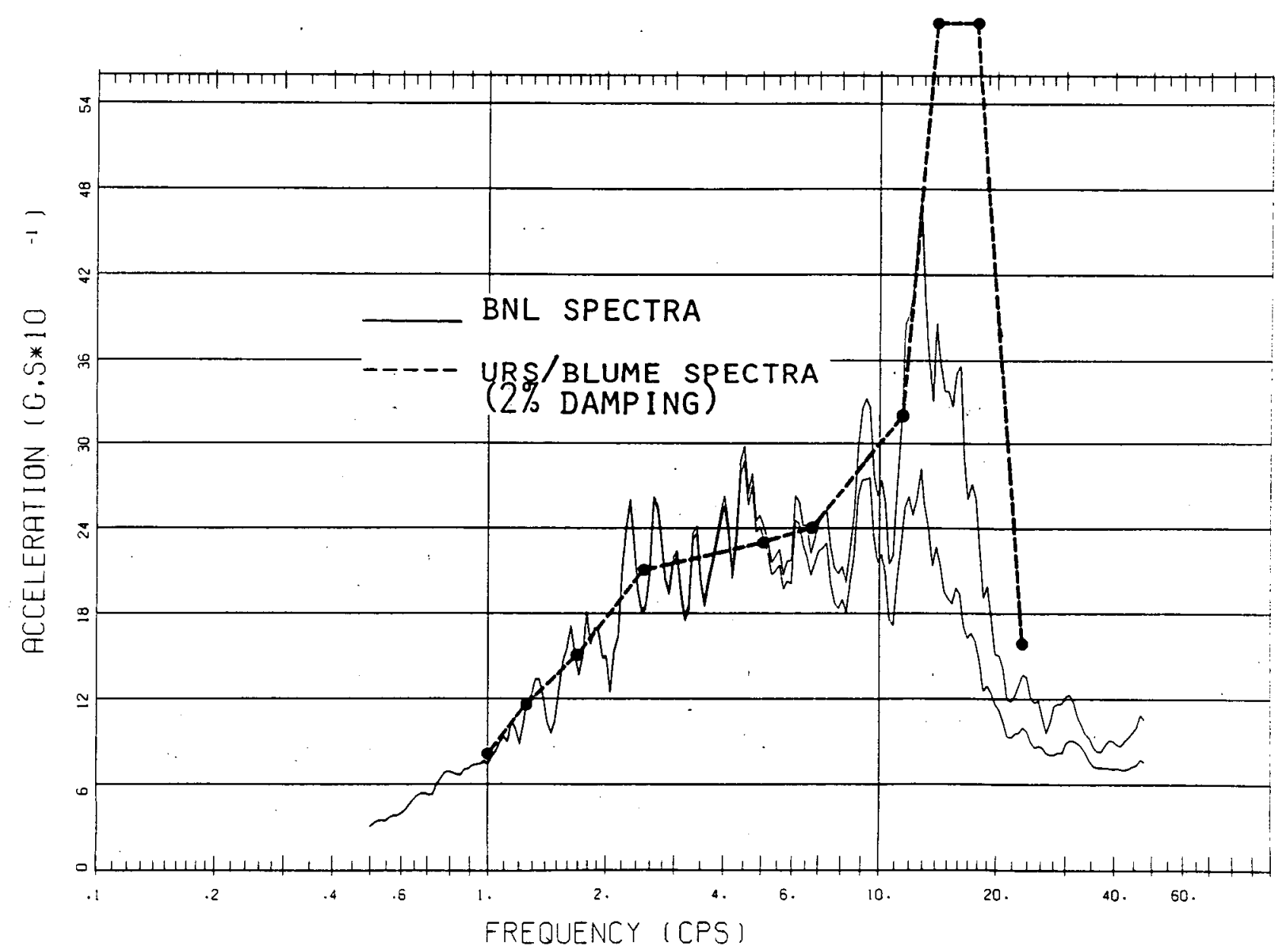




\subsection{Two-Dimensional Model Evaluations}

\subsection{General}

The floor response spectra that were generated by URS/Blume and reported in Ref. [1] were obtained from a two-dimensional model of the containment annulus structure. This model, shown in Figure 6.1, taken from page 54 of Ref. [1] is made up from five frames that correspond to the locations of the five fan coolers located on the concrete floor at elevation $140 \mathrm{ft}$. These frames all share a common inside column which represents the crane wall. A schematic view of this structural idealization is shown in Figure 6.2.

The properties given to this model were obtained on the basis of tributary areas assigned to each frame. These areas were defined by the lines that bisect the angles between adjacent frames and by the exterior circumferential beams. Stiffness and mass calculations for the model were gotten by use of the above defined boundaries. Based on these assumptions the stiffness assigned to beams comprising the five frame model represent are equivalent stiffness of all actual radial steel girders. The masses were lumped at the midspan of each beam. Raw floor response spectra for this model were calculated using 2,3 and $4 \%$ equipment damping.

A copy of the computer printout containing the input data used by URS/Blume for the two-dimensional model was transmitted to BNL. These data were employed to generate floor response spectra using the BNL version of the SAPV code. Computer runs were also made to verify the floor response spectra obtained from the BNL code using the STRUDL code of the McDonnell Douglas Automation Co. Details pertaining to these tasks follow.

\subsection{Verification of floor spectra results}

At NRC's request, BNL verified results of the floor response spectra generated from BNL'S SAPV version with those obtained from the STRUDL McDonnell Douglas Automation Co. computer code. For this purpose the input 


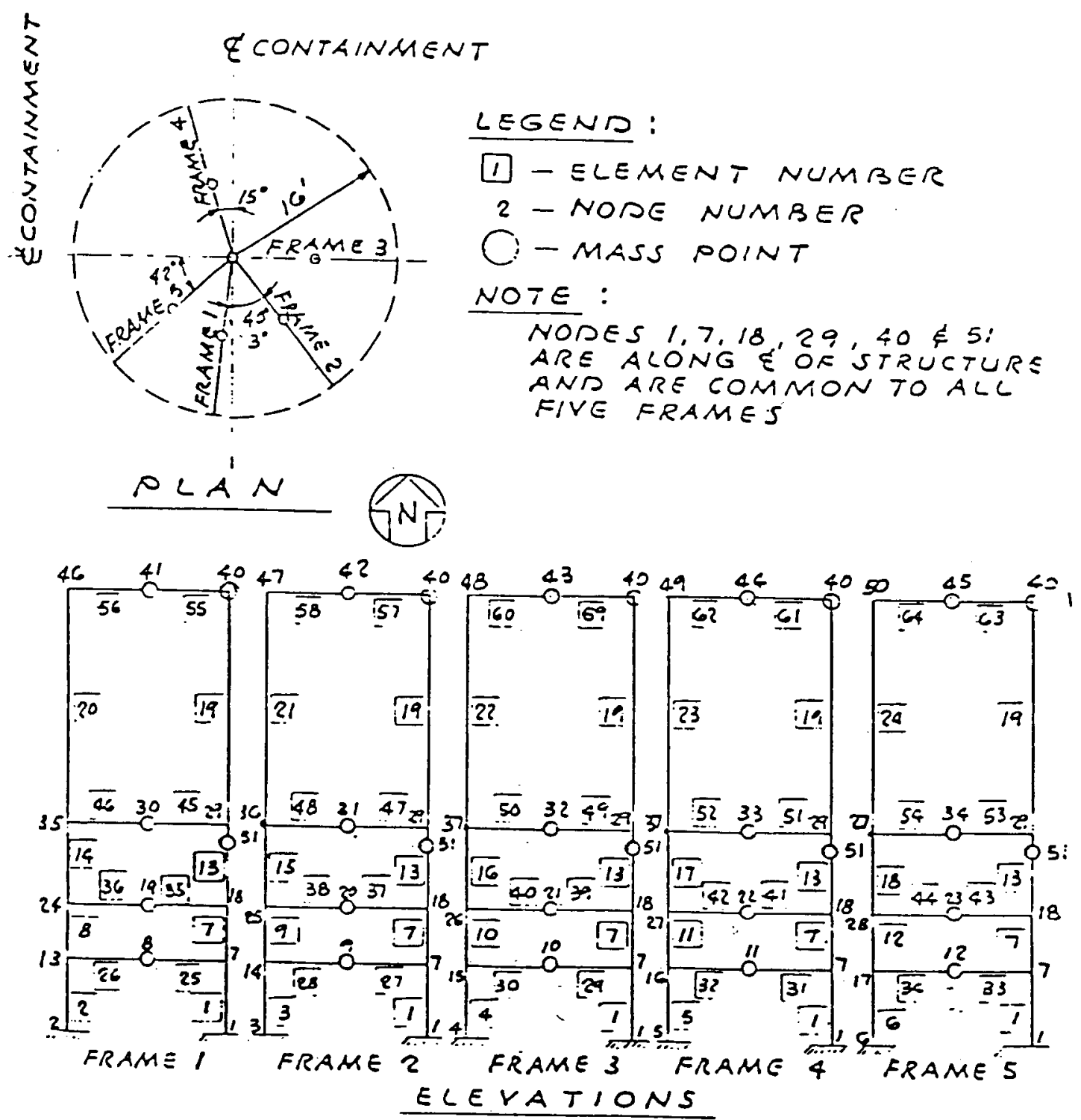

Figure 6.1 - URS/Blume mathematical model of containment annulus structure. 


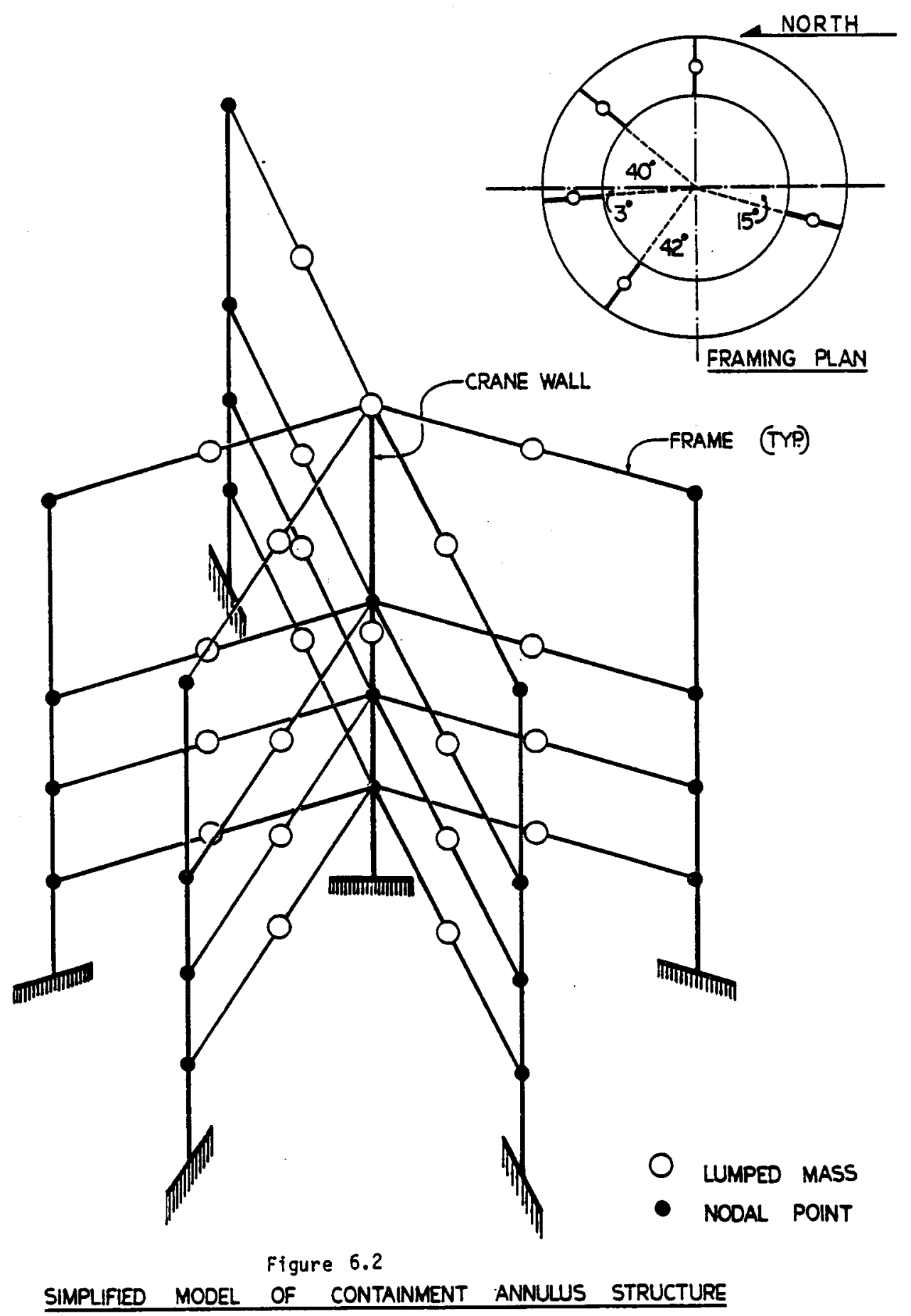


data of the two-dimensional model of the containment annulus structure given to BNL during the San Francisco meeting $(10 / 14 / 81)$ were used. It was also assumed that top floor to crane wall connnections were shear type, and that all other connections were rigid. In addition all nodal points were assigned two degrees-of-freedom, i.e., one vertical translation and one rotation in the plane of the frames. A free-vibration analysis was perfomed by use of both computer codes. A total of thirty modes were computed. These results are shown in Table 6.1. Fran this table it can be seen that the eigenvalue solution results obtained by use of both computer codes are in good agreement.

Furthermore, floor response spectra were generated for $2 \%$ equipment damping. Results from these evaluations are given in Figures 6.3 to 6.8. For comparative purposes the spectral curves obtained from the STRUDL and BNL SAPV codes for each nodal point are shown plotted together in the same figure. In these plots the solid line represents the floor response spectrum obtained from the STRUDL code of MCDonnell Douglas Co. The dashed line represents the corresponding spectrum obtained from the BNL version of SAPV code. From these plots it can be seen that the results obtained from the two computer codes are in good agreement.

\subsection{Results from URS/BIume Input Data}

When the actual input data used by URS/BIume for the two-dimensional model became available, computer runs were made using these input data. Floor response spectra were generated and compared with those transmitted to BNL. In these evaluations the following parameters were taken to be identical as those used by URS/BIume.

(a) One degree-of-freedom, i.e., vertical translation, was assigned to all nodal points attached to the crane wall. For all other nodal points two degrees-of-freedom were used, i.e., one vertical translation and one rotation in the plane of each frame. 
(b) Totally eighteen modes were used in the eigenvalue solution.

(c) The modal equations were integrated with a time step equal to 0.003 seconds. The total acceleration response time histories were computed over a duration equal to 15 seconds.

Results from the eigenvalue solution obtained by BNL together with the URS/BIume results are given in Table 6.2. From this table it can be seen that these results are identical. In addition, computer runs were made to compute floor response spectra. The latter were then compared with the corresponding raw spectra transmitted in digitized form by URS/BIume. Figures 6.9 to 6.16 demonstrate the results of these evaluations. The solid line represents the URS/BTume raw floor response spectra whereas the dashed line represents the corresponding BNL evaluated spectra.

Fram these figures it can be concluded that the spectral curves obtained by BNL are in good agreement with those computed by URS/Blume. It should be noted, however, that the number of spectrum points calculated by URS/Biume is equal to 97. The corresponding BNL floor spectra were computed at 198 spectral frequencies. Thus the small differences shown in the figures can be attributed to the fact that the BNL spectra is more refined.

\subsection{Comparison between raw and broadened spectra}

A final task, under the 2-D model evaluations, involves a comparison between the URS/Blume broadened floor spectra and the corresponding raw spectra. The former are reported in Ref. [1] whereas the latter were transmitted to BNL in digitized form. Spectral curves at $2 \%$ equipment damping were campared. Results of this comparison are shown in Figures 6.17 to 6.24. In these figures the solid line represents the raw spectral curve whereas the dashed line represents the corresponding broadened spectra.

By inspection of these figures the following may be concluded:

(a) The broadened spectra are generally in good agreement with the corresponding raw spectra.

(b) At low spectral frequencies, it can be seen that the broadened spectra values are only averages of the corresponding raw spectra. 
Table 6.1

20 MODEL. COMPARISON OF MODAL FREQUENCIES (CPS)

Mode No.

STRUDL

SAPV

(MCDONNELL DOUGLAS)

(BNL)

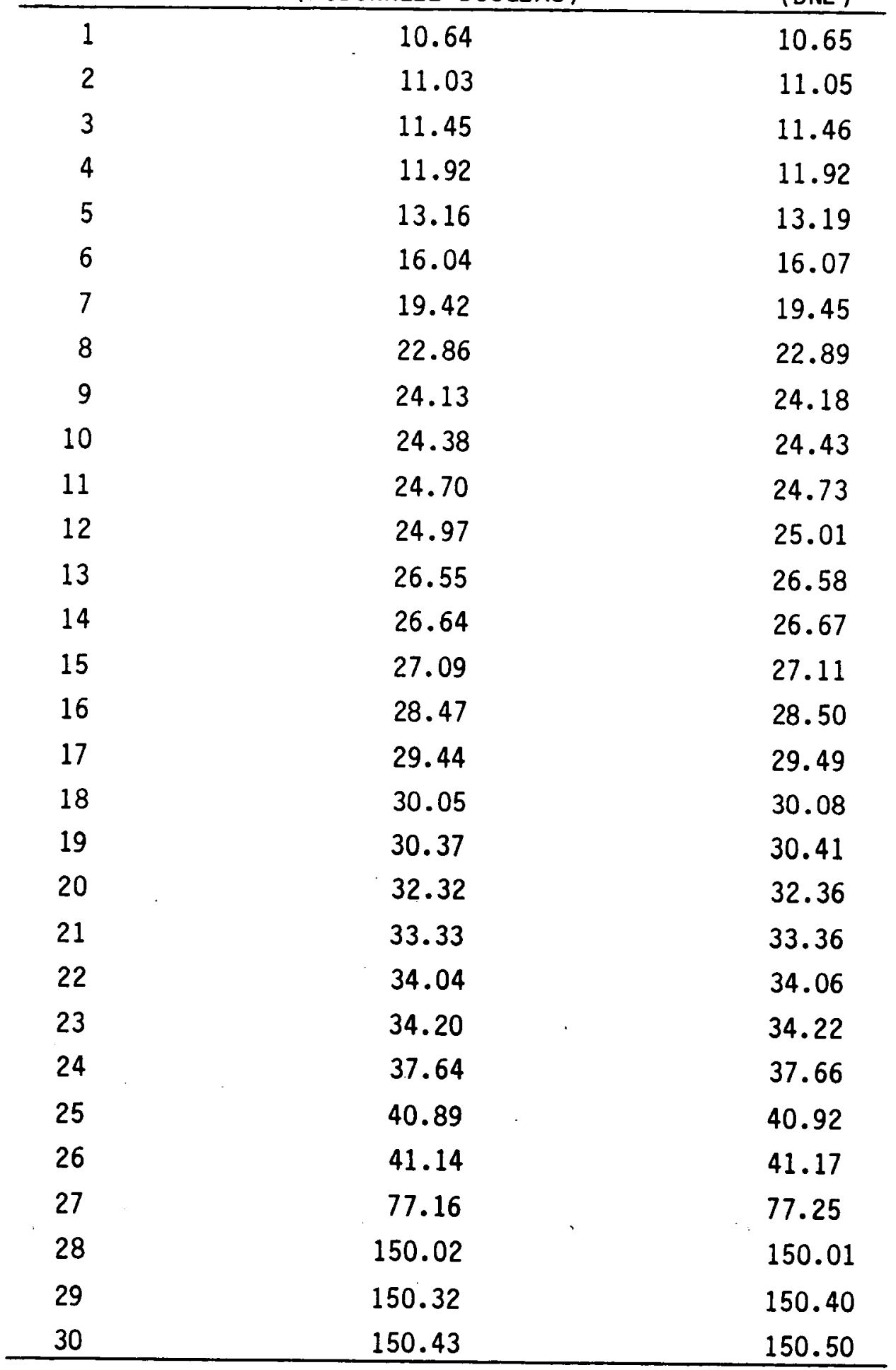




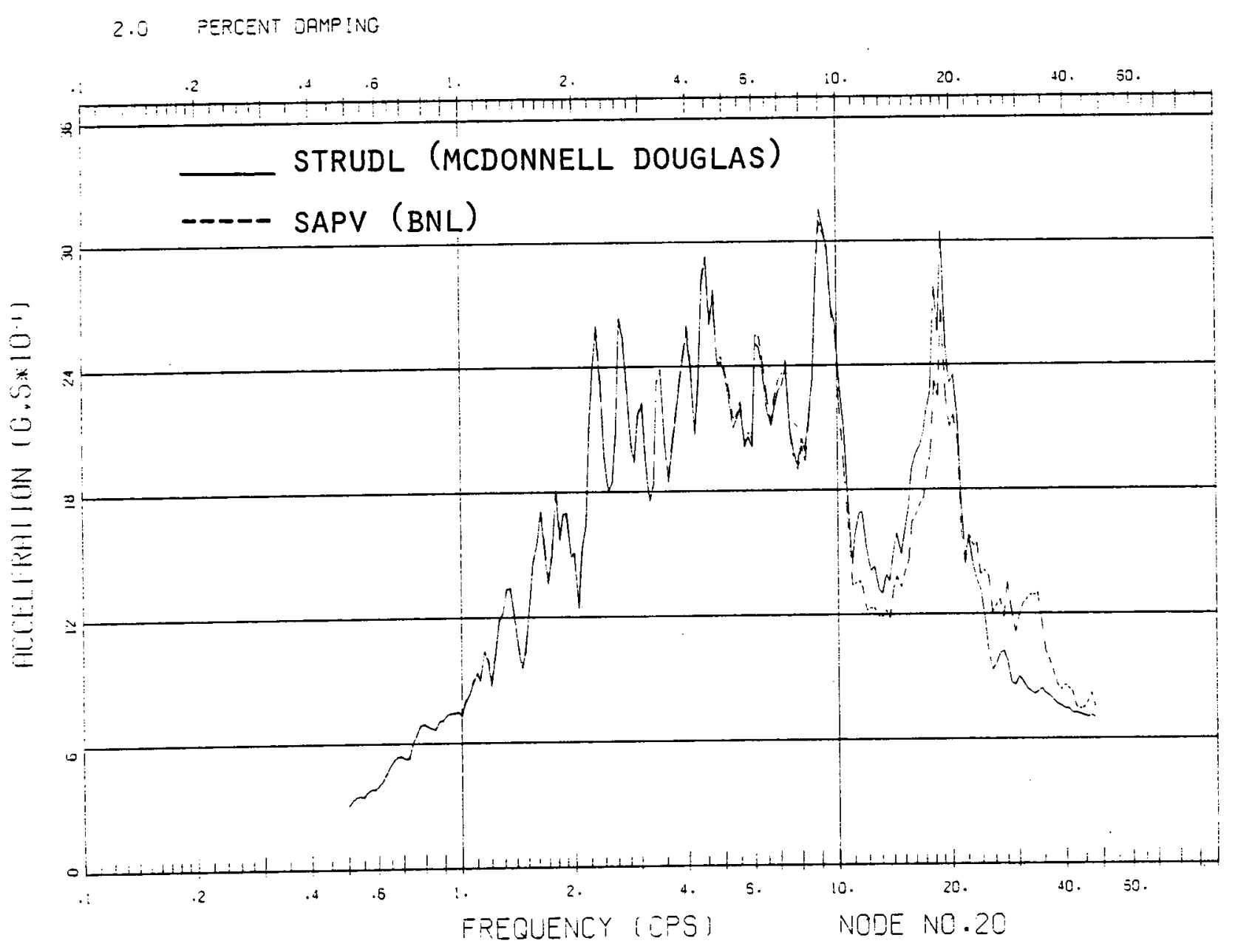

Figure 6.3 - 2 Dode 20 . SAPV (BML) versus STRUDL (MCDonnell Douglas). 


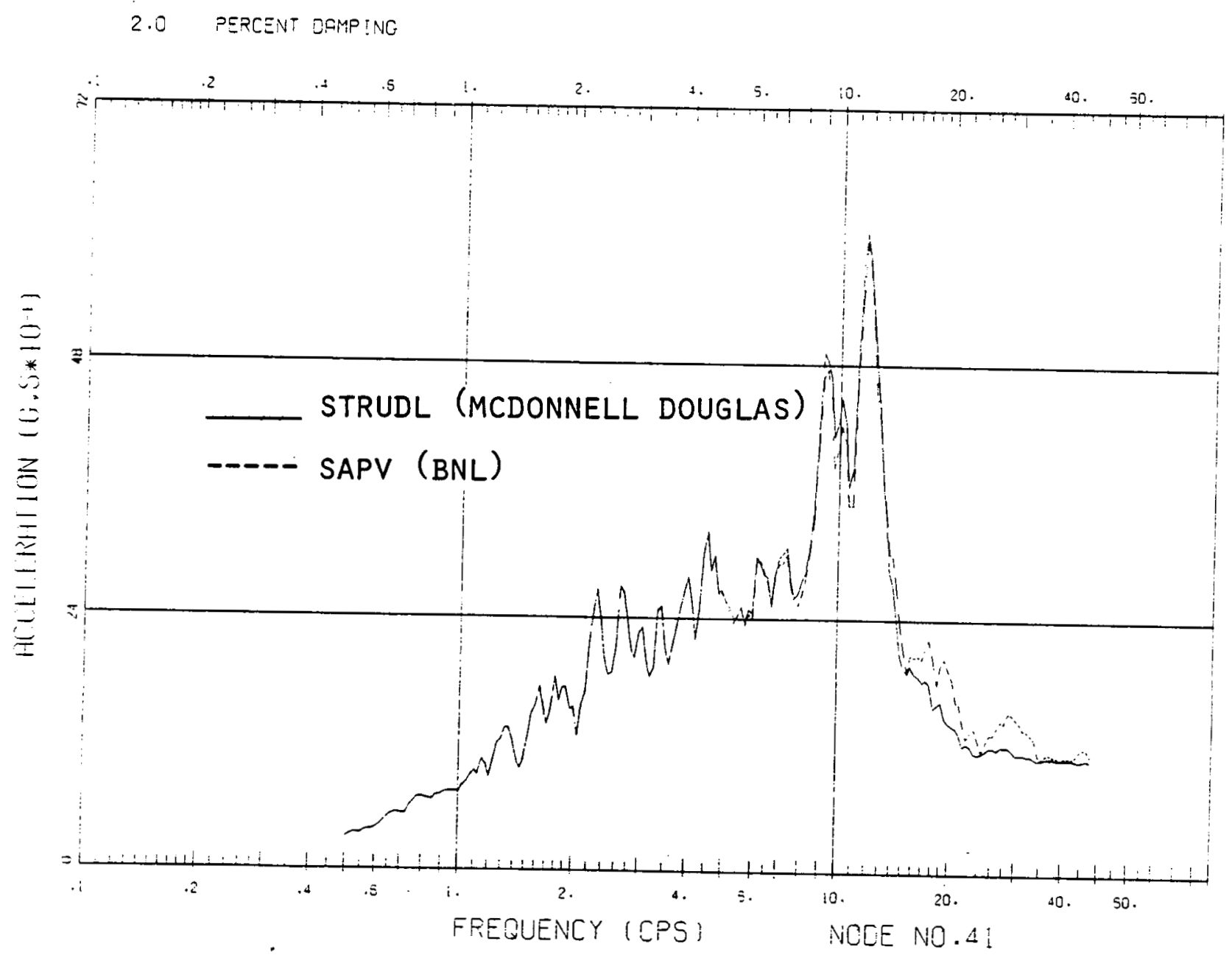

Figure 6.4 - 2D Model. SAPV (BNL) versus STRUDL (MCDonnell Douglas). Node 41 


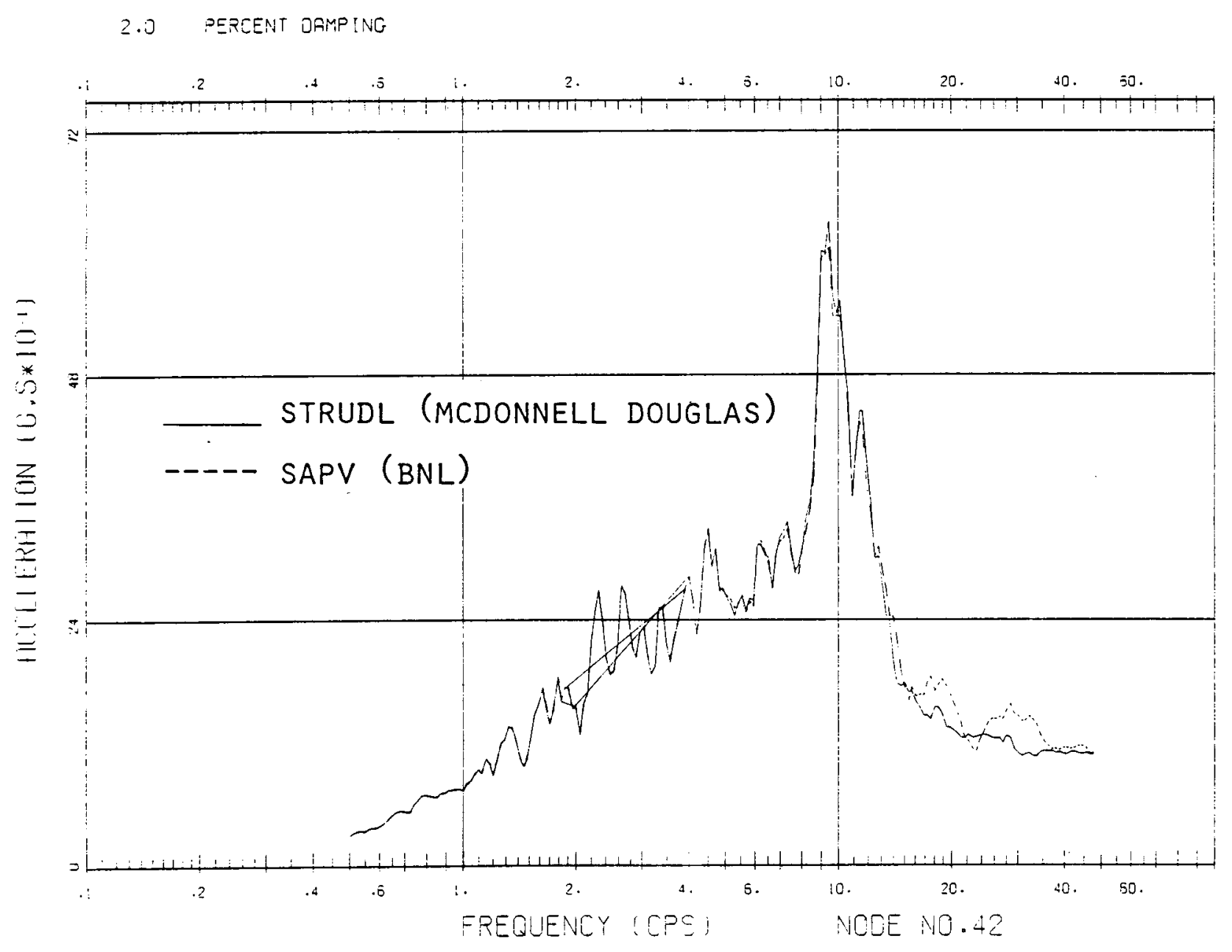

Figure 6.5 - 20 Model. SAPV. (BNL) versus STRUDL (McDonnell Douglas). Node 42 


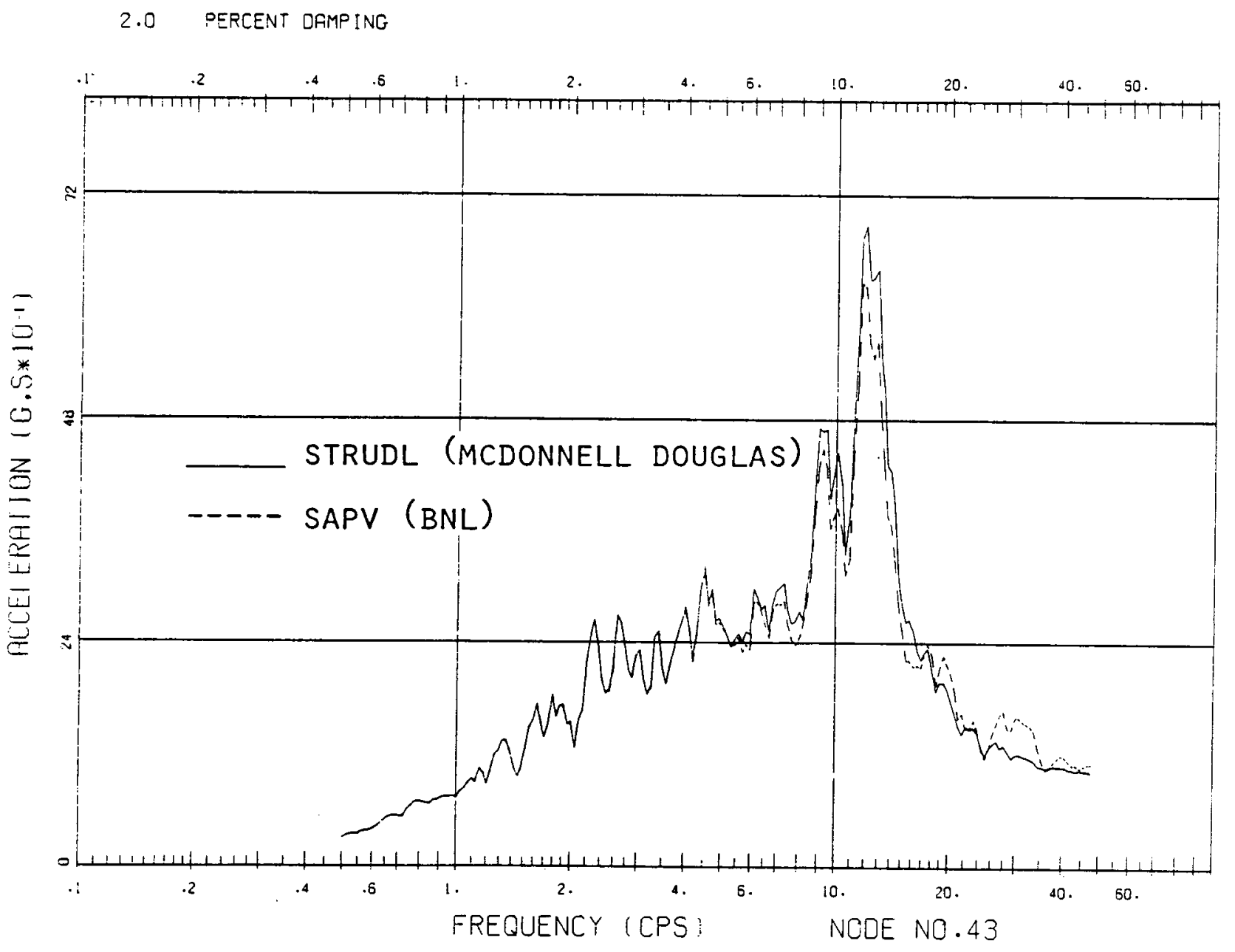

Figure 6.6 - 2D Model. SAPV (BML) versus STRUDL (MCDonnell Douglas). Node 43 


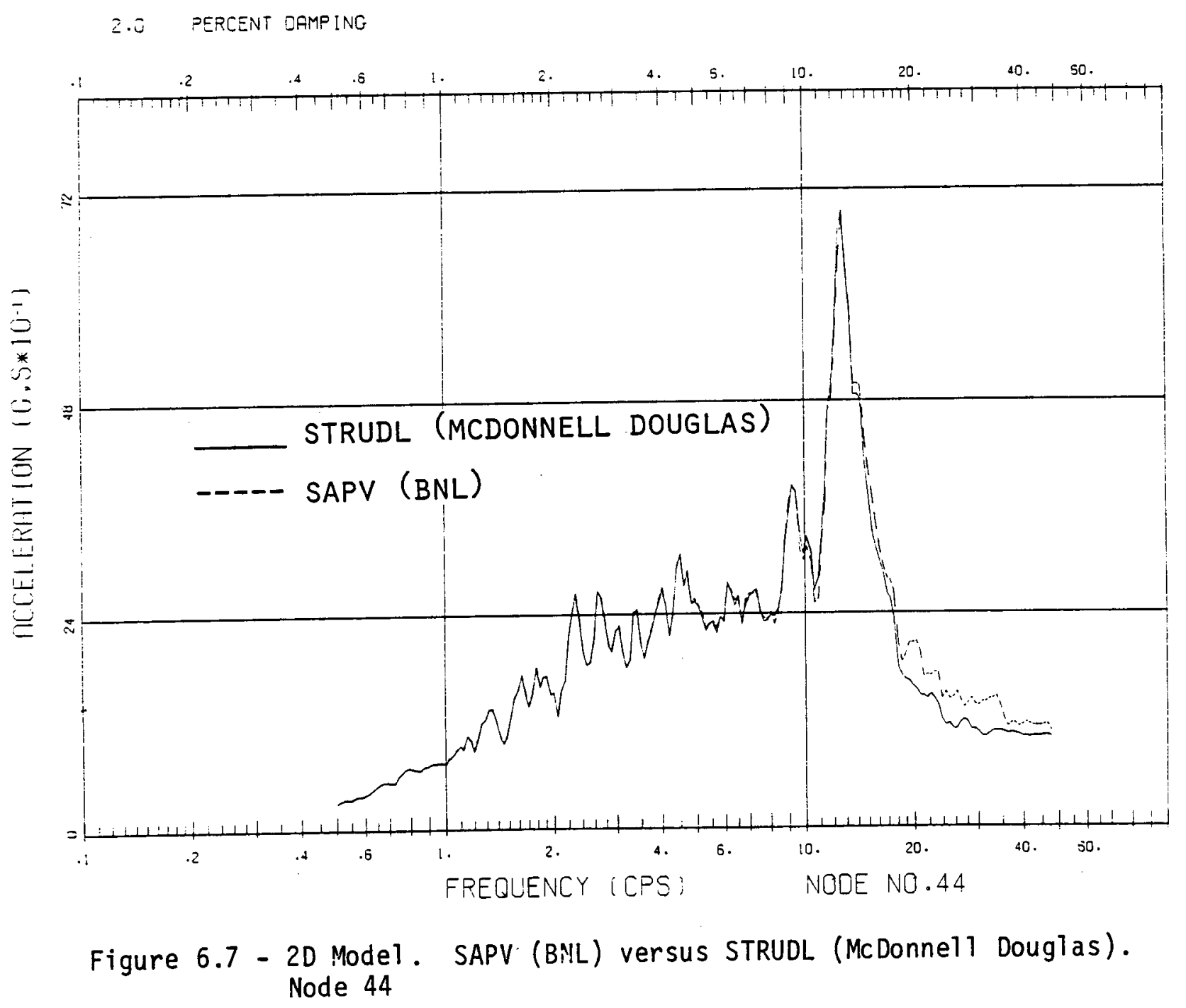




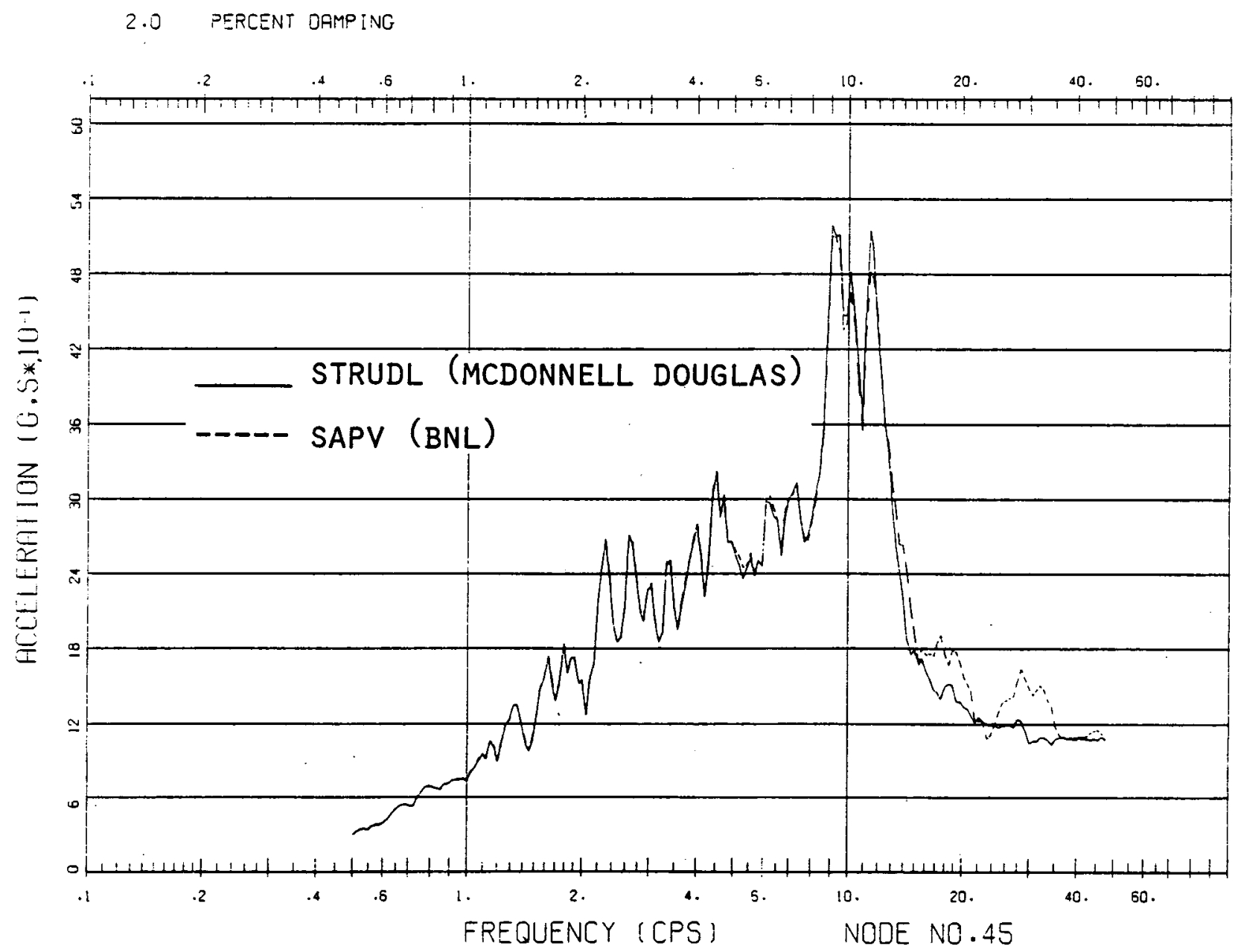

Figure 6.8 - 20 Model. SAPV (BNL) versus STRUDL (McDonnell Douglas). Node 45 
Table 6.2

2D MODEL. COMPARISON OF MODAL FREQUENCIES (CPS) Mode No. SAPV (BNL) URS/Blume

\begin{tabular}{rrr}
1 & 13.20 & 13.20 \\
2 & 13.56 & 13.56 \\
3 & 13.81 & 13.81 \\
4 & 14.17 & 14.17 \\
5 & 16.01 & 16.01 \\
6 & 16.31 & 16.31 \\
7 & 19.86 & 19.86 \\
8 & 23.57 & 23.57 \\
9 & 24.89 & 24.89 \\
10 & 25.35 & 25.35 \\
11 & 25.73 & 25.73 \\
12 & 25.80 & 25.80 \\
13 & 27.73 & 27.73 \\
14 & 28.09 & 28.09 \\
15 & 28.19 & 28.09 \\
16 & 31.13 & 31.13 \\
17 & 31.72 & 31.72 \\
18 & 32.12 & 32.12 \\
\hline
\end{tabular}




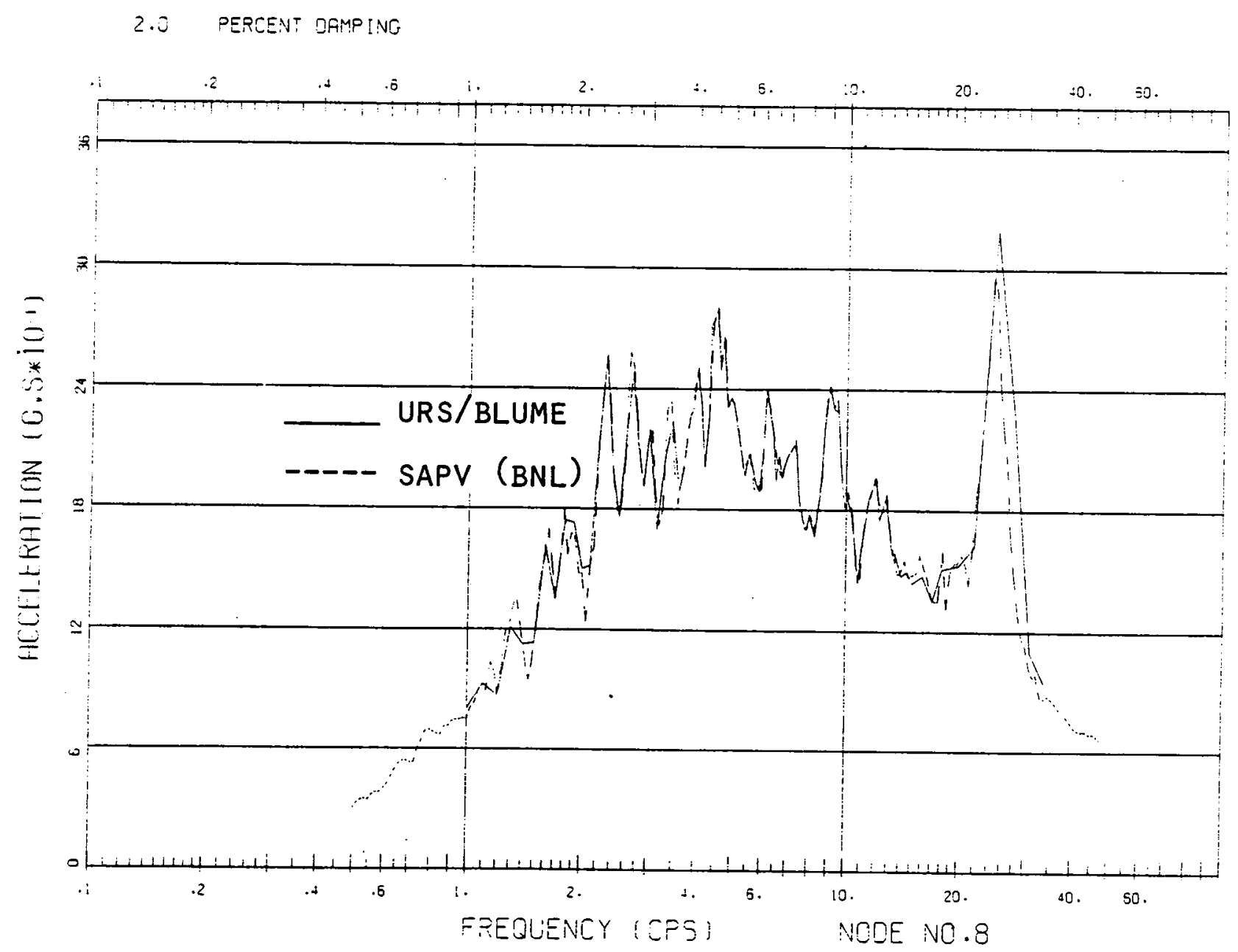

Figure 6.9 - 2D Model. SAPV (BNL) versus URS/Blume floor response spectra. Node 8 


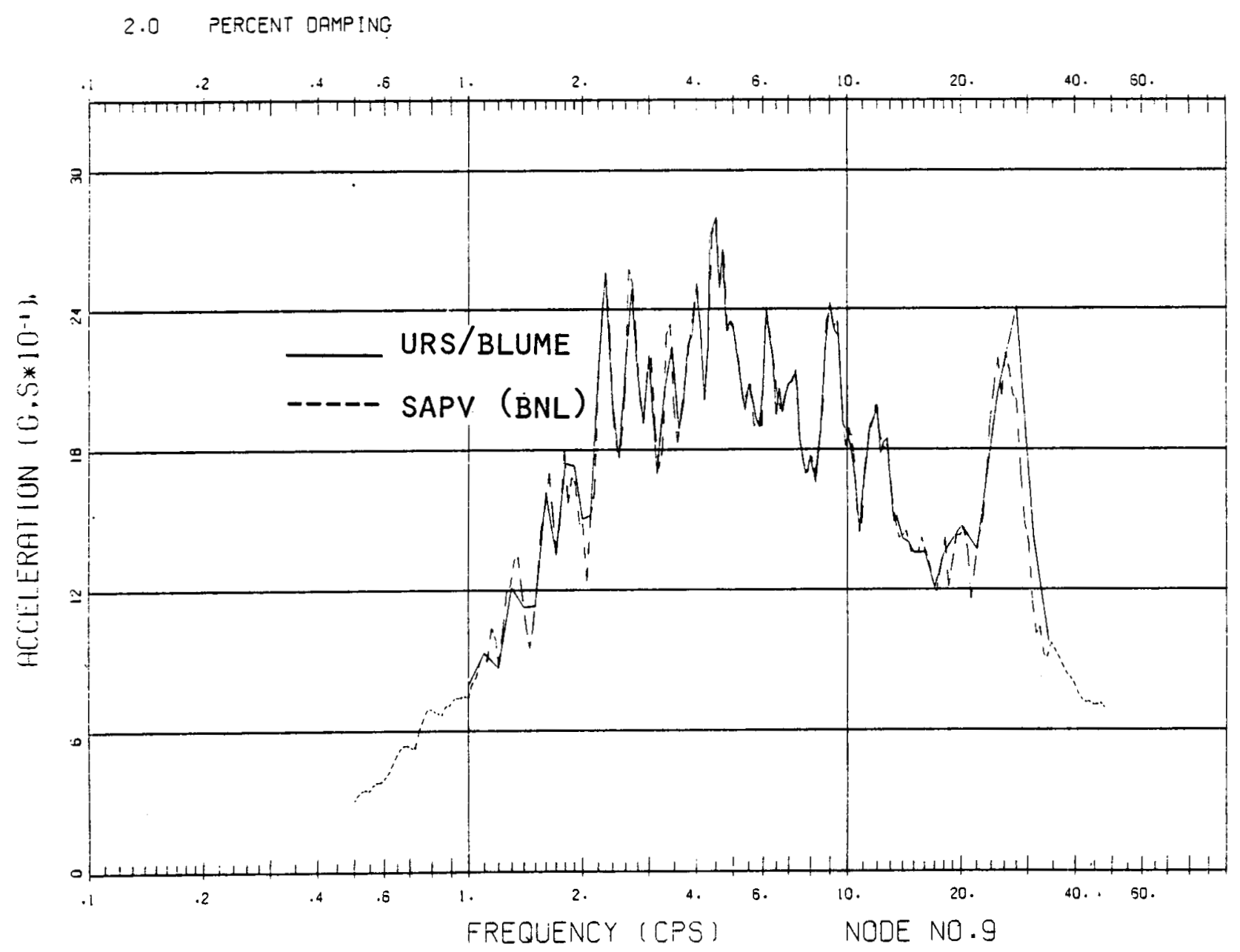

Figure 6.10 - 2D Model. SAPV (BNL) versus URS/Blume floor response spectra. Node 9 


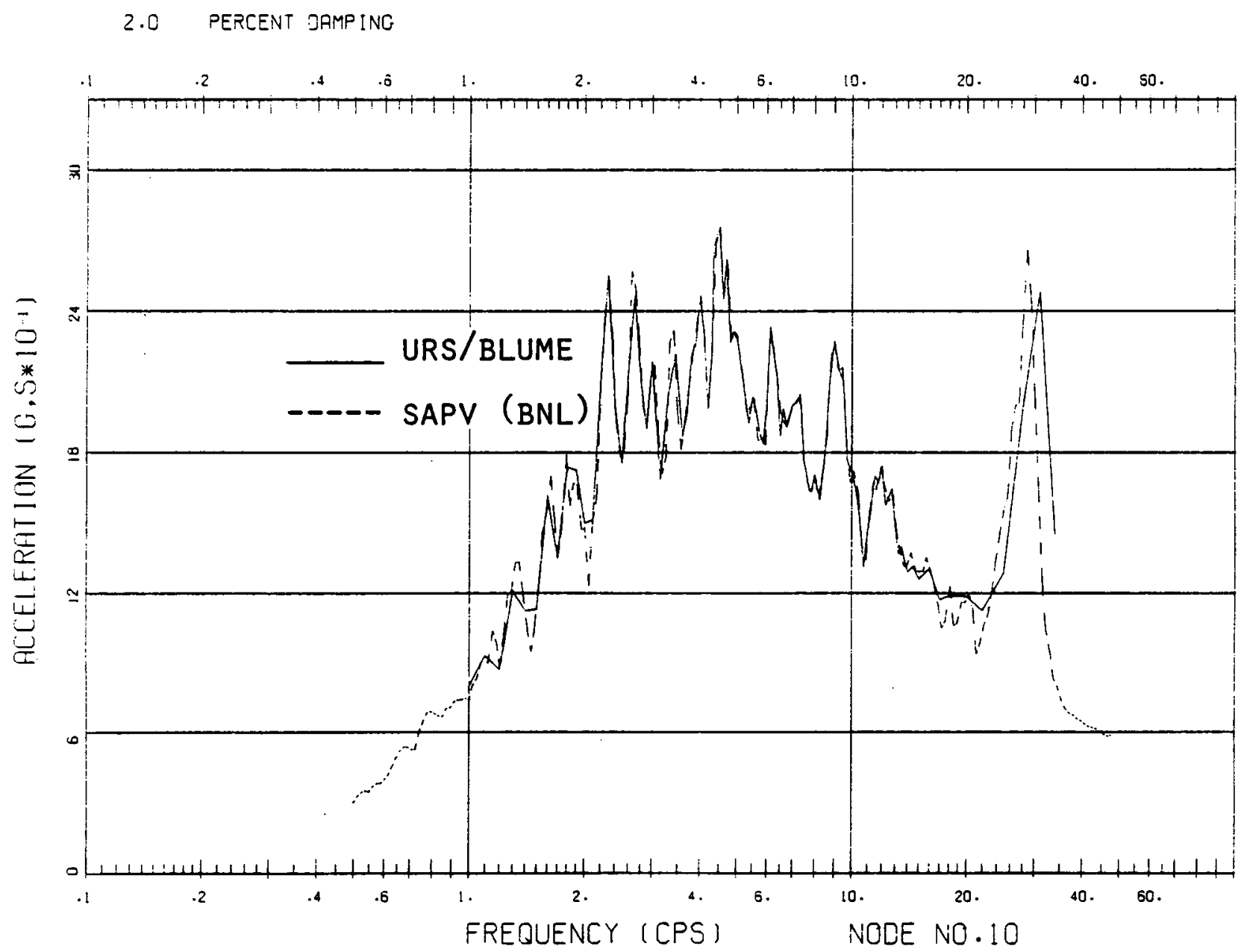

Figure 6.11 - 2D Mode1. SAPV (BNL) versus URS/Blume floor response spectra. Node 10 


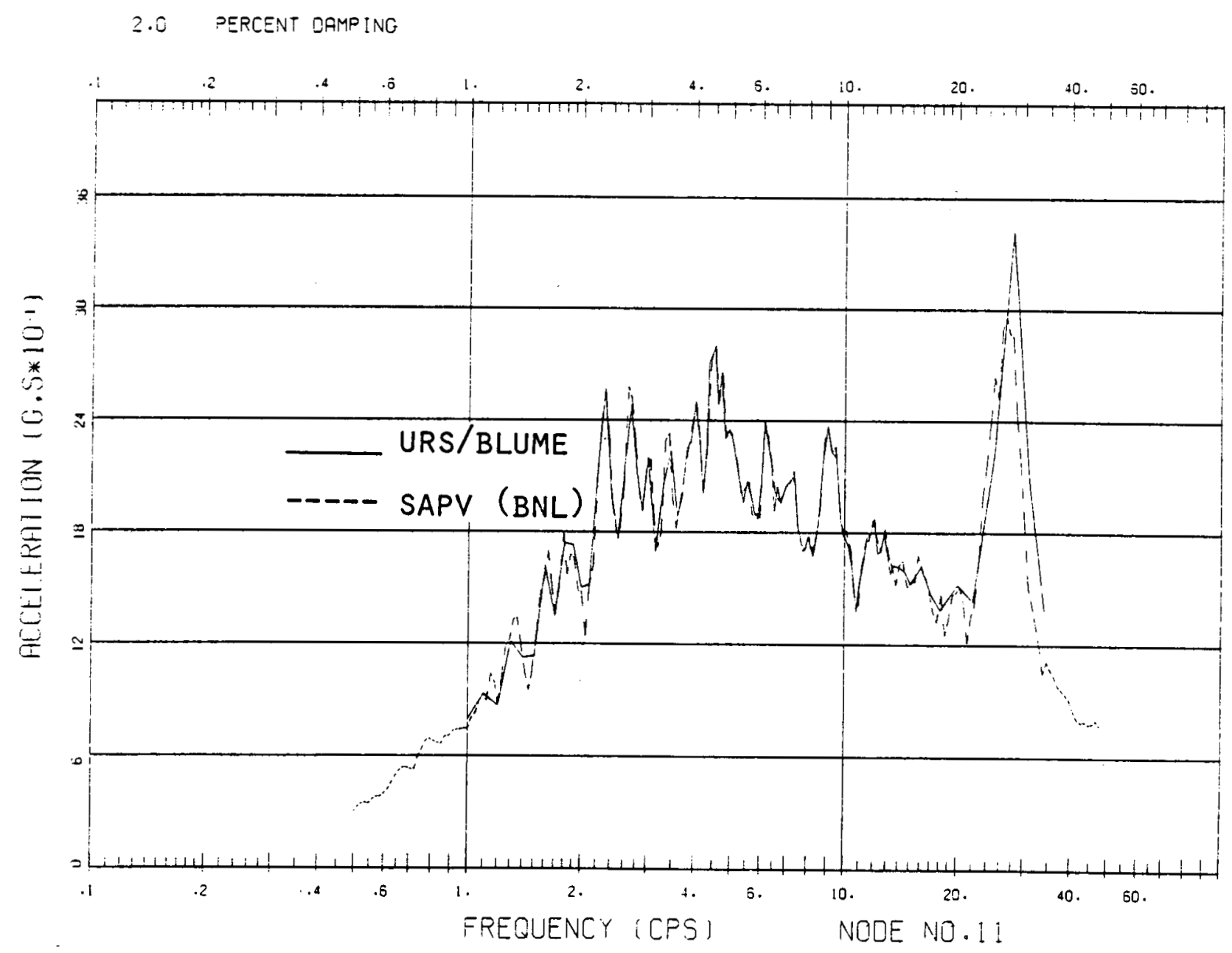

Figure 6.12 - 2D Model. SAPV (BNL) versus URS/Blume floor response spectra. Node 11 


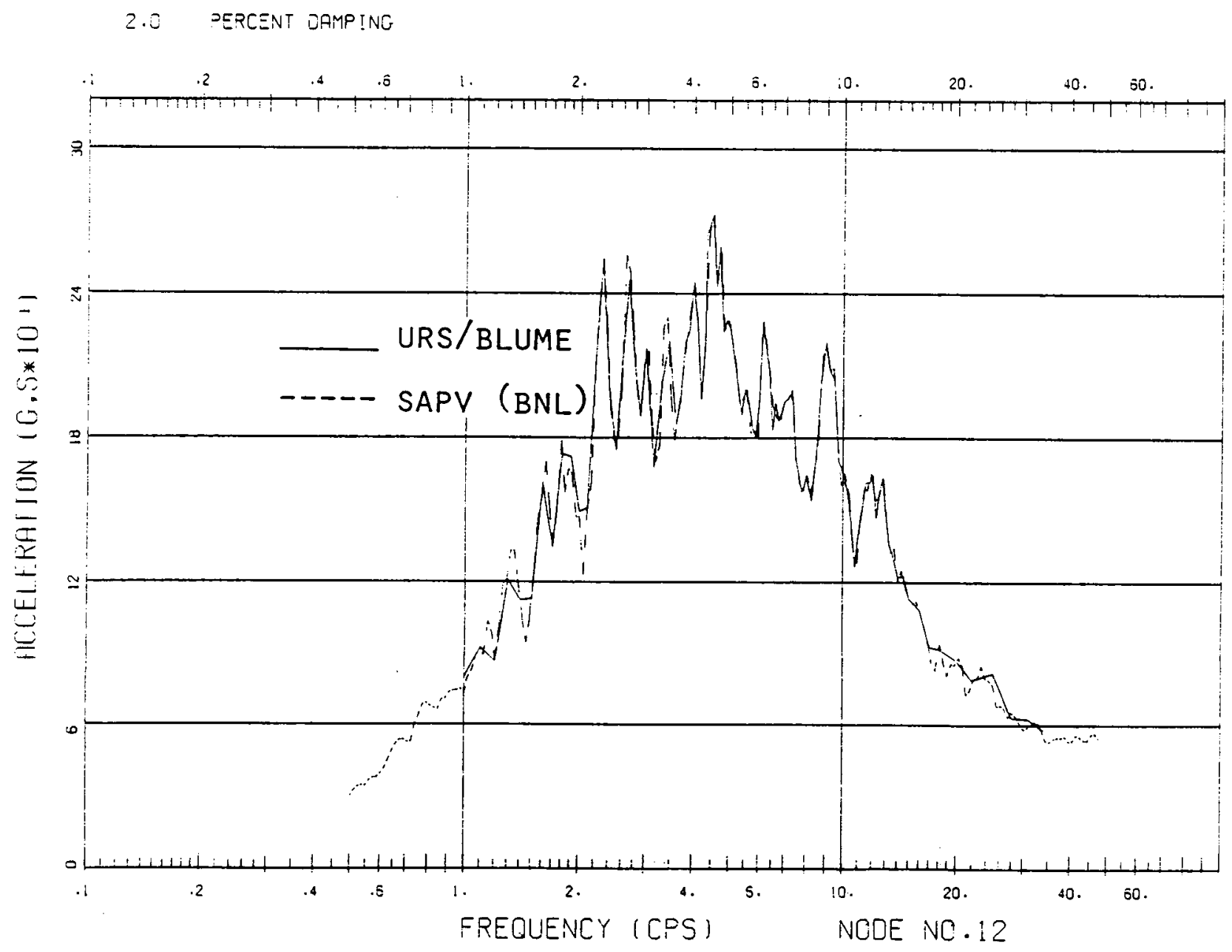

Figure 6.13 - 2D Model. SAPV (BNL) versus URS/Blume floor response spectra. Node 12 


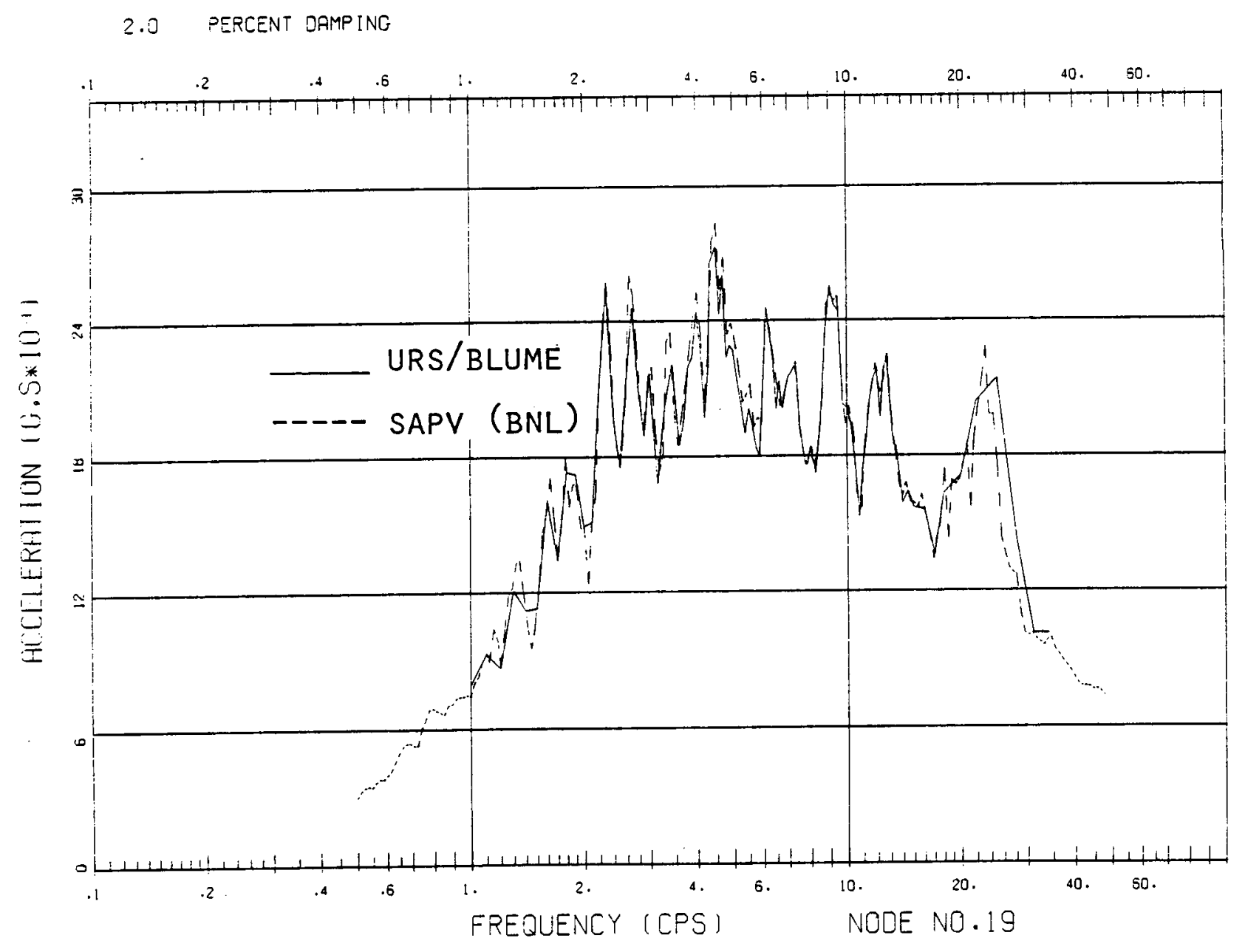

Figure 6.14 - 20 Model. SAPV (BNL) versus URS/Blume floor response spectra. Node 19 


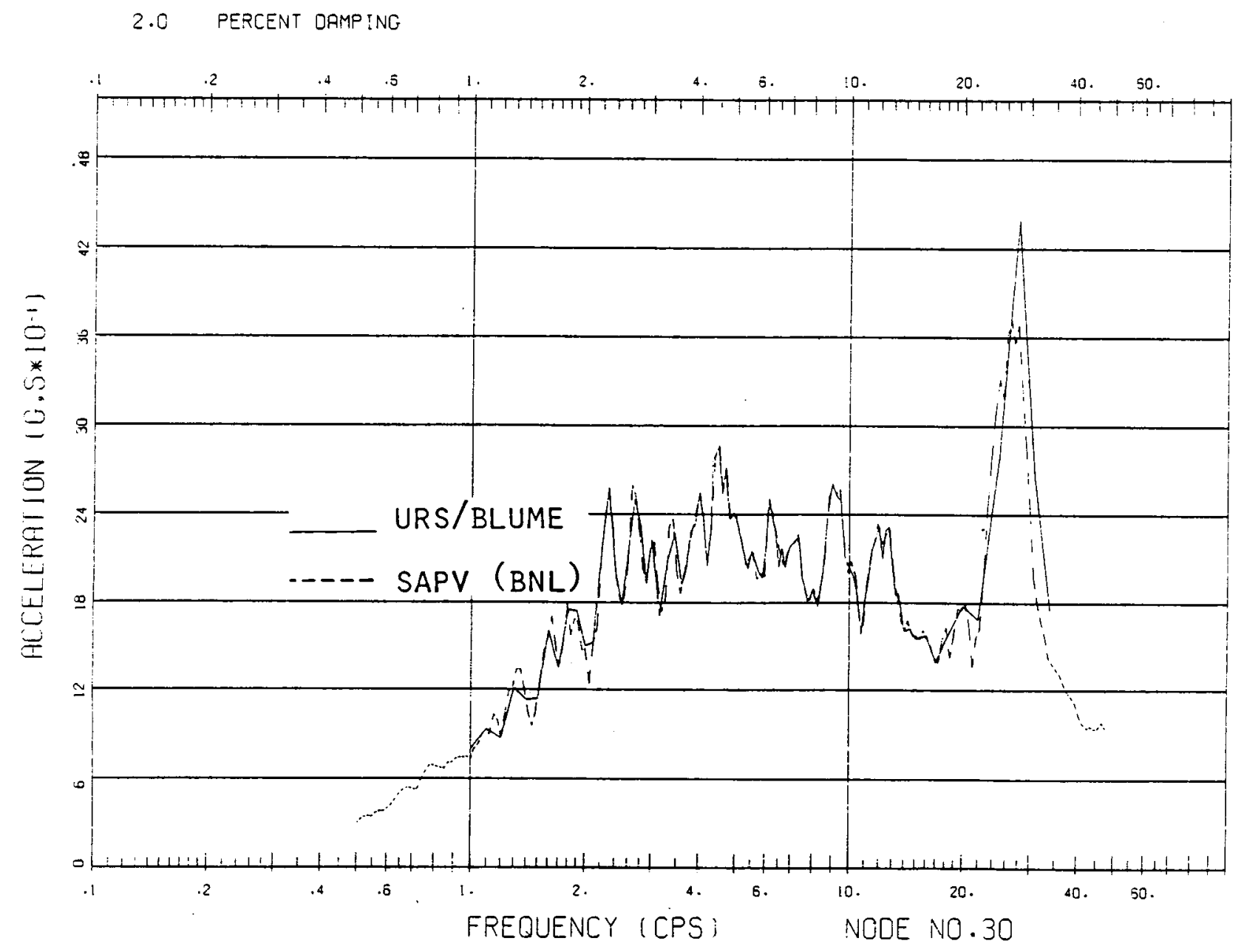

Figure 6.15 - 2D Model. SAPV (BNL) versus URS/Blume floor response spectra. Node 30 


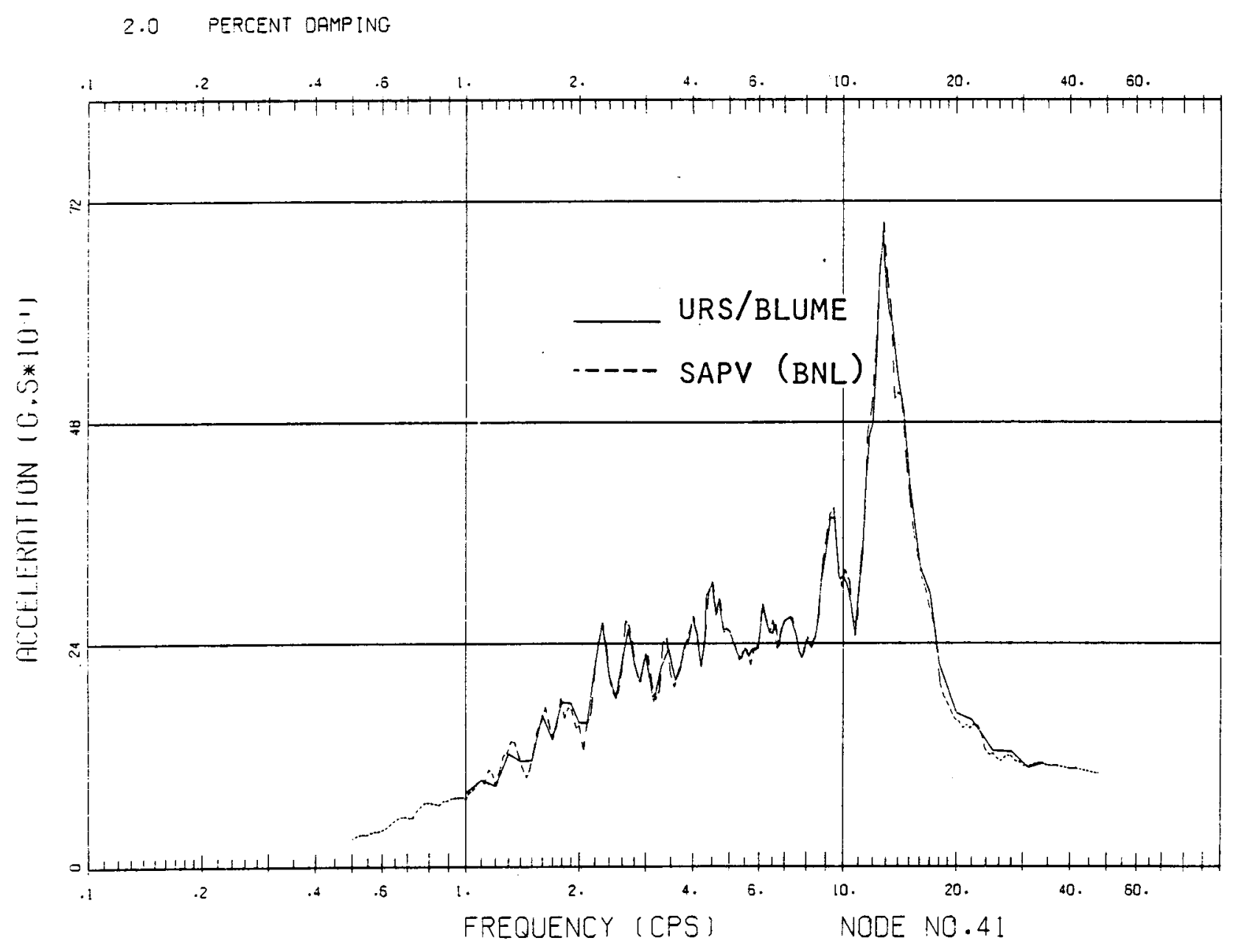

Figure 6.16 - 2D Model. SAPV (BNL) versus URS/BIume floor response spectra. Node 41 


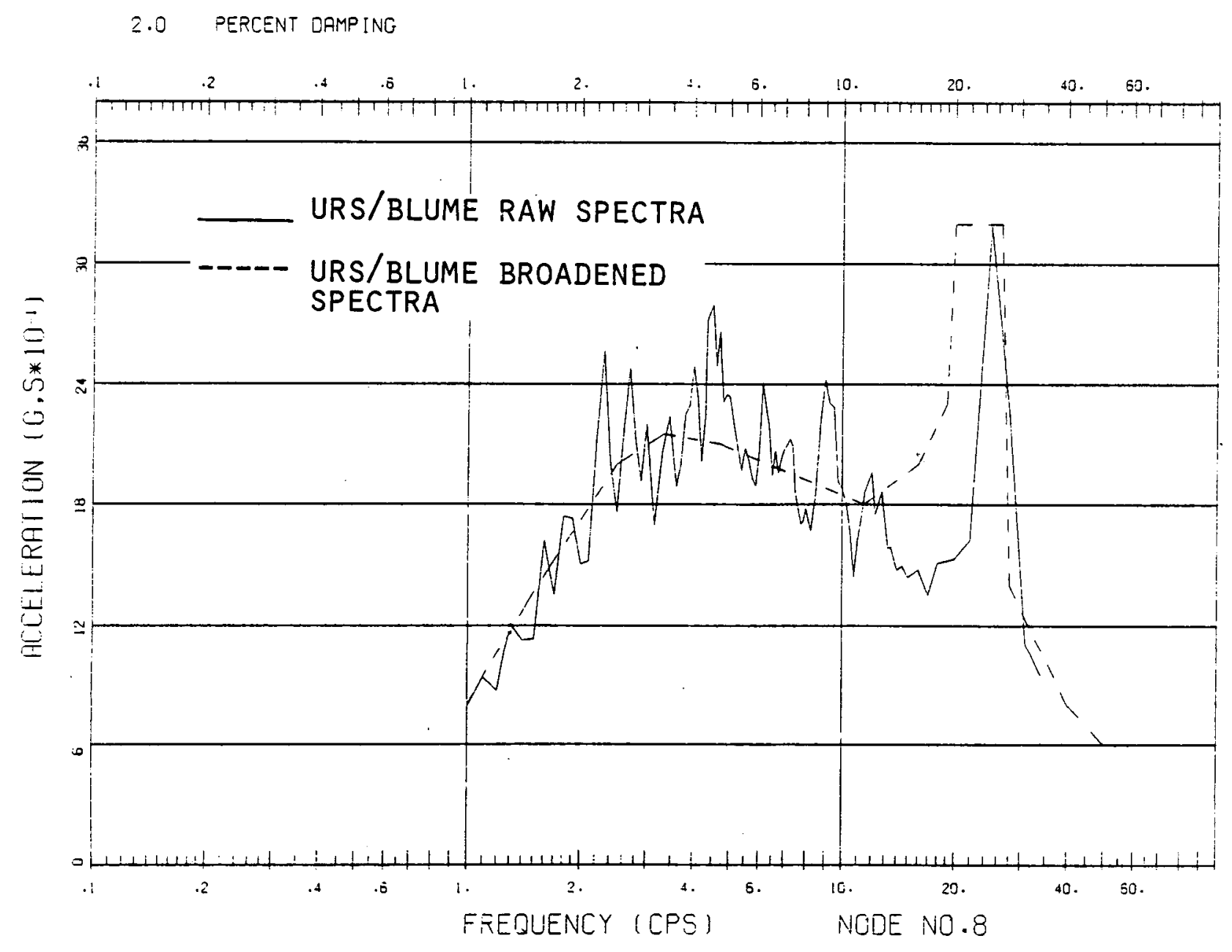

Figure 6.17 - 20 Model. Raw versus broadened URS/Blume floor response spectra. Node 8 


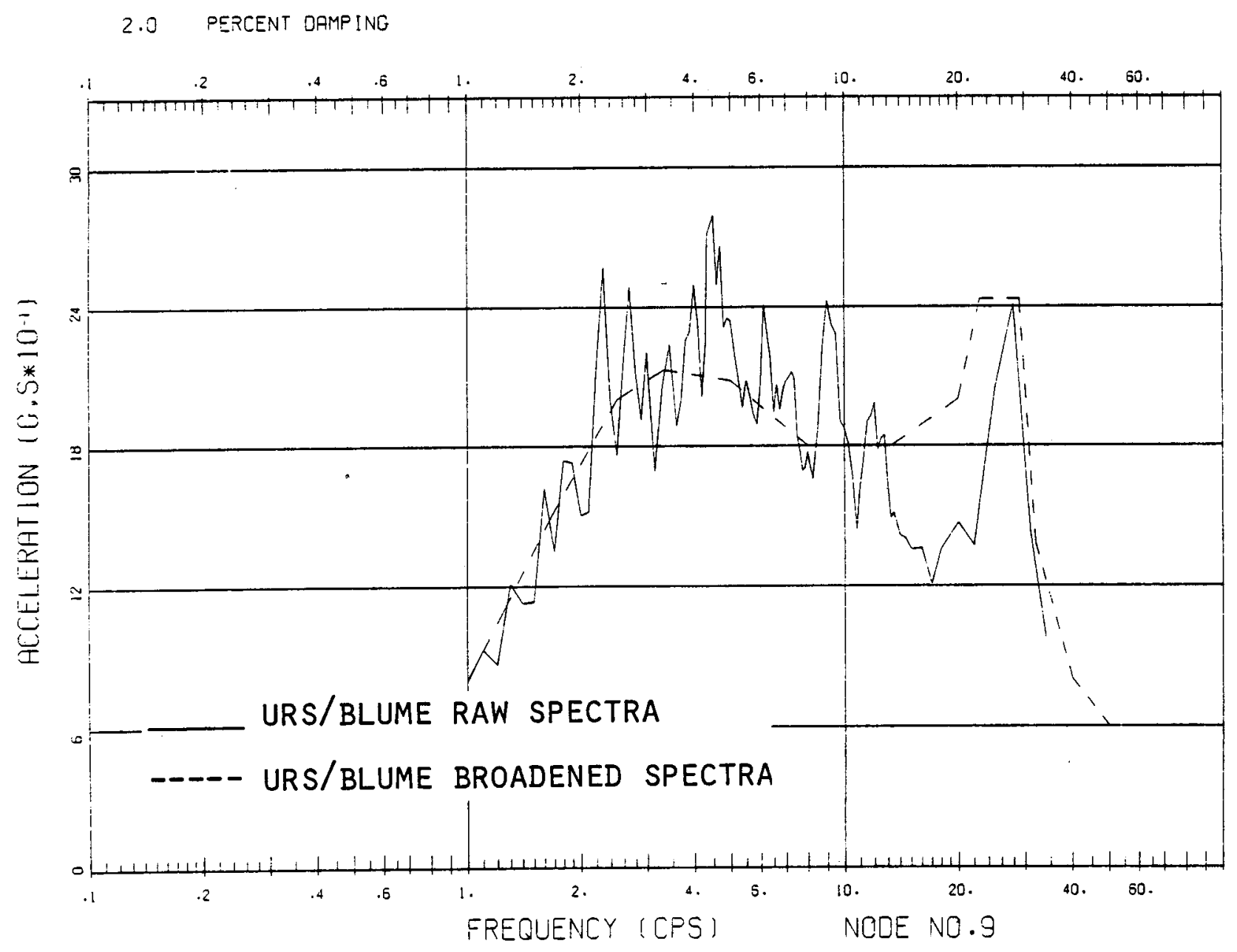

Figure 6.18 - 2D Model. Raw versus broadened URS/Blume floor response spectra. Node 9 


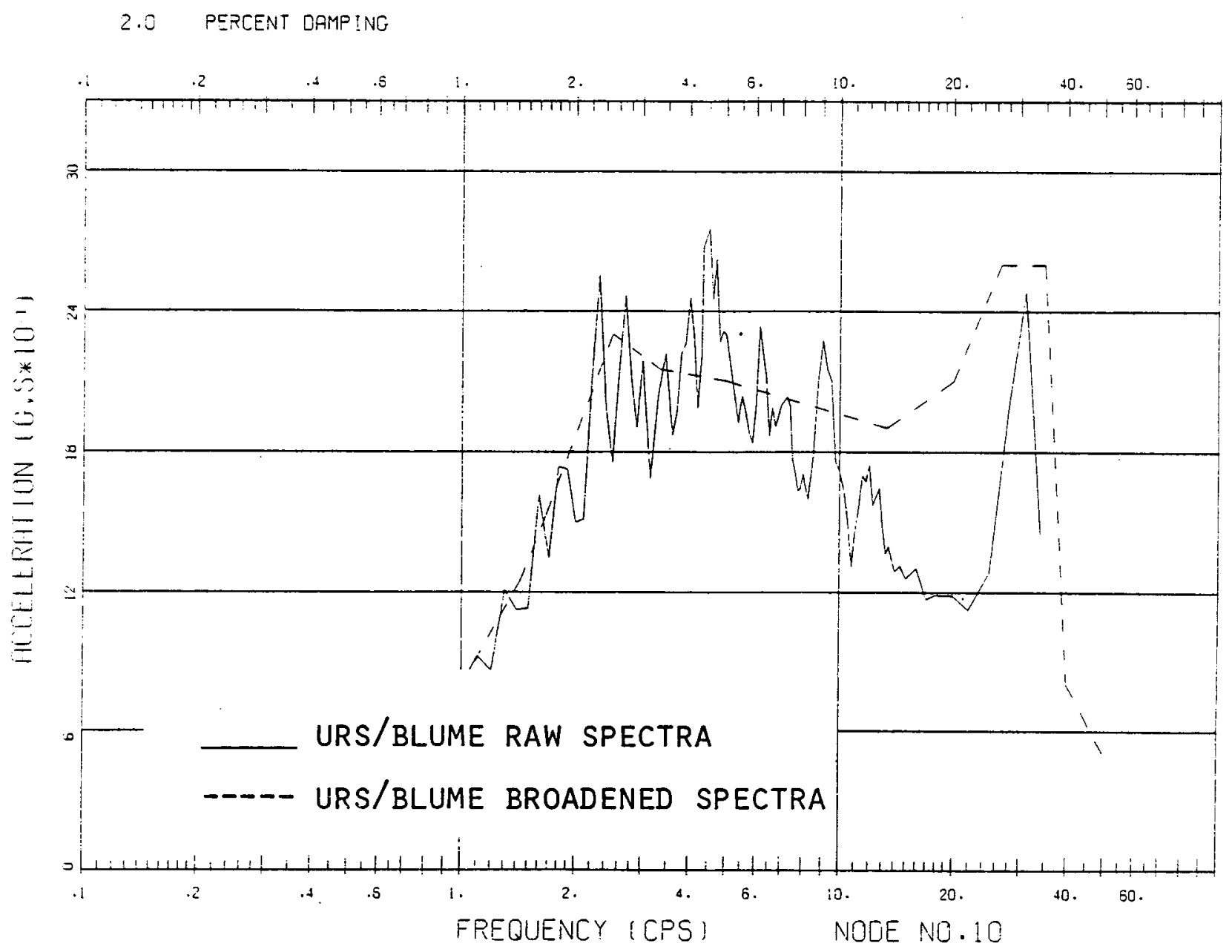

Figure 6.19 - 2D Model. Raw versus broadened URS/BI ume floor response spectra. Node 10 


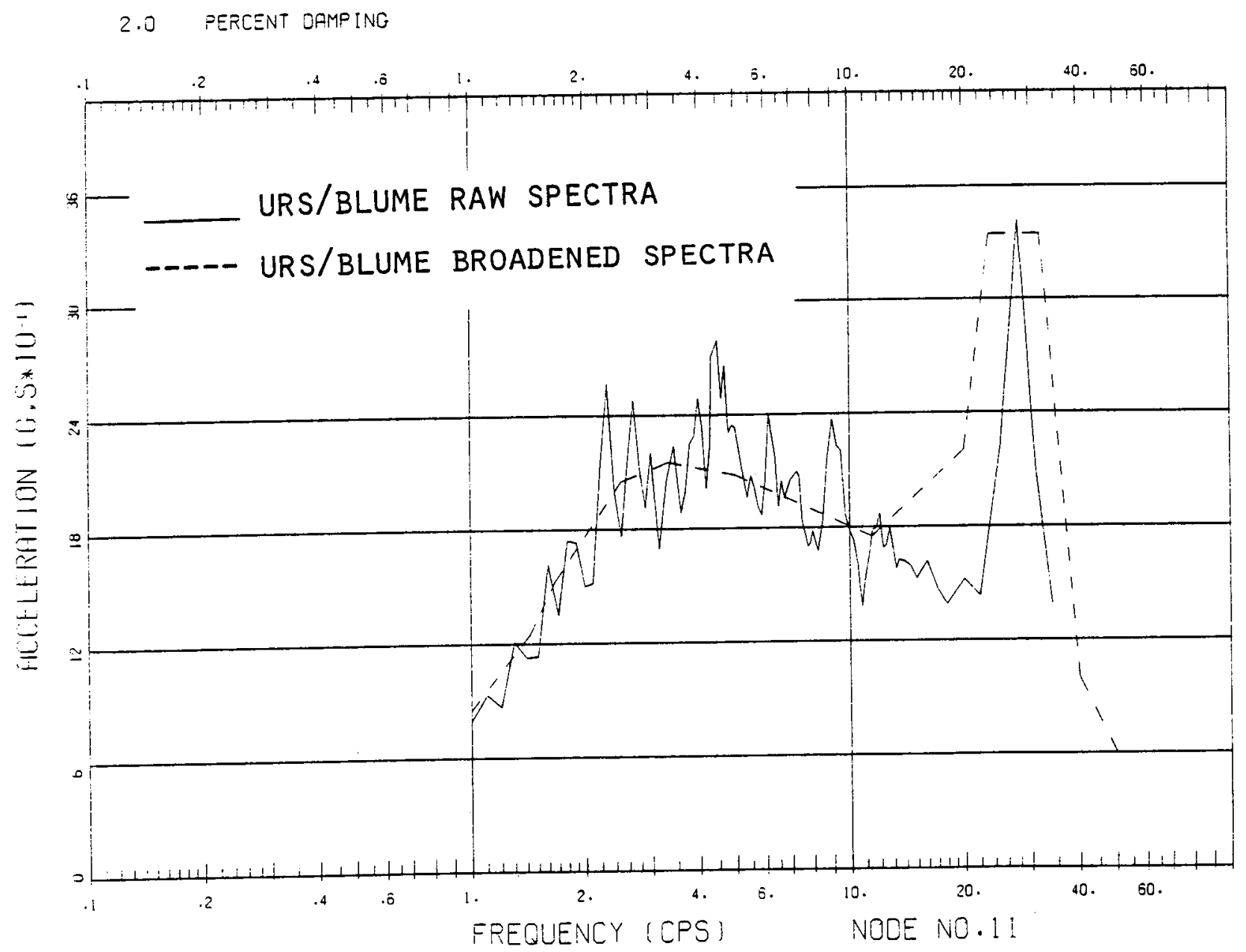

Figure 6.20 - 20 Model. Raw versus broadened URS/Blume floor response spectra. Node 11 


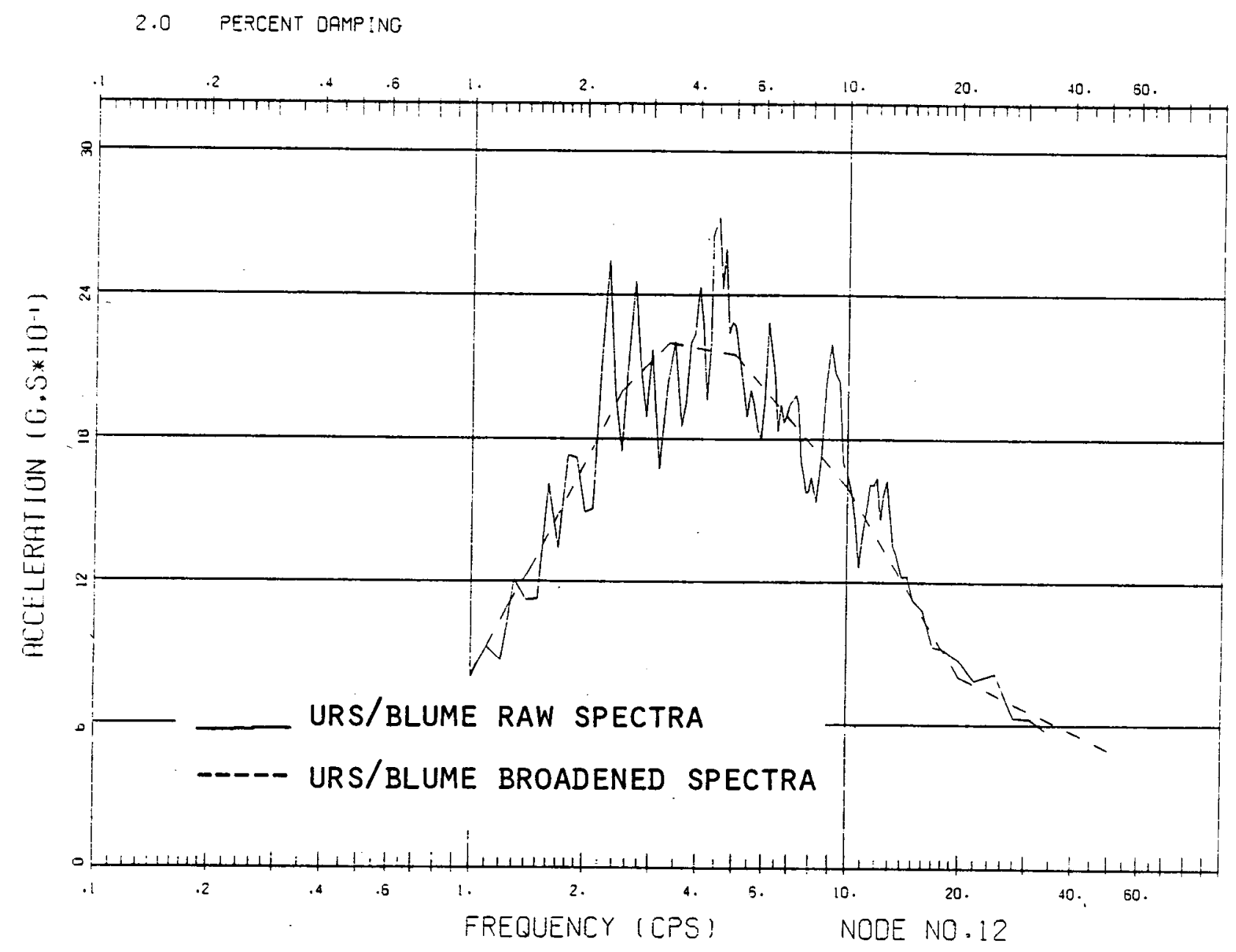

Figure 6.21 - 2D Mode1. Raw versus broadened URS/BI ume floor response spectra. Node 12 


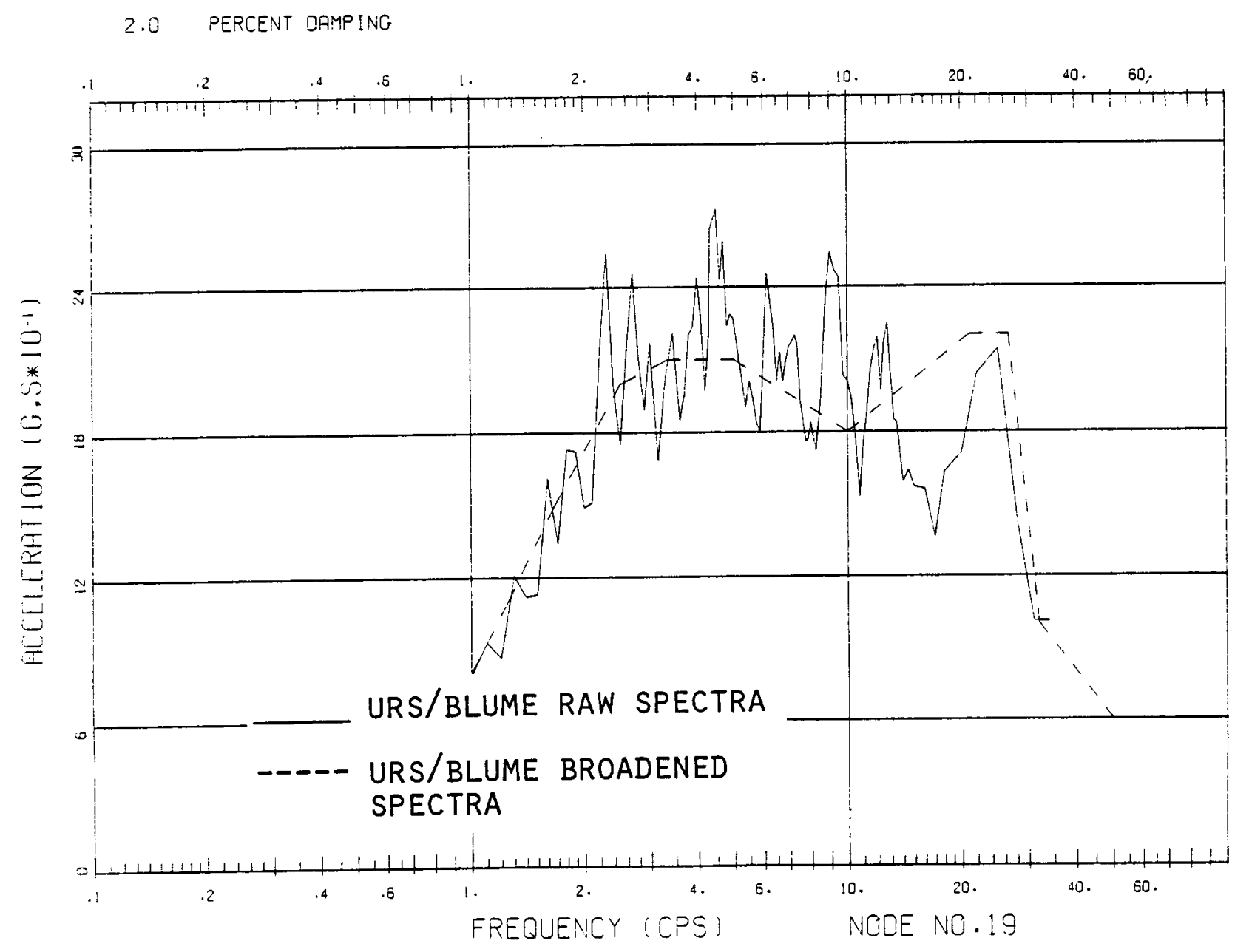
Figure 6.22 - 2D Model. Raw versus broadened URS/Blume floor response
spectra. Node 19 


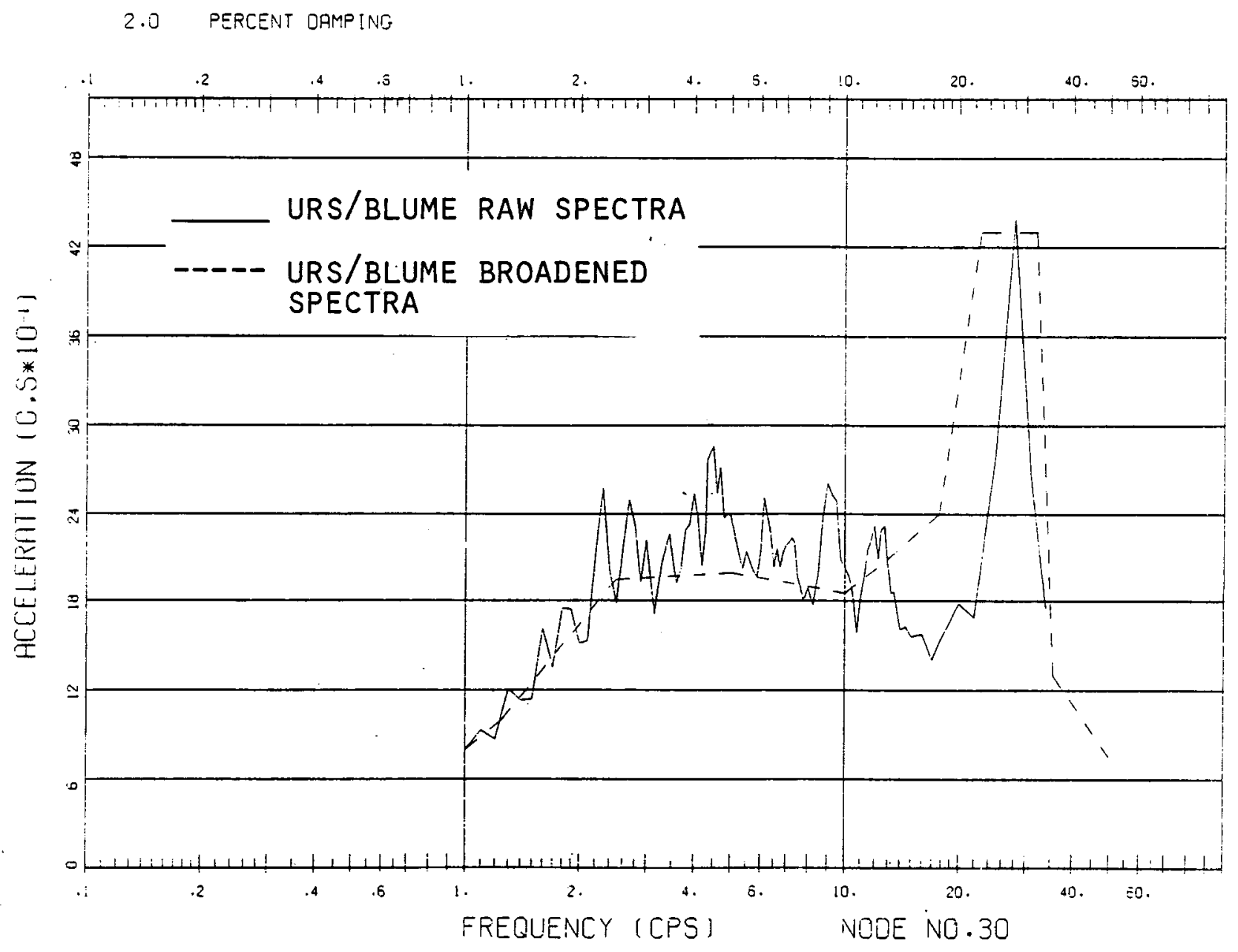

Figure 6.23 - 20 Modèl. Raw versus broadened URS/BI ume floor response spectra. Node 30 


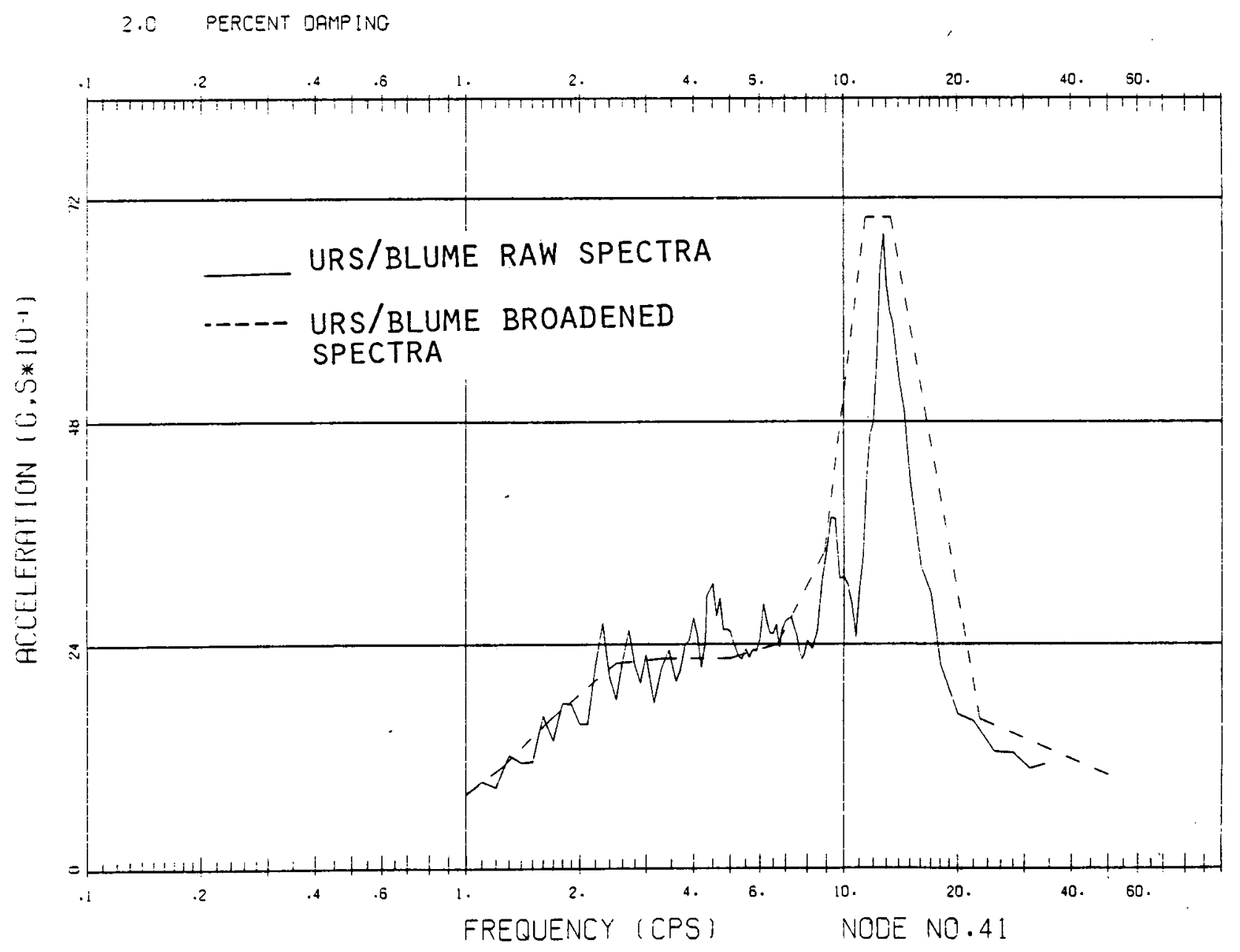

Figure 6.24 - 20 Model. Raw versus broadened URS/BI ume floor response spectra. Node 41 


\subsection{Description of Piping Mathematical Model}

There are approximately 60 piping problems associated with the annulus structure of the Diablo Canyon Unit 1 power plant. Of these some 25 problems required reanalysis by PG\&E or Westinghouse as a consequence of the diagram error. That is for 25 problems the response spectra defining the seismic loadings were affected by the diagram error. As a result of the reanalysis PG\&E indicated that pipe stresses increased by $4-5 \%$ whereas support loads increased by as much as $100 \%$.

During the October audit of the plant approximately 10 piping problems were given either cursory or detailed reviews. Although inconsistencies in analysis procedure were noted the review indicated that the piping systems would not experience significant stress changes when analyzed with the corrected spectra. Following the audit two PG\&E piping problems in the annulus region were selected for detailed confirmatory analysis. These were problems identified by PG\&E problem nos. 6-11 and 4A-26.

\subsection{Problem 6-11}

The problem designated $6-11$ is part of the safety injection system entitled "Safety Injection RCS Loop 182". It consists of $12 \mathrm{IN}, \mathrm{SCH} 40$ stainless steel pipe run between elevations $102^{\prime}$ and $110^{\prime}$ and extending over an arc of $130^{\circ}$ of the annulus region. It is bounded by two fixed anchors and is supported from annulus steel at approximately 13 points. Figure 7.1 shows the PG\&E piping isometric diagram with BNL finite element model node points for the problem. A pictorial representation of the annulus structure and the pipe are shown in Figure 7.2.

The finite element model of the system consists of 58 pipe elements, 75 nodes and 16 boundary elements. Of the boundary elements five are snubbers while the remainder are rigid supports. The pipe weight density was taken as $8.708 \mathrm{lb} /$ in and includes the weight of pipe, fluid and insulation. The system 
design temperature and pressure were taken as $400^{\circ} \mathrm{F}$ and 600 psig respectively. The material modulus of elasticity, Poisson's ratio and coefficient of thermal expansion were $27.7 \times 10^{6}$ psi, 0.3 and $9.35 \times 10^{-6}$ IN/IN $/{ }^{\circ} \mathrm{F}$ respectively. All of the above values are consistent with the information provided for this problem.

The node numbering for the pipe elements of the model are identical to those used by the applicant. Where it was found that additional points were required in the $B N L$ model to represent the system, these additional points were given the prefix $A$ (i.e., 29A). Although the node numbering is consistent with the applicant's, node locations are not identical. The BNL locations are consistent with the as-built dimensions of the system and 5D bends, where appropriate, while the applicant's node locations correspond to design dimensions and long radius elbows.

\subsection{Problem 4A-26}

The problem designated $4 A-26$ is part of the coolant water system entitled "CCW Supply to Reactor Coolant Pumps, Part 3". It consists of 6 IN, 4 IN and 2-1/2 IN SCH 40 steel pipe run between elevations $101^{\prime}$ and $110^{\prime}$ and extending over an arc of $60^{\circ}$ of the annulus region. It is bounded at two points by anchors while the remaining end terminates in a three-way rigid, translational support (node 25). It is supported at 13 points from the annulus steel. Figure 7.3 shows the PG\&E piping isometric diagram with BNL finite element model node points for the problem. A pictorial representation of the annulus structure and the pipe are shown in Figure 7.4 .

The finite element model of the system consists of 55 pipe elements, 84 nodes and 20 boundary elements. Of the boundary elements five have been taken as flexible elements (horizontal supports at nodes 16, 19, 29, 32 and 43) to conform with the applicant's model of the system. The pipe weight densities were $2.623,1.639$ and $0.6561 \mathrm{~b} /$ in for the 6,4 and 2-1/2 IN pipe respectively 
and includes the weight of pipe, fluid and insulation. The system design temperature and pressure were taken as $125^{\circ} \mathrm{F}$ and $500 \mathrm{psia}$ respectively. Unlike problem 6-11, the design pressure and temperature for this line could not be determined from PG\&E supplied data. A conservative value for the design pressure was thus used. In any case this pressure value will have little affect on the overall stress results. The material modulus of elasticity, Poisson's ratio and coefficient of thermal expansion were $27.8 \mathrm{x}$ $10^{6} \mathrm{psi}, 0.3$ and $6.25 \times 10^{-6} \mathrm{IN} / \mathrm{IN} /{ }^{\circ} \mathrm{F}$.

The camments regarding node numbering and dimensions for problems 6-11 apply to this problem as well. The values used for the spring stiffness of the flexible support elements were identical to those used by the applicant although attempts to independently verify these values were inconclusive. In any case these values are sufficiently large so that the supports will appear rigid.

As mentioned above one branch of this problem does not terminate in a fixed anchor. Instead the finite element model includes some pipe from an adjacent problem and it is obvious that a structural overlap procedure was used in the evaluation. As indicated by the dashed portion of Figure 7.3 the overlap extends over two supports of the adjacent problem. A review of other PG\&E supplied information indicates that the complete overlap includes all the pipe to the anchor at node 1 and the support at node 16. The overlap region then includes six support points and one anchor with rigid restraints acting in all three coordinate directions. A somewhat better choice of the overlap for this problem would have included the next two restraints from the adjacent problem in this problem. However, the overlap employed does meet the intent of the requirements regarding overlap extent expressed in NUREG/CR 1980 . Other recommendations regarding overlap support forces and input spectra expressed in NUREG/CR1980 were not adhered to. 


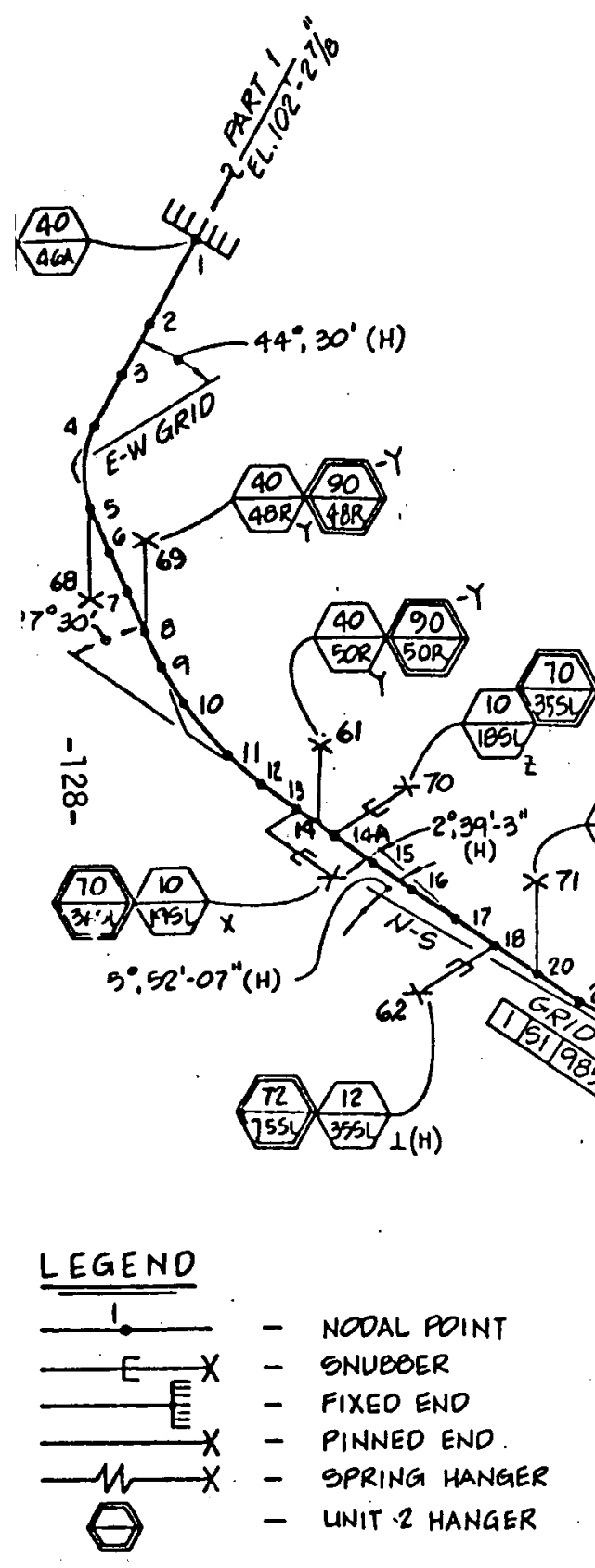

PGEE REF. OWG. NO. 497989

1

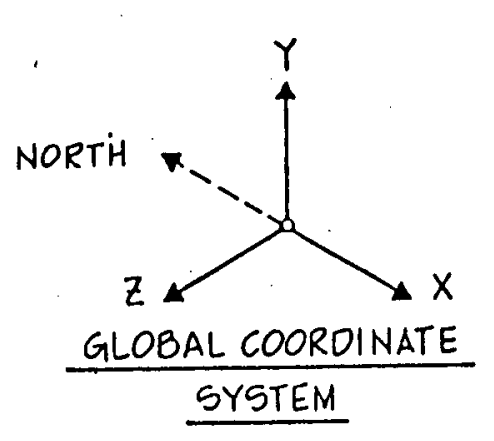

$28 R-\frac{6}{28 R}$

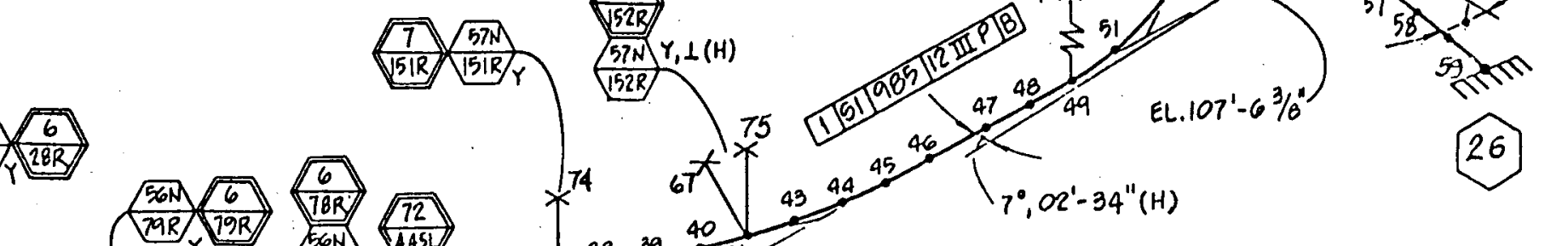

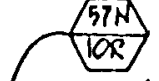

$\perp(H)$

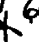

$8 \cdot 02 ! 0$

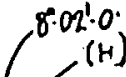

ANALYSIS NO. $6-11$

REV.NO. $6 \quad 11-30-81$

NOTE:

SIGN REVERSAL REQUIRED

FOR UNIT?

(THIS IS A UNIT I CONFIGURATION)

DIABLO CANYON NUCLEAR POWER PLANT UNIT 1 \& 2 SAFETY INJECTION RCS

Figure 7.1

HANGE SYMIOLS AHO CONFIG, VE RIFIED

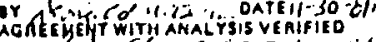
or f.

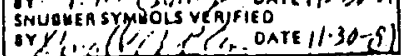




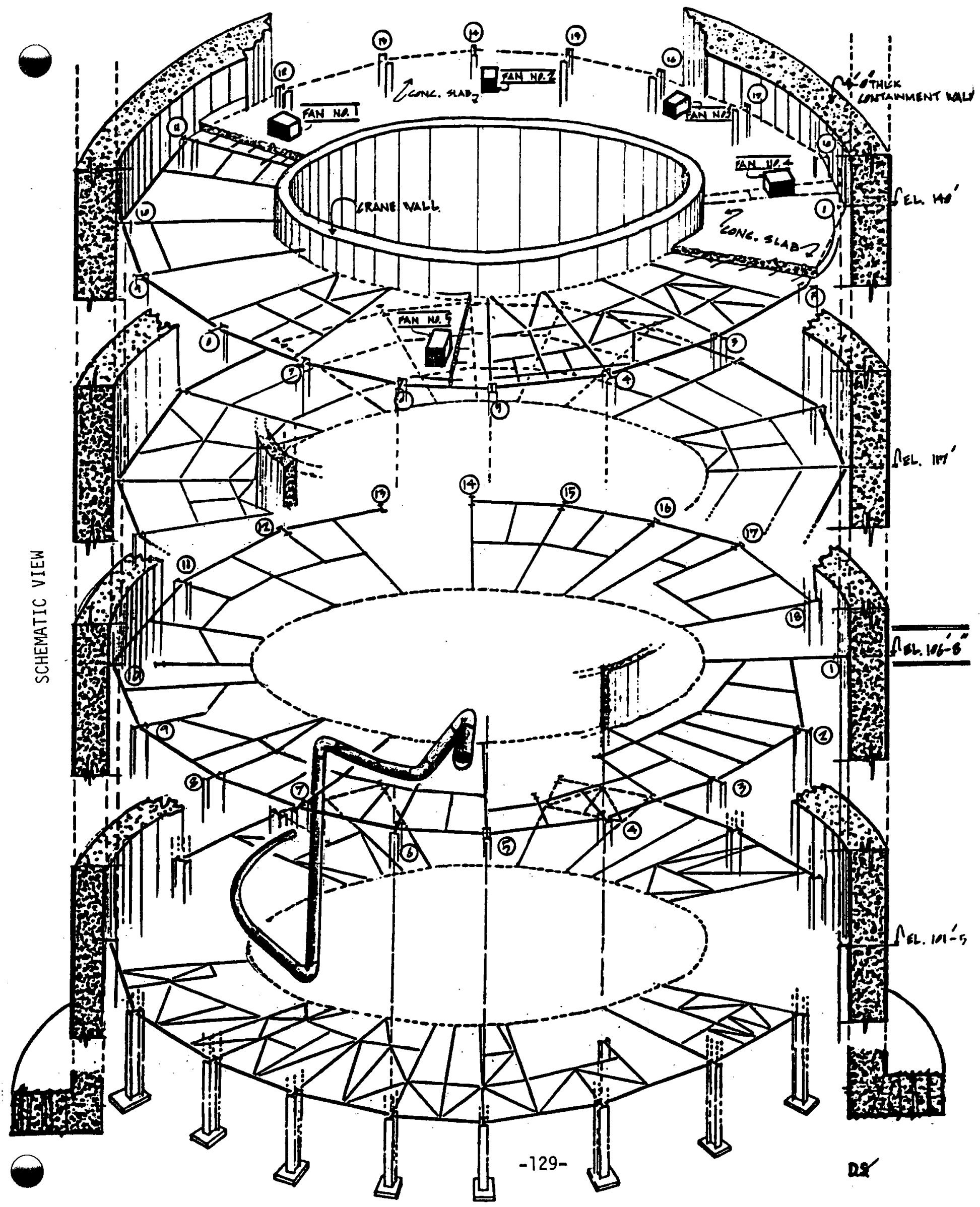

Figure 7.2 


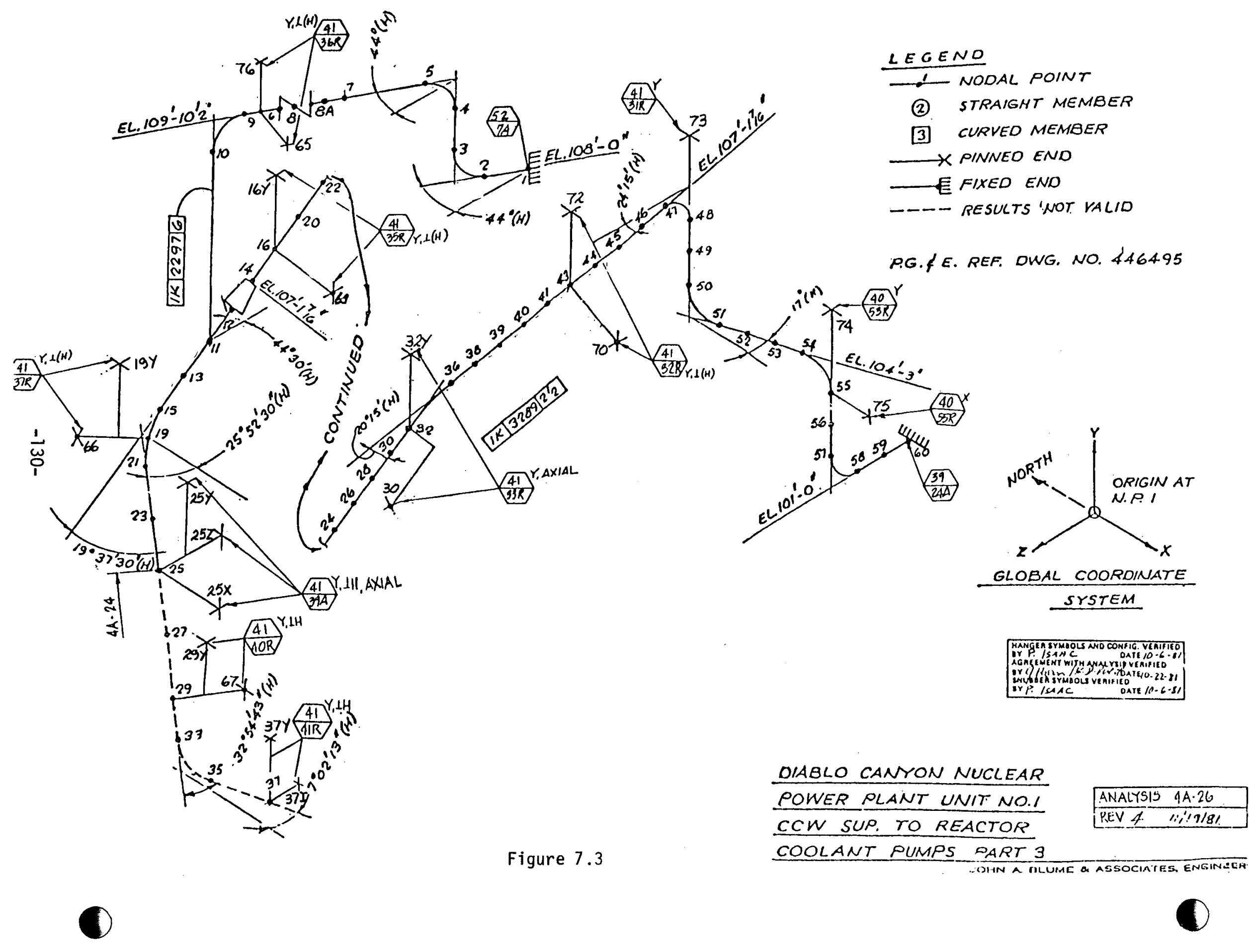




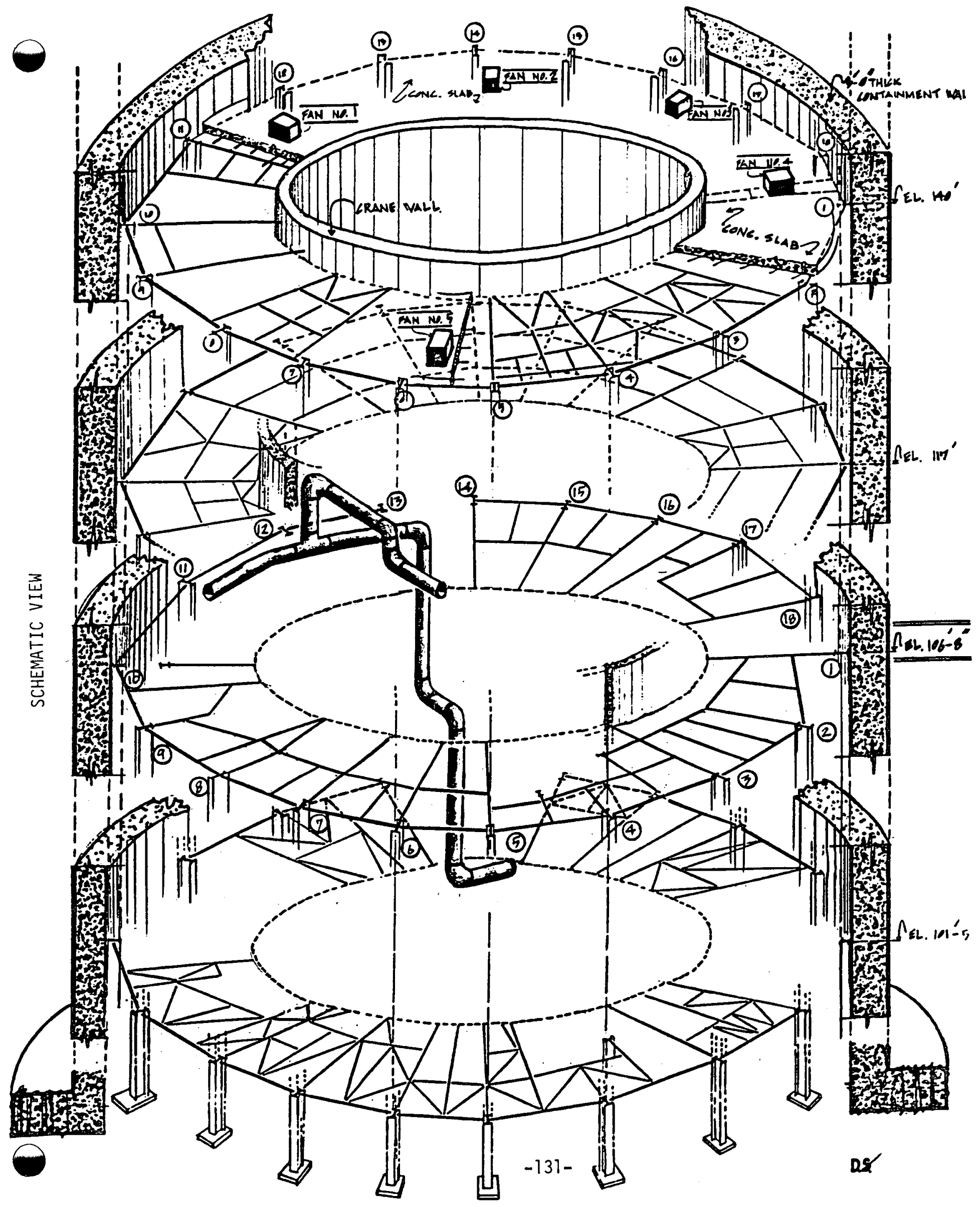

Figure 7.4 


\subsection{Piping Evaluations}

A number of evaluations were made for the two piping systems. These included:

(a) A frequency determination for problem 6-11 using the PG\&E mathematical model

(b) frequency determinations for both problems using BNL mathematical models

(c) envelope spectrum evaluations for both problems using BNL models and $P G \& E$ supplied spectra. These were performed for $X-Y$ inputs with no clustering, $Y-Z$ inputs with no clustering and $X-Y-Z$ inputs with clustering

(d) envelope spectrum evaluations for both problems using BNL models and BNL developed spectra for annulus structure models $A \& B$ for all the calculational modes mentioned under item (c)

(e) multiple independent support response spectrum evaluations using the BNL models and BNL developed spectra for the annulus structure model $B$ considering only $X-Y-Z$ inputs with clustering

(f) ASME class $2 / 3$ evaluations for both problems using BNL models and the annulus structure model $B$ envelope spectra

(g) ASME class $2 / 3$ evaluations for both problems using BNL models and the annulus structure model $B$ individual support spectra.

In this report only the essential and final results are reported. These include frequency comparisons, boundary element force comparisons and selected stress results from the ASME evaluations. When possible, comparisons are made to PG\&E results.

\subsection{Frequency Comparisons}

Using the BNL developed finite element models the first fifteen natural frequencies for each piping problem were determined. These results are presented in the second column of Table 8.1 for problem 6-11 and in the second column of Table 8.2 for problem $4 A-26$. The first column of each table is 
simply the mode number while the third column of each table present.s the corresponding PG\&E estimates for the natural frequencies.

As can be seen from Table 8.1, the natural frequencies predicted with the BNL model of problem 6-11 are all consistently higher than those predicted by the applicant. This was expected and is due to the applicants decision to model five bends, shown on the as-built drawings as 50 bends, as long radius elbows. The substitution of a long radius elbow for a 50 bend has a softening effect on a system. To verify this presumption a subsequent BNL evaluation of problem 6-11 natural frequencies using the applicants model produced frequency results which were nearly identical to those predicted by the applicant.

Referring to Table 8.2 no consistent trend is obvious when the natural frequencies predicted with the BNL model of problem 4A-26 are compared to the applicant results. For most modes the BNL estimates are low while for some they are high. These results were surprising as again a 50 bend was modeled as a long radius elbow in the applicants model and higher BNL estimates for the frequencies were expected. A detailed review of the applicants model for this problem revealed that a minor geometry error existed in the model and system dimensions were different. A further review of the as-built drawings for the pipe run indicated that sufficient ambiguity in dimensions existed to allow both models to be correct.

\subsection{Results Based on Uniform Support Excitation}

Seismic evaluations of each problem were made using uniform, envelope spectrum, response spectrum methods. This mode of evaluation correspond to the method currently used by applicants to qualify their piping and is the method used by PG\&E to qualify all the annulus region piping. The BNL studies included evaluations based on PG\&E supplied horizontal spectra (see Fig. 8.13) and PG\&E supplied and BNL developed vertical spectra for annulus structure models $A$ and $B$. These were performed for $X-Y$ and $Y-Z$ inputs with no clustering (matching PG\&E procedures) and for simultaneous $X-Y-Z$ inputs with cluster- 
ing using a cluster factor of 0.1 (per Reg. Guide 1.92). Although initially only dynamic evaluations were made, the final calculations consisted of complete class 2 evaluations.

Figures 8.1 - 8.4 show the broadened vertical envelope response spectra for the two problems. Each figure shows both the BNL developed spectra and the corresponding PG\&E spectra. Figures 8.1 and 8.2 show the BNL spectra developed using the model A configuration for the annulus steel while Figures 8.3 and 8.4 show the $B N L$ spectra for the model $B$ configuration. The PG\&E supplied horizontal envelope response spectra were used as the excitation for the two horizontal directions for each problem. Referring to Figures 8.1 8.4 it can be seen that the BNL developed vertical response spectra for both problems and both models exceed PG\&E supplied spectra.

\subsubsection{Force Comparison}

A reasonable comparison of the results from only the dynamic evaluations can be made by comparing the boundary element forces predicted with the BNL models to those predicted by the applicant. Since a large number of evaluations were made, only a selected few comparisons will be presented. These are shown in Tables 8.3 thru 8.8 .

The results for each evaluation type are presented in tabular form in a consistent format. The first column identifies the piping model nodal point to which the support is attached and also the global direction in which it acts where $H$ indicates a skewed horizontal support. The remaining columns present both BNL and PG\&E predictions of the boundary element forces. Each of these columns has a heading and footnotes which define the mode of the computation. The variables in the mode of computation include; the type of calculation (uniform or independent support motion), the directions of the input excitation (simultaneous in $X-Y, Y-Z$ or $X-Y-Z$ ), the summation rule used between directional components and the use or lack of clustering between modes. Lastly only the results for a representative number of supports are presented in each table. 
At the beginning of the study the only spectra available were those provided by PG\&E. Using these and the BNL models of the piping, uniform envelope response spectrum analyses were made. The results of these analyses are shown in Table 8.3 for problem 6-11 and Table 8.4 for problem 4A-26. Results are shown for $X-Y$ excitation alone, $Y-Z$ excitation alone (the modes of calculation used by the applicant), and for simultaneous $X-Y-Z$ excitation with clustering (current industry practice).

Referring to Table 8.3 no consistent trend is apparent between the PG\&E and BNL results for the same calculational procedure. The largest forces are predicted for $Y-Z$ excitation with either the BNL or PG\&E calculation providing the greater result. If these maxima are compared to the last column, again no consistent trend is evident. Clearly the PG\&E results cannot be considered conservative but are of the same magnitude as would be predicted using current calculational procedures.

Referring to Table 8.4 the BNL results for $Y-Z$ excitation for problem 4A-26 consistently exceed the corresponding PG\&E estimates. Further if the BNL maxima are compared with those predicted using current methods, the last column, they are low for the most part. A judgement based only on these results would indicate a deficiency in the PG\&E evaluations requiring further investigation.

The latest BNL estimates for the support forces based on uniform support excitation were developed using the annulus structure model B spectra. Tables 8.5 and 8.6 summarize these results for the two problems. Again the corresponding PG\&E results are presented. Referring to both tables it can be seen that the support force predictions based on the annulus structure model $B$ spectra are all greater than the corresponding PG\&E results. In addition if all the BNL results are compared, columns 2, 4 and 6 , the predictions based on current practice are always the greatest for problem 6-11. Referring to the spectra drawings, Figures 8.3 and 8.4 , the great disparity between the BNL 
spectra and the PG\&E spectra produce the differences noted here. Given the magnitude of the support force increases a reevaluation of all support designs would seem warranted for these probiems.

\subsubsection{Stress Results}

Stress evaluation in accordance with ASME criteria for class 2 piping and uniform support excitation were made for both problems. Only the envelope response spectra and seismic anchor movements for the model $B$ annulus steel configuration were used for these evaluations. The BNL computer code PSAFE2 was employed for this purpose. This code performs the stress evaluations in accordance with ASME-BPVC Section III, Subarticle NC-3600.

The input for the ASME evaluation runs include the temperature, pressure and seismic anchor movements as well as the excitation response spectra. These input parameters were taken from the PG\&E supplied data for both problems with the exception of the vertical seismic anchor movement displacements which were determined from time history analyses using the model $B$ annulus steel structure configuration. Regarding seismic anchor movements only those displacements greater than $1 / 16$ in. were considered as any displacements smaller are within the clearance gap incorporated at supports.

The pertinent input parameters for probiem 6-11 were:

$\begin{array}{lcccc}\text { Temperature } & =350^{\circ} \mathrm{F} & & \\ \text { Pressure } & =350 & \text { psi } & & \\ & & & & \\ & \text { node } & X & Y & Z \\ \text { Seismic } & 8 & & .1325 & \\ \text { Anchor } & 37 & & .186 & \\ \text { Movements (in) } & 55 & & -.154 & \\ & 59 & 1.2 & .45 & .17\end{array}$

Service level $D$ allowable stress, $S_{h}=15.3 \times 2.4=36.72 \mathrm{Ksi}$ 
As indicated the only point experiencing horizontal displacements is point 59 . This point is affixed to the containment vessel which expands under the effects of containment pressure. The vertical displacement of point 55 was taken negative as this yields the most unfavorable displacement pattern vis-a-vis system stresses.

The pertinent input parameters for problem 4A-26 were:

$\begin{array}{lcc}\text { Temperature } & 125^{\circ} \mathrm{F} & \\ \text { Pressure } & 165 & \mathrm{psi} \\ & & \\ & \text { node } & Y \\ & 6 & .0651 \\ \text { Seismic } & 16 & .1216 \\ \text { Anchor } & 25 & .1325 \\ \text { Movements (in) } & 48 & .0892 \\ & 55 & -.0892\end{array}$

Service level $D$ allowable stress, $S_{H}=15.0 \times 2.4=36 \mathrm{Ksi}$

As can be seen there are no horizontal seismic anchor movement displacements for this problem. All such displacenents were less than the $1 / 16$ in clearance gap dimension. Again the displacement of one point (55) was taken negative to yield a most unfavorable combination. The sign for points 6,16 and 25 were not varied as time history results for the annulus structure showed these points to exhibit in phase motions.

The solution for probiem 6-11 showed that the system satisfied the service level $D$ allowables at all points except two. Overstressing occurred 
at nodal points 58 and 59 . These results are summarized in Table 8.9 along with the corresponding results from the independent support motion computation. In general the component of stress caused by the seismic dynamic loading dominated and produced the overstress conditions noted.

The solution for problem 4A-26 showed that the system satisfied the service level D stress allowable. Again the seismic dynamic stress components daminated but were not great enough to cause an overstress condition. On the basis of current design practice this system is acceptable.

\subsection{Results Based on Independent Support Excitation}

Although the design of piping systems based on uniform support excitation represents current industry practice, there is a growing trend to adapt independent support excitation analysis methods for the evaluation of the seismic dynamic components of response. Analysis by these methods are thought to be more realistic and provide safe designs while reducing the level of conservatism inherent in them.

For the sake of completeness, solutions for both problems were developed using the independent support excitation methodology. It was anticipated that these solutions would show reductions in stress levels possibly eliminating the overstress conditions in problem 6-11.

The first phase of these analyses was to develop response spectra for each support point in each problem. These were prepared from the time history records developed for the model $B$ annulus steel structure configuration. Following a comparison of these spectra the supports for each problem were segregated into excitation groups such that all supports within a single group exhibited essentially equivalent excitation spectra. This accomplished, the 
PSAFE2 computer code was used to perform the independent support excitation dynamic analyses and the subsequent class 2 evaluations.

For each problem it was found necessary to separate the supports into four excitation groups. Figures 8.5 - 8.8 show the broadened vertical response spectra for each group for problem 6-11. Figures $8.9-8.12$ show the equivalent spectra for problem 4A-26. On each figure are also noted the support node numbers of supports belonging to that group. As can be seen, the spectra for the first group in each case are essentially ground motion spectra while the spectra for the fourth group in each case exhibit the highest peaks and are as sociated with only one support. Each support group for each problem has associated with it horizontal excitation spectra identical to those provided by PG\&E and used in the uniform support motion analyses. These PG\&E provided spectra are depicted in Figure 8.13.

The independent support excitation evaluations were performed only with the spectra developed for the model $B$ annulus steel structure configuration. The evaluation included simultaneous $X-Y-Z$ excitation with SRSS summation over directional components, clustering between modes with a cluster factor of 0.1 and absolute summation between excitation group contributions. The pertinent results are summarized in the following sections.

\subsubsection{Force Comparison}

In the uniform support excitation section comparisons were made to the PG\&E results. In this section comparisons will be made only to the corresponding BNL uniform support excitation solutions with simultaneous $X-Y-Z$ inputs. Table 8.7 presents just this data for problem 6-11. Table 8.8 presents the comparison for problem 4A-26.

A review of both tables will indicate that the support forces predicted with independent support excitation are all typically greater than the forces predicted with uniform support excitation. Only for a few nodes in problem 6-11 is the reverse true. This is contrary to expectation and seems to 
contradict the basic reason for using independent support methods, a reduction in the level of conservatism.

Two reasons for these unanticipated results may be advanced. First, in order to be conservative and lacking a regulatory position, the group contributions have been summed using the absolute sum rule.

By adopting this procedure the assumption has been made that the group responses are completely out of phase. A less conservative procedure would have been to use the SRSS sum rule thereby assuming random phasing between groups. Second, independent support motions can excite dominant antisymetric modes in a system while uniform support motions will not. These antisymetric modes can contribute significantly to response.

A review was made of the mode shapes and participation factors associated with each problem. Indeed it was found that the fundamental modes for each problem exhibited strong antisymmetric characteristics. These are excited by the independent support inputs producing large participation factors and consequently large response for the individual group excitations. Secondly, each problem was rerun using the SRSS summing procedure between groups. This produced a marked reduction in overall response providing results which more closely corresponded to the uniform support motion results.

In any case the use of independent support motion analysis methods do not change the basic results. The BNL predicted support forces all exceed those predicted and used in design by PG\&E.

\subsubsection{Stress Results}

Stress evaluations in accordance with the ASME-BPVC Section III, Subarticle NC-3600, for class 2 piping and independent support excitation were made for both problems. The BNL computer code PSAFE2 was used for this purpose. 
The inputs for the independent support motion stress evaluations were identical to those used for the uniform support motion evaluations with the exception of the input spectra. That is the temperature, pressure, deadweight and seismic anchor movements are all identical for the two analysis approaches and the reader is referred to the uniform support motion section for this data. The results are shown in Table 8.9 .

A review of the stress data for problem 6-11 presented in Table 8.9 shows that the independent support motion evaluation resulted in a net reduction of stress for the high stressed points. The stress reductions at these points are on the order of $1 / 3$. The overstress at point 58 is completely alleviated. The stress at point 59, the right side anchor point, remains slightly above the allowable stress level.

The reduction of stress level at the peak stress points for problem 6-11 coincides with the reduction of support forces noted in the preceding section. Although the majority of support forces showed an increase with independent support excitation some of those as sociated with point 59 showed a decrease. obviously those support reactions must contribute strongly to the stress.

For problem 4A-26 independent support excitation produced higher dynamic loads throughout the pipe run. This was shown by the marked increase in support forces presented in the last section and is evidenced in Table 8.9 by the increased stresses. These are points which satisfied the stress criterion when uniform support excitation was used (uniform stress results are also presented in the table). For this problem the use of the independent support motion analysis method penalizes the design, although the stresses remain below the service allowable. 
To summarize the overall stress results:

For problem 6-11 a possible stress condition exists at the right most anchor (point 59).

For problem 4A-26 all stresses satisfy the service level D allowable. 
Table 8.1

PROBLEM 6-11 FREQUENCY COMPARISON

\begin{tabular}{ccc} 
Mode & $\begin{array}{c}\text { Frequency } \\
\text { BNL }\end{array}$ & $\begin{array}{c}\text { Frequency }(\mathrm{Hz}) \\
\text { PG\&E }\end{array}$ \\
\hline 1 & & \\
2 & 7.24 & 6.96 \\
3 & 10.14 & 9.23 \\
4 & 14.58 & 14.19 \\
5 & 15.99 & 15.31 \\
6 & 17.20 & 15.75 \\
7 & 17.99 & 17.61 \\
8 & 22.28 & 22.17 \\
9 & 23.63 & 23.14 \\
10 & 27.86 & 27.10 \\
11 & 29.21 & 27.55 \\
12 & 29.51 & 28.85 \\
13 & 31.55 & 30.33 \\
14 & 34.02 & 32.73 \\
15 & 34.78 & 32.93 \\
& 35.12 & 33.77 \\
\hline
\end{tabular}


Table 8.2

PROBLEM 4A-26 FREQUENCY COMPARISON

\begin{tabular}{rrc} 
Mode & $\begin{array}{c}\text { Frequency } \\
\text { BNL }\end{array}$ & $\begin{array}{c}\text { Frequency } \\
\text { PG\&E }\end{array}$ \\
\hline & & \\
1 & 5.05 & 5.46 \\
2 & 14.63 & 14.49 \\
3 & 15.67 & 16.54 \\
4 & 18.29 & 18.43 \\
5 & 20.37 & 19.39 \\
6 & 22.60 & 21.66 \\
7 & 23.64 & 24.50 \\
8 & 28.67 & 31.35 \\
9 & 32.20 & 34.23 \\
10 & 34.83 & 37.87 \\
11 & 37.96 & 38.06 \\
12 & 43.55 & 38.68 \\
13 & 46.78 & 40.95 \\
14 & 47.42 & 42.17 \\
15 & 47.73 & 43.87 \\
\hline
\end{tabular}


Table 8.3

PROBLEM 6-11 SUPPORT FORCE COMPARISON PG\&E SPECTRA

\begin{tabular}{|c|c|c|c|c|c|}
\hline \multirow[b]{2}{*}{ Node } & \multicolumn{2}{|c|}{$X-Y$ Input } & \multicolumn{2}{|c|}{$Y-Z$ Input } & \multirow{2}{*}{$\frac{X-Y-Z \text { Inp }}{B N L}$} \\
\hline & BNL & PG\&E & BNL & PG\&E & \\
\hline $1 x$ & 618 & 1240 & 1831 & 1751 & 2112 \\
\hline Y & 77 & 81 & 89 & 98 & 96 \\
\hline Z & 792 & 1084 & 1383 & 1326 & 1810 \\
\hline$x x$ & 7498 & 8315 & 9452 & 10760 & 9032 \\
\hline$Y Y$ & 54434 & 68809 & 34422 & 68809 & 70172 \\
\hline$Z Z$ & 6258 & 8697 & 9700 & 13616 & 8139 \\
\hline $5 Y$ & 364 & 425 & 382 & 425 & 424 \\
\hline $8 Y$ & 769 & 790 & 784 & 790 & 876 \\
\hline $13 \mathrm{H}$ & 3304 & 3313 & 3627 & 3113 & 4621 \\
\hline $18 \mathrm{H}$ & 240 & 303 & 497 & 214 & 306 \\
\hline $29 \mathrm{H}$ & 3071 & 3014 & 3783 & 3918 & 3393 \\
\hline $32 \mathrm{H}$ & 4984 & 4399 & 5142 & 4704 & 4691 \\
\hline $55 \mathrm{H}$ & 5060 & 4222 & 5895 & 6564 & 7018 \\
\hline $59 x$ & 1691 & 1980 & 2330 & 2306 & 2483 \\
\hline$Y$ & 5797 & 5269 & 4885 & 5056 & 4571 \\
\hline Z & 555 & 394 & 719 & 776 & 894 \\
\hline$x x$ & 82437 & 84987 & 81644 & 100328 & 98951 \\
\hline YY & 16917 & 11931 & 26100 & 32503 & 30068 \\
\hline $\mathrm{ZZ}$ & 614000 & 596118 & 535615 & 601012 & 494778 \\
\hline
\end{tabular}

$X-Y$ and $Y-Z, A B S$ between directions, $C F=0.0$

$X-Y-Z$, SRSS between directions, $C F=0.1$ 
Table 8.4

PROBLEM 4A-26 SUPPORT FORCE COMPARISON PG\&E SPECTRA

\begin{tabular}{|c|c|c|c|c|c|}
\hline \multirow[b]{2}{*}{ Node } & \multicolumn{2}{|c|}{$X-Y$ Input } & \multicolumn{2}{|c|}{ Y-Z Input } & \multirow{2}{*}{$\frac{X-Y-Z \text { Input }}{\text { BNL }}$} \\
\hline & BNL & PG\&E & BNL & PG\&E & \\
\hline $1 x$ & 163 & 115 & 215 & 114 & 249 \\
\hline$Y$ & 35 & 31 & 31 & 30 & 38 \\
\hline$z$ & 156 & 128 & 222 & 149 & 256 \\
\hline$x x$ & 2239 & 1896 & 2910 & 1854 & 3379 \\
\hline$Y Y$ & 2236 & 1678 & 1650 & 1424 & 1997 \\
\hline$Z Z$ & 1898 & 1528 & 2671 & 1500 & 3067 \\
\hline $6 Y$ & 208 & 129 & 225 & 187 & 251 \\
\hline $16 \mathrm{H}$ & 237 & 188 & 510 & 416 & 555 \\
\hline$Y$ & 198 & 112 & 204 & 164 & 220 \\
\hline $32 \mathrm{H}$ & 102 & 60 & 193 & 122 & 214 \\
\hline $29 \mathrm{H}$ & 32 & 24 & 36 & 20 & 45 \\
\hline$Y$ & 30 & 19 & 41 & 16 & 45 \\
\hline $43 \mathrm{H}$ & 136 & 108 & 289 & 257 & 313 \\
\hline $60 x$ & 26 & 16 & 34 & 24 & 37 \\
\hline$Y$ & 22 & 57 & 41 & 20 & 40 \\
\hline$z$ & 37 & 54 & 70 & 56 & 69 \\
\hline$x x$ & 479 & 709 & 900 & 872 & 873 \\
\hline YY & 1075 & 702 & 832 & 1310 & 990 \\
\hline$Z Z$ & 465 & 236 & 655 & 577 & 731 \\
\hline
\end{tabular}

$X-Y$ and $Y-Z$, $A B S$ between directions, $C F=0.0$

$X-Y-Z$, SRSS between directions, $C F=0.1$ 
Table 8.5

PROBLEM 6-11 SUPPORT FORCE COMPARISON MODEL B SPECTRA

\begin{tabular}{|c|c|c|c|c|c|}
\hline \multirow[b]{2}{*}{ Node } & \multicolumn{2}{|c|}{$X-Y$ Input } & \multicolumn{2}{|c|}{$Y-Z$ Input } & \multirow{2}{*}{$\frac{X-Y-Z \text { Inpu }}{\text { BNL }}$} \\
\hline & BNL & PG\&E & BNL & $P G \& E$ & \\
\hline $1 x$ & 613 & 1240 & 1785 & 1751 & 2042 \\
\hline Y & 92 & 81 & 108 & 98 & 108 \\
\hline$z$ & 823 & 1084 & 1362 & 1326 & 1760 \\
\hline$x x$ & 10231 & 8315 & 12538 & 10760 & 10928 \\
\hline YY & 60162 & 68809 & 39494 & 68809 & 71723 \\
\hline$Z Z$ & 10631 & 8697 & 14184 & 13616 & 10943 \\
\hline $5 Y$ & 394 & 425 & 419 & 425 & 453 \\
\hline $8 Y$ & 801 & 790 & 831 & 790 & 905 \\
\hline $13 \mathrm{H}$ & 7230 & 3313 & 7234 & 3113 & 7429 \\
\hline $18 \mathrm{H}$ & 328 & 303 & 263 & 214 & 361 \\
\hline $29 \mathrm{H}$ & 8005 & 3014 & 8275 & 3918 & 7551 \\
\hline $32 \mathrm{H}$ & 13164 & 4399 & 12924 & 4704 & 12065 \\
\hline $55 \mathrm{H}$ & 8576 & 4222 & 9384 & 6564 & 9651 \\
\hline $59 x$ & 3103 & 1980 & 3711 & 2306 & 3485 \\
\hline$Y$ & 17529 & 5269 & 16559 & 5056 & 15864 \\
\hline Z & 933 & 394 & 1100 & 776 & 1174 \\
\hline$x x$ & 187862 & 84987 & 183764 & 100328 & 186089 \\
\hline YY & 33732 & 11931 & 42047 & 32503 & 41677 \\
\hline $\mathrm{ZZ}$ & 1871788 & 596118 & 1777017 & 601012 & 1698506 \\
\hline
\end{tabular}

$X-Y$ and $Y-Z$, ABS between directions, $C F=0.0$

$X-Y-Z$, SRSS between directions, $C F=0.1$ 
Table 8.6

PROBLEM 4A-26 SUPPORT FORCE COMPARISON MODEL B SPECTRA

\begin{tabular}{|c|c|c|c|c|c|}
\hline \multirow[b]{2}{*}{ Node } & \multicolumn{2}{|c|}{$X-Y$ Input } & \multicolumn{2}{|c|}{$Y-Z$ Input } & \multirow{2}{*}{$\frac{X-Y-Z \text { Inf }}{B N L}$} \\
\hline & BNL & PG\&E & BNL & PG\&E & \\
\hline $1 x$ & 203 & 115 & 247 & 114 & 294 \\
\hline$Y$ & 47 & 31 & 43 & 30 & 53 \\
\hline Z & 180 & 128 & 241 & 149 & 276 \\
\hline$x x$ & 2719 & 1896 & 3263 & 1854 & 3850 \\
\hline$Y Y$ & 3086 & 1678 & 2490 & 1424 & 3280 \\
\hline $\mathrm{ZZ}$ & 2271 & 1528 & 2983 & 1500 & 3422 \\
\hline $6 Y$ & 278 & 129 & 289 & 187 & 334 \\
\hline $16 \mathrm{H}$ & 247 & 188 & 515 & 416 & 559 \\
\hline$Y$ & 254 & 112 & 268 & 164 & 296 \\
\hline $32 \mathrm{H}$ & 121 & 60 & 203 & 122 & 225 \\
\hline $29 \mathrm{H}$ & 36 & 24 & 40 & 20 & 48 \\
\hline$Y$ & 43 & 19 & 50 & 16 & 55 \\
\hline $43 \mathrm{H}$ & 144 & 108 & 294 & 257 & 316 \\
\hline $60 x$ & 32 & 16 & 35 & 24 & 47 \\
\hline$Y$ & 78 & 57 & 95 & 70 & 106 \\
\hline Z & 63 & 54 & 84 & 56 & 89 \\
\hline$x x$ & 965 & 709 & 1188 & 872 & 1315 \\
\hline YY & 1255 & 702 & 1632 & 1310 & 1961 \\
\hline ZZ & 368 & 236 & 671 & 577 & 737 \\
\hline
\end{tabular}

$X-Y$ and $Y-Z, A B S$ between directions, $C F=0.0$

$X-Y-Z$, SRSS between directions, $C F=0.1$ 
Table 8.7

PROBLEM 6-11 SUPPORT FORCE COMPARISON MODEL B SPECTRA

\begin{tabular}{|c|c|c|}
\hline Node & $\begin{array}{l}\text { Unif. Sup. Mot. } \\
X-Y-Z \text { Inputs }\end{array}$ & $\begin{array}{l}\text { Ind. Sup. Mot. } \\
X-Y-Z \text { Inputs }\end{array}$ \\
\hline $1 x$ & 2042 & 5012 \\
\hline$Y$ & 108 & 211 \\
\hline$z$ & 1760 & 4108 \\
\hline$x x$ & 10928 & 22131 \\
\hline$Y Y$ & 71723 & 152704 \\
\hline$Z Z$ & 10943 & 19715 \\
\hline $5 Y$ & 453 & 1030 \\
\hline $8 Y$ & 905 & 2233 \\
\hline $13 \mathrm{H}$ & 7429 & 9076 \\
\hline $18 \mathrm{H}$ & 361 & 644 \\
\hline $29 H$ & 7551 & 6994 \\
\hline $32 \mathrm{H}$ & 12065 & 9205 \\
\hline $55 \mathrm{H}$ & 9651 & 12844 \\
\hline $59 x$ & 3485 & 4828 \\
\hline$Y$ & 15864 & 7366 \\
\hline$z$ & 1174 & 1567 \\
\hline$x x$ & 186089 & 169037 \\
\hline$Y Y$ & 41677 & 51424 \\
\hline $\mathrm{ZZ}$ & 1698506 & 826802 \\
\hline
\end{tabular}


Table 8.8

PROBLEM 4A-26 SUPPORT FORCE COMPARISON MODEL B SPECTRA

\begin{tabular}{|c|c|c|}
\hline Node & $\begin{array}{l}\text { Unif. Sup. Mot. } \\
X-Y-Z \text { Inputs }\end{array}$ & $\begin{array}{l}\text { Ind. Sup. Mot } \\
X-Y-Z \text { Inputs }\end{array}$ \\
\hline $1 X$ & 294 & 439 \\
\hline$Y$ & 53 & 64 \\
\hline$Z$ & 276 & 439 \\
\hline$x x$ & 3850 & 5858 \\
\hline YY & 3280 & 3695 \\
\hline$Z Z$ & 3422 & 5327 \\
\hline $6 Y$ & 334 & 495 \\
\hline $16 \mathrm{H}$ & 559 & 1167 \\
\hline$Y$ & 296 & 449 \\
\hline $32 \mathrm{H}$ & 225 & 452 \\
\hline $29 \mathrm{H}$ & 48 & 59 \\
\hline$Y$ & 55 & 90 \\
\hline $43 \mathrm{H}$ & 316 & 667 \\
\hline $60 x$ & 47 & 70 \\
\hline$Y$ & 106 & 183 \\
\hline$z$ & 89 & 167 \\
\hline$x x$ & 1315 & 2275 \\
\hline YY & 1961 & 3442 \\
\hline$Z Z$ & 737 & 1496 \\
\hline
\end{tabular}


Table 8.9

ASME CLASS 2 EQUATION 9 SATISFACTION

\begin{tabular}{|c|c|c|c|c|c|c|c|}
\hline $\begin{array}{c}\text { Element } \\
\qquad \#\end{array}$ & $\begin{array}{c}\text { Node } \\
\#\end{array}$ & $\begin{array}{c}\text { Pressure } \\
\text { ksi }\end{array}$ & $\begin{array}{l}\text { Dead- } \\
\text { we ight } \\
\text { ksi }\end{array}$ & $\begin{array}{l}\text { SAM } \\
\text { ksi }\end{array}$ & $\begin{array}{c}\text { Earthquake } \\
\text { ksi }\end{array}$ & $\begin{array}{l}\text { Total } \\
\text { ksi }\end{array}$ & $\begin{array}{c}\text { Allowable } \\
\text { ksi }\end{array}$ \\
\hline \multicolumn{8}{|l|}{$6-11$} \\
\hline \multirow[t]{2}{*}{45} & 57 & 2.975 & 2.081 & 3.592 & $20.199(U)$ * & 28.847 & 36.72 \\
\hline & & & & & $10.906(I)^{\star}$ & 19.554 & 36.72 \\
\hline \multirow[t]{2}{*}{45} & 58 & 2.975 & 3.104 & 7.137 & $28.980(U)$ & 42.197 & 36.72 \\
\hline & & & & & $14.726(I)$ & 27.943 & 36.72 \\
\hline \multirow[t]{2}{*}{46} & 59 & 2.975 & 4.256 & 10.762 & $37.914(U)$ & 55.907 & 36.72 \\
\hline & & & & & 18.754 (I) & 36.747 & 36.72 \\
\hline \multicolumn{8}{|l|}{$4 A-26$} \\
\hline \multirow[t]{2}{*}{21} & 11 & .584 & .343 & 15.059 & $8.056(U)$ & 24.043 & 36.0 \\
\hline & & & & & $17.011(\mathrm{I})$ & 32.998 & 36.0 \\
\hline \multirow[t]{2}{*}{21} & 12 & .584 & .339 & 8.726 & $9.322(U)$ & 18.972 & 36.0 \\
\hline & & & & & $19.812(\mathrm{I})$ & 29.462 & 36.0 \\
\hline \multirow[t]{2}{*}{22} & 16 & .584 & .934 & 3.158 & $12.763(U)$ & 17.438 & 36.0 \\
\hline & & & & & $26.849(I)$ & 31.525 & 36.0 \\
\hline \multirow[t]{2}{*}{29} & 16 & .584 & .934 & 3.158 & $12.763(\mathrm{U})$ & 17.438 & 36.0 \\
\hline & & & & & $26.849(1)$ & 31.525 & 36.0 \\
\hline
\end{tabular}

*Note: $U=$ Uni form Support Excitation

$I$ = Independent Support Excitation 


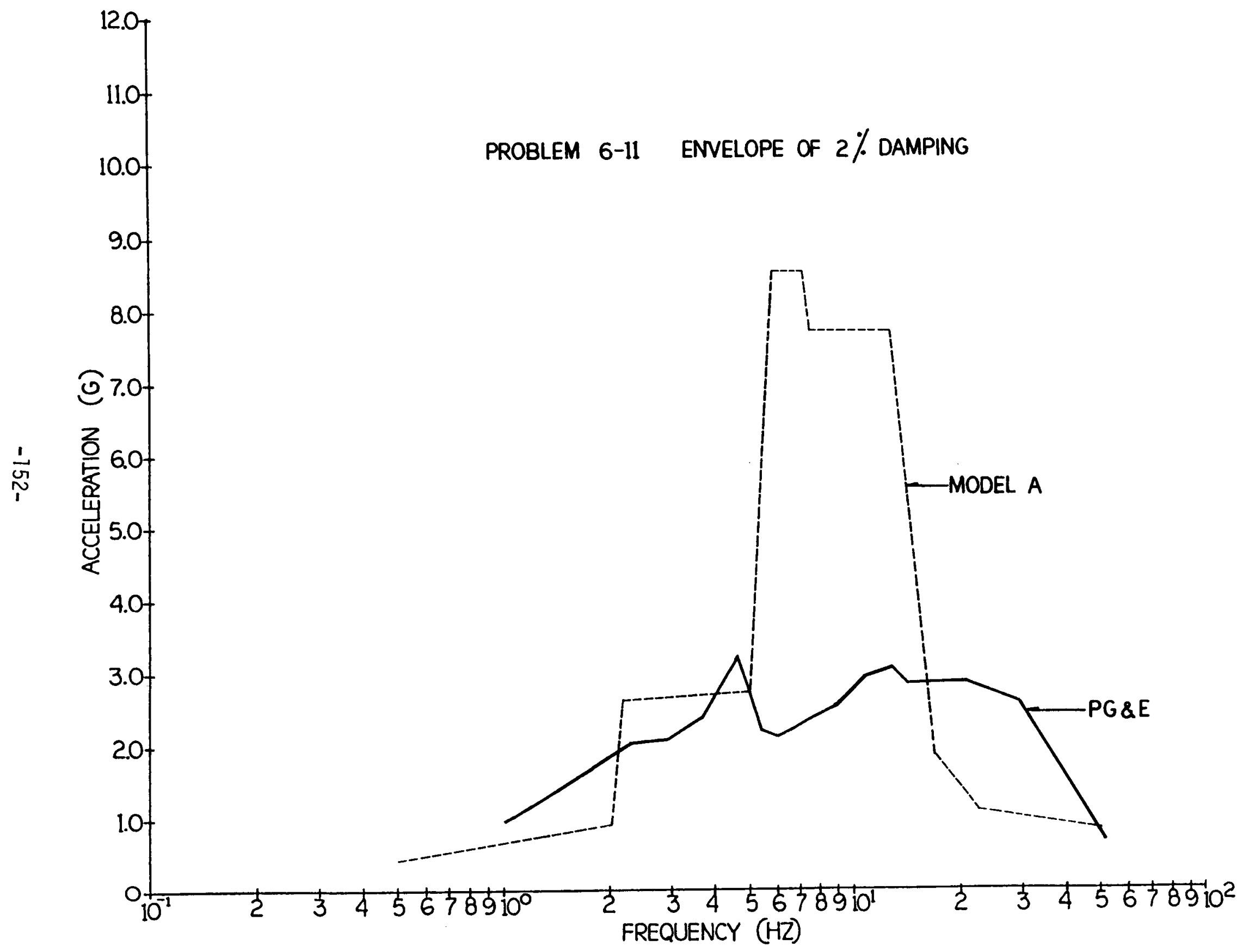

Figure 8.1 


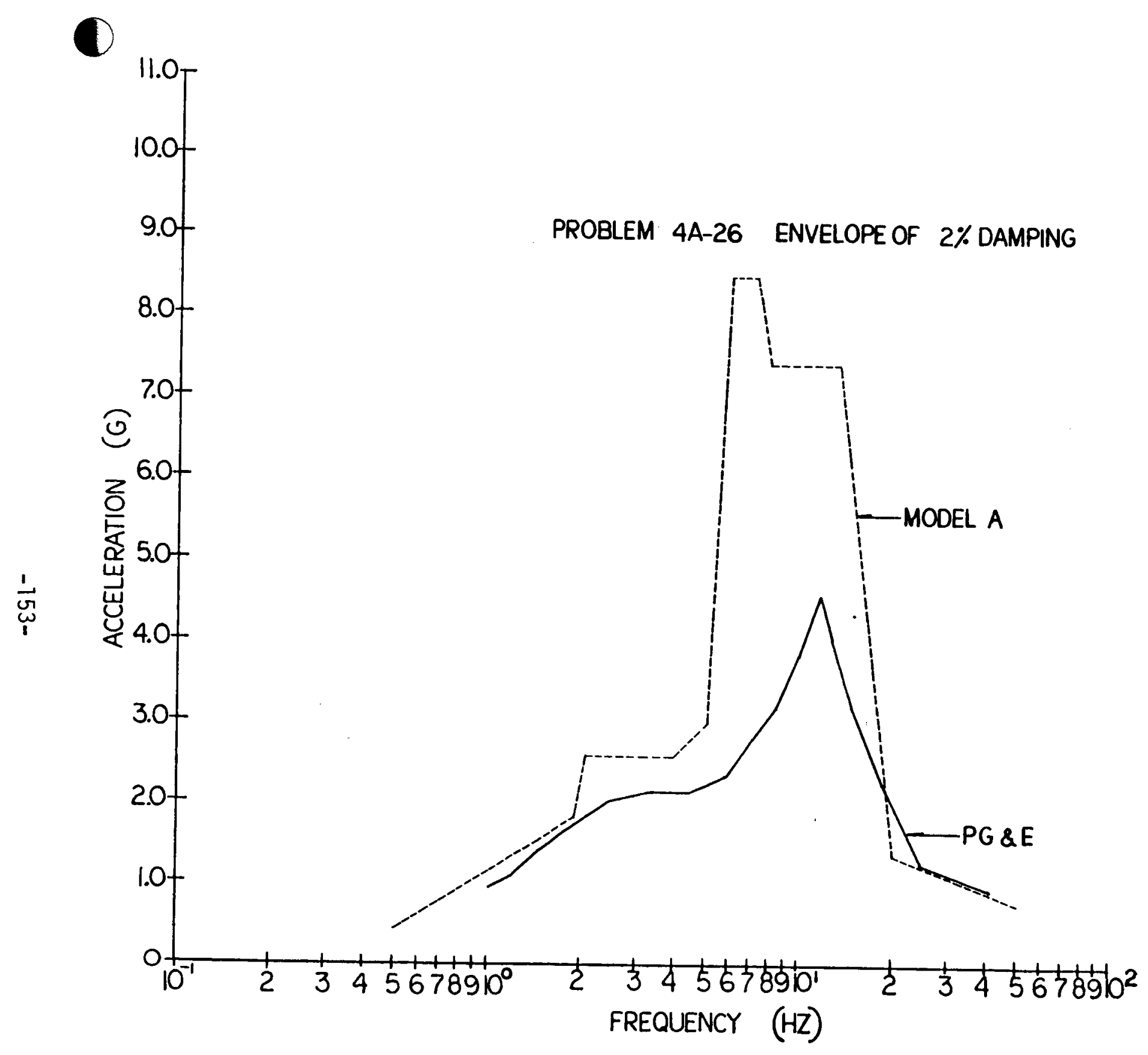

Figure 8.2 


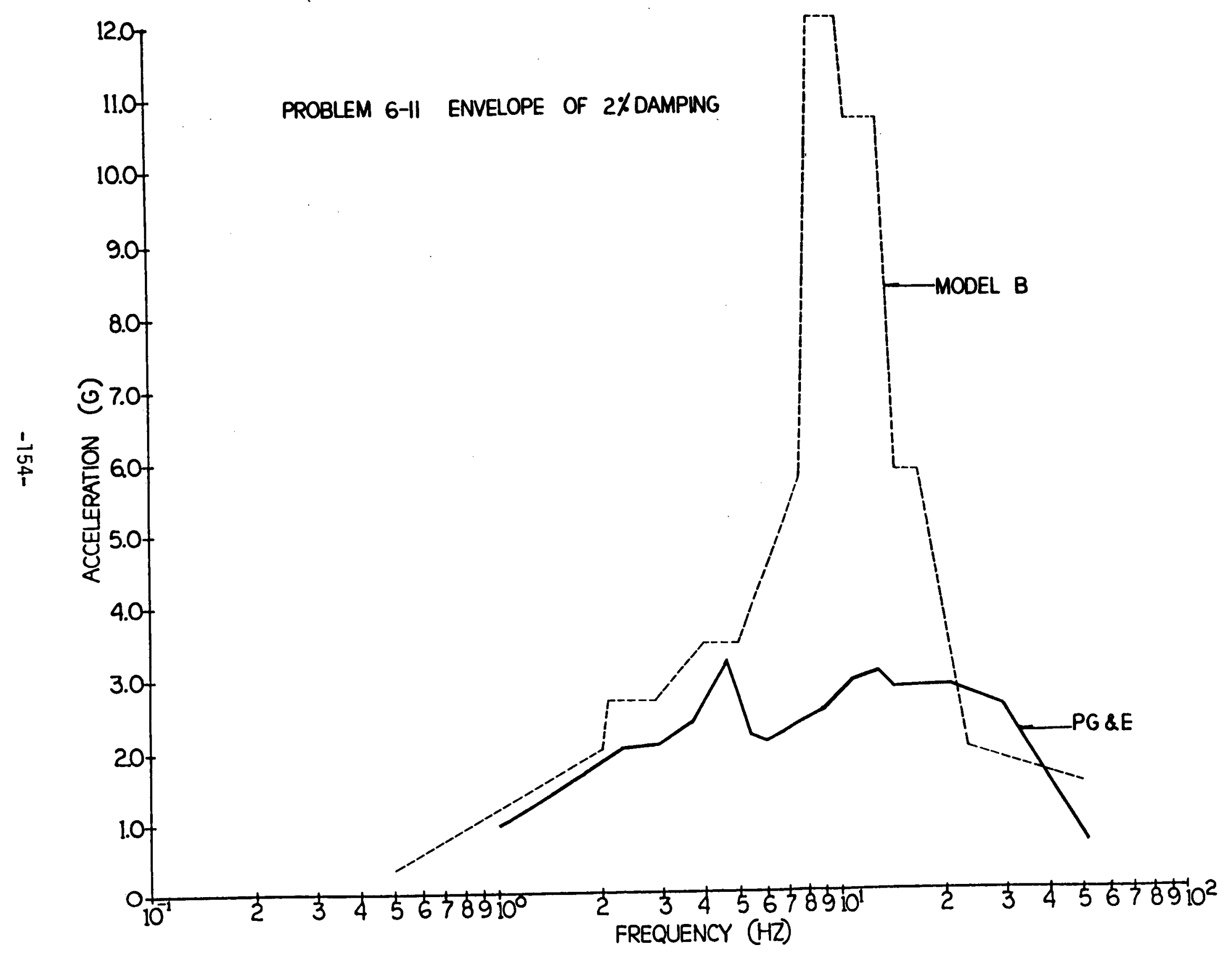

Figure 8.3 


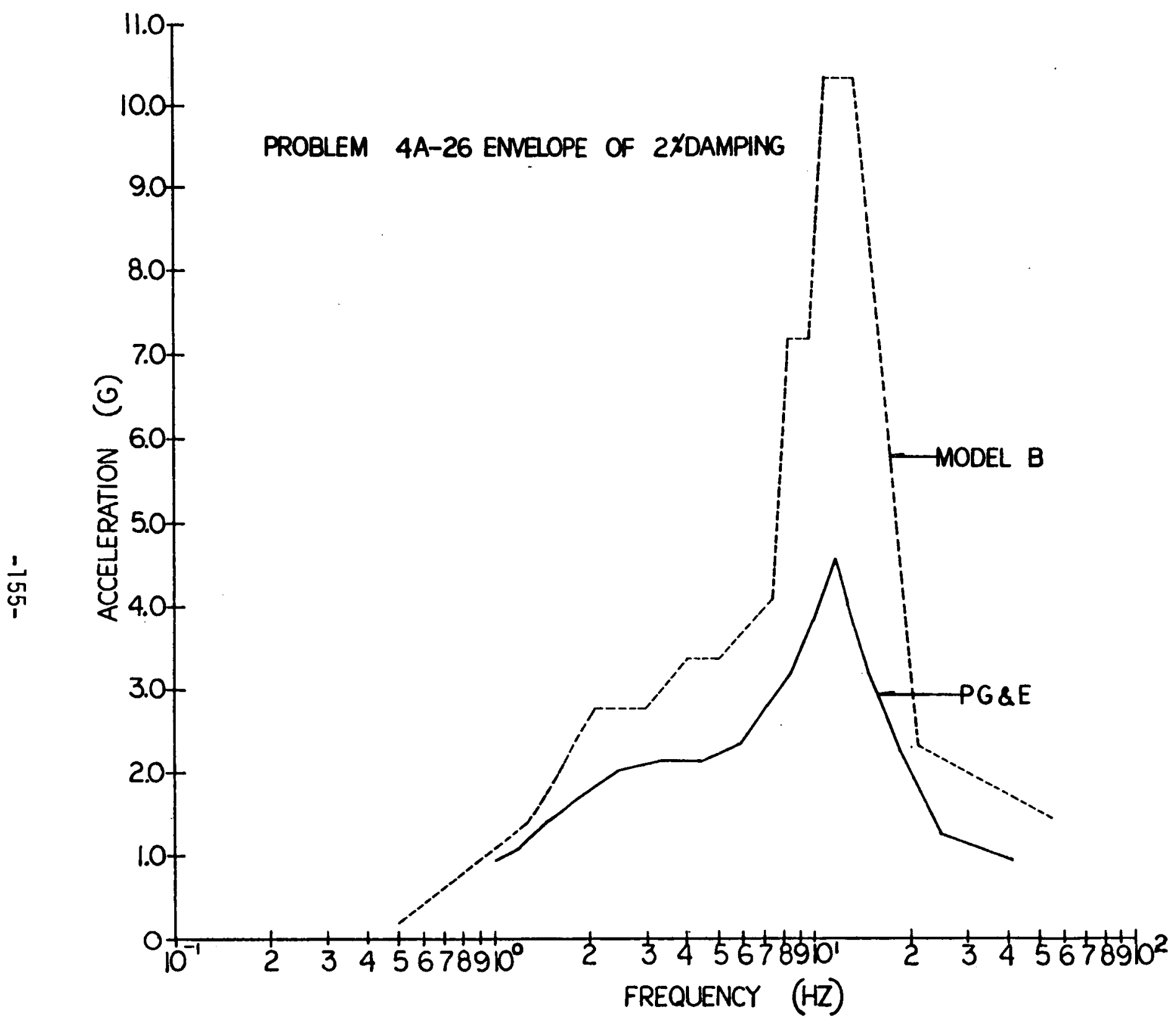

Figure 8.4 


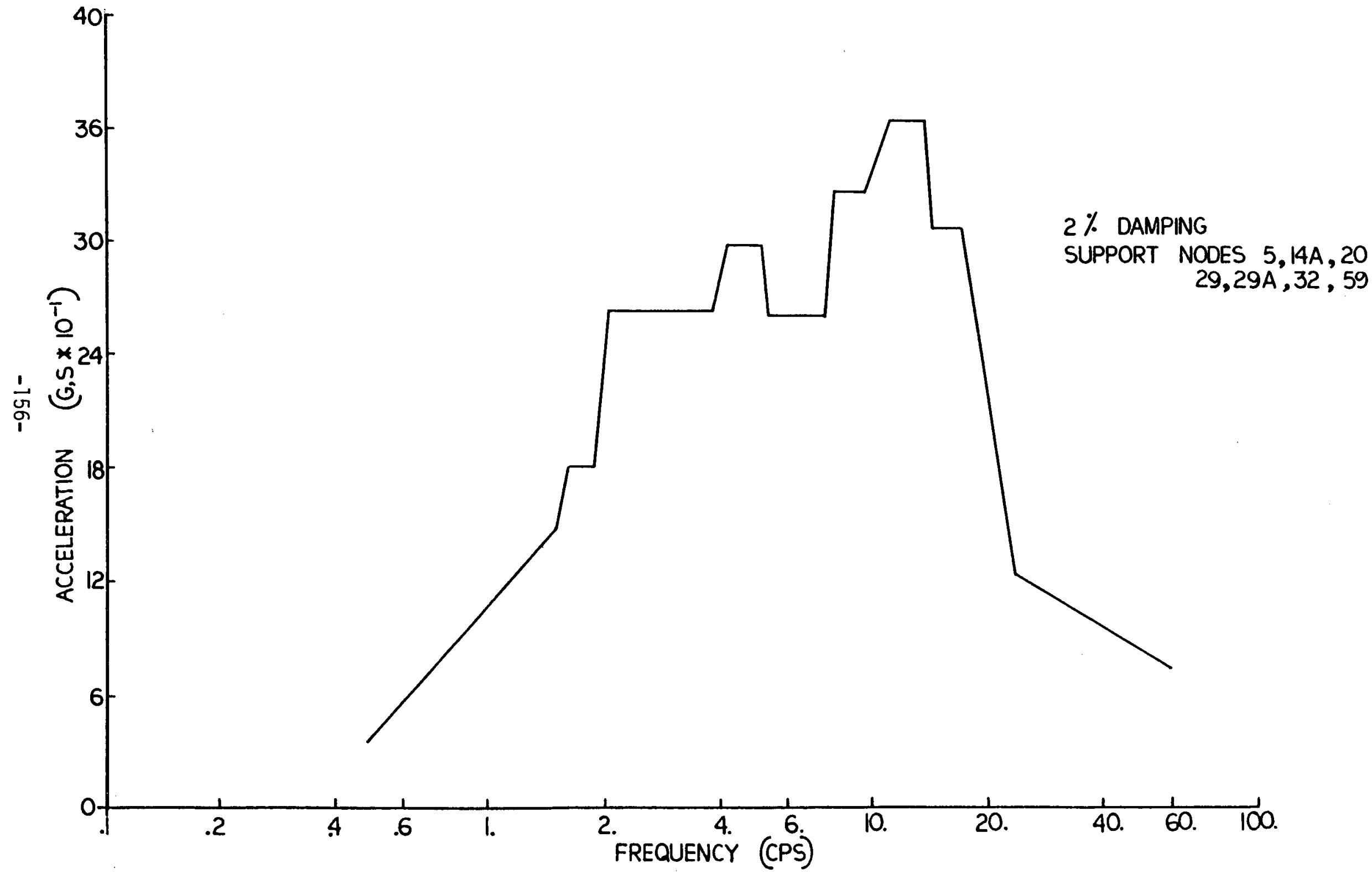

PROBLEM 6-II MODEL B GROUP 1

Figure 8.5 


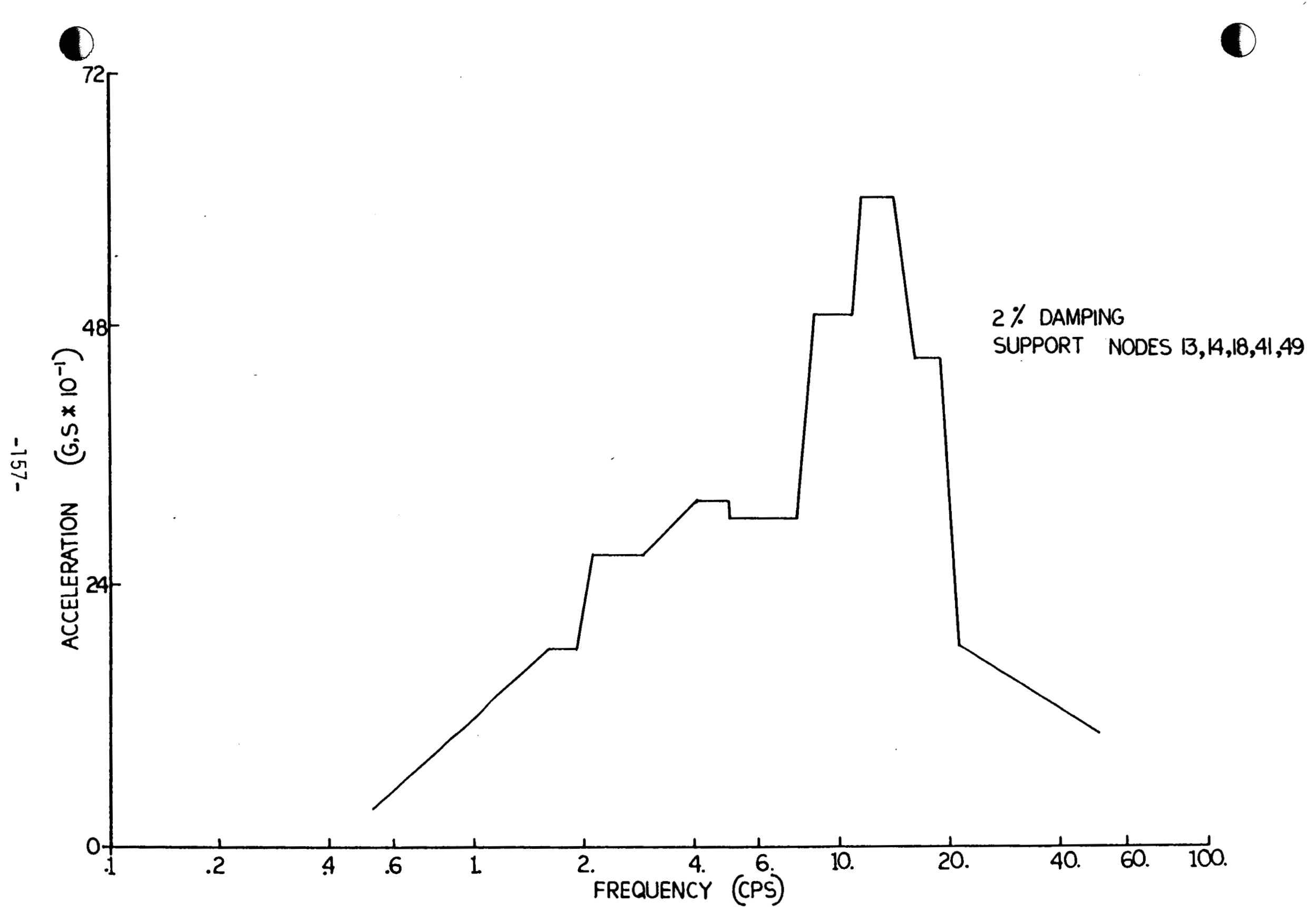

PROBLEM 6-11 MOOEL B GROUP 2

Figure 8.6 


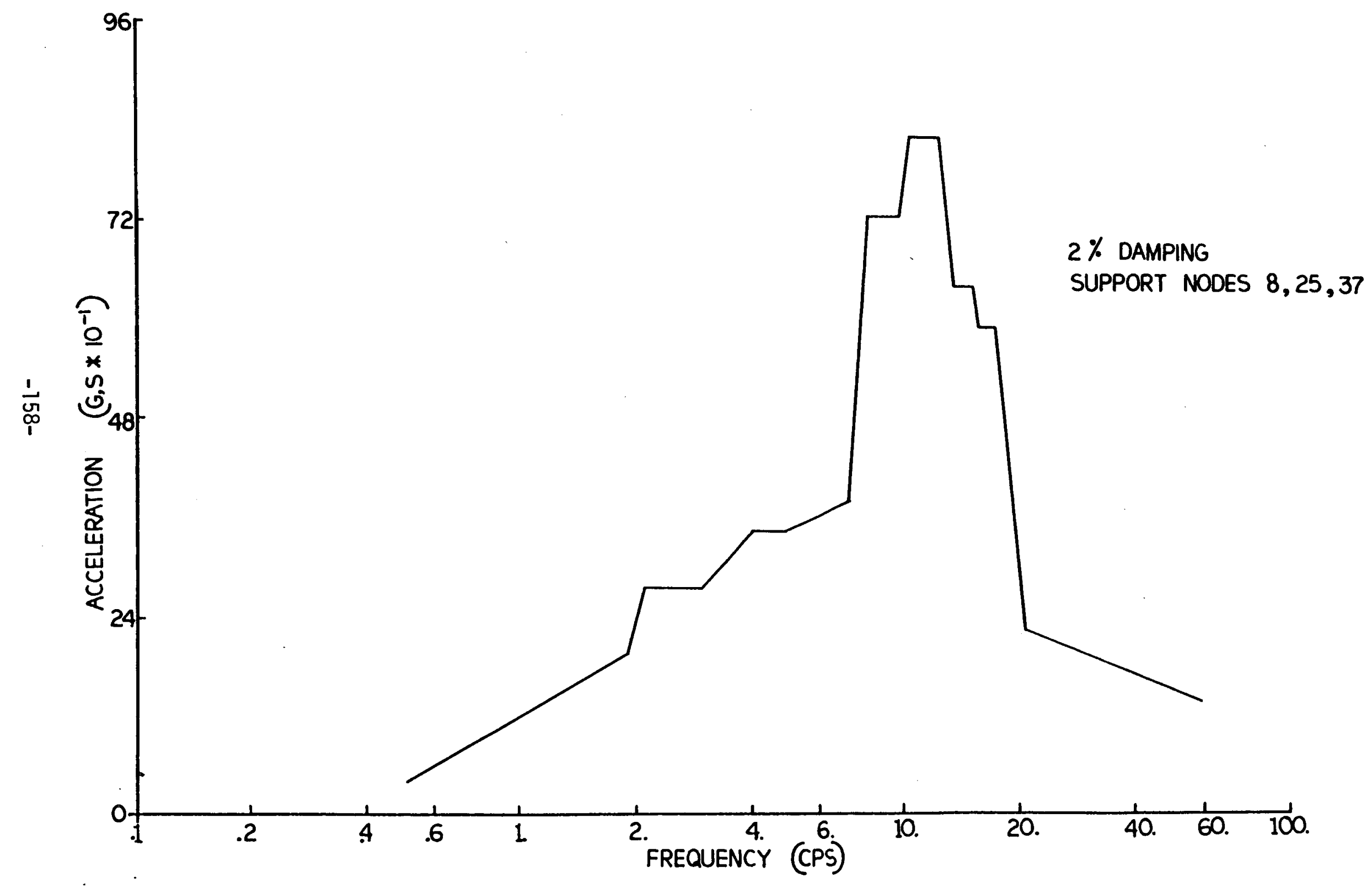

PROBLEM 6-1I MODEL B GROUP 3

Figure 8.7 


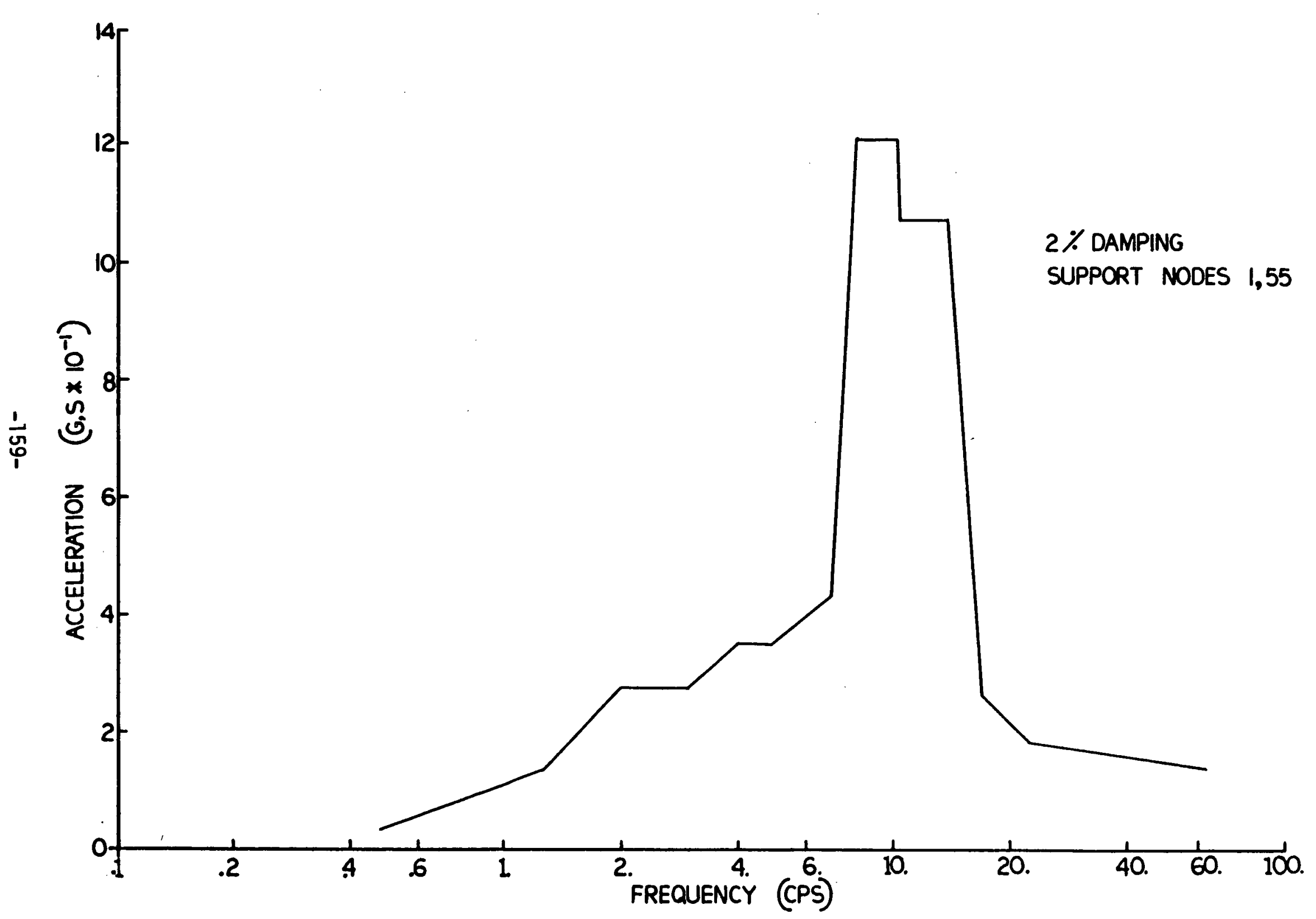

PROBLEM 6-H MODEL B GROUP 4

Figure 8.8 


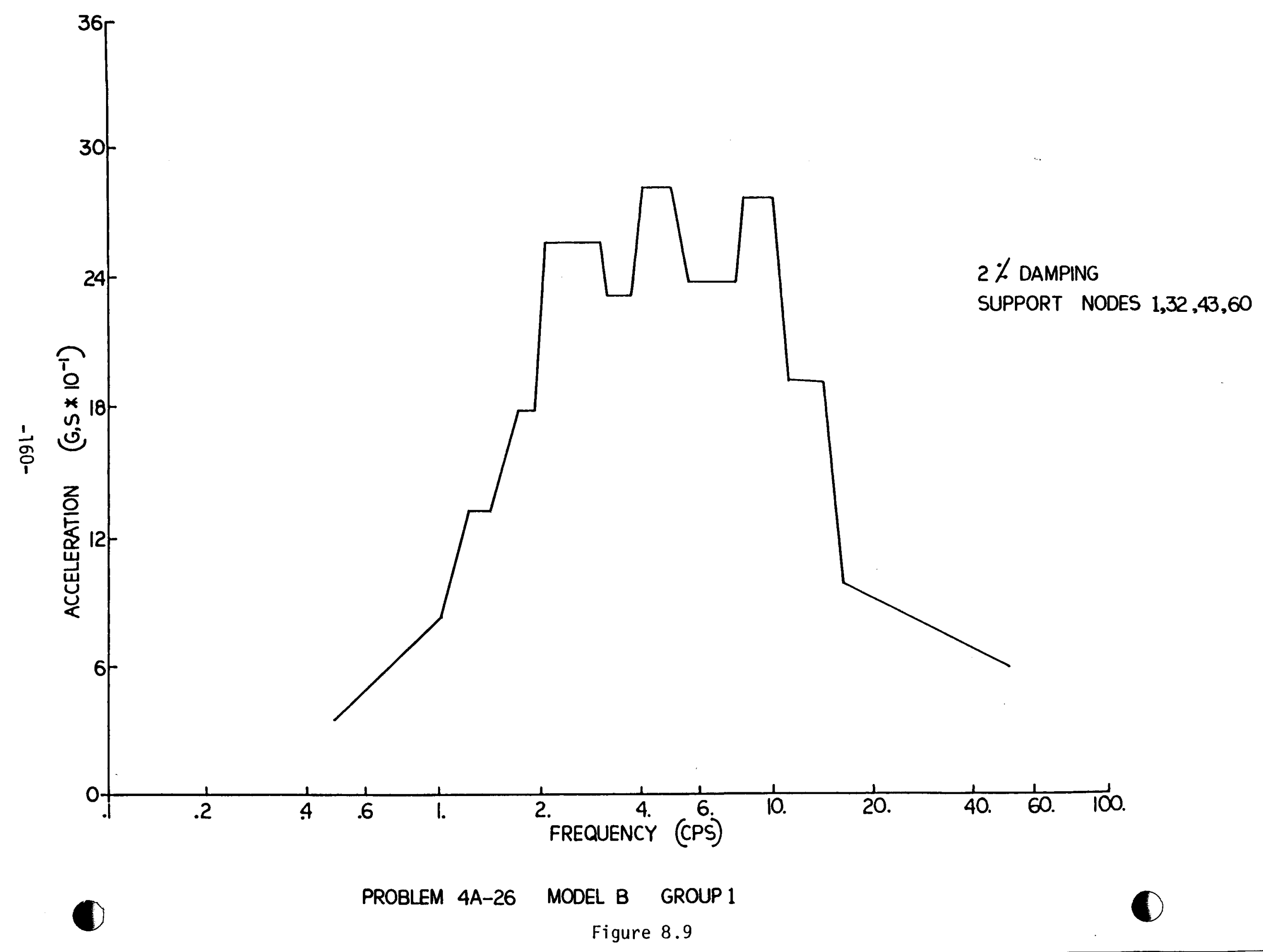




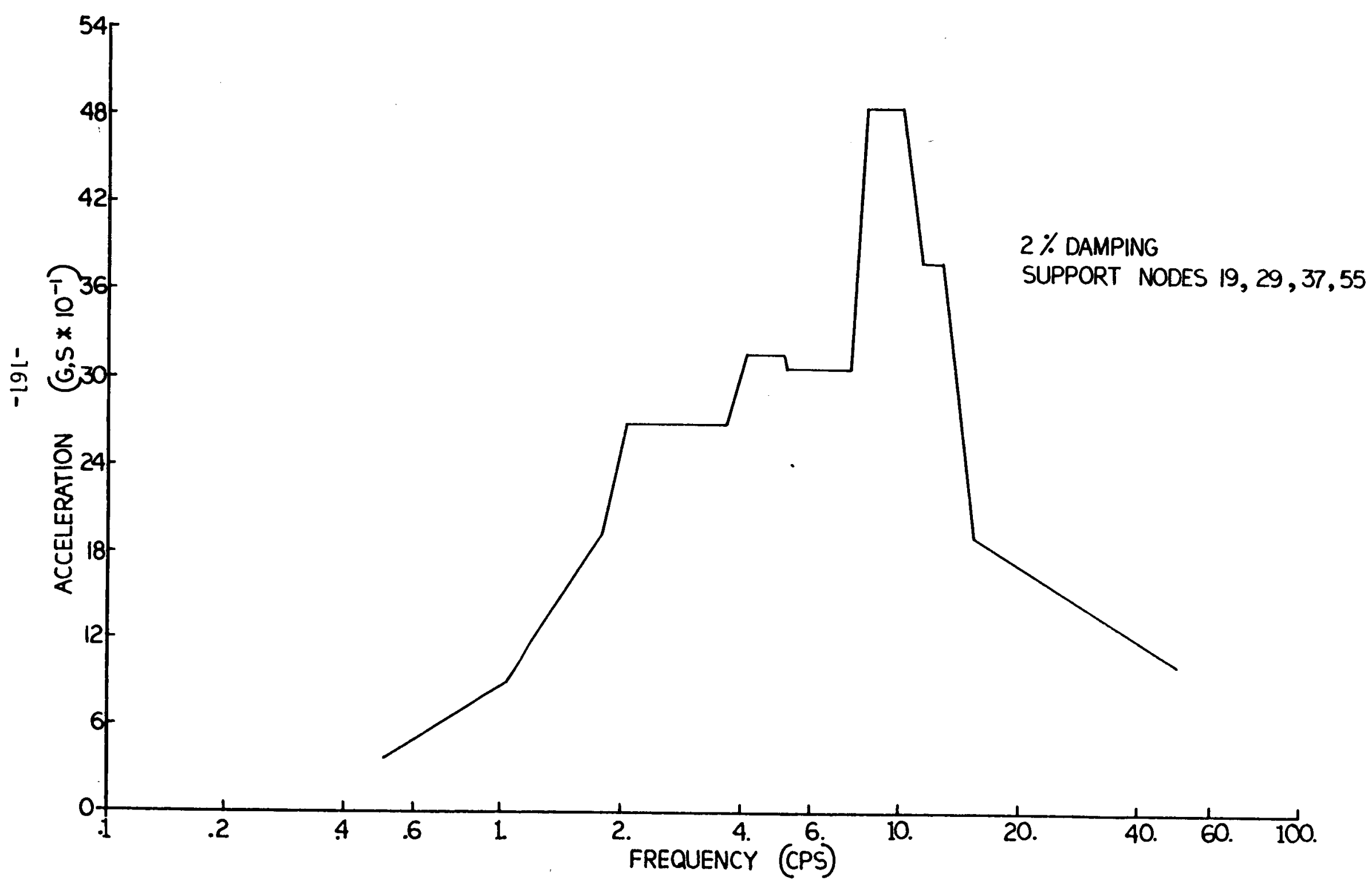

PROBLEM 4A-26 MODEL B GROUP 2

Figure 8.10 


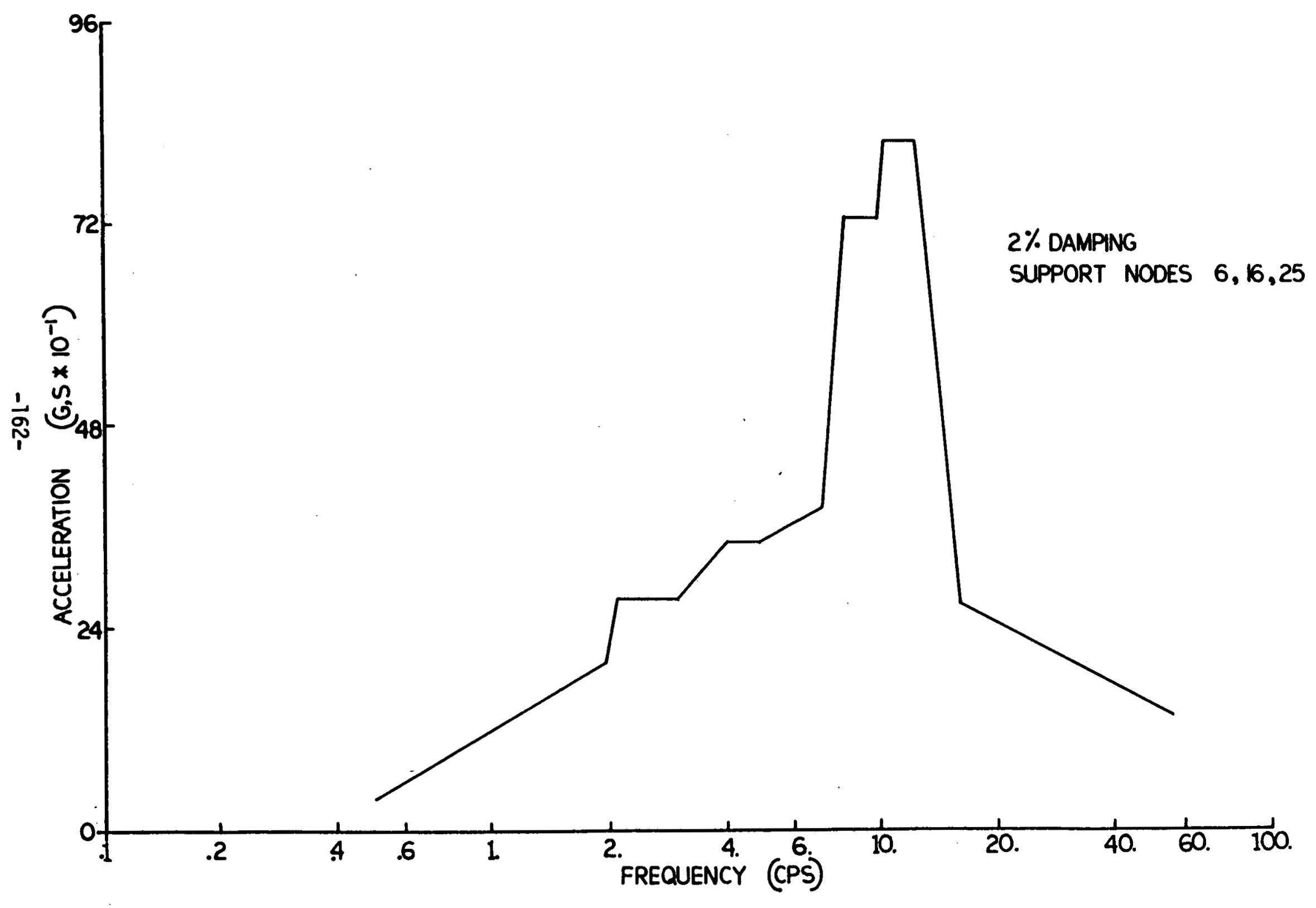

PROBLEM 4A-26 MODEL B GROUP 3

Figure 8.11 


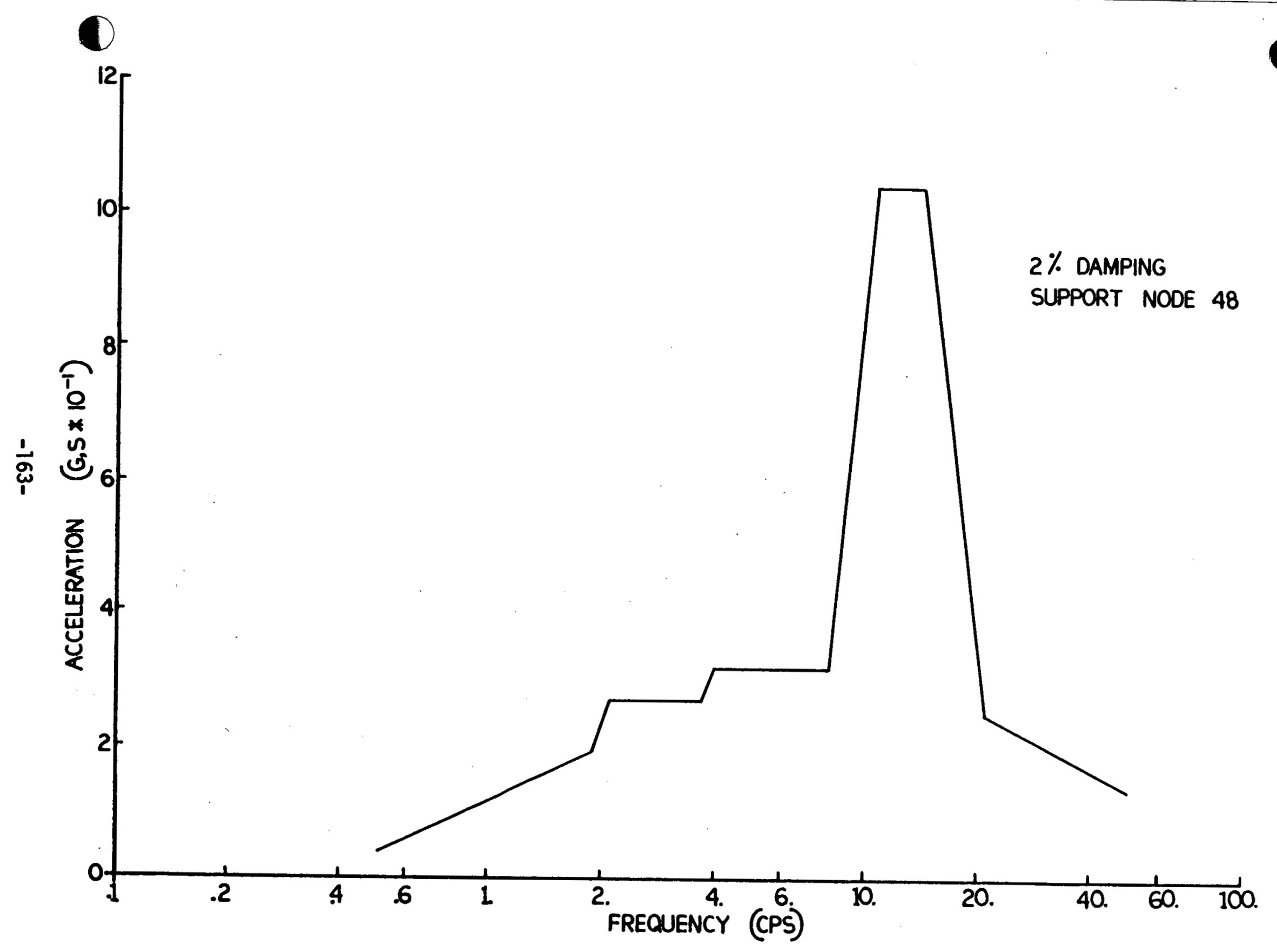

PROBLEM 4A-26 MODEL B GROUP 4

Figure 8.12 


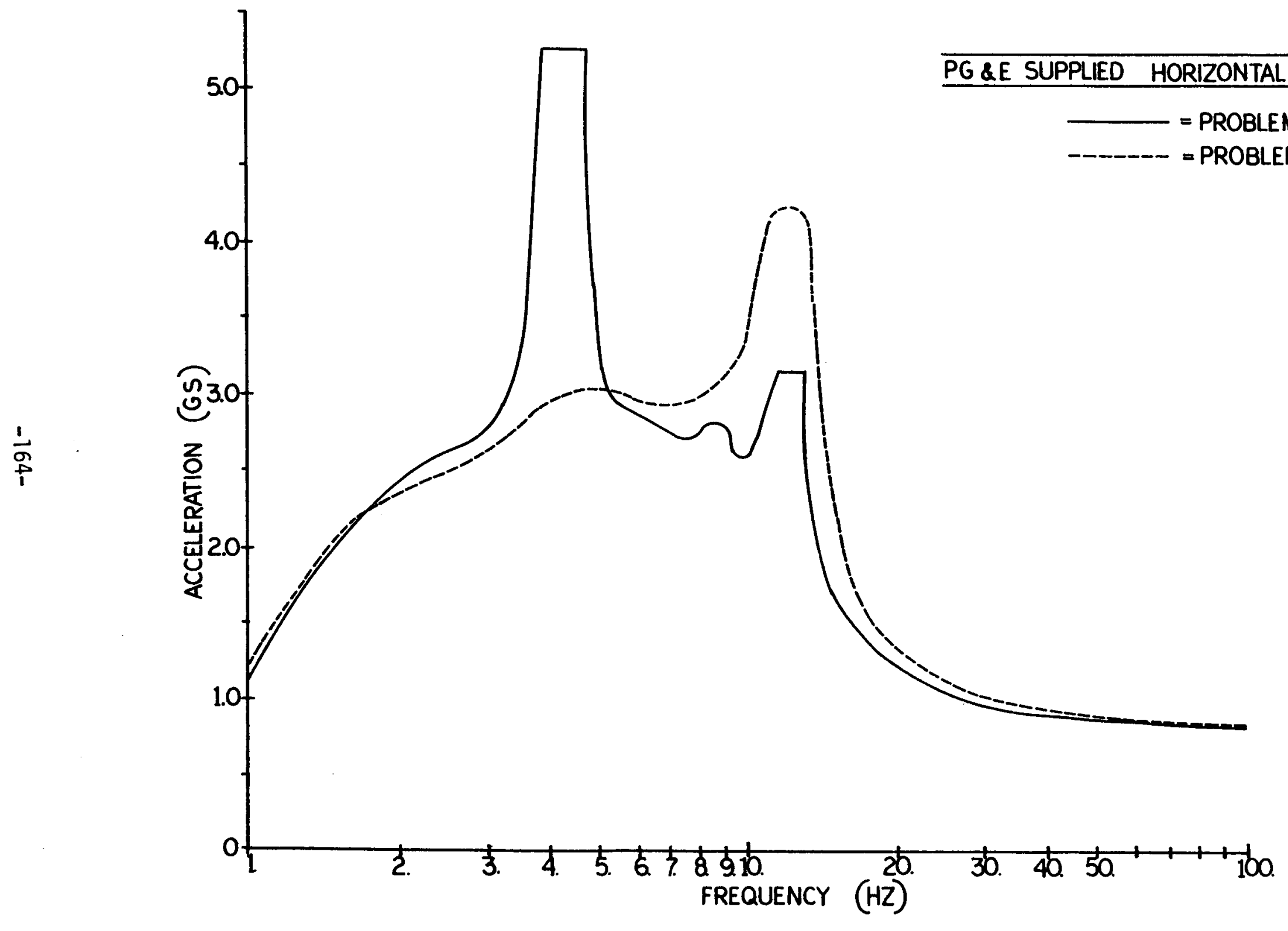

FIGURE 8.13 


\section{References}

[1] "Diablo Canyon Nuclear Plant Unit 1, Containment Structure, Dynamic Seismic Analysis for 7.5M Hosgri Earthquake", URS/John A. Blume \& As sociates, Engineers, May 1979.

[2] "A Structural Analysis Program for Static and Dynamic Response of Linear Systems", K. J. Bathe, E. L. Wilson, F. E. Peterson, University of California, Berkeley, California (USC 1976 version).

[3] "Soil-structure Interaction Methods - SIM Code", C. A. Miller, NUREG/CR-1717, Vol. II. December 1980.

[4] "PSAFE2-Piping Analysis Program", M. Subudhi and P. Bezler (1981 version) to be published. 